\title{
III. Die kriegsgeschichtliche Kooperation im Spannungsfeld des Kalten Krieges
}

Nachdem bislang die Entstehung und Entwicklung der kriegsgeschichtlichen Kooperation weitestgehend chronologisch dargestellt wurde, soll im Folgenden auf drei Aspekte der Zusammenarbeit vertiefend eingegangen werden: den Umgang der Historical Division mit Kriegsverbrechern; die Verbreitung und Verwendung der deutschen Studien innerhalb der U.S. Armee; und die Bedeutung der kriegsgeschichtlichen Kooperation für die geschichtspolitischen Aktivitäten der ehemaligen Wehrmachtselite.

Dass sich die amerikanischen Offiziere der Historical Division kaum dafür interessierten, ob und in welchem Umfang die für sie tätigen Deutschen während des Zweiten Weltkrieges für Kriegsverbrechen und Völkermord verantwortlich waren, wurde bereits angedeutet. Im ersten der folgenden Kapitel soll diese Frage nach dem Umgang der Historical Division mit mutmaßlichen, aber auch verurteilten Kriegsverbrechern näher betrachtet werden. Dabei geht es zum einen um das Verhältnis der Historical Division zu den amerikanischen Strafverfolgungsbehörden in Nürnberg, insbesondere dem Office of the Chief of Counsel for War Crimes. An verschiedenen Beispielen soll hier aufgezeigt werden, wie die Historical Division ganz konkret versuchte, deutsche Offiziere vor Strafverfolgung zu schützen, und wie sie sich im Falle einer Anklage für die Berücksichtigung mildernder Umstände einsetzte. Zum anderen wird die Entnazifizierung der ehemaligen deutschen Offiziere näher betrachtet. Schließlich wird dargestellt werden, wie verurteilte Kriegsverbrecher wie Albert Kesselring, Walter Warlimont und andere von ihren Gefängnissen in Werl und Landsberg aus weiter an der kriegsgeschichtlichen Kooperation beteiligt waren und wie die Historical Division sich für ihre vorzeitige Entlassung einsetzte.

Im zweiten Kapitel dieses Teils wird der Frage nach der Verbreitung und Verwendung der kriegsgeschichtlichen Studien innerhalb der U.S. Armee nachgegangen. Um zu verstehen, warum die Nachfrage nach deutschen Studien zwischen 1948 und 1954 eine Hochphase erlebte und danach rapide nachließ, ist es zunächst notwendig, sich die amerikanische Militärstrategie der 1940er und 1950er Jahre vor Augen zu führen. Vor dem Hintergrund der massiven Einsparungen im Budget der U.S. Armee unter der Truman- und anschließend der Eisenhower-Administration, die sich natürlich auch auf das historische Programm der Landstreitkräfte auswirkten, wird außerdem dargestellt, wie die Historical Division die Kooperation mit der ehemaligen Wehrmachtselite im Kampf gegen Budget- und Personalkürzungen instrumentalisierte. Anschließend wird darauf eingegangen, welche Dienststellen der amerikanischen Streitkräfte die deutschen Materialen verwendeten; dabei werden einige der wichtigsten deutschen Studien kurz inhaltlich skizziert. Im letzten Teil dieses Kapitels wird schließlich am Beispiel der mobilen Verteidigung diskutiert, welchen Einfluss die in den deutschen Studien kondensierten Erfahrungen der ehemaligen Wehrmachtselite auf die Entwicklung der operativen Doktrin der U.S. Armee hatten.

Im dritten und letzten Kapitel dieses Teils werden noch einmal die kultur- und mentalitätsgeschichtlichen Aspekte der kriegsgeschichtlichen Kooperation in den 
Mittelpunkt der Betrachtung gerückt. Zum einen wird die Frage nach Kontinuität und Wandel im Selbstverständnis der ehemaligen Wehrmachtselite im Spannungsfeld von Niederlage, Besatzung und Kaltem Krieg aufgeworfen. Dabei wird einerseits die rhetorisch-ideologische Westorientierung der deutschen Offiziere beleuchtet, andererseits ihre fortdauernde Abgrenzung vom Osten näher erläutert. Im zweiten Teil des Kapitels geht es dann darum darzustellen, welche geschichtspolitischen Ziele die ehemalige Wehrmachtselite im Rahmen der kriegsgeschichtlichen Kooperation verfolgte und auf welche Argumentationsstrategien sie dabei zurückgriff. Vor diesem Hintergrund wird schließlich im letzten Unterkapitel die Bedeutung der Hisorical Division als Agentur der Artikulation analysiert und gefragt, welche konkreten Hilfestellungen die amerikanische Behörde den deutschen Offizieren bei der Umsetzung ihrer Geschichtspolitik bot.

\section{Moral vs. Pragmatismus: Der Umgang der Historical Division mit Kriegsverbrechern}

\subsection{Die Historical Division im Konflikt mit dem Office of the Chief of Counsel for War Crimes}

\section{Konflikt mit dem Office of the Chief of Counsel for War Crimes (OCCWC)}

Kehren wir gedanklich wieder in die Frühphase der kriegsgeschichtlichen Zusammenarbeit zwischen der Historical Division und der ehemaligen Wehrmachtselite zurück, als die deutschen Offiziere sich noch in Kriegsgefangenschaft beziehungsweise Zivilinternierung befanden. Hintergrund der teilweise mehrjährigen Internierung der deutschen Militärs war die 1943 formulierte Absicht der Alliierten, die Verantwortlichen von Kriegs- und Menschenrechtsverbrechen juristisch zur Verantwortung zu ziehen; neben der Bestrafung der Schuldigen sollten die Prozesse außerdem dazu dienen, der deutschen Bevölkerung die Abgründe des Totalitarismus vor Augen zu führen und so zur Umerziehung und Demokratisierung der deutschen Gesellschaft beitragen. ${ }^{1}$ Dazu planten die Amerikaner all diejenigen Personen zu verhaften und anzuklagen, die Kriegs- und NS-Verbrechen begangen bzw. befohlen hatten oder mit deren Wissen und Zustimmung solche Verbrechen ausgeführt worden waren. In der Folge hatten verschiedene Abteilungen der U.S. Streitkräfte Suchlisten mutmaßlicher Kriegsverbrecher erstellt. ${ }^{2}$ Im April 1945 hatte die Direktive JCS 1067 der Vereinten Stabschefs schließlich die Verhaftung und Internierung aller Militärs angeordnet, die möglicherweise an der Planung und Durchführung von Kriegs- und NS-Verbrechen beteiligt waren. In diese Kategorie fielen neben den höchsten Truppenkommandeuren der Wehr-

1 Buscher, The U.S. War Crimes Trial Program in Germany, 1946-1955, S. 8-9; Weinke, Die Verfolgung von NS-Tätern im geteilten Deutschland, S. 26.

2 Kathrin Meyer, Die Internierung von NS-Funktionären in der US-Zone Deutschlands, in: Dachauer Hefte 19 (2003), S. 27-29. 
macht auch die meisten der Generalstabsoffiziere. ${ }^{3}$ Alle mutmaßlichen Kriegsverbrecher sollten bis zur Verhandlung ihrer Fälle vor dem Nürnberger Hauptkriegsverbrechertribunal oder einem der darüber hinaus stattfindenden Prozesse bzw. bis zu ihrer Entnazifizierung interniert bleiben. ${ }^{4}$

Es lag in der Natur der kriegsgeschichtlichen Kooperation, dass die Mitarbeiter der Historical Division insbesondere an der Zusammenarbeit derjenigen deutschen Offiziere interessiert waren, die in den höchsten Positionen in $\mathrm{OKW}, \mathrm{OKH}$, den Heeresgruppen, Armeeoberkommandos und Armeekorps gedient hatten und damit an eben jenen Männern, die prominent auf verschiedenen Kriegsverbrecherlisten vertreten waren. ${ }^{5}$ Franz Halder stand zum Beispiel auf der Liste des Central Registry of War Criminals and Security Suspects (CROWCASS); Heinz Guderians Name fand sich sowohl auf der CROWCASS-Liste als auch auf der Liste der War Crimes Group (WCG) des Theater Judge Advocate for War Crimes. Das Gleiche galt für Günther Blumentritt. Georg von Küchler und Walter Warlimont standen auf der Liste des Office of the Chief of Counsel for War Crimes. ${ }^{6}$

Schon bald kristallisierte sich heraus, dass die Interessen der Historical Division quer zum Bemühen des OCCWC verliefen, mutmaßliche deutsche Kriegsverbrecher zu identifizieren, zu vernehmen und gegebenenfalls anzuklagen. Während die Historical Division die Wehrmachtsführer in ihren Lagern in Allendorf und Garmisch mehr oder weniger hofierte, ${ }^{7}$ arbeiteten die Ermittler und Ankläger des OCCWC daran, einzelne deutsche Generäle und Offiziere vor Gericht zu stellen und andere als Zeugen der Anklage vorzuladen. Zu diesem Zweck transferierte das OCCWC immer wieder deutsche Offiziere als Angeklagte oder Zeugen in eines ihrer Untersuchungsgefängnisse in Nürnberg oder Dachau. Anders als in Allendorf bzw. Garmisch wurde dort mit den Deutschen nicht wie mit geschätzten Kollegen umgegangen, sondern wie mit mutmaßlichen Kriegsverbrechern. Diese als ungerecht und unwürdig empfundene Behandlung führte regelmäßig dazu, dass die deutschen Offiziere ihre Arbeit für die Historical Division vorübergehend und in Ausnahmefällen sogar gänzlich einstellten. ${ }^{8}$ Auch beklagten sich deutsche Offiziere

3 Endfassung der amerikanischen Besatzungsdirektive JCS 1067 vom 26. April 1945 (Auszug), in: Vollnhals (Hg.), Entnazifizierung, S. 100; Rau-Kühne, Wer spät kam, den belohnte das Leben, in: Junker (Hg.), Die USA und Deutschland im Zeitalter des Kalten Krieges 1945-1990, S. 113.

4 Vgl. Meyer, Die Internierung von NS-Funktionären in der US-Zone Deutschlands, S. 27-47.

5 Vgl. James F. Scoggin und Frank C. Mahin, Memorandum an Harold E. Potter, 8. 9. 1946, in: NARA, RG 549, Box 2, Folder 3/6.

6 A. J. Edwards, Liste der auf Kriegsverbrecherlisten geführten deutschen Mitarbeiter in Neustadt, 24. 11. 1947, in: NARA, RG 549, Box 4, Folder 2.

7 Vgl. oben, Teil II, Kapitel 2.1.

8 So weigerte sich zum Beispiel Gustav Hartneck nach einem Aufenthalt in Nürnberg, weiterhin als Zeuge für die Historical Division zu arbeiten: Gustav Hartneck, Schreiben an den deutschen Direktor des Lagers Steinbel [Franz Halder], 11. 10. 1947, in: NARA, RG 549, Box 3140, Folder 4. Auch General Hans von Salmuth und Admiral Otto Schniewind weigerten sich während ihres Aufenthaltes in Nürnberg, Fragen der Historical Division zu beantworten. Vgl. James F. Scoggin, Schreiben an General Zimmermann, 4. 2. 1947, in: NARA, RG 549, Box 8, Folder 1; Frank J. Vida, Schreiben an Harold E. Potter betr. Prisoners of War Transferred to Nurnberg, 14. 5. 1947, in: NARA, RG 549, Box 3, Folder 4. 
immer wieder, dass die Bedingungen im Nürnberger Gefängnis es ihnen unmöglich machen würden, historische Arbeiten auszuführen, da es in den ungeheizten Zellen nicht einmal Tische und Stühle gäbe. ${ }^{9}$ Außerdem befürchteten sie, dass die in Nürnberg angefertigten Arbeiten vor Gericht gegen sie verwendet werden würden. ${ }^{10}$

Angesichts dieser negativen Auswirkungen auf die Arbeitsmoral ihrer deutschen Mitarbeiter empfanden die Offiziere der Historical Division die Tätigkeit des OCCWC als äußerst lästige Beeinträchtigung ihrer Mission und hatten wenig für die strafrechtliche Verfolgung der deutschen Militärs wegen mutmaßlicher Kriegsverbrechen übrig. Frank C. Mahin hielt die Nürnberger Prozesse zum Beispiel für eine Verunglimpfung des deutschen Militärs und bezeichnete sie sogar als „Hexenkessel des Rufmords“. 11 Sein Kollege und Freund James F. Scoggin empfand die regelmäßigen Forderungen des OCCWC nach Überstellung bestimmter deutscher Offiziere als „Plünderungen“.12 Tatsächlich rangierten die Bedürfnisse der amerikanischen Kriegsgeschichtsschreibung in den Augen der meisten Offiziere der Historical Division eindeutig vor der Notwendigkeit, Kriegsverbrechen $\mathrm{zu}$ ahnden. ${ }^{13}$ Dies zeigte sich bereits im Februar 1946, als Harold E. Potter durchzusetzen versuchte, dass der Historical Division ein privilegierter Zugriff auf kriegsgefangene Offiziere gewährt würde. ${ }^{14}$ Sobald ein Kriegsgefangener in die Obhut der War Crimes Commission übergehe, so Potter, sei er - unabhängig vom Ausgang seines Verfahrens - für die Historical Division verloren. Der Chief Historian forderte deshalb, dass „die Historical Division erste Priorität im Bezug auf mutmaßliche Kriegsverbrecher" erhalten „und dass hochrangige kriegsgefangene deutsche Offiziere durch die Historical Division freigegeben werden“ müssten, „bevor sie in Bezug auf Kriegsverbrechen befragt" würden. ${ }^{15}$ Dieses kühne Ansinnen wurde allerdings vom U.S. Chief of Counsel, Brigadier General Telford C. Taylor, rundweg abgelehnt. ${ }^{16}$

${ }^{9}$ Horst von Buttlar, Schreiben an James F. Scoggin, 24. 2. 1947, in: NARA, RG 549, Box 3142, Folder 5; Operational History (German) Section, Weekly Report No. A-1, 7. 12. 1946, in: NARA, RG 549, Box 1, Folder 1.

${ }^{10}$ Siehe zum Beispiel Walter Warlimont, Schreiben an James F. Scoggin, 25.11.1946, in: NARA, RG 549, Box 8, Folder 4.

${ }^{11}$ Frank C. Mahin, Schreiben an S.L.A. Marshall, 1. 12.1953, in: UTEP, MS 186, S.L.A. Marshall Papers, Box 83, Folder 1409.

12 James F. Scoggin und Frank C. Mahin, Seventh Campaign Group Report 4. 5.-30. 6. 1947, High Command Group Report, 1.7.-31.12.1947, 31.12.1947, in: NARA, RG 549, Box 1, Folder 3g.

${ }^{13}$ Vgl. zum Beispiel Operational History (German) Section, Weekly Report No. 21, 1. 6. 1946, in: NARA, RG 549, Box 1, Folder 1; Ders., Weekly Report No. 35, 7. 9. 1946, in: NARA, RG 549, Box 1, Folder 1; Frank C. Mahin, Memorandum an Col. Charles W. Pence betr. Nürnberg, 17.2. 1947, in: NARA, RG 549, Box 3, Folder 4.

${ }^{14}$ C. H. Prizer, Memorandum to Chief, Historical Division, 4. 3. 1946, in: NARA, RG 498, Box 3, Folder 5.

${ }^{15}$ Harold E. Potter, Schreiben an den Chief of Staff, EUCOM betr. Availability of German General Officers (PW) for preparation of history operations against U.S. Troops, 22. 2. 1946, in: NARA, RG 549, Box 2, Folder 3/6. Originalzitat: „Action recommended: [...] 5. That the Historical Division be given first priority on War Crimes suspects and that high ranking German officer PWs be cleared by this Division before they are interrogated for War Crimes."

${ }^{16}$ Robert J. Gill, Schreiben an Harold E. Potter betr. Staff Study on Use of German General Officers (PW) for Historical Interrogations, 23.3. 1946, in: NARA, RG 498, Box 3, Folder 5. 
Das Verhältnis zwischen der Historical Division und dem OCCWC war also durch diametral entgegengesetzte Interessen und einem „beklagenswerten Mangel an Verbindung und Koordination" gekennzeichnet. ${ }^{17}$ Daran konnten auch Konferenzen zur Verbesserung der Zusammenarbeit im September und Oktober 1946 nicht grundsätzlich etwas ändern. ${ }^{18}$ Die Historical Division sah sich deshalb bald in einem regelrechten Wettbewerb mit dem OCCWC um die deutsche Wehrmachtsgeneralität. ${ }^{19}$ In der Folge entwickelte sich ein stetiges Hin und Her zwischen den beiden Dienststellen, bei dem zahlreiche, für die Historical Division tätige deutsche Offiziere mehrfach von Allendorf und Garmisch nach Nürnberg oder Dachau und Tage oder Wochen, manchmal Monate später wieder zurückverlegt wurden. ${ }^{20}$

Da die Historical Division keinen bevorzugten Zugriff auf die deutschen Offiziere hatte, kam sie den Anforderungen des OCCWC meist nur widerwillig nach und tat alles in ihrer Macht stehende, um den Transfer ihrer wichtigsten Mitarbeiter nach Nürnberg zu verhindern oder hinauszuzögern und deren Aufenthalt dort möglichst zu verkürzen. Sie bemühte sich außerdem, die Bedenken der deutschen Offiziere zu zerstreuen, dass ihre in den kriegsgeschichtlichen Berichten gemachten Angaben vor Gericht gegen sie verwendet werden könnten. Als zum Beispiel Walter Warlimont im November 1946 nach Allendorf kam, nachdem er fast das gesamte vorausgegangene Jahr in Gefängnissen des OCCWC verbracht hatte, versprach James F. Scoggin ihm, dass die von ihm verfassten Studien als „privilegierter Informationsaustausch“ behandelt werden würden: „Captain Mahin und ich“, so beteuerte der Amerikaner, „,werden [die Berichte] unter Verschluss halten und werden deren Inhalt bis nach Ihrem Prozess oder bis klar wird, dass Sie gar nicht angeklagt werden, niemandem außerhalb der Historical Division zugänglich machen. "21 Warlimont akzeptierte diese Regelung dankbar. ${ }^{22}$

Warlimonts Sorgen waren nicht aus der Luft gegriffen: Im Herbst 1946 zeichnete sich immer deutlicher ab, dass der OKW-General wegen Kriegsverbrechen

${ }^{17}$ Scoggin und Mahin, Memorandum an Harold E. Potter, 8. 9. 1946, in: NARA, RG 549, Box 2, Folder 3/6. Originalzitat: „There is a lamentable absence of liaison and coordination between the Tribunal and the [Historical] Division."

18 Operational History (German) Section, Weekly Report No.37, 21. 9. 1946, in: NARA, RG 549, Box 1, Folder 1; Operational History (German) Section, Weekly Report No. 38, 28. 9. 1946, in: NARA, RG 549, Box 1, Folder 1.

${ }^{19}$ Howard P. Hudson, Report on Operational History (German) Section, 24. 7. 1946, S. 27 , in: NARA, RG 319, Box 11, Folder 4.

${ }^{20}$ Horst von Buttlar war zum Beispiel vom 13. Januar bis 14. Februar 1947 in Nürnberg und wurde anschließend wieder nach Allendorf zurückverlegt: Buttlar, Schreiben an James F. Scoggin, 24. 2. 1947; Alfred Toppe wurde Ende August 1946 von Allendorf nach Nürnberg überstellt, von dort am 27. November 1946 nach Garmisch verlegt und kehrte dann am 27. Januar 1947 nach Allendorf zurück: Alfred Toppe, Schreiben an Frank C. Mahin, 5. 3. 1947, in: NARA, RG 549, Box 3142, Folder 5.

${ }^{21}$ James F. Scoggin, Schreiben an Walter Warlimont, 20.11. 1946, in: NARA, RG 549, Box 8, Folder 4. Originalzitat: „Captain Mahin and I will keep it [the documents] under lock and key and will not reveal its contents to anyone outside the Historical Division until after your trial, or until it becomes certain that you will not be tried at all."

22 Warlimont, Schreiben an James F. Scoggin, 25. 11. 1946, in: NARA, RG 549, Box 8, Folder 4. 
angeklagt werden würde. Tatsächlich musste ihn die Historical Division bereits Ende Dezember, und damit nur sechs Wochen nach seinem Eintreffen in Allendorf, erneut nach Nürnberg überstellen. Für die Operational History (German) Section war das ein schwerer Schlag. Denn dort schätzte man Warlimont als einen „Mann von fast unvergleichbarer Erfahrung, Wichtigkeit, Fähigkeit und Kooperationsbereitschaft" und war überzeugt, dass er auch in Zukunft von großer Bedeutung für die Arbeit der Abteilung sein würde. ${ }^{23}$ Es schien James F. Scoggin daher geraten, sich beim OCCWC für den deutschen General einzusetzen. Auch wenn er die Chancen, eine Anklage des ehemaligen stellvertretenden Chefs des Wehrmachtsführungsstabes tatsächlich verhindern zu können, als gering einschätzte, bat er Harold E. Potter, das OCCWC wissen zu lassen, dass die Historical Division auch weiterhin „sehr großes Interesse“ an Warlimonts Mitarbeit habe. Außerdem sollte Potter darauf drängen, dass die „kooperative Haltung“ des Deutschen „größtmögliche Berücksichtigung" bei der Entscheidung finden sollte, ob Warlimont angeklagt werden würde oder nicht bzw. dass seine Kooperationsbereitschaft im Falle einer Anklage mildernd berücksichtigt würde. ${ }^{24}$

Letztlich bewirkten die Hilfeleistungen der Historical Division zumindest im Fall von Walter Warlimont allerdings wenig. Im November 1947 wurde er zusammen mit 13 weiteren hochrangigen Militärs im sogenannten OKW-Prozess angeklagt. Die Operational History (German) Section musste damit - zumindest vorübergehend - nicht nur auf Warlimont, sondern auch auf Wilhelm Ritter von Leeb, Georg von Küchler, Hans von Salmuth, Georg-Hans Reinhardt, Karl Hollidt und Rudolf Schniewindt verzichten. Aus Sicht der Historical Division versetzte das OCCWC der kriegsgeschichtlichen Kooperation damit den „bisher schwersten Schlag“: Auf einmal verlor die Operational History (German) Section „zwei Feldmarschälle, vier Truppengeneräle und den [...] Stellvertreter von Jodl“ und musste somit mehrere wichtige Positionen in Allendorf neu besetzen. ${ }^{25}$

Auch an der Person von Franz Halder lässt sich der Konflikt zwischen der Historical Division und dem OCCWC festmachen. Obschon eine Anklage im Falle von Franz Halder schnell vom Tisch war, da Telford C. Taylor es nicht für opportun hielt, einen Mann anzuklagen, der mehrere Monate als Gefangener Hitlers in verschiedenen Konzentrationslagern verbracht hatte, ${ }^{26}$ so wurde der ehemalige

${ }^{23}$ James F. Scoggin, Letter of Transmittal an Harold E. Potter, 31. 12. 1946, in: NARA, RG 549, Box 3, Folder 4. Originalzitat: „Warlimont is a man of almost incomparable experience, importance, ability, and cooperation. We have needed him, we do need him, and we will need him."

24 Ders., Entwurf eines Schreibens von Harold E. Potter an OCCWC betr. Future Disposition of POW (General der Artillerie) Walter Warlimont, 31.12.1946, in: NARA, RG 549, Box 3, Folder 4. Originalzitat: „This Division wishes to affirm its very keen interest in securing once more the services of [Walter Warlimont] at the earliest possible date. Further, this Division urges that the cooperative attitude of subject POW be given maximum consideration possible in the determination of whether or not he is to be tried, and - if he is tried - that his cooperative attitude be considered in extenuation."

25 Operational History (German) Section, Weekly Report No. A-42, 7. 10. 1947, in: NARA, RG 549, Box 1, Folder 1.

${ }^{26}$ Frank C. Mahin, Minutes on Conference at Nuernberg, 3 April 1947, 8. 4. 1947, in: NARA, RG 549, Box 3, Folder 4; vgl. auch Ueberschär, Generaloberst Franz Halder, S. 86-87. 
Generalstabschef doch immer wieder als Zeuge oder zu Konsultationen bezüglich seines Kriegstagebuches nach Nürnberg beordert. So zum Beispiel im Januar 1947, als das OCCWC Halders Anwesenheit in Nürnberg verlangte, um Unklarheiten in dessen Aufzeichnungen zu klären. ${ }^{27}$ Halder erinnerte sich mit großem Missfallen an seine Zeit im Nürnberger Gefängnis zwischen Januar und August 1946 zurück und zeigte sich dementsprechend wenig begeistert von der Aussicht, in den Justizpalast zurückzukehren. Er drohte damit, seine Arbeit für die Historical Division im Falle seiner Transferierung nach Nürnberg endgültig einzustellen. ${ }^{28}$ Da Halder als unentbehrlich und unersetzlich für die Arbeit der Operational History (German) Section galt, setzte die Historical Division alle Hebel in Bewegung, um ihn in Allendorf zu behalten. Harold E. Potter wandte sich deshalb hilfesuchend an den Chief of Staff der U.S. Streitkräfte in Europa, Lieutenant General Clarence R. Huebner. Dieser wies das OCCWC daraufhin prompt an, einen Vertreter nach Allendorf zu entsenden, der vor Ort mit Halder an der Übersetzung seines Tagebuchs arbeiten sollte. ${ }^{29}$

Auch als das OCCWC Halder im November 1947 erneut anforderte, brachte James F. Scoggin seine „sehr starke Ablehnung“ eines solchen Ansinnens deutlich zum Ausdruck:

„Nuernberg's need for Halder is much less than ours: a. We have already permitted [Arnold] Lissance, who transcribed Halder's diary, to monopolize Halder for week after week. Although Lissance's work with Halder is worth while, ours is certainly more important. b. Nuernberg has 4 or 5 men who want to talk to Halder about his diary; we have 150 men who want to talk with him almost continuously about the Wehrmacht from 1938-45. c. Nuernberg must complete its indictments by $31 \mathrm{Dec}[$ ember 19]47; we must retrench from 150 writers to 50 by 31 Dec[ember 19]47. So far as is known, Nuernberg has no deadline for its trials; we must terminate our writing by 31 Mar[ch 19]47.“30

Dieses Mal ließ sich Halders Überstellung jedoch nicht verhindern. Dass seine Frau ihn nach Nürnberg begleiten konnte und die beiden in privaten Quartieren untergebracht wurden, ${ }^{31}$ scheint den ehemaligen Generalstabschef jedoch besänftigt zu haben - jedenfalls stellte er seine Kooperation mit der Historical Division entgegen seiner früheren Androhung nicht ein.

${ }^{27}$ Operational History (German) Section, Weekly Report No. A-8, 27. 1. 1947, in: NARA, RG 549, Box 1, Folder 1.

${ }^{28}$ Ders., Operations Log Operational History (German) Section, 8. 2. 1947, in: NARA, RG 549 , Box 5, Folder 2.

${ }^{29}$ Harold E. Potter, Schreiben an den Chief of Staff, USFET, LTG Clarence R. Huebner betr. Movement of PW (Genobst) Halder to Nuremberg for Interrogation by Subsequent Proceedings Authority, 8. 2.1947, in: NARA, RG 549, Box 3, Folder 4; Asst to the Chief of Staff Colonel John G. Hill, Notiz an General Huebner, 8. 2. 1947, in: NARA, RG 549, Box 3, Folder 4; Harold E. Potter, Memorandum an den Chief, Operational History Branch, 10. 2. 1947, in: NARA, RG 549, Box 3, Folder 4.

${ }^{30}$ James F. Scoggin, Memorandum an Lt. Col. James W. Coutts, 16.11.1947, in: NARA, RG 549, Box 3, Folder 4.

${ }^{31}$ James W. Coutts, Memo an Harold E. Potter, 25. 11. 1947, in: NARA, RG 549, Box 3, Folder 4 . 


\section{Kampf gegen die Auslieferung an andere Staaten: Die Fälle Hans Gustav Felber, Heinz Guderian und Wilhelm Bittrich}

Abgesehen von der Verfolgung von Kriegsverbrechern durch amerikanische Behörden stieß sich die Historical Division auch an der Auslieferung deutscher Militärs an andere alliierte Staaten. Da eine Auslieferung die deutschen Offiziere dem Zugriff der Operational History (German) Section gänzlich zu entziehen drohte, versuchte die Historical Division wiederholt, die Überstellung einiger besonders wichtiger deutscher Offiziere an Drittstaaten zu verhindern. Als Polen zum Beispiel im Herbst 1947 die Auslieferung von mehreren für die Historical Division tätigen deutschen Offizieren (darunter zwei Offiziere der Waffen-SS) beantragte, legte die Historical Division Veto gegen eine Überstellung an die polnische Regierung ein, da „die Abziehung dieser Offiziere [von der kriegsgeschichtlichen Arbeit] und deren Übergabe an die Polen die ausgezeichnete Kooperation zerstören würde“.32 In den Augen der Historical Division besaßen die deutschen Militärs „wertvolle Informationen für die [amerikanische] Regierung und ihre Auslieferung sollte sich an diesem Faktum orientieren und an keinem anderen" .33 Mögliche „moralische Verpflichtungen“, die deutschen Offiziere vor Gericht zu stellen, hatten demnach hinter Nützlichkeitserwägungen zurückzustehen. ${ }^{34}$

Etwa ein halbes Jahr später, im März 1948, setzte sich Harold E. Potter dafür ein, dass der ehemalige General der Infanterie Hans Gustav Felber ${ }^{35}$ nicht an Jugoslawien ausgeliefert wurde. In einem Schreiben an die Legal Division von OMGUS begründete Potter seinen Einspruch damit, dass eine Auslieferung Felbers, der momentan in Neustadt an kriegsgeschichtlichen Studien arbeite, aber Ende März entlassen werden sollte, an das kommunistische Jugoslawien ein „Sicherheitsproblem" ${ }^{\text {"36 }}$ darstellen würde. Potter führte weiter aus:

„Felber has been engaged on activities important to our National Defense and of necessity knows the organization, work plan, and personnel involved at the Neustadt Camp. He is also aware of the names of personnel employed by our Armed Forces on highly classified projects. [...] It is considered unwise to present this source of information to the Yugoslav Government, and it is believed that consideration should be given to denial or postponement of Felber's extradition to Yugoslavia, upon his release from employment by this office."

Tatsächlich wurde Felber nicht an Jugoslawien ausgeliefert. ${ }^{37}$ Nach seiner Entlassung aus der Zivilinternierung trat er im Juli 1948 als technischer Angestellter in die Feinkostfabrik seiner Schwiegereltern in Frankfurt ein. ${ }^{38}$

32 Harry J. Malony, Memorandum for Deputy Chief of Staff on Historical Studies, German Army, 28. 10. 1947, in: NARA, RG 319, Box 7, Folder 8.

${ }^{33}$ Ebd.

${ }^{34}$ Ebd.

${ }^{35}$ Hans-Gustav Felber (1889-1962) war von Mitte August 1943 bis Herbst 1944 Oberbefehlshaber Südost.

${ }^{36}$ Harold E. Potter, Schreiben an die Legal Division OMGUS betr. Extradition of Former German Officer, 2.3. 1948, in: NARA, RG 549, Box 3172, Folder 2.

${ }^{37}$ Vernehmungsprotokoll vom 16.3.1949 im Ermittlungsverfahren der Oberstaatsanwaltschaft beim Landgericht in Frankfurt gegen Hans Gustav Felber, in: HHStAW, Abt. 631a, Nr. 1431.

${ }^{38}$ Zwar leitete die Oberstaatsanwaltschaft beim Landgericht Frankfurt 1949 ein Ermittlungsverfahren gegen Felber wegen des Verdachts auf völkerrechtswidrige Geiselerschie- 
Auch bei anderen deutschen Offizieren suchte die Historical Division eine Auslieferung zu verhindern: Zwischen 1947 und 1949 stellte die polnische Regierung mindestens zwei Anträge auf Auslieferung Heinz Guderians, um ihn im Zusammenhang mit der Niederschlagung des Warschauer Aufstands vom Sommer 1944 vor Gericht zu stellen. ${ }^{39}$ Beide Male lehnten die USA eine Überstellung des Generaloberst ab. Im Dezember 1947 begründete der Deputy Judge Advocate for War Crimes die Ablehnung des Gesuchs damit, dass amerikanische Behörden - sprich die Historical Division - die Anwesenheit Guderians „für eine unbestimmte Zeitspanne" benötigen würden. ${ }^{40}$ Guderian arbeitete denn auch weiter für die Historical Division, die seine Beiträge als „außerordentlich wichtige“ Informationsquelle für die nachrichtendienstliche Abteilung der U.S. Armee sowie für Planung und Training der U.S. Streitkräfte einschätzte. ${ }^{41}$

Nachdem auch die zweite Anfrage der Polen 1948 abgelehnt worden war, veranlasste die Historical Division, dass Guderian sich in der oberbayerischen Kleinstadt Dietramszell niederließ, „wo er der Öffentlichkeit weniger ausgesetzt sein würde“. Außerdem ließ Harold E. Potter Guderian wissen, dass er auf die Zuständigkeit der Historical Division verweisen solle, falls seine künftige kriegsgeschichtliche Arbeit durch Maßnahmen des U.S. Militärs oder von OMGUS behindert werden würde. ${ }^{42}$ Guderian war der Historical Division für diese „Lösung“ sehr dankbar, nach der „alles wunschgemäß geregelt“ sei. Dem noch bevorstehenden Spruchkammerverfahren sah er angesichts der Tatsache, dass die Spruchkammern in Neustadt fast alle Generalstabsoffiziere und Generale als unbelastet eingestuft hatten, „mit Ruhe entgegen“. 43

Als Guderian Anfang 1949 einen Artikel im Armored Cavalry Journal veröffentlichte, befürchtete die Historical Division, dass dies einen erneuten Antrag auf Auslieferung seitens der Polen nach sich ziehen könnte. Daher wandte sich Harry J. Malony im Februar 1949 quasi in einem präventiven Schritt an General Stafford Leroy Irwin, den Director of Intelligence im Department of the Army, und ließ ihn wissen, dass die Historical Division angesichts Guderians „bisheriger Beiträge, seiner Kenntnis klassifizierter Teile des historischen Programms und seiner gegenwärtigen Arbeit für die U.S. Armee“ großes Interesse daran habe, seine Aus-

Bungen in seiner Zeit als Militärbefehlshaber Südost ein, das Verfahren wurde jedoch im August 1953 eingestellt. Vgl. Ermittlungsverfahren der Oberstaatsanwaltschaft beim Landgericht Frankfurt gegen Hans Gustav Felber, in: HHStAW, Abt.631a, Nr. 1432, Bl. 257-283.

${ }^{39}$ Vgl. Walde, Guderian, S. 277.

${ }^{40}$ Major Fred W. Ludecke, Schreiben an das Polish War Crimes Liaison Detachment, 9. 12. 1947, in: BArch, N 802/103.

${ }^{41}$ Harry J. Malony, Memorandum for General Irwin, 14.2. 1949, in: NARA, RG 319, Box 8, Folder 5; Harold E. Potter, Schreiben an Heinz Guderian, 15. 6. 1948, in: NARA, RG 549, Box 3143, Folder 4.

42 Potter, Schreiben an Heinz Guderian, 15. 6. 1948, in: NARA, RG 549, Box 3143, Fol$\operatorname{der} 4$.

${ }^{43}$ Heinz Guderian, Schreiben an Geyr von Schweppenburg, 31.5. 1948, in: IfZArch, ED $91 / 18$. 
lieferung zu verhindern. ${ }^{44}$ Um die Aufmerksamkeit der Öffentlichkeit nicht auf Guderians Nachkriegsaktivitäten zu lenken, zögerte die Historical Division außerdem die Entnazifizierung des deutschen Offiziers hinaus. ${ }^{45}$ Im Juli 1949 beteuerte die Historical Division schließlich noch einmal ihren „Wunsch, Guderians Auslieferung zu blockieren ". 46 Tatsächlich wurde der Deutsche nicht an Polen ausgeliefert; alle Anklagen wegen Kriegsverbrechen wurden mangels Beweisen fallengelassen. ${ }^{47}$ Trotz seiner herausgehobenen militärischen Stellung während des Dritten Reiches musste sich der ehemalige Generaloberst auch nie einer formellen Entnazifizierung stellen - das Verfahren wurde im März 1950 eingestellt. ${ }^{48}$

Im Falle des Waffen SS-Generals Wilhelm Bittrich ${ }^{49}$ konnte die Historical Division die Auslieferung dagegen nicht verhindern - wohl auch deshalb, weil es sich bei dem Antragsteller nicht um ein osteuropäisches Land, sondern um Frankreich handelte. Am 13. Januar 1948 lieferten die Amerikaner Bittrich an die französische Regierung aus, die ihn wegen Kriegsverbrechen vor Gericht stellen wollte. Die Anklage betraf die Ermordung französischer Widerstandskämpfer im Februar 1944 durch die 9. SS-Panzerdivision „Hohenstaufen“, deren Kommandeur Bittrich zu diesem Zeitpunkt gewesen war. Allerdings zögerte sich die Prozesseröffnung hinaus und Bittrich saß jahrelang in Marseilles in Untersuchungshaft, bevor die französischen Behörden schließlich im Juni 1953 Anklage erhoben. Zunächst musste nämlich langwierig geklärt werden, ob Bittrich weiterhin als Kriegsgefangener zu behandeln sei und damit bestimmte Sonderrechte nach der Genfer Konvention zur Behandlung von Kriegsgefangenen von 1929 beanspruchen konnte. ${ }^{50}$

In diesem Zusammenhang wandte sich Bittrich 1951 hilfesuchend an die Historical Division in Karlsruhe. Dort erinnerte man sich gerne an dessen „treu“" Mitarbeit und hatte ein starkes Interesse daran, dass der frühere Waffen-SS General sich auch in Zukunft an der kriegsgeschichtlichen Kooperation beteiligen würde. ${ }^{51}$

${ }^{44}$ Malony, Memorandum for General Irwin, 14. 2. 1949, in: NARA, RG 319, Box 8, Folder 5. Originalzitat: „This memorandum is submitted to [...] reaffirm [the Historical] Division's desire to prevent the extradition of Guderian in view of his past contributions, his familiarity with classified portions of the historical program, and his current work for the U.S. Army."

${ }^{45}$ Ebd.

${ }^{46}$ Frank C. Mahin, Report of Activities, Foreign Studies Section (20.6.-11.7. 1949), 11. 7. 1949, in: NARA, RG 319, Box 23, Progress Reports, Foreign Sudies 1949.

${ }^{47}$ Macksey, Generaloberst Heinz Guderian, in: Ueberschär (Hg.), Hitlers militärische Elite, S. 85-86.

48 Vgl. Walde, Guderian, S. 279.

${ }^{49}$ Bittrich war am 8. Mai 1945 in Österreich in amerikanische Gefangenschaft gegangen und arbeitete ab August 1946 für die Historical Division an Studien zu den Operationen in der Normandie und Nordfrankreich. James W. Coutts, Bestätigung der Mitarbeit, 22. 12. 1947, in: NARA, RG 549, Box 2, Folder: Wilhelm Bittrich; Operational History (German) Section, Campaign: Northern France, in: NARA, RG 549, Box 3, Folder 11.

50 Vgl. Mühleisen, Wilhelm Bittrich, in: Smelser/Syring (Hg.), Die SS: Elite unter dem Totenkopf, S. 84-85.

${ }^{51}$ Vgl. u. a. W. S. Nye, Schreiben an Thomas H. Young, 9. 5. 1951, in: NARA, RG 549, Box 3154, Folder 4; Thomas H. Young, Schreiben an Albert Pascalet, Verteidiger von Wilhelm Bittrich, 5. 5. 1951, in: NARA, RG 549, Box 3154, Folder 4; Ders., Schreiben an den Commander-in-Chief, Headquarters, European Command, 18. 5. 1951, in: NARA, 
Um Bittrich für eine solche Mitarbeit zu gewinnen, unterstützte die Historical Division den Deutschen daher 1951 aktiv in seiner Verteidigung. Um den guten Willen der kriegsgeschichtlichen Abteilung zu unterstreichen, besuchte Colonel Thomas H. Young Bittrich im März 1951 in seinem Gefängnis in Marseilles und informierte sich vor Ort über die Situation des ehemaligen Generals. ${ }^{52}$ Bittrichs Verteidiger Albert Pascalet versicherte Young, dass es keinerlei Beweise für Bittrichs Schuld gebe. Er wies jedoch nachdrücklich darauf hin, dass es angesichts der in Marseilles herrschenden, ,außerordentlich feindlichen“ Stimmung gegen seinen Mandanten „unmöglich“ sein würde, Gerechtigkeit für Bittrich zu erlangen, da die aufgeladene Atmosphäre das örtliche Militärgericht zuungunsten seines Mandanten beeinflusse. ${ }^{53}$ Young versprach daraufhin, sich für Bittrich einzusetzen. Tatsächlich begab sich Young von Marseilles nach Genf und brachte Bittrichs Fall dort beim Verwaltungsdirektor des Internationalen Roten Kreuzes vor, der zusagte, sich für eine Verlegung des Gerichtsortes einzusetzen. ${ }^{54}$

Wenig später, am 18. April 1951, kontaktierte Pascalet seinerseits die Historical Division, und bat um weitere Unterstützung bei der Verteidigung seines Mandanten. Um Bittrichs andauernde Kriegsgefangenschaft zu belegen, bat Pascalet die Historical Division Dokumente zu beschaffen, die bestätigen würden, dass Bittrich zum Zeitpunkt seiner Auslieferung an Frankreich im Januar 1948 noch immer den Status eines Kriegsgefangenen innegehabt habe. ${ }^{55}$ Das war jedoch höchst unwahrscheinlich. Denn die meisten der in Allendorf für die Historical Division tätigen Offiziere waren im Juni 1947 aus der Kriegsgefangenschaft entlassen und entweder freigesetzt oder in den Status von Zivilinternierten überführt worden. Pascalet hielt die Unterscheidung zwischen Kriegsgefangenen- und Zivilinterniertenstatus jedoch für spitzfindig. Er hoffte die französischen Behörden überzeugen zu können, dass Bittrich als Kriegsgefangener zu betrachten sei - denn dies hätte bedeutet, dass der Fall auf der Grundlage von Artikel 63 der Genfer Konvention verhandelt werden würde. Damit würde Bittrichs Prozess nicht vor dem aus niedrigeren Offiziersrängen zusammengesetzten Militärgericht in Marseilles, sondern vor einem aus Generälen bestehenden Gerichtshof in Paris stattfinden. ${ }^{56}$ Dahinter stand das doppelte Kalkül, dass die Verhandlung so zum einen nicht von der angespannten Atmosphäre in Marseilles beeinflusst werden würde, und dass zum anderen Vertreter seines eigenen Standes Bittrich eventuell geneigter sein wür-

RG 549, Box 3154, Folder 4; Hugh M. Cole, Memorandum betr. The Ardennes Campaign and General Wilhelm Bittrich, 19. 6. 1951, in: NARA, RG 549, Box 3154, Folder 4.

52 Wilbur S. Nye, Schreiben an Lt. Col. Gerald L. Roberson, Military Mission to French Forces of Occupation, Baden-Baden, 20.3. 1951 in: NARA, RG 549, Box 3154, Folder 4.

53 Thomas H. Young, Schreiben an Lt. Col. Woodrow W. Stromberg, Chief, Training Branch, Military Assistance Advisory Group, American Embassy, France, 24. 4. 1951, in: NARA, RG 549, Box 3154, Folder 4.

${ }^{54}$ Ebd.

55 Albert Pascalet, Schreiben an Thomas H. Young, 18.4.1951, in: NARA, RG 549, Box 3154, Folder 4.

56 Thomas H. Young, Schreiben an Colonel W. S. Nye, 26. 4. 1951, in: NARA, RG 549, Box 3154, Folder 4; Schreiben des Comité International de la Croix-Rouge. Agence Centrale des Prisonniers de Guerre. Délégation en France an Thomas H. Young betr. General Wilhelm Bittrich, 28. 4. 1951, in: NARA, RG 549, Box 3154, Folder 4. 
den. ${ }^{57}$ Falls die amerikanischen Behörden also die entsprechenden Dokumente zur Verfügung stellen könnten - ein Vorgang, der nach Pascalets Auffassung eine Frage der richtigen „Interpretation“ der Dinge darstellte - würde sich dies ungemein positiv auf den Fall auswirken. ${ }^{58}$

Pascalets Argumentation fiel bei Thomas H. Young auf äußerst fruchtbaren Boden. Denn der Amerikaner betrachtete es geradezu als „moralische Pflicht", Bittrich nach Kräften zu unterstützen:

„From the time of his being taken prisoner up to the recent date, General Bittrich has collaborated faithfully in [...] the historical program [...]. As a result of this association, if not for other reasons, this division feels it to be our moral duty to provide the defense with whatever evidence is favorable to it which may be found in our files. " 59

Young versprach Bittrichs Anwalt, bei seinen Bemühungen, „vollständige Gerechtigkeit“ für Bittrich zu erreichen, „keinen Stein auf dem anderen zu lassen“ ${ }^{60}$ In den folgenden Wochen setzte Young tatsächlich alle Hebel in Bewegung, um dem Deutschen zu helfen. Auf der Suche nach den benötigten Dokumenten wandte er sich zum Beispiel an die Judge Advocate Division von EUCOM. ${ }^{61}$ Darüber hinaus trat er mit der zentralen Rechtsschutzstelle im Bundesjustizministerium in Verbindung. ${ }^{62}$ Da sich der Chef der Historical Division, EUCOM, Wilbur S. Nye, gerade in Washington aufhielt, nutzte Young außerdem die Gelegenheit und bat ihn, sich wegen der benötigten Unterlagen direkt mit dem Provost Marshal im Pentagon in Verbindung zu setzen. ${ }^{63}$

Anfang Mai besuchte Nye daraufhin persönlich das Enemy Prisoner of War Information Bureau in Fort Holabird, Maryland, um die benötigten Unterlagen ausfindig zu machen. Allerdings erwiesen sich die gefundenen Informationen als wenig hilfreich. Nyes Recherchen ergaben zwar, dass einige wenige der deutschen Offiziere in Allendorf, die von alliierten Mächten als mutmaßliche Kriegsverbrecher geführt wurden, den Status von Kriegsgefangenen auch über den 30. Juni 1947 hinaus behalten hatten. Allerdings fand sich in Bittrichs Akte keinerlei Hinweis, dass er zu dieser kleinen Gruppe gehört hatte. ${ }^{64}$ Nye leitete dennoch alle in

57 Dr. Th. Breymeier, Schreiben an Heinz Guderian, 18. 7. 1952, in: BArch, N 802/75.

58 Pascalet, Schreiben an Thomas H. Young, 18. 4. 1951, in: NARA, RG 549, Box 3154, Folder 4 .

59 Thomas H. Young, Internal Route Slip an die Judge Advocate Division, EUCOM betr. Bittrich Case, 4. 5. 1951, in: NARA, RG 549, Box 3154, Folder 4.

${ }^{60}$ Young, Schreiben an Albert Pascalet, 5. 5. 1951, in: NARA, RG 549, Box 3154, Folder 4. Originalzitat: „As I told you and General Bittrich at the time of my recent visit to Marseilles, I will not leave a stone unturned in my efforts to see that General Bittrich obtains complete justice in his pending case."

${ }^{61}$ Ders., Internal Route Slip an die Judge Advocate Division, EUCOM betr. Bittrich Case, 4. 5. 1951, in: NARA, RG 549, Box 3154, Folder 4; Lt. Col. T. L. Borom, Internal Route Slip der Judge Advocate War Crimes Branch an die Historical Division betr. Bittrich Case, 16. 5. 1951, in: NARA, RG 549, Box 3154, Folder 4.

62 Young, Schreiben an Albert Pascalet, 5. 5. 1951, in: NARA, RG 549, Box 3154, Folder 4; Thomas H. Young, Schreiben an Dr. Gawlik, Zentrale Rechtsschutzstelle, Bundesjustizministerium, 17. 5. 1951, in: NARA, RG 549, Box 3154, Folder 4.

${ }^{63}$ Young, Schreiben an Colonel W. S. Nye, 26. 4. 1951, in: NARA, RG 549, Box 3154, Folder 4.

${ }^{64}$ Nye, Schreiben an Thomas H. Young, 9. 5. 1951, in: NARA, RG 549, Box 3154, Folder 4. 
Fort Holabird lagernden relevanten Dokumente zu Bittrich an Young weiter. Dabei unterstrich er noch einmal das nach wie vor große Interesse der Historical Division an einer weiteren Kooperation mit dem Deutschen:

„Bittrich is absolutely the key informant in the volume which Dr. Hugh Cole is writing on the Ardennes Campaign. Unless and until Cole gets more data from Bittrich, this work is going to suffer or be held up, and the United States has [sic] already spent many thousands of dollars on the project. We feel that Bittrich will open the way to our obtaining data from other former SS commanders and staff officers (many of whom served under Bittrich) and who so far have refused to cooperate. I believe that Bittrich, who will owe us a lot, will be most helpful." 65

Aus diesen Ausführungen wird deutlich, dass die Historical Division den WaffenSS-General keineswegs nur aus einem Gefühl der „moralischen Verpflichtung“ gegenüber einem früheren Mitarbeiter heraus unterstützte, sondern dass sie mit der Hilfestellung für Bittrichs Verteidigung ein ganz konkretes eigennütziges Interesse verfolgte. Bittrich sollte zum einen zusätzliche Informationen für die amtliche amerikanische Kriegsgeschichte zur Ardennen-Offensive liefern und darüber hinaus weitere ehemalige Waffen-SS-Offiziere zur Kooperation mit der Historical Division bewegen, die sich einer Zusammenarbeit bislang verweigert hatten. Die Frage, ob Bittrich tatsächlich für Kriegsverbrechen verantwortlich war oder nicht, spielte bei den Überlegungen der Historical Division keine Rolle.

Zusammen mit Nyes Brief erhielt Young auch die Unterlagen aus Fort Holabird. Diese enthielten unter anderem eine Bescheinigung über Bittrichs Internierung durch die Amerikaner, die der Direktor des Enemy Prisoner of War Information Bureau, Lieutenant Colonel Joseph O. C. Ducharme, auf Basis der vorhandenen Dokumente ausgestellt hatte. Der letzte Satz der Bescheinigung lautete: „All United States-held internees were discharged from prisoner-of-war status prior to 4 July 1947."66 Diese Formulierung deutete indirekt darauf hin, dass auch Bittrich 1947 aus der Kriegsgefangenschaft entlassen worden war, und drohte daher den Zweck des Schreibens zu konterkarieren. Young bat Ducharme daher, ihm ein weiteres Exemplar der Bescheinigung zuzusenden - dieses Mal ohne den verräterischen letzten Satz. „Unter den gegebenen Umständen“, so Young,

„die es ehemaligen deutschen Offizieren zunehmend schwierig machen ein gerechtes Verfahren in Frankreich zu erhalten, sollten wir es den Anklägern überlassen, belastende Fakten oder Umstände dieser Art auszugraben, und nicht die Verteidigung behindern, indem wir Informationen weitergeben, die nicht in den Akten sichtbar sind."67

Auf Grundlage der von der Historical Division beschafften Dokumente ${ }^{68}$ verfasste Pascalet schließlich ein Memorandum, das Bittrich als Kriegsgefangenen darstell-

${ }^{65}$ Ebd.

${ }^{66}$ Zit. nach Thomas H. Young, Schreiben an Lt. Col. Joseph O. C. Ducharms, Director, Enemy Prisoner of War Information Bureau, Fort Holabird, Maryland, 17. 5. 1951, in: NARA, RG 549, Box 3154, Folder 4.

${ }^{67}$ Ebd. Originalzitat: „I feel that under the circumstances, which make it exceedingly difficult for ex-German officers to obtain a just trial in France, we should leave it to the prosecution to dig up damaging facts or circumstances of this nature and not handicap the defense by including information which is not shown in the records."

${ }^{68}$ Ders., Schreiben an Albert Pascalet, 18. 5. 1951, in: NARA, RG 549, Box 3154, Folder 4. 
te, und er war optimistisch, dass das Berufungsgericht in Paris sich seiner Ansicht anschließen würde. ${ }^{69}$

Auch nachdem er die gewünschten Dokumente an Pascalet weitergeleitet hatte, setzte Thomas H. Young sein Engagement für dessen Mandanten fort. Er kontaktierte zum Beispiel Major General George J. Richards, den Chief der Military Advisory Group in der amerikanischen Botschaft in Paris, bezüglich Bittrichs Verfahren. In seinem Schreiben schloss sich Young der Meinung Albert Pascalets an, dass ein Verfahren vor einer Jury aus Generälen in Paris zum Vorteil Bittrichs sein würde. Das Militärgericht in Marseilles, so Young, bestünde aus ehemaligen Angehörigen der Résistance, deren militärischer Rang zu niedrig und deren Erfahrung zu gering sei, „um die Implikationen der Verantwortlichkeiten eines kommandierenden Generals im Felde angemessen abwägen zu können “ ${ }^{70}$ Young bat Richards daher, den Franzosen gegenüber bei Gelegenheit deutlich zu machen, dass die Amerikaner es gerne sähen, wenn Bittrichs Fall vor einem Gericht aus Generälen verhandelt werden würde. ${ }^{71}$

Schließlich wandte sich Young sogar an den Commander-in-Chief von EUCOM, General Thomas T. Handy. Young betonte die Bedeutung Bittrichs für die Historical Division und legte dem Oberbefehlshaber die schwierige Situation folgendermaßen dar: Bittrich werde nunmehr seit drei Jahren in Frankreich festgehalten, ohne dass ihm der Prozess gemacht worden sei. Da dies den Bedingungen widerspreche, zu denen die USA Bittrich im Januar 1948 an die Franzosen ausgeliefert hätten, bat er ihn, die Rücktransferierung des Deutschen an die Vereinigten Staaten zu verlangen, falls die Franzosen ihn nicht innerhalb von sechs Monaten vor Gericht stellen würden. ${ }^{72}$ Dieser Vorstoß blieb allerdings ohne Erfolg. Das Office of the Deputy Chief of Staff for Operations, EUCOM war nicht überzeugt, dass Bittrich unentbehrlich für die Fertigstellung des Ardennen-Manuskriptes sei; auch ein entsprechendes Memorandum von Hugh M. Cole änderte letztlich nichts an dieser Einschätzung. ${ }^{73}$ EUCOM unternahm daher keinerlei Schritte, um eine Rückführung Bittrichs an die USA zu erreichen.

${ }^{69}$ Albert Pascalet, Schreiben an Thomas H. Young, 23.11.1951, in: NARA, RG 549, Box 3155, Folder 8.

70 Thomas H. Young, Schreiben an Major General George J. Richards, Chief, Military Assistance Group, American Embassy, France, 16. 5. 1951, in: NARA, RG 549, Box 3154, Folder 4. Originalzitat: „[H]e will be faced with the double handicap of a hostile locality and a hostile tribunal composed for the most part of ex-members of the ,Maquis with insufficient rank and experience to properly weigh the implications of a Commanding Generals responsibilities in the field."

${ }^{71} \mathrm{Ebd}$.

72 Young, Schreiben an den Commander-in-Chief, Headquarters, European Command, 18. 5. 1951, in: NARA, RG 549, Box 3154, Folder 4.

73 Thomas H. Young, Schreiben an R. C. Hagen, President, HICOG Extradition Board, 21.6. 1951, in: NARA, RG 549, Box 3154, Folder 4; W. S. Nye, Schreiben an Hugh M. Cole, OCMH, 11.6.1951, in: NARA, RG 549, Box 3154, Folder 4; Brigadier General Edward T. Williams, Schreiben an die Historical Division, EUCOM, betr. Extradition of Former German General Wilhelm Bittrich, 7.6.1951, in: NARA, RG 549, Box 3154, Folder 4; W. S. Nye, Schreiben an Chief of Staff, EUCOM, 2. 7. 1951, in: NARA, RG 549, Box 3154, Folder 4. 
Pascalet und die Historical Division waren letztlich nicht erfolgreich: Sie konnten nicht verhindern, dass Wilhelm Bittrich der Kriegsgefangenenstatus aberkannt wurde. Der Prozess gegen Bittrich begann am 16. Juni 1953 vor einem einfachen Militärgericht in Marseilles. Da Bittrich zunächst nichts von der Erschießung der 17 französischen Widerstandskämpfer durch Soldaten seiner Division gewusst und, nachdem er von dem Vorfall erfahren hatte, sofort ein Verfahren gegen die Beteiligten eingeleitet hatte, entschied das Gericht, dass die ihm zur Last gelegten Anklagepunkte nicht in vollem Umfang zu halten seien. Am 23. Juni wurde Bittrich zu einer Gefängnisstrafe von fünf Jahren verurteilt, die durch die Untersuchungshaft als verbüßt galt. Nach seiner Entlassung aus dem Gefängnis ließ er sich im Juli 1953 in Münsing am Starnberger See nieder. ${ }^{74}$

Auch wenn die Hilfestellung der Historical Division letztendlich keinen Einfluss auf den Prozessverlauf hatte, zeigte sich Wilhelm Bittrich dankbar für die geleistete Unterstützung. Nach seiner Entlassung verfasste der ehemalige Waffen-SS-General mehrere Studien für die kriegsgeschichtliche Abteilung der U.S. Armee. ${ }^{75}$ Im August 1953 erklärte er sich bereit, für die Historical Division eine detaillierte Studie über die Operationen des II. SS-Panzerkorps während der Ardennen-Offensive zu erstellen. ${ }^{76}$ Im Juli 1954 reichte er eine Studie mit dem Titel „Das II. SS-Panzerkorps von September bis November 1944“ ein, die die Nummer P-155 erhielt. Darin erörterte er die Rückzugsgefechte seines Panzerkorps von der Seine über die Maas, durch Nordholland bis zum Niederrhein und schließlich die Bereitstellung des Korps für die Ardennen-Offensive. ${ }^{77}$ Auch die Hoffnung der Historical Division, dass Bittrich weitere ehemalige Waffen-SS-Offiziere für eine Zusammenarbeit gewinnen würde, scheint sich erfüllt zu haben. Zumindest steuerten vier ehemalige Waffen-SS-Offiziere zwischen 1951 und 1952 Studien zur Ardennen-Offensive bei. ${ }^{78}$

${ }^{74}$ Mühleisen, Bittrich, S. 85.

${ }^{75}$ Dabei dürfte neben der Dankbarkeit für die Fürsprache der kriegsgeschichtlichen Abteilung auch Bittrichs prekäre finanzielle Lage eine Rolle gespielt haben. Bereits im Sommer 1951 hatte er Bekannte in Deutschland um finanzielle Unterstützung bitten müssen; als er schließlich aus der Haft entlassen wurde, mussten er und seine schwer kranke Ehefrau von Bittrichs kleiner Rente und finanziellen Zuwendungen des „Sozialwerkes Paul Hausser" leben. Sie konnten die zusätzlichen Einnahmen, die mit der Abfassung kriegsgeschichtlicher Studien verbunden waren, also sicherlich gut gebrauchen. Wilhelm Bittrich, Brief vom 23. 7. 1951, in: BArch, MSg 194/201; zu Bittrichs finanzieller Situation vgl. auch Mühleisen, Bittrich, S. 85.

76 W. S. Nye, Schreiben an Major General A. C. Smith, 6. 8. 1953, in: NARA, RG 549, Box 1149, Folder 2; OCMH Major Leonard O. Friesz, Schreiben an Chief, Historical Division, Hqs. USAREUR betr. Assignment for General Bittrich, 14. 8. 1953, in: NARA, RG 549 , Box 1149, Folder 2.

77 Wilhelm Bittrich, MS \# P-155. Das II. SS-Panzerkorps von September bis November 1944, in: BArch, MSg 2/5379.

${ }^{78}$ Friedrich Wilhelm Fock, MS \# P109d. Ardennes Follow-Up - Arko 102, in: NARA, Mikrofiche Publication M 1035: Foreign Military Studies; Heinz Harmel, MS \# P109f. Ardennes Follow-Up - 10th SS Panzer Division, in: NARA, Mikrofiche Publication M 1035: Foreign Military Studies; Otto Weidinger, MS \# P109b. Ardennes Follow-Up - 4th SS Panzer Grenadier Regiment, in: NARA, Mikrofiche Publication M 1035: Foreign Military Studies; Günther Wisciceny, MS \# P109a. Ardennes Follow-Up - 3d SS Panzer Grenadier Regiment, in: NARA, Mikrofiche Publication M 1035: Foreign Military Studies. 


\subsection{Entnazifizierung durch die Lagerspruchkammer Neustadt}

Wie alle höheren Militärs mussten sich auch die deutschen Offiziere im Dienst der Historical Division der Entnazifizierung unterziehen, bevor sie endgültig aus der Zivilinternierung entlassen werden konnten. Wie bereits ausgeführt wurde, hatten sowohl die deutschen Offiziere als auch die Historical Division großes Interesse an der raschen Durchführung der Entnazifizierungsverfahren, da nur nach deren Abschluss eine bezahlte Beschäftigung der Deutschen im Rahmen der kriegsgeschichtlichen Kooperation möglich war. Die Historical Division hatte sich deshalb schon seit Anfang 1947 für die beschleunigte Verhandlung der Neustädter Offiziersfälle eingesetzt. Doch erst nachdem Ende August 1947 der Konflikt mit der Militärregierung durch die Intervention Dwight D. Eisenhowers beigelegt worden war, konnte die Historical Division im September schließlich konkrete Schritte zur Einrichtung einer Sonderspruchkammer im Lager Neustadt unternehmen. ${ }^{79}$

In den kommenden Wochen arbeiteten die Offiziere der Operational History (German) Section mit dem hessischen Ministerium für politische Befreiung zusammen, um die Entnazifizierung der ehemaligen Generäle und Generalstabsoffiziere endlich auf den Weg zu bringen. Allerdings gestaltete sich die Einrichtung und Inbetriebnahme der Spruchkammer in den folgenden Monaten äußerst schwierig. Die anhaltende Verzögerung hatte mehrere Gründe. Da die in Neustadt internierten Deutschen nicht nur aus Hessen, sondern zum Teil auch aus Bayern und Württemberg-Baden stammten, musste die Spruchkammerarbeit zwischen den Befreiungsministerien ${ }^{80}$ der drei Länder koordiniert werden. ${ }^{81}$ Die drei Behörden zogen nicht an einem Strang, sondern stritten wochenlang über ihre jeweils unterschiedlichen Durchführungsbestimmungen zum Befreiungsgesetz. ${ }^{82}$ Darüber hinaus hatten die Denazification Division der Landesmilitärregierung und das hessische Befreiungsministerium einer- und die Historical Division andererseits divergierende Vorstellungen über Sinn und Zweck der zu errichtenden Sonderspruchkammer. Sowohl Hubert I. Teitelbaum von der Denazification Division als auch der hessische Befreiungsminister Gottlob Binder und führende Beamte seines Ministeriums maßen der Entnazifizierung der in Neustadt versammelten Wehrmachtselite große Bedeutung bei und befürchteten, dass die Historical Division versuchen würde, den Ausgang der Verfahren zugunsten ihrer deutschen Mitarbeiter zu beeinflussen. ${ }^{83}$ Die Historical Division erwartete ihrer-

${ }^{79}$ Vgl. oben, Teil II, Kapitel 2.3.

${ }^{80}$ In Hessen und Württemberg-Baden trugen die zuständigen Ministerien den Namen „Ministerium für politische Befreiung“, das bayerische Ministerium hieß „Staatsministerium für Sonderaufgaben“. Der Einfachheit halber wird im Folgenden pauschal von „Befreiungsministerien" die Rede sein.

${ }^{81}$ Internierte, die ihren offiziellen Wohnsitz in der französischen oder britischen Besatzungszone hatten, konnten nicht in Neustadt entnazifiziert werden. Allerdings siedelte die große Mehrzahl der in Neustadt versammelten Offiziere mit Hilfe der Historical Division offiziell in die amerikanische Zone über. Auf etwaige Einzelfälle aus den anderen Zonen wird deshalb hier nicht näher eingegangen.

82 Vgl. Schuster, Die Entnazifizierung in Hessen 1945-1954, S. 185.

${ }^{83}$ Joachim Oppenheimer, Aktennotiz [Durchschlag], 16. 9. 1947, in: HHStAW, Abt. 501/3; Chief Enforcement Branch John A. Stark, Denazification Division, OMGH, Memoran- 
seits die „schnellste Durchführung de[r] Spruchkammerverfahren, damit die [deutschen] Offiziere [auch weiterhin] für die freie Mitarbeit“ zur Verfügung stünden. ${ }^{84}$ Als die Lager-Spruchkammer Ende 1947 endlich die Arbeit aufnahm, schienen Probleme bei der Verpflegung des Spruchkammerpersonals den Verdacht der hessischen Ministerialbeamten zu bestätigen - woraufhin das Spruchkammerpersonal seine Arbeit vorübergehend einstellte. Schließlich führten massive Unstimmigkeiten innerhalb der hessischen Kammer und Vorwürfe der kommunistischen Agitation gegen den Kammervorsitzenden im Mai 1948 zur Auflösung der hessischen Spruchkammer, noch bevor alle anhängigen Verfahren verhandelt worden waren. Zwischen September 1947 und Mai 1948 entfaltete sich somit in Neustadt ein groteskes Schauspiel teils parallel verlaufender, dann wieder konkurrierender Interessen, bei dem das eigentliche Anliegen der Sonderspruchkammer - die Entnazifizierung eines beträchtlichen Teils der ehemaligen Wehrmachtselite - rasch aus dem Blick geriet.

\section{Die schwierige Einrichtung der Spruchkammer}

Die Schwierigkeiten begannen bereits kurz nachdem der hessische Befreiungsminister Gottlob Binder im Oktober 1947 die Einrichtung der Sonderspruchkammer in die Wege leitete. Um den verschiedenen Zuständigkeiten und Rechtsauslegungen der drei involvierten Länder gerecht zu werden, bestimmte er, dass drei selbständige Spruchkammern in Neustadt eingerichtet werden sollten, die jeweils die Fälle der in Hessen, Württemberg-Baden und Bayern beheimateten Internierten verhandeln sollten. Die administrative Koordination aller drei Spruchkammern lag federführend beim hessischen Befreiungsministerium, das auch das technische Personal für alle drei Kammern stellte. Die Ministerien in Stuttgart und München sollten zusätzlich eigene Vorsitzende und Ankläger nach Neustadt entsenden. Um die Arbeit der Spruchkammer zu unterstützen, sagte die Historical Division ihrerseits zu, Wohn- und Arbeitsräume sowie Verpflegung für das Spruchkammerpersonal zur Verfügung zu stellen. ${ }^{85}$

Als im Oktober Vertreter der württemberg-badischen und hessischen Ministerien nach Neustadt reisten, um die Bedingungen vor Ort zu evaluieren und Vorbereitungen für die Ermittlungsarbeit der öffentlichen Ankläger zu treffen, ${ }^{86}$ war

dum an Mr. Teitelbaum betr.: Historical Research Enclosure, Neustadt Germany, 31. 10. 1947, in: NARA, RG 260, Box 1114, Folder 3; Hubert Teitelbaum, Schreiben an den Minister für politische Befreiung, Hessen betr. Verhandlungen deutscher Wehrmachtskommandeure und Generalstabsoffiziere in Neustadt, 21. 10. 1947, in: HHStAW, Abt. 501/52.

${ }^{84}$ Oel, Bericht betr. Offiziersinternierungslager Neustadt, 6. 9. 1947, in: HHStAW, Abt. 501/3.

${ }^{85}$ Gottlob Binder, Schreiben an die Operational History (German) Branch, Office of the Chief Historian, Hq. EUCOM: Durchführung von Spruchkammerverfahren gemäß dem Gesetz vom 5.3.1946 gegen die Insassen des Internierungslagers Neustadt (Marburg), 3. 10. 1947, in: HHStAW, Abt. 501/3; Gustav Hünninger, Besprechungsnotiz, 18. 9. 1947 in: HHStAW, Abt. 501/3.

86 Thiel, Besuch des Herrn Lehmann, Neustadt/Lager, 24. 10. 1947, in: HHStAW, Abt. 501/3; Erich Haag, Tätigkeitsbericht des öffentlichen Klägers Württemberg-Baden in Neustadt/ Krs. Marburg/Lahn, 16. 10. 1947, in: HStAS, EA 11/101/1898; vgl. auch Toppe, The Story of a Project. The Writing of Military History at Allendorf and Neustadt, in: Detwiler/ Burdick/Rohwer (Hg.), World War II German Military Studies, Bd. 1, S. 56. 
jedoch zunächst unklar, ob Bayern überhaupt Personal für die Tätigkeit an der Sonderspruchkammer bereitstellen würde. ${ }^{87}$ Erst mit wochenlanger Verzögerung sandte das bayerische Ministerium schließlich doch noch Otto Lechleitner als Vorsitzenden und Manfred Frey als öffentlichen Kläger nach Neustadt. Nachdem sich herausstellte, dass Württemberg-Baden für vergleichsweise wenige Fälle zuständig sein würde - Hessen hatte über 100 Fälle zu bearbeiten, während auf Bayern nur etwa halb so viele und auf Württemberg-Baden gar nur rund 20 Fälle entfielen -, wollte auch das württemberg-badische Ministerium kein ständiges Personal nach Neustadt entsenden. Stattdessen beabsichtigte der württembergische Anklagevertreter, seine Fälle in Ludwigsburg oder Stuttgart zu bearbeiten und nur zu den mündlichen Verhandlungen nach Neustadt zu reisen. ${ }^{88}$ Die Situation blieb mehrere Monate ungeklärt. Erst nachdem die amerikanische Militärregierung das Fernbleiben des württembergischen Personals von Neustadt beanstandet hatte, benannte Württemberg-Baden schließlich Anfang Februar 1948 einen Ankläger und einen Vorsitzenden, die jedoch ihre Fälle grundsätzlich in Stuttgart vorbereiteten und nur für die wenigen mündlichen Verhandlungen nach Neustadt kamen. ${ }^{89}$

Doch nicht nur Bayern und Württemberg-Baden ließen sich zunächst Zeit mit der endgültigen Benennung ihres Spruchkammerpersonals, auch der hessische Befreiungsminister Gottlob Binder konnte mangels geeigneten Personals vorläufig lediglich einen Geschäftsstellenleiter, Hans Lehmann, nach Neustadt abstellen, der die Einrichtung der Spruchkammer vorbereiten sollte. ${ }^{90}$ Der Rechtsanwalt Günther Draub nahm seine Arbeit als hessischer Ankläger erst Ende November auf. Noch schwieriger gestaltete sich die Suche nach einem geeigneten Kammer-

${ }^{87}$ Gustav Hünninger, Aktennotiz betr. Errichtung einer Sonderspruchkammer für die Internierten des Lagers Neustadt bei Marburg - Beteiligung des bayerischen Ministeriums für Sonderaufgaben und des Ministeriums für politische Befreiung, Stuttgart, an dieser Kammer, 3. 10. 1947, in: HHStAW, Abt. 501/3; Operational History (German) Section, Weekly Report No. A-43, 14. 10. 1947, in: NARA, RG 549, Box 1, Folder 1; Ders., Weekly Report No.A-44, 21. 10. 1947, in: NARA, RG 549, Box 1, Folder 1; Haag, Tätigkeitsbericht des öffentlichen Klägers Württemberg-Baden in Neustadt/Krs. Marburg/Lahn, 16. 10. 1947, in: HStAS, EA 11/101/1898; Office of the Military Government Württemberg-Baden C. M. Engelbrecht, Schreiben der Denazification Division, Liaison and Review Branch, OMGWB an den württemberg-badischen Befreiungsminister Gottlob Kamm, 10.11.1947, in: HStAS, EA 11/101/44; Skubich, Bericht über die Besprechung betreffend die Errichtung von Spruchkammern in Neustadt am 17.11. 1947, in: HStAS, EA 11/101/1898.

${ }^{88}$ Rapp, Aktenvermerk betr. Besprechung mit Herrn Haag, 28.11. 1947, in: HStAS, Bestand EA 11/101/1898.

${ }^{89}$ Hans Lehmann, Schreiben an Regierungsrat Gustav Hünninger, 19.1.1948, in: HHStAW, Abt. 501/3; Gustav Hünninger, Vorlage für Herrn Minister Binder, 29.1. 1948, in: HHStAW, Abt. 501/3; Schuster, Die Entnazifizierung in Hessen 1945-1954, S. 185-186; Rapp, Spruchkammer Neustadt bzw. Behandlung der Generalstabsoffiziere, 13. 1. 1948, in: HStAS, Bestand EA 11/101/1898; Gustav Hünninger, Aktennotiz, 4.2.1948, in: HHStAW, Abt. 501/3; Noske, Bericht der Herren Dr. Hartman, Heidenheim und Fuchs, Stuttgart, über das Ergebnis ihrer Reise nach Lager Neustadt am 10. 2. 1948, 11. 2. 1948, in: HStAS, EA 11/101/1898.

${ }^{90}$ Skubich, Bericht über die Besprechung betreffend die Errichtung von Spruchkammern in Neustadt am 17.11. 1947, in: HStAS, EA 11/101/1898. 
vorsitzenden. Da sich monatelang niemand für die Stelle fand, betreute der bayerische Vorsitzende Otto Lechleitner die hessischen Fälle zunächst kommissarisch mit. Erst Ende Februar 1948 übernahm schließlich Walther Gerbeth den Vorsitz der hessischen Kammer. ${ }^{91}$

\section{Unerwünschte Presseberichterstattung}

Obwohl die Historical Division die Einrichtung der Neustädter Sonderspruchkammern begrüßte - immerhin hatte sie selbst monatelang darauf hingearbeitet $^{92}$ - bereitete die Entnazifizierung der ehemaligen Wehrmachtsgeneralität Harold E. Potter weiterhin einiges Kopfzerbrechen. Der Chef der Historical Division befürchtete, dass die bevorstehenden Spruchkammerverfahren das Medieninteresse stärker als bisher auf die historische Kooperation zwischen der U.S. Armee und der ehemaligen Wehrmachtselite lenken würde. 1945 und 1946 hatten deutsche und amerikanische Zeitungen zwar gelegentlich kurze Beiträge über das historische Projekt veröffentlicht, aber obwohl diese Berichterstattung den Offizieren der Historical Division ein wenig auf die Nerven ging, rief sie keine ernsthafte Besorgnis hervor. ${ }^{93}$ Dies drohte sich nun durch die bevorstehenden Spruchkammerverfahren zu ändern. Um eine Verstimmung der deutschen Mitarbeiter zu vermeiden, die in der Vergangenheit immer sehr sensibel auf jegliche Medienberichte über ihre kriegsgeschichtliche Tätigkeit reagiert hatten, lotete Harold E. Potter im Oktober 1947 Möglichkeiten aus, die Veröffentlichungen der Presse über das historische Projekt zu unterbinden oder zumindest auf ein Minimum zu reduzieren. ${ }^{94}$

Dabei war Potter durchaus bewusst, dass er eine Berichterstattung über die Entnazifizierung an sich nicht würde verhindern können. Allerdings hätte er gerne dafür gesorgt, dass sich die Journalisten ausschließlich auf die Spruchkammerverfahren beschränken und Hinweise auf die kriegsgeschichtliche Tätigkeit der deutschen Offiziere und insbesondere die Arbeiten zur Ostfront aussparen müssten. Die Historical Division hoffte so zu verhindern, dass die Sowjetunion auf den gewandelten Charakter der deutsch-amerikanischen Kooperation unter dem Dach der Historical Division aufmerksam werden würde, die mittlerweile nicht mehr in erster Linie der Vervollständigung der amerikanischen Kriegsgeschichte diente, sondern verstärkt darauf ausgerichtet war, strategisches und ope-

${ }^{91}$ Günther Draub, Schreiben an den hessischen Befreiungsminister Gottlob Binder, 19. 1. 1948, in: HHStAW, Abt. 501/3; vgl. auch Schuster, Die Entnazifizierung in Hessen 1945-1954, S. 190; Günther Draub, Schreiben an den hessischen Befreiungsminister Gottlob Binder, 21. 1. 1948, in: HHStAW, Abt. 501/3. Zu den Schwierigkeiten, einen Vorsitzenden zu finden, vgl. Gustav Hünninger, Schreiben an Landgerichtsrat Dr. Warmbrunn betr. Einspruchsverfahren Rechtsanwalt Dr. Heckert, Frankfurt, 26. 11. 1947, in: HHStAW, Abt. 501/3.

92 Vgl. oben, Teil II, Kapitel 2.3.

${ }^{93}$ Howard P. Hudson, Memorandum to Colonel Pence. Publicity on this project, 3. 7. 1946, in: NARA, RG 549, Box 3, Folder 1; Harold E. Potter, Memorandum to Colonel Pence, 2. 8. 1946, in: NARA, RG 549, Box 3, Folder 1.

${ }^{94}$ Daniel T. Murphy, Recommendations for the Press at Neustadt, 29.9.1947, in: NARA, RG 549, Box 3, Folder 1; Harold E. Potter, Schreiben an Harry J. Malony, 3. 10. 1947, in: NARA, RG 260, OMGUS, Shipment 5, Box 268-3, Folder 3. 
rationelles Wissen über die Rote Armee und die sowjetische Kriegführung von der Wehrmachtselite an die U.S. Armee zu transferieren.

Um die Möglichkeiten einer solchen Zensur zu eruieren, wandte sich Potter an den Leiter der Public Information Division von EUCOM, Colonel George S. Eyster. Gemeinsam entwickelten die beiden eine Strategie, um die Berichterstattung zu limitieren. Nach den Vorstellungen der beiden sollten die größten Nachrichtenagenturen Associated Press (AP), United Press Association (UPA) und Internal News Services (INS) per Anweisung dazu verpflichtet werden, „keine Berichte über das historische Projekt zu veröffentlichen".95 Darüber hinaus sollten auch der deutschen Presse Interviews mit den ehemaligen Wehrmachtsoffizieren für die Dauer der Verhandlungen verboten und nur solche Artikel zur Veröffentlichung zugelassen werden, die sich ausschließlich mit den Spruchkammerverhandlungen befassten. ${ }^{96}$

Mit diesen Vorschlägen trat Eyster Anfang Oktober sowohl an die Public Information Division des Department of the Army in Washington als auch an den Direktor der OMGUS-Information Control Division, Colonel Gordon E. Textor, heran. ${ }^{97}$ Textor gab die Anfrage an die ihm unterstellte Press Control Branch weiter. Deren Leiter Arthur D. Eggleston teilte ihm einige Tage später mit, dass die Zensurbestrebungen der Historical Division völlig unrealistisch seien. In einem Memorandum vom 14. Oktober führte er aus:

„Without a direct order to each of the 48 newspapers in the U.S. Zone, there is no assurance that the history-writing aspect will not appear in one of them. And of course, there is and can be no assurance that the story will not appear in one of the 45 British zone papers, one of the 31 French zone papers or one of the 30 Soviet-licensed papers. ${ }^{\text {"9 } 98}$

Eggleston wies außerdem darauf hin, dass die von Potter und Eyster geforderte Beschränkung der deutschen Berichterstattung einen „enormen Rückschritt“ in der auf Pressefreiheit abzielenden Medienpolitik der amerikanischen Militärregierung bedeuten würde. ${ }^{99}$

${ }^{95}$ David M. Powler, Memorandum for Record, 2. 10. 1947, in: NARA, RG 549, Box 3, Folder 1; Potter, Schreiben an Harry J. Malony, 3. 10.1947, in: NARA, RG 260, OMGUS, Shipment 5, Box 268-3, Folder 3. Originalzitat: The Chief, Public Information Division, Department of the Army „would be requested to advise the chief wire services (AP, UP and INS) at their headquarters, that no stories are to be published about the project.“

96 Potter, Schreiben an Harry J. Malony, 3. 10. 1947, in: NARA, RG 260, OMGUS, Shipment 5, Box 268-3, Folder 3; Powler, Memorandum for Record, 2. 10. 1947, in: NARA, RG 549, Box 3, Folder 1.

97 George S. Eyster, Schreiben an Floyd L. Parks, Public Information Division, Department of the Army, 6. 10. 1947, in: NARA, RG 260, OMGUS, Shipment 5, Box 268-3, Folder 3; Ders., Schreiben an Gordon E. Textor, Director, Information Control Division, OMGUS, 6. 10. 1947, in: NARA, RG 260, OMGUS, Shipment 5, Box 268-3, Folder 3.

98 Arthur Eggleston, Memorandum to Colonel Textor on Trials of German Officers, 14. 10. 1947, in: NARA, RG 260, OMGUS, Shipment 5, Box 268-3, Folder 3.

${ }^{99}$ Ebd. Originalzitat: „There is no way in which Colonel Textor can tell the German papers to restrict coverage to open court proceedings without Military Government taking a long step backward and reinstituting pre-publication censorship of material that does not, in itself violate directives." 
Die Press Control Branch riet daher von Eysters und Potters Vorschlägen ab und empfahl stattdessen eine offensive Medienstrategie, bei der die Historical Division selbst von Zeit zu Zeit Pressemitteilungen über das Geschichtsprojekt herausgeben sollte, um die Neugier der Journalisten zu befriedigen und gleichzeitig zu kanalisieren. ${ }^{100}$ Basierend auf Egglestons Memorandum teilte Colonel Textor George S. Eyster am 15. Oktober mit, dass die Public Information Division den von den Amerikanern lizenzierten Zeitungen zwar mitteilen würde, dass die deutschen Offiziere während der Spruchkammerverfahren nicht für Interviews zur Verfügung stünden, darüber hinaus würden jedoch keinerlei Zensurmaßnahmen ergriffen werden. ${ }^{101}$

Damit waren Harold E. Potters Bemühungen, die Presseberichterstattung über das deutsch-amerikanische Geschichtsprojekt zu beschneiden, gescheitert. In der Folge stieg die Zahl der Artikel über die Kooperation im Laufe des Jahres 1948 an und der Ton der Berichterstattung wurde kritischer. ${ }^{102}$ Auch die Befürchtungen der Historical Division, dass die Spruchkammerverfahren die Aufmerksamkeit der ostdeutschen Medien und damit der sowjetischen Besatzungsmacht verstärkt auf die kriegsgeschichtliche Kooperation lenken würden, bewahrheiteten sich. Bereits im November 1947 und damit lange vor dem Beginn der ersten Verhandlungen in Neustadt überschütteten ostdeutsche Zeitungen die Historical Division und ihre deutschen Mitarbeiter mit beißender Kritik und Polemik und stellten pessimistische Prognosen über den Ausgang der geplanten Entnazifizierung. So prophezeite Berlin am Mittag, dass sich „die Generalobersten Guderian und Halder, Stabschefs während 5 Kriegsjahren, politisch gereinigt wie Phönix aus der Asche erheben“ würden. ${ }^{103}$ Der Artikel traf den Nagel auf den Kopf, als er die Kooperation als eine Kriegsgeschichte charakterisierte, die von denen verfasst werde, „die allen Grund haben, ihre eklatante Niederlage mit irgendeinem Mythos zu umgeben " ${ }^{104}$ Dabei, so stellte der Autor hellsichtig fest, hätten die ehemaligen Generäle „schon den Dreh gefunden, um zu beweisen, dass der Dolchstoss gegen

100 Ebd.

101 Gordon E. Textor, Schreiben an George S. Eyster, Chief, Public Information Division, EUCOM, 15. 10. 1947, in: NARA, RG 260, OMGUS, Shipment 5, Box 268-3, Folder 3.

102 Vgl. zum Beispiel Nazi Generals Will Be Tried As ,Militarists. About 200 Working for U.S. Army Historical Unit Go To De-Nazification Court, in: Herald Tribune, 23. 10. 1947; Herbert Büchs, Schreiben an Albert Kesselring, 17. 11. 1947, in: NARA, RG 549, Box 8, Folder 1; Kurt Gerber, Reports on This Camp Published in the Press and Heard Over the Radio, 11. 11. 1947, in: NARA, RG 549, Box 3, Folder 1; Russell Jones, Army Denies Favoritism to High Germans, in: Stars and Stripes, 25. 10. 1947; Ders., Special Courts to Try Top German Officers, in: Stars and Stripes, 24. 10. 1947; Operational History (German) Section, Extract from ,Berlin am Mittag, dated 3. 11. 1947, in: NARA, RG 549, Box 3, Folder 1; Ders., Translation of newspaper artcile published in the ,Neue Zeitung' of 27.10.1947, in: NARA, RG 549, Box 3, Folder 1; Ders., Weekly Report No. A-45. Week ending 25.10.1947, in: NARA, RG 549, Box 1, Folder 1; 8 Generals Freed, Two Found Guilty. Denazification Court Acquits Former German Leaders Aiding in War History, in: The New York Times, 2. 3. 1948, S. 5.

103 Operational History (German) Section, Extract from ,Berlin am Mittag', 3. 11. 1947, in: NARA, RG 549, Box 3, Folder 1.

104 Ebd. 
ihren Angriffskrieg von ihrem Chef Hitler selbst geführt wurde, weil er auf ihre Meisterregeln nicht hörte". 105

Im Mai 1948 schoss sich auch die Neue Berliner Illustrierte auf das Neustädter Projekt ein und veröffentlichte eine Seite mit Karikaturen, ironischen Gedichten und beißenden Kommentaren. Eines dieser Gedichte hob erneut die apologetischen Motive der deutschen Militärs hervor und wies außerdem auf die anti-russische Ausrichtung der deutsch-amerikanischen Kooperation hin:

\section{„An hundert Generale von Hitlers O-Ka-We, die bauen am Ehrenmale der unbesiegten Armee.}

Sie schreiben die Kriegsgeschichten, die sie sechs Jahre vollbracht, in täglichen Wehrmachtsberichten mit ,Endsieg' und ,Kesselschlacht'.

Sie haben die beste Erfahrung in Tarnung und Mimikry. Man setzt sie nicht zwecklos in Nahrung, die ,Meister' der Strategie:

Millionen zu Tode hetzten die Hundert vom Führungsstab, und von der Verantwortung setzten sie taktisch-elastisch sich ab.

Sie halten die Stellung von gestern, sie igeln sich ein, zur Zeit in Care-Paket Widerstandsnestern, zum rollenden Einsatz bereit.

Sie stehen im Lager auf Posten.

Es flammt schon ihr Horizont:

Sie schreiben - mit Stossrichtung Osten,

Auch in der westdeutschen Presse mehrten sich Anfang 1948 die kritischen Berichte. Am 16. März 1948 publizierte die Süddeutsche Zeitung einen Artikel mit dem Titel „Generale unter sich - Zusätzliche Kalorien für militärische Geschichtsschreibung", der nur am Rande auf die Spruchkammerverfahren einging und stattdessen ausführlich auf die privilegierte Behandlung der ehemaligen Wehrmachtselite im Lager Neustadt hinwies. Dabei zögerte der Autor nicht, seine recht kritische, um nicht zu sagen zynische Haltung gegenüber dem kriegsgeschichtlichen Projekt zum Ausdruck zu bringen: „Die Generäle, die einst die Geschichte des Krieges mit Blut schrieben", so der Wortlaut,

„sind nun äußerlich wesentlich friedlicher geworden, denn sie schreiben die Geschichte der vergangenen Jahre - für die sie zum Teil verantwortlich sind -, diesmal mit Tinte und im Auftrag der amerikanischen historischen Abteilung."107

105 Ebd.

106 B. Idamann, Gedicht, in: Neue Berliner Illustrierte, 2. Maiheft 1948.

107 Generäle unter sich. Zusätzliche Kalorien für militärische Geschichtsschreibung, in: Süddeutsche Zeitung, 16.3.1948. 
Der Artikel wies außerdem darauf hin, dass die ehemaligen Generäle für ihre Arbeit großzügig entschädigt würden und zum Beispiel monatlich zwischen „450 und 700 RM netto" sowie amerikanische Zigaretten, Carepakete und Textilien erhielten und zudem mit ihren Familien in „netten Zweizimmerwohnungen“ wohnten. Für das „leibliche Wohl“ sei durch „gute Verpflegung“ gesorgt und auch „der geistigen Zerstreuung [werde] durch Kino, Theater und Konzertaufführungen reichlich Genüge getan" ${ }^{108}$ Ein anderer Artikel, der wenig später in der Frankfurter Rundschau erschien, wies ebenfalls auf die befremdliche Diskrepanz zwischen der privilegierten Stellung der ehemaligen Wehrmachtselite in Neustadt und den Sorgen und Nöten der breiten deutschen Bevölkerung hin. ${ }^{109}$ Der Autor äußerte zudem den Verdacht, dass die Militärs in Neustadt ihre „alten Traditionen“ kultivierten: „Sie haben zwar ihre Uniformen abgelegt, aber die meisten haben sich hinsichtlich ihrer Denkweise in keiner Weise geändert. Krieg ist ihr Beruf und sie leben noch heute davon." 110

\section{Reibereien zwischen der Historical Division, der Denazification Division und dem Befreiungsministerium}

Nicht nur die Presse beäugte die Vorgänge in Neustadt kritisch. Sowohl die Denazification Division der Landesmilitärregierung als auch das hessische Befreiungsministerium hatten der Einrichtung einer Sonderspruchkammer für die in Neustadt versammelte Wehrmachtselite ebenfalls von Anfang an skeptisch gegenübergestanden. Sie waren der entsprechenden Anordnung von OMGUS deshalb nur recht widerwillig nachgekommen. Angesichts des offensichtlichen Interesses der Historical Division an der fortdauernden Kooperation der deutschen Offiziere vermutete der Direktor der Denazification Division, Hubert I. Teitelbaum, dass die Historical Division „starke[n] Druck“ auf die Vorsitzenden und Ankläger der Neustadter Spruchkammern ausüben könnte. ${ }^{111}$ Teitelbaum wies das Befreiungsministerium daher wiederholt an, alles zu tun, „um eine korrekte und sachliche Durchführung der Verfahren in Neustadt zu gewährleisten",112 und untersagte den Spruchkammerangehörigen, die Fälle mit dem amerikanischen Personal der Historical Division zu besprechen. ${ }^{113}$

108 Ebd.

109 Walter P. Schmid, Generäle schreiben Geschichte, in: Frankfurter Rundschau, 27. 3.1948.

110 Operational History (German) Section, Translation of article by Walter P. Schmidt, Generals Write History. A Glance Behind the Barbed Wire Fence of Camp Neustadt, published in the Frankfurter Rundschau, 27.3. 1948, in: NARA, RG 549, Box 3, Folder 1 .

111 Oberregierungsrat Hill, Aktennotiz: Spruchkammer für Generale etc. - Besprechung mit Landesmilitärregierung, Mr. Teitelbaum am 11.9.1947, 12.9. 1947, in: HHStAW, Abt. 501/627.

112 Oel, Vollstreckungsamt des Obersten Klägers, Aktennotiz, 13. 9. 1947, in: HHStAW, Abt. 501/627; Oberregierungsrat Hill, Aktennotiz: Spruchkammer für Generale etc. Besprechung mit Landesmilitärregierung, Mr. Teitelbaum am 11.9.1947, 12.9. 1947, in: HHStAW, Abt. 501/627.

113 Teitelbaum, Schreiben an den Minister für politische Befreiung, Hessen, betr. Verhandlungen deutscher Wehrmachtskommandeure und Generalstabsoffiziere in Neustadt, 21. 10. 1947, in: HHStAW, Abt. 501/52. 
Im hessischen Befreiungsministerium traf dieses Misstrauen gegenüber der Historical Division auf offene Ohren. Die hessischen Ankläger waren ohnehin beunruhigt über die allgemeine Entwicklung der Entnazifizierung ${ }^{114}$ und befürchteten nun, „dass sich die Generäle, die über weitreichende Beziehungen verfüg[t] en und sich wahrscheinlich der besten Rechtsanwälte bedienen w[ü]rden, gegenüber den Klägern in einer besseren Position bef[ä]nden. "115 Falls die Anklageerhebung „gegen diese Führer des preußischen Militarismus zu einer Farce“ werde und die Verfahren mit Freisprüchen endeten, hätte dies zur Folge, „dass sich unzählige kleine Betroffene in Stadt und Land auf diese Urteile berufen [würden] und mit Recht dann nicht mehr zu verurteilen" seien. ${ }^{116}$ Gottlob Binder sah sich deshalb veranlasst, gegenüber der Historical Division nachdrücklich darauf hinzuweisen, dass „die Durchführung der Verfahren in objektiver Weise und durchaus den Vorschriften des Gesetztes zur Befreiung von Nationalsozialismus und Militarismus [...] entsprechend zu erfolgen“ habe. Die Betroffenen dürften also „weder eine besondere Bevorzugung“ erfahren, noch sollten die Verfahren „in oberflächlicher Weise oder übereilt durchgeführt werden“.117 Auch Harold E. Potters wiederholte Beteuerungen, dass die Historical Division keinerlei bevorzugte Behandlung der deutschen Offiziere erwarte, sondern „lediglich daran interessiert [sei], dass diese Betroffenen nicht benachteiligt" würden, ${ }^{118}$ konnten die grundsätzlichen Bedenken des Befreiungsministeriums und der Denazification Division letztlich nicht zerstreuen.

Die Historical Division reagierte ihrerseits verstimmt auf die andauernde Verzögerung bei der Entnazifizierung. ${ }^{119}$ Schließlich sollte Sinn und Zweck der Sonderspruchkammer ja die Beschleunigung der Verfahren bei möglichst geringer Beeinträchtigung der historischen Arbeit sein. Angesichts des „Versagens“ des hessischen Befreiungsministers, die Entnazifizierung zügig auf den Weg zu bringen, versuchte der Leiter der Operational History (German) Section, Colonel James W. Coutts, im November 1947 eine Planänderung durchzusetzen. Angeregt durch ein Memorandum von Franz Halder schlug er vor, den deutschen Offizieren nun doch die Möglichkeit zu geben, vor der Spruchkammer ihres jeweiligen Heimatortes zu erscheinen. Aus Coutts' Sicht hatte dieses Vorgehen mehrere Vorteile: Eine rasche Entnazifizierung der deutschen Offiziere vor ihren jeweiligen Heimatspruchkammern würde die Entnazifizierung der deutschen Mitarbeiter insgesamt beschleunigen. Darüber hinaus würde sich das antizipierte Medieninteresse

114 Vgl. allgemein Schuster, Entnazifizierung in Hessen.

115 Oppenheimer, Aktennotiz [Durchschlag], 16. 9. 1947, in: HHStAW, Abt. 501/3.

116 Ebd.

117 Binder, Schreiben an die Operational History (German) Branch, Office of the Chief Historian, Hq. EUCOM: Durchführung von Spruchkammerverfahren gemäß dem Gesetz vom 5.3.1946 gegen die Insassen des Internierungslagers Neustadt (Marburg), 3. 10. 1947, in: HHStAW, Abt. 501/3.

118 Teitelbaum, Schreiben an den Minister für politische Befreiung, Hessen, betr. Verhandlungen deutscher Wehrmachtskommandeure und Generalstabsoffiziere in Neustadt, 21. 10. 1947, in: HHStAW, Abt. 501/52.

119 Vgl. Operational History (German) Section, Weekly Report No. B-7, 25.3. 1948, in: NARA, RG 549, Box 1, Folder 1. 
so auf viele verschiedene Spruchkammern verteilen und nicht auf Neustadt - und somit das Projekt der Historical Division - konzentrieren. ${ }^{120}$ Die Spruchkammern in Neustadt sollten dennoch eingerichtet werden und zur Entnazifizierung der permanenten, also nach dem 1. Januar 1948 noch in Neustadt befindlichen Offiziere $^{121}$ dienen sowie für die Entnazifizierung derjenigen Mitarbeiter, bei denen eventuell eine Aussetzung des Urteils nötig sein würde. ${ }^{122}$

Allerdings weigerte sich Gottlob Binder auf einer Konferenz am 4. Dezember 1947, einer Regelung zuzustimmen, die es den unter Zivilinternierung stehenden deutschen Offizieren erlauben würde, in Freiheit auf ihr Spruchkammerverfahren $\mathrm{zu}$ warten und währenddessen von zu Hause aus für die Historical Division zu arbeiten. ${ }^{123}$ Stattdessen bestand er darauf, dass - anders als in WürttembergBaden und Bayern, wo die deutschen Offiziere bis zu ihrem Spruchkammerverfahren nach Hause beurlaubt wurden - die in Hessen ansässigen Offiziere (und damit die große Mehrheit der deutschen Militärs) nach ihrer Entlassung aus Neustadt ins Zivilinternierungslager Darmstadt überstellt wurden, um dort ihr Verfahren abzuwarten. ${ }^{124}$ Hintergrund dieser strikten Haltung war nicht zuletzt eine entsprechende Anordnung der Denazification Division der Landesmilitärregierung. ${ }^{125}$

Erst nach heftigem Protest der Historical Division gab Teitelbaum schließlich nach und wies das Befreiungsministerium an, die deutschen Offiziere in Darmstadt freizulassen. ${ }^{126}$ Gottlob Binder hatte keine andere Wahl, als der Anweisung der Landesmilitärregierung Folge zu leisten und die unter Zivilinternierung stehenden ehemaligen Offiziere im Lager Darmstadt auf freien Fuß zu setzen. Allerdings wies er die öffentlichen Ankläger in Darmstadt und Neustadt ausdrücklich an, „zu prüfen, ob in dem einen oder anderen Fall [...] so starke Belastungsmomente vorl[ä]gen, dass sich daraus ein Fluchtverdacht oder eine Verdunkelungsgefahr" ergebe. ${ }^{127}$ In diesen Fällen sollten sofort Haftbefehle erlassen und die Freisetzung somit verhindert werden. ${ }^{128}$

120 James W. Coutts, Memorandum an Harold E. Potter betr. Re-evaluation of Spruchkammern Policy for employees, HDIE, 20. 11. 1947, in: NARA, RG 549, Box 4, Folder 2.

121 Vgl. hierzu oben, Teil II, Kapitel 2.3.

122 James W. Coutts, Memorandum an Harold E. Potter betr. Re-evaluation of Spruchkammern Policy for employees, HDIE, 20. 11. 1947, in: NARA, RG 549, Box 4, Folder 2.

123 James W. Coutts, Memorandum an Harold E. Potter betr. Recent development of Spruchkammer proceedings for German writers from Land Hesse, 11.12.1947, in: NARA, RG 549, Box 4, Folder 2.

124 Gottlob Binder, Rundschreiben betr. Internierte ehemalige Offiziere in den Lagern Neustadt und Darmstadt, 11. 11. 1947, in: HHStAW, Abt. 501/4; zur Argumentation des hessischen Befreiungsministeriums siehe auch A. J. Edwards, Minute on the Wiesbaden Conference on 15 Dec 47, 16. 12. 1947, in: NARA, RG 549, Box 4, Folder 2.

125 Binder, Rundschreiben betr. Internierte ehemalige Offiziere in den Lagern Neustadt und Darmstadt, 11.11. 1947, in: HHStAW, Abt. 501/4.

126 K. K. Neumann, Schreiben im Auftrag des Direktors der Denazification Division an den Befreiungsminister betr.: Arrest and Detention of Civilian Internees, 16. 12. 1947, in: HHStAW, Abt. 501/4.

127 Gottlob Binder, Rundschreiben betr. Internierte ehemalige Offiziere in den Lagern Neustadt und Darmstadt, o. D., in: HHStAW, Abt. 501/4.

128 Ebd. 


\section{Konflikt um die Verpflegung des Spruchkammerpersonals}

Während die Suche nach geeigneten Anklägern und Vorsitzenden noch andauerte, sah sich das Verwaltungspersonal der Lagerspruchkammer im Dezember 1947 mit existenziellen Problemen ganz anderer Art konfrontiert. Anfang Oktober hatte Harold E. Potter dem hessischen Befreiungsministerium die volle Unterstützung der Historical Division bei der Einrichtung der Spruchkammer zugesagt und sich bereit erklärt, dass die U.S. Armee sowohl Räumlichkeiten als auch eine freie Mittagsmahlzeit für das Spruchkammerpersonal zur Verfügung stellen würde. Tatsächlich empfanden die Mitarbeiter der Spruchkammern das Verhältnis zu den Amerikanern im Oktober und November 1947 als „in jeder Weise ausreichend und entgegenkommend" und die Ausgabe der versprochenen Mittagsmahlzeit klappte zunächst reibungslos. ${ }^{129}$ Allerdings machte sich bald das Gefühl breit, dass die Spruchkammer für die amerikanischen Offiziere in Neustadt „nur ein geduldetes Übel“ sei und die Historical Division die ehemaligen Wehrmachtsführer bei der Zuteilung von Mobiliar und Nahrungsmitteln deutlich bevorzugte. ${ }^{130}$ In den Augen der Kammerangehörigen ergab sich so eine groteske Situation: „Uns geht es schlecht, weil wir ,die Kammer' sind und [wir] erfreuen uns keinerlei Ansehens bei den Amerikanern, den Betroffenen geht es gut, weil sie Betroffene sind und sicherlich Sympathien genießen."131

Als sich im Dezember schließlich herausstellte, dass die Verpflegung des Spruchkammerpersonals nicht aus eigens zugewiesenen Vorräten stammte, sondern „aus den für die ehemaligen Generäle und Generalstabsoffiziere bereiteten Essen entnommen" wurde, reagierten die Kammermitglieder empört. In ihren Augen entstand damit der „fragwürdige Zustand [...], dass die Kammermitglieder auf Kosten der Betroffenen ihr Essen erh[ie]lten“. ${ }^{32}$ Hans Lehmann beschwerte sich daraufhin sowohl beim amerikanischen Lagerkommandanten als auch bei dessen Versorgungsoffizier und verwies auf die Zusage der Historical Division, für die Verpflegung der Kammer aufzukommen. Beide erklärten jedoch, sie könnten offiziell keine zusätzliche Verpflegung für die Spruchkammerangehörigen anfordern und sähen sich auch außerstande, die Sache an höherer Stelle zu klären. ${ }^{133}$ Daraufhin verwahrte sich Lehmann wiederholt beim Befreiungsministerium gegen diesen „absolut unwürdigen Zustand“ und bat um Klärung der Angelegenheit. ${ }^{134}$

129 Hans Lehmann, Schreiben an Regierungsrat Hünninger betr. Verpflegung der Sonderspruchkammer Neustadt, 8. 1. 1948, in: HHStAW, Abt. 501/3; Memorandum, 6. 4. 1948; ohne Angabe des Autors, aber aller Wahrscheinlichkeit nach von Hans Lehmann, in: HHStAW, Abt. 501/3.

130 Memorandum, 6. 4. 1948, ohne Angabe des Autors, aber aller Wahrscheinlichkeit nach von Hans Lehmann, in: HHStAW, Abt. 501/3.

131 Ebd.

132 Hans Lehmann, Schreiben an den Minister für politische Befreiung, Gottlob Binder, 16. 12. 1947, in: HHStAW, Abt. 501/3.

133 Hans Lehmann, Schreiben an Regierungsrat Hünninger betr. Verpflegung der Sonderspruchkammer Neustadt, 8. 1. 1948, in: HHStAW, Abt. 501/3.

134 Gustav Hünninger, Aktennotiz für Minister durch Ministerialdirektor betr. Verpflegung des Personals der Lager-Spruchkammer Neustadt, 7.1.1948, in: HHStAW, Abt. 501/3; Hans Lehmann, Schreiben an Regierungsrat Hünninger betr. Verpflegung der Sonderspruchkammer Neustadt, 8. 1.1948, in: HHStAW, Abt. 501/3. 
Trotz Lehmanns wiederholten Beschwerden zeichnete sich in der Verpflegungsfrage jedoch zunächst keine Lösung ab. Im Gegenteil: Als die Anzahl der deutschen Offiziere - und damit auch die Menge der in Neustadt verfügbaren Verpflegung - entsprechend der Regelungen des STAPLE-Plans ${ }^{135}$ Anfang Januar von 150 auf 50 reduziert wurde, spitzte sich die Situation weiter zu. Am 6. Januar wurde den Spruchkammerangehörigen die Ausgabe des Mittagessens sogar ganz verweigert. Nachdem Lehmann mit der amerikanischen Lagerleitung verhandelt hatte, wurde eine provisorische Regelung getroffen, laut der das Spruchkammerpersonal künftig aus dem übriggebliebenen Essen der deutschen Offiziere versorgt werden sollte. ${ }^{136}$ Dabei kam es im Laufe des Januars immer wieder vor, dass diese Reste nicht für alle Mitarbeiter der Spruchkammern ausreichten. Auch eine eigenverantwortliche Verpflegung auf Marken in den Neustädter Gaststätten war angesichts der ohnehin angespannten Versorgungslage im kleinen Neustadt nicht möglich. Anfang Januar informierte Lehmann deshalb das hessische Befreiungsministerium, dass die Spruchkammer ihre Aufgabe nicht würde erfüllen können, falls keine Lösung in der Essensfrage gefunden würde. ${ }^{137}$

Auch in den folgenden zwei Wochen stellte sich trotz mehrfacher Anfragen des Befreiungsministeriums bei der Landesmilitärregierung keine Besserung ein und die Deutschen hatten zunehmend das Gefühl, von den amerikanischen Dienststellen hingehalten zu werden. ${ }^{138}$ Um ihrer Notlage nochmals Ausdruck zu verleihen, richteten Draub, Lechleitner und der bayerische Ankläger Manfred Frey schließlich am 26. Januar einen gemeinsamen Appell an Befreiungsminister Binder, in dem sie ihn eindringlich aufforderten, bei der Militärregierung endlich eine Lösung der Verpflegungsfrage zu erreichen: „Es ist für unsere Arbeit untragbar“, so brachten die drei Männer die Problematik auf den Punkt, „dass wir in der Frage der Verpflegung auf die Gnade und Barmherzigkeit der Leute angewiesen sind, über deren Schuld und Sühne wir in nächster Zeit zu entscheiden haben. "139 Auch die Befreiungsministerien in München und Stuttgart wurden nun auf die untragbare Situation aufmerksam und drohten, ihr Personal aus Neustadt abzuziehen. ${ }^{140}$

Die Frage drängt sich auf, ob die Historical Division den Kammermitgliedern bewusst das Essen vorenthielt, um so aktiv Druck auf die Spruchkammer auszuüben. Der Verdacht entbehrt nicht einer gewissen Plausibilität - immerhin hatten

$135 \mathrm{Zu}$ den Details des STAPLE-Plans siehe oben, Teil II, Kapitel 2.3.

136 Hans Lehmann, Schreiben an Regierungsrat Hünninger betr. Verpflegung der Sonderspruchkammer Neustadt, 8. 1. 1948, in: HHStAW, Abt. 501/3.

137 Ebd.; Telegramm an Hünninger, 24. 1. 1948, in: HHStAW, Abt. 501/3.

138 Gustav Hünninger, Aktennotiz für Ministerialdirektor Knappstein betr. Regelung der Verpflegungsfrage bei der Sonderspruchkammer Neustadt, 28.1.1948, in: HHStAW, Abt. 501/3.

139 Otto Lechleiter u. a., Schreiben an Befreiungsminister Gottlob Binder betr. Verpflegung der Angestellten der Spruchkammer Hessen und Bayern, Neustadt, 26.1.1948, in: HHStAW, Abt. 501/3.

140 Gustav Hünninger, Schreiben an das Bayerische Staatsministerium für Sonderaufgaben, 19.2. 1948, in: HHStAW, Abt. 501/3; Ziebill, Schreiben des Präsidenten der Berufungskammer Nürnberg-Fürth an den hessischen Minister für politische Befreiung, 3. 2. 1948, in: HHStAW, Abt. 501/3. 
sowohl die Denazification Division als auch das Befreiungsministerium von Anfang an eben dies befürchtet. Und auch die Spruchkammerangehörigen in Neustadt waren bald überzeugt, dass sie aus der Sicht der Amerikaner „auf der verkehrten Seite" standen. ${ }^{141}$ Eine milde Urteilspraxis der Neustädter Kammer lag zweifelsohne im Interesse der Operational History (German) Section, die bei ihrer Mission auf den guten Willen und die Kooperationsbereitschaft der deutschen Offiziere angewiesen war. ${ }^{142}$ Tatsächlich wünschten sich die amerikanischen Offiziere in Neustadt eine möglichst günstige Beurteilung für ihre deutschen Mitarbeiter und betrachteten die Entnazifizierung wohl insgesamt als ein lästiges - aber eben notwendiges - Übel. ${ }^{143}$

Eben weil die Historical Division zur Fortführung ihrer Kooperation mit den deutschen Offizieren auf deren Entnazifizierung angewiesen war, erscheint es insgesamt betrachtet jedoch eher unwahrscheinlich, dass die Amerikaner ausgerechnet über die Verweigerung der Verpflegung versucht haben sollen, Einfluss auf die Arbeit der Kammer zu nehmen. Schließlich waren sowohl die Historical Division als auch ihre Protegés an einer möglichst schnellen Durchführung der Verfahren interessiert. Der Mangel an Verpflegung verzögerte die Arbeit der Spruchkammer jedoch und wäre somit als Mittel zur Beschleunigung der Verfahren denkbar kontraproduktiv gewesen. Es scheint vielmehr, als sei die Verpflegung des Spruchkammerpersonals den ungeklärten Zuständigkeiten und langwierigen Dienstwegen innerhalb der U.S. Armee zum Opfer gefallen. Nachdem jedenfalls sowohl die Landesmilitärregierung als auch die Historical Division bei EUCOM vorgesprochen hatten, ${ }^{144}$ genehmigte das EUCOM-Hauptquartier schließlich im Februar zusätzliche Mahlzeiten zur Versorgung des Spruchkammerpersonals für Februar und März 1948. ${ }^{145}$ Damit erfolgte die Versorgung der Kammern künftig „völlig unabhängig von der Verpflegung“ der Lagerinsassen. ${ }^{146}$

141 Memorandum, 6. 4. 1948, ohne Angabe des Autors, aber aller Wahrscheinlichkeit nach von Hans Lehmann, in: HHStAW, Abt. 501/3.

142 Armin Schuster vertritt denn auch die These, die Historical Division habe versucht, über die Verpflegung direkten Einfluss auf die Spruchkammerarbeit zu nehmen. Allerdings stützt Schuster seine Vermutung ausschließlich auf Quellen des Befreiungsministeriums, die Seite der Historical Division bleibt dabei unberücksichtigt. Vgl. Schuster, Entnazifizierung in Hessen, S. 184-188.

143 Siehe zum Beispiel James F. Scoggin, Brief an Frank C. Mahin: „Late News Flashes“, 9. 2. 1948, in: NARA, RG 549, Box 5, Folder 2; vgl. auch Günther Blumentritt, Schreiben an James F. Scoggin, 30.4.1948, in: NARA, RG 549, Box 3, Folder: Blumentritt, Guenther.

144 Operational History (German) Section, Weekly Report No. B-4, 4. 2. 1948, in: NARA, RG 549, Box 1, Folder 1.

145 Karl Heinrich Knappstein, Schreiben an Befreiungsminister Binder, Regierungsrat Gustav Hünninger und Oberregierungsrat Hill, 6.2.1948, in: HHStAW, Abt. 501/3; Operational History (German) Section, Weekly Report No. B-5, 13.2. 1948, in: NARA, RG 549, Box 1, Folder 1.

146 SS\&P Division, Hq. EUCOM an Chief, Historical Division, EUCOM betr. Special Rations for Indigenous Personnel, 4.2.1948, in: NARA, RG 549, Box 3134, Folder 4; Gottlob Binder, Schreiben an Dr. Ziebill, 9. 2. 1948, in: HHStAW, Abt. 501/3; Hünninger, Schreiben an das Bayerische Staatsministerium für Sonderaufgaben, 19. 2. 1948, in: HHStAW, Abt. 501/3. 


\section{Neustadt als Zentralstelle für die Entnazifizierung von Generälen und Generalstabsoffizieren?}

Nachdem sich Günther Draub einige Wochen in seine Tätigkeit als öffentlicher Kläger eingearbeitet hatte, wurde rasch deutlich, dass die Entnazifizierung der in Neustadt versammelten Wehrmachtsgeneralität spezifische Fallstricke mit sich brachte. So wies der ehemalige Generalleutnant Theodor Groppe, der der Kammer als militärischer Sachverständiger zur Seite stand, ${ }^{147}$ wiederholt darauf hin, dass es unbedingt erforderlich sei, einen ehemaligen Offizier als Beisitzer zu bestellen, der während der Verhandlung militärische Sachfragen klären und so eine beschönigende Verwischung der Tatsachen zugunsten der Betroffenen verhindern könne. ${ }^{148}$ Angeregt von Groppe reifte in Draub bald der Gedanke, dass sich mit der Sonderspruchkammer Neustadt die einmalige Gelegenheit bot, nicht nur die für die Historical Division tätigen deutschen Offiziere, sondern alle in Hessen beheimateten Generäle zentral vor dieser Kammer zu entnazifizieren. ${ }^{149}$

Aus Draubs Sicht stellten die „Generalsfälle“ spezielle Anforderungen an die Spruchkammern. Die „besondere Generalsmentalität“ und die militärtechnischen Einzelheiten der Fälle erforderten historische „Kleinarbeit“ - ein Umstand, dem eine „gewöhnliche Spruchkammer“ ohne die entsprechende Expertise und Erfahrung mit der Entnazifizierung hochrangiger Militärs „einfach nicht gewachsen sein“ könne. ${ }^{150}$ Draub befürchtete, dass die Mehrheit der Generäle mit dem Verweis auf den vermeintlich unpolitischen Charakter ihrer Handlungen vor und während des Krieges erfolgreich vor Verurteilungen nach Artikel 8 des Befreiungsgesetzes $^{151}$ bewahrt werden würde. In etwa 95 Prozent der Fälle, so prophe-

147 Der NS-kritische Theodor Groppe (1882-1973) war 1940 in die „Führerreserve“ versetzt und Ende 1941 wegen seiner „politischen Unzuverlässigkeit" unehrenhaft aus der Wehrmacht verabschiedet worden. Im August 1944 war er von der Gestapo verhaftet worden und hatte sich seiner für Ende April 1945 angesetzten Hinrichtung nur durch Flucht entziehen können. Er galt daher nach dem Krieg als politisch unbelastet. Theodor Groppe, Generalleutnant, in: Bradley/Hildebrand/Rövekamp (Hg.), Die Generale des Heeres 1921-1945, Bd. 4, S. 437-438; vgl. auch Mühleisen, Theodor Groppe, in: Kurtrierisches Jahrbuch 27 (1987), S. 145-210.

148 Theodor Groppe, Schreiben an Günther Draub, 12. 12. 1947, in: HHStAW, Abt. 501/4; Ders., Schreiben an Günther Draub, 17. 1. 1948, in: HHStAW, Abt. 501/3.

149 Günther Draub, Schreiben an den hessischen Minister für politische Befreiung, 23. 12. 1947, in: HHStAW, Abt. 501/4.

150 Ders., Schreiben an den hessischen Befreiungsminister betr.: Allgemeine Fragen des hiesigen Verfahrens und Bestellung eines Vorsitzenden für Hessen der Spruchkammer Neustadt, 21. 1. 1948, in: HHStAW, Abt. 501/3.

151 Artikel 8 des Befreiungsgesetzes lautete: „I. Militarist ist: 1. wer das Leben des deutschen Volkes auf eine Politik der militärischen Gewalt auszurichten suchte; 2. wer für die Beherrschung fremder Völker, ihre Ausnutzung und Verschleppung eingetreten oder verantwortlich ist; 3. wer die Aufrüstung zu diesen Zwecken förderte. II. Militarist ist insbesondere, soweit er nicht Hauptschuldiger ist, 1. wer durch Wort und Schrift militaristische Lehren oder Programme aufstellte oder verbreitete oder außerhalb der Wehrmacht in einer Organisation tätig war, die der Förderung militaristischer Ideen diente; 2. wer vor 1935 die planmäßige Ausbildung der Jugend für den Krieg organisierte oder an dieser Organisation teilnahm; 3. wer als Inhaber einer Kommandogewalt verantwortlich dafür ist, dass nach dem Einmarsch in Deutschland Stadt und Land sinnlos verwüstet wurden; 4. wer ohne Rücksicht auf seinen Rang als Angehöriger der 
zeite Draub, werde der Spruch schließlich lauten: „Vom Gesetz zwar betroffen, aber nicht belastet." 152

Ein solches Ergebnis wäre angesichts „der Erfahrungen der letzten Jahrzehnte“ ausgesprochen „bedenklich und unerfreulich“ - schließlich könne kein Zweifel daran bestehen, „dass die deutsche Wehrmacht, als Ganzes gesehen, an dem Aufstieg des Nationalsozialismus, seiner Herrschaft, seiner Aufrechterhaltung trotz des Widerstandes einer ganzen Welt und natürlich auch an seinem Fall maßgeblich beteiligt war" ${ }^{153}$ So habe der preußisch-deutsche Militarismus, der sich unter anderem im „Autoritätshunger des deutschen Offiziers“, seiner Sehnsucht nach einem Führer und einer Erneuerung des „Glanz[es] der Fahnen“ ausdrückte, den „geistigen Kitt“ für die „Einheit von Wehrmacht und Partei“ dargestellt. ${ }^{154}$ Die außenpolitischen Erfolge der Jahre 1938 bis 1941 hätten schließlich auch die in Teilen der Wehrmachtsführung bis dahin durchaus vorhandene Kritik an Hitler „erschüttert“. So sei aus dem Glauben an den „Führer“ ein „Wunderglaube“ geworden, der zusammen mit

„der eingeimpften Gehorsamspflicht und in Verbindung mit den pervertierten Treuegefühlen monarchistischen Charakters das Gros der Generalität [...] davon abgehalten ha[be], über das Ausmaß der bevorstehenden deutschen Katastrophe überhaupt ernsthaft nachzudenken". 155

Daraus ergab sich für Draub, dass die Generalität in ihrer Gesamtheit „ein unendliches Maß an Schuld gegenüber dem deutschen Volke" trage. ${ }^{156}$

Aufgrund der mangelnden Präzision des Befreiungsgesetzes befürchtete Draub, dass die Führungsschicht der Wehrmacht trotz ihrer historischen Verantwortung „für gänzlich unbemakelt“ erklärt werden würde. Um einen solchen „moralischen Misserfolg“ der Entnazifizierung zu verhindern, erachtete er es für unbedingt notwendig, die deutsche Generalität zentral vor einer auf Militärs spezialisierten Spruchkammer zu entnazifizieren. ${ }^{157}$ Mit der Sonderspruchkammer Neustadt bestand in Draubs Augen bereits eine solche spezielle Spruchkammer. Der Ankläger forderte das Befreiungsministerium deshalb wiederholt auf, die wachsenden Erfahrungswerte der Spruchkammer Neustadt zu nutzen und die Entnazifizierung aller in Hessen ansässigen Generäle unabhängig von ihrer Beziehung zur Historical Division in Neustadt zu zentralisieren. ${ }^{158}$ Trotz Draubs enthusiasti-

Wehrmacht, des Reichsarbeitsdienstes, der Organisation Todt (OT) oder der Transportgruppe Speer seine Dienstgewalt zur Erlangung besonderer persönlicher Vorteile oder zu rohen Quälereien seiner Untergebenen missbrauchte."

152 Günther Draub, Schreiben an den hessischen Befreiungsminister betr. Vorschlag betr. das Verfahren für die Fälle der Spruchkammer Neustadt-Lager, 8. 2. 1948, in: HHStAW, Abt. 501/2.

153 Ebd.

154 Ebd.

155 Ebd.

156 Ebd. Interessanterweise klammerte Draub die Schuld gegenüber den von Deutschland überfallenen Nationen aus.

157 Ebd.

158 Draub, Schreiben an den hessischen Minister für politische Befreiung, 23. 12.1947 in: HHStAW, Abt. 501/4; Günther Draub, Schreiben an Gustav Hünninger, 12.1.1948 in: HHStAW, Abt.501/3; Draub, Allgemeine Fragen des hiesigen Verfahrens und Be- 
schem Eintreten für ein solches Szenario, bei dem er auch von Theodor Groppe unterstützt wurde, konnte er das Befreiungsministerium nicht für seine Idee gewinnen. Der hessische Oberste Kläger, Joachim Oppenheimer, fand Draubs Vorschlag zwar „an sich [...] vernünftig“, hielt es jedoch angesichts der „technischen Schwierigkeiten “ in Neustadt - vor allem der ungeklärten Verpflegungsfrage und der ambivalenten Haltung der Historical Division - nicht für geraten, eine solche Sonderspruchkammer für Generäle ausgerechnet in Neustadt einzurichten. ${ }^{159}$

\section{Die Affäre Gerbeth - oder: Kommunistische Propaganda in Neustadt?}

Dass Günther Draub sich mit seiner Idee einer zentralen Entnazifizierung aller Wehrmachtsgeneräle schließlich nicht durchsetzen konnte, lag auch daran, dass die hessische Spruchkammer in Neustadt einfach nicht zur Ruhe kam und im Befreiungsministerium Anfang 1948 nicht unbedingt durch ihre sachliche Arbeit, sondern zunehmend durch persönliche Aversionen und Querelen zwischen Günther Draub, Hans Lehmann und dem Kammervorsitzenden Walther Gerbeth auffiel, der am 25. Februar endlich in Neustadt eingetroffen war. Der Hintergrund des Zerwürfnisses dürfte dabei nicht zuletzt in der unterschiedlichen politischen Gesinnung des Christdemokraten Draub und des KPD-Anhängers Gerbeth gelegen haben. Das Verhältnis war von Anfang an gespannt und Gerbeth empfand sich selbst als einen „Fremdkörper“ unter den seit Monaten aufeinander eingespielten Kammerangehörigen. ${ }^{160}$ Die latenten Animositäten entwickelten sich im Frühjahr 1948 schließlich zu einem Kleinkrieg zwischen Draub und Lehman einerseits und Walter Gerbeth anderseits, der dann im Mai zur vorzeitigen Auflösung der hessischen Spruchkammer führen sollte.

Nur knapp drei Wochen nachdem Gerbeth seine Arbeit aufgenommen hatte, gingen beim Befreiungsministerium erstmals Beschwerden über seine Verhandlungsführung und sein angeblich „unglaublich tiefes Niveau“ ein. ${ }^{161}$ Joachim Oppenheimer maß den Vorwürfen zunächst keine große Bedeutung bei. ${ }^{162}$ In den kommenden Wochen bombardierten Günther Draub und Hans Lehman das Ministerium jedoch förmlich mit Beschwerdebriefen, in denen sie Gerbeth unter anderem mangelnde Bildung vorwarfen und feststellten, dass seine Sprüche „flüchtig, oberflächlich und auch stilistisch wenig gelungen“ seien. Schwerwiegender als die Auslassungen über Gerbeths Bildungsniveau war allerdings der

stellung eines Vorsitzenden für Hessen der Spruchkammer Neustadt, 21. 1. 1948, in: HHStAW, Abt. 501/3; Ders., Vorschlag betr. das Verfahren für die Fälle der Spruchkammer Neustadt-Lager, 8. 2. 1948, in: HHStAW, Abt. 501/2.

159 Oppenheimer, Stellungnahme zur Vorlage des 1. öffentlichen Klägers der SK NeustadtLager, 9. 1. 1948, in: HHStAW, Abt. 501/4.

160 Protokoll der Aussage Walther Gerbeths gegenüber Joachim Oppenheimer, 13. 5. 1948, in: HHStAW, Abt. 501/1220.

161 Gustav Hünninger, Aktennotiz an Befreiungsminister Binder, 10. 3. 1948, in: HHStAW, Abt. 501/3; Joachim Oppenheimer, Aktennotiz der Abt. IV über den Vorsitzenden Gerbeth der SK Neustadt Lager, an Befreiungsminister Binder, 19.3. 1948, in: HHStAW, Abt. 501/1220.

162 Ebd. 
Vorwurf, der Vorsitzende würde in unzulässiger, gar privater und familiärer Weise mit Betroffenen verkehren und dabei „kommunistische Propaganda“ mit dem Ziel betreiben, die ehemaligen Offiziere zur Arbeit in der sowjetischen Besatzungszone anzuwerben. ${ }^{163}$

Angesichts dieser ernsten Anschuldigungen veranlasste der Befreiungsminister Anfang Mai eine Untersuchung der Angelegenheit durch den Obersten Kläger. ${ }^{164}$ $\mathrm{Zu}$ diesem Zweck lud Oppenheimer zunächst Günther Draub und Hans Lehmann vor, die in offiziellen Aussagen ihre Vorwürfe erneut bekräftigten. ${ }^{165}$ Allerdings musste Draub auch einräumen, dass die von Gerbeth gefällten Sprüche „im Ergebnis richtig“ seien und „dem aus den Akten ersichtlichen und durch die Verhandlung erwiesenen Sachverhalt" entsprächen. ${ }^{166}$ Gerbeth selbst bestritt „ganz entschieden, in irgendeiner Form im Auftrage oder Sinne der KPD irgendwelche Propaganda gemacht zu haben". ${ }^{67}$ Auch habe er niemals versucht, die deutschen Offiziere „ausländischen Mächten dienstbar zu machen, indem [er] sie mit einem milden Spruch köderte“. 168 Auf Anfrage Oppenheimers stellte der die Dienstaufsicht führende Vorsitzende der Frankfurter Spruchkammer, an der Gerbeth vor seiner Versetzung nach Neustadt tätig gewesen war, ihm insgesamt ein gutes Zeugnis aus. Hans Albrecht beschrieb Gerbeth als „einen der fleißigsten und emsigsten“ Frankfurter Vorsitzenden, der zwar gerne seine eigene Vergangenheit als politisch Verfolgter ${ }^{169}$ „etwas in den Vordergrund“ stelle, dessen persönliches Verhalten jedoch immer „einwandfrei“ gewesen sei. ${ }^{170}$ Auch Gerbeths Sekretärin und Protokollführerin bei der Neustädter Spruchkammer fand nur gute Worte für ihren Vorgesetzten: Seine Verhandlungsführung sei „korrekt und sachlich“, gegenteilige Behauptungen entbehrten „jeder Grundlage“. Auch sei es „absurd, behaupten $\mathrm{zu}$ wollen, er habe innerhalb der Kammer kommunistische Propaganda getrieben“ - ganz im Gegenteil: Man hätte kaum „merken können, dass [Gerbeth] der KPD angehörte“. ${ }^{171}$ Nachdem er alle Seiten gehört hatte, kam Oppenheimer zu dem Schluss, dass der Vorwurf der kommunistischen Propaganda „nicht ge-

163 Bennemann, Bericht des Geschäftsstellenleiters Lehmann, Spruchkammer NeustadtLager, 28.4.1948, in: HHStAW, Abt.501/1220; Ders., Aktennotiz, 5. 5. 1948, in: HHStAW, Abt. 501/1220; Günther Draub, Schreiben an Gottlob Binder, 17. 5. 1948, in: HHStAW, Abt. 501/1280.

164 Joachim Oppenheimer, Aktennotiz, 14. 5. 1948, in: HHStAW, Abt. 501/1220.

165 Protokoll der Aussage Günther Draubs gegenüber Joachim Oppenheimer, 12. 5. 1948, in: HHStAW, Abt. 501/1220; Vernehmungsprotokoll von Hans Lehmann gegenüber Joachim Oppenheimer, 12. 5. 1948, in: HHStAW, Abt. 501/1220.

166 Protokoll der Aussage Günther Draubs gegenüber Joachim Oppenheimer, 12. 5. 1948, in: HHStAW, Abt. 501/1220.

167 Protokoll der Aussage Walther Gerbeths gegenüber Joachim Oppenheimer, 13. 5. 1948, in: HHStAW, Abt. 501/1220.

168 Ebd.

169 Gerbeth war 1933 von den Nationalsozialisten von seiner Stellung als Schulrektor entbunden und 1934 verhaftet und wegen der Vorbereitung zum Hochverrat angeklagt worden. Er hatte daraufhin drei Jahre in Haft verbracht. Vgl. ebd.

${ }^{170}$ Hans Albrecht, Schreiben an Joachim Oppenheimer, 13.5.1948, in: HHStAW, Abt. 501/1220.

${ }^{171}$ Rita Zubrod, Schreiben an Joachim Oppenheimer, 20.5.1948, in: HHStAW, Abt. 501/1220. 
nügend substantiiert" und der Verdacht, Offiziere für die Sowjets anzuwerben, „durch nichts bewiesen“ sei. Hinsichtlich des unzulässigen Umgangs mit Betroffenen befand er Gerbeth allerdings für schuldig. ${ }^{172}$

Die Angelegenheit hatte die Sonderspruchkammer insgesamt in Misskredit gebracht, denn auch Günther Draub und Hans Lehmann hatten im Befreiungsministerium keinen guten Eindruck hinterlassen. Joachim Oppenheimer konnte sich des Gefühls nicht erwehren, dass sich sowohl Draub als auch Lehmann bei ihren Aussagen von „persönlichen Gefühlen“ leiten ließen. ${ }^{173}$ Außerdem missfiel es dem Obersten Kläger, dass die beiden hinter dem Rücken des Befreiungsministeriums in der Sache Kontakt zur nachrichtendienstlichen Abteilung der amerikanischen Landesmilitärregierung aufgenommen hatten. ${ }^{174}$ Oppenheimer empfahl dem Befreiungsminister daher am 13. Mai, sowohl Gerbeth als auch Draub aus Neustadt abzuziehen. Gottlob Binder folgte dem Vorschlag seines Obersten Klägers und verfügte die Abberufung der beiden zum 30. Juni ebenso wie die Entlassung des gesamten Spruchkammerpersonals. ${ }^{175}$

Die Affäre strapazierte schließlich auch die Geduld der Denazification Division über Gebühr. Da sich sowohl Gerbeth als auch Draub in seinen Augen als inkompetent erwiesen hatten, widerrief Hubert I. Teitelbaum am 26. Mai für beide die Genehmigung der Landesmilitärregierung zur Ausübung ihrer Ämter. ${ }^{176}$ Die wenigen noch ausstehenden Entnazifizierungsverfahren wurden zur weiteren Bearbeitung an den Berufungskläger der Berufungskammer Marburg, Julius Schmidt, übergeben. ${ }^{177}$

\section{Zum Ausgang der Verfahren}

Trotz des schwelenden Konflikts um die Essenszuteilung für das Spruchkammerpersonal und trotz der persönlichen Animositäten hatten Mitte Januar 1948 schließlich die mündlichen Verhandlungen in Neustadt begonnen. Dabei machte sich die durch die zu diesem Zeitpunkt noch ungelöste Verpflegungsfrage ange-

172 Joachim Oppenheimer, Schreiben an Befreiungsminister Binder: Zwischenbericht in Sachen Gerbeth, 14. 5. 1948, in: HHStAW, Abt. 501/1220.

173 Protokoll der Aussage Günther Draubs gegenüber Joachim Oppenheimer, 12. 5. 1948, in: HHStAW, Abt. 501/1220; Vernehmungsprotokoll von Hans Lehmann, in: HHStAW, Abt. 501/1220.

174 Oppenheimer, Aktennotiz, 14. 5. 1948, in: HHStAW, Abt. 501/1220; vgl. auch Theodor Groppe, Eidesstattliche Versicherung, 26. 5. 1948, in: BArch, N 739/22.

175 Oberregierungsrat Hill, Spruchkammer Neustadt-Lager, 13.5.1948, in: HHStAW, Abt. 501/3.

176 Hubert Teitelbaum, Schreiben an das hessische Befreiungsministerium: Public Prosecutor Guenther Draub and Chairman Walter Gerbeth, 26.5.1948, in: HHStAW, Abt. 501/1220.

177 Joachim Oppenheimer, Schreiben an Julius Schmidt betr. Spruchkammer Neustadt, 25. 5. 1948, in: HHStAW, Abt. 501/1280; Julius Schmidt, Schreiben an Regierungsrat Hünninger betr. Auflösung der Spruchkammer Neustadt-Lager, 8. 6. 1948, in: HHStAW, Abt. 501/1176. Am 13. Mai waren insgesamt noch 28 Fälle nicht verhandelt worden, darunter 25 hessische und 2 württemberg-badische Fälle sowie der Fall Franz Halders vor der bayerischen Kammer. Vgl. Roster of Generals and GSC Officers whose Spruchkammer Trials Have Not Been Completed Yet, 13.5.1948, in: NARA, RG 549, Box 3172, Folder 2. 
spannte Atmosphäre natürlich auch in dem improvisierten Gerichtssaal bemerkbar. Viele Lagerinsassen wohnten den mündlichen Verhandlungen regelmäßig bei und verliehen ihrer Meinung zu Verlauf und Ergebnis der Verfahren deutlich hörund sichtbar Ausdruck, so dass sich die Spruchkammern mit einem mehr oder weniger feindlich eingestellten Publikum und dessen gehässigen und teils sogar bedrohlichen Kommentaren konfrontiert sahen. ${ }^{178}$ Der bayerische Ankläger Manfred Frey erhielt sogar einen anonymen Drohbrief, in dem er als „größter Halunke auf Erden“ beschimpft wurde, für den der Galgen schon bereitstehe. ${ }^{179}$

Abgesehen von der feindlichen Stimmung erschwerte außerdem der besondere Charakter der drei Sonderspruchkammern, die ja ausschließlich Militärs entnazifizieren sollten, die Arbeit der Ankläger - ganz so wie es Günther Draub und Theodor Groppe bereits Wochen zuvor vorhergesagt hatten. Die ehemaligen Offiziere sagten vor der Kammer füreinander aus und attestierten sich gegenseitig eine anti-nationalsozialistische und anti-militaristische und, ganz im Gegenteil, liberale und demokratische Haltung. ${ }^{180}$ Für die Kammern war es weitgehend unmöglich, das Gegenteil zu beweisen. Auch bei der Beurteilung von Sachfragen, wie zum Beispiel der Verantwortlichkeit einzelner Offiziere bei der militärischen Aufrüstung in den 1930er Jahren oder der bewussten Beteiligung an einer Politik der militärischen Gewalt, mussten sich die Kammern aufgrund ihrer eigenen weitgehenden Unkenntnis der militärischen Verhältnisse auf die unter den gegebenen Umständen zumindest fragwürdige Wahrhaftigkeit der Aussagen ehemaliger Offiziere verlassen, die teilweise selbst noch auf ihre Entnazifizierung warteten. ${ }^{181}$ Das Ergebnis der Verhandlungen in Neustadt ist also unter diesen, in mehrfacher Hinsicht ungünstigen Bedingungen zu betrachten.

Als Erstes behandelte die bayerische Kammer am 15. Januar den Fall des ehemaligen Infanteriegenerals Karl Weisenberger. Nach zwei Verhandlungstagen reihte die bayerische Spruchkammer Weisenberger als Militarist in „Kategorie II“ ein und verurteilte ihn zu zwei Jahren Arbeitslager und einer finanziellen Sühneleistung von mehreren tausend Reichsmark. ${ }^{182}$ Da Weisenberger im Rahmen der von $G-1$ in Auftrag gegebenen Studie zur Mobilisierung der Wehrmacht ${ }^{183}$ an ei-

178 Protokoll der Aussage Walther Gerbeths gegenüber Joachim Oppenheimer, 13. 5. 1948, in: HHStAW, Abt. 501/1220; Walter P. Schmidt, Generaele schreiben Geschichte, in: Frankfurter Rundschau, 27.3. 1948.

179 Ebd.; vgl. auch Generäle unter sich, in: Süddeutsche Zeitung, 16.3. 1948.

180 Schmidt, Generäle schreiben Geschichte, in: Frankfurter Rundschau, 27. 3. 1948.

181 Groppe, Schreiben an Günther Draub, 12.12.1947, in: HHStAW, Abt. 501/4; Ders., Schreiben an Günther Draub, 17.1.1948, in: HHStAW, Abt. 501/3; vgl. hierzu u. a. Draub, Schreiben an den hessischen Befreiungsminister Binder betr. Vorschlag betr. das Verfahren für die Fälle der Spruchkammer Neustadt-Lager, 8. 2. 1948, in: HHStAW, Abt. 501/2.

182 Über die Höhe der finanziellen Sühneleistung finden sich unterschiedliche Angaben in den Quellen: Während die Historical Division in ihrem Bericht von 5000 Reichsmark sprach, nannte die Marburger Presse die Summe von 12000 RM. Vgl. Draub, Schreiben an den hessischen Befreiungsminister Gottlob Binder, 19.1.1948, in: HHStAW, Abt. 501/3; Operational History (German) Section, Weekly Report No. B-3, 27. 1. 1948, in: NARA, RG 549, Box 1, Folder 1.

183 Siehe oben, Teil II, Kapitel 2.3. 
nem Manuskript zu Nachschub, Ersatz und Verwaltung im Wehrkreis XIII (Nürnberg) arbeitete, ${ }^{184}$ wurde die Urteilsvollstreckung bis nach dem Ende des STAPLEProjekts aufgeschoben. ${ }^{185}$ Unter den ehemaligen Offizieren in Neustadt galt das Urteil als relativ milde - immerhin hatte sich Karl Weisenberger noch in der Endphase des Krieges öffentlich zu Hitler bekannt und den Endsieg propagiert. ${ }^{186}$

Die erste Verhandlung der hessischen Kammer fand einige Wochen später, am 5. Februar, mit dem Fall des Waffen-SS-Generals und ehemaligen Befehlshabers des Ersatzheeres Hans Jüttner statt. ${ }^{187}$ Der in der Provinz Posen geborene und aus kleinbürgerlichen Verhältnissen stammende Jüttner ${ }^{188}$ war bereits im Februar 1931 in die SA und im Juni des gleichen Jahres in die NSDAP eingetreten und hatte sich zwischen 1931 und 1935 vor allem in den Dienst des paramilitärischen Ausbildungswesens der NSDAP gestellt. ${ }^{189}$ Am 17. Mai 1935 wurde der Weltkriegsveteran als Hauptsturmführer in die SS übernommen, in der er schließlich während des Krieges zu einem „der wichtigsten Berater“ Heinrich Himmlers „in militärorganisatorischen Fragen und Angelegenheiten der bewaffneten SS“ aufstieg. ${ }^{190}$ Als Stabschef des SS-Führungshauptamtes (Sommer 1940 bis Januar 1943) und Chef des SS-Führungshauptamtes (ab 30. Januar 1943) war Jüttner vor allem für die Aufstellung, Ausbildung und Ausrüstung von neuen Waffen-SSDivisionen zuständig. ${ }^{191}$ Nach dem Attentatsversuch vom 20. Juli 1944 ernannte Himmler ihn dann in seiner Funktion als neuer Chef der Heeresrüstung und Befehlshaber des Ersatzheeres zu seinem Stabschef und ständigen Vertreter. Da Himmler kaum Zeit hatte, sich selbst um die Geschäfte des Ersatzheeres zu kümmern, wurde Jüttner somit praktisch zum Chef über das Ausbildungs-, Ersatzund Rüstungswesen der Waffen-SS und des Heeres. ${ }^{192}$ Bei Kriegsende flüchtete Jüttner nach Norddeutschland, wo er sich schließlich den westlichen Alliierten ergab.

Hans Jüttner war keineswegs nur ein „unbedeutender Funktionär im nationalsozialistischen Staat “. ${ }^{193}$ Der SS-Obergruppenführer leistete vielmehr einen wich-

184 Weisenberger (1890-1952) war im August 1944 zum Kommandierenden General des Stellvertretenden Generalkommandos des XIII. Armeekorps in Nürnberg ernannt worden.

185 A. L. Yakoubian (Office of the Military Government Hesse), Aufschiebung eines Urteils der Neustädter Spruchkammer (Suspension of a Sentence of the Neustadt Spruchkammer), in: HHStAW, Abt. 501/53.

186 Operational History (German) Section, Weekly Report No. B-3, 27. 1. 1948, in: NARA, RG 549, Box 1, Folder 1; Auftakt der Neustädter Spruchkammer. General Weisenbergers gesammelte Schriften, in: Marburger Presse, 16.1.1948; General vor der Spruchkammer, in: Frankfurter Rundschau, 17. 1. 1948.

187 Die württemberg-badische Kammer verhandelte ihren ersten Fall erst am 23. März 1948.

188 Jüttner wurde am 2. März 1894 in Schmiegel in der preußischen Provinz Posen geboren; er starb am 24. Mai 1965.

189 Schulte, Hans Jüttner, in: Smelser/Syring (Hg.), Die SS: Elite unter dem Totenkopf, S. 278.

190 Ebd., S. 276.

191 Ebd., S. 280-282.

192 Ebd., S. 276 u. S. 285.

193 Ebd., S. 276 u. S. 286. 
tigen Beitrag sowohl zum „Aufstieg der SS und der Stabilisierung der NS-Terrorherrschaft" als auch zur Verfolgung vermeintlicher oder tatsächlicher NS-Gegner in Deutschland und Europa: Er war fast zwei Jahre lang für die Inspektion der Konzentrationslager zuständig; außerdem waren einige der ihm unterstellten Ausbildungs- und Ersatzeinheiten der Waffen-SS im Herbst 1941 an Exekutionen tschechischer Zivilisten beteiligt und auch bei der Niederschlagung des Aufstandes im Warschauer Ghetto im Frühjahr 1943 „musste der zuständige SS- und Polizeiführer vor allem auf die Jüttner unterstellten Warschauer Ausbildungseinheiten zurückgreifen“. 194 Da Jüttner jedoch formal nur eine höchst eingeschränkte Kommandogewalt über Verbände der Waffen-SS ausgeübt hatte, machten ihn die Alliierten nach dem Krieg nicht für Verbrechen der Fronteinheiten der Waffen-SS verantwortlich. ${ }^{195}$ Das Entnazifizierungsverfahren vor der Sonderspruchkammer im Lager Neustadt blieb das einzige Verfahren, in dem Hans Jüttner Rechenschaft für seine Rolle im Nationalsozialismus ablegen musste. Die hessische Kammer reihte ihn in die Gruppe der „Hauptschuldigen“ ein, verurteilte ihn zu zehn Jahren Arbeitslager und ordnete die Beschlagnahmung seines gesamten Vermögens an. ${ }^{196}$

Verurteilungen wie die Weisenbergers oder Jüttners blieben in Neustadt die Ausnahme. Die überwiegende Mehrheit der rund 200 Verfahren ${ }^{197}$ wurde eingestellt. Wie Draub befürchtet hatte, galten die meisten ehemaligen Generäle damit als „Zwar vom Gesetz betroffen, aber nicht belastet“. Unter diesen Nicht-Belasteten waren auch Hans von Greiffenberg und Günther Blumentritt, der sein Verfahren zum Beispiel als „[s]ehr sachlich“ und den Vorsitzenden wie den Ankläger als „höflich“ und „interessiert“ empfand und sich sehr angetan zeigte, dass „[a]lle Herren der Spruchkammer [...] sehr entgegenkommend“ gewesen seien und ihm sogar ihre „Hochachtung“ ausgesprochen hätten. ${ }^{198}$

Auch die meisten anderen Offiziere kamen ohne Bestrafung davon. Allein die hessische Kammer stellte zwischen 1. März und 30. April 1948 insgesamt 90 Verfahren ein, ein Angeklagter wurde als „entlastet“ (Gruppe V), 19 Offiziere wurden als „Mitläufer“ (Gruppe IV), sechs als „Minderbelastete“ und nur einer als „Mili-

194 Ebd., S. 284.

195 Ebd., S. 284 u. S. 286. Auch in der Forschung hat Hans Jüttner bisher wenig Beachtung gefunden, in der Literatur zur Waffen-SS wird er meist nur am Rande erwähnt. Vgl. hierzu den kurzen Forschungsüberblick bei Schulte, S. 287-288.

196 „Wer gegen mich ist, den zerschmettere ich“, in: Marburger Presse, 27.2. 1948. Allerdings wurde das Urteil 1949 von der Berufungskammer Gießen revidiert, die Jüttner lediglich als „Belasteten“ einstufte und zu vier Jahren Arbeitslager verurteilte, die zudem durch die Haft als abgeleistet galten. Vgl. Eintrag „Jüttner, Hans“, Munzinger Online/Personen - Internationales Biographisches Archiv.

197 Die Angaben zur Gesamtzahl der in Neustadt verhandelten Fälle differieren in den Quellen, sie liegt aber wohl zwischen 200 und 220, wobei die hessische Kammer die große Mehrheit der Fälle zu bearbeiten hatte. Vgl. Noske, Bericht der Herren Dr. Hartman, Heidenheim, und Fuchs, Stuttgart, über das Ergebnis ihrer Reise nach Lager Neustadt am 10.2. 1948, 11.2. 1948, in: HStAS, EA 11/101/1898; Toppe, The Story of a Project, in: Detwiler (Burdick/Rohwer (Hg.), World War II German Military Studies.

198 Blumentritt, Schreiben an James F. Scoggin, 30. 4. 1948, in: NARA, RG 549, Box 3, Folder: Blumentritt, Guenther. 
tarist“ (Gruppe II) eingestuft. ${ }^{199}$ Die hessische Kammer reihte schließlich einzig und allein Hans Jüttner in die Gruppe der „Hauptschuldigen“ (Gruppe I) ein. Angesichts dieses Ergebnisses konnte Alfred Toppe triumphierend feststellen: „Bei über 90 Prozent der behandelten Fälle von Offizieren (außer der SS) ist also festgestellt worden, dass keinerlei Belastung vorlag. Kommentar überflüssig. " 200

Die hohe Zahl der Verfahrenseinstellungen in Neustadt war allerdings nichts Außergewöhnliches, sondern spiegelt die insgesamt sehr hohe Zahl der eingestellten Entnazifizierungsverfahren wider. Von den in Hessen bis zum 15. April 1948 bearbeiteten knapp 900000 Fällen sind knapp 700000 eingestellt worden. Insofern der zweithäufigste Spruch die Betroffenen in die Kategorie IV der „Mitläufer" einreihte, entspricht das Neustädter Ergebnis ebenfalls in etwa dem gesamthessischen Bild (vgl. Tab. 7 im Tabellenanhang). ${ }^{201}$

Obwohl die Entnazifizierung der ehemaligen Offiziere also insgesamt nicht vom Gesamtbild der Entnazifizierung in Hessen abwich, regte sich angesichts der Tatsache, dass es sich bei den Insassen des Lagers Neustadt um hochrangige militärische Repräsentanten des Dritten Reiches handelte, Kritik an den allzu milde erscheinenden Sprüchen. Bereits nach dem Spruch gegen Karl Weisenberger beklagte sich der als militärischer Sachverständiger bei den Neustädter Spruchkammern beschäftigte ehemalige Generalleutnant Theodor Groppe über die mangelnde Expertise des Spruchkammerpersonals und das daraus resultierende „Fehlurteil“. In Groppes Augen, der selbst wegen seiner kritischen Haltung zum NS-Regime Ende 1941 aus dem aktiven Dienst entlassen worden war und daher als politisch unbelastet galt, hätte Weisenberger in die Gruppe I der „Hauptschuldigen" eingeordnet werden müssen. ${ }^{202}$

Angesichts der Urteilspraxis der Neustädter Sonderspruchkammern fühlte sich auch Hubert I. Teitelbaum von der Denazification Division in seinem Argwohn bestätigt. In einem Schreiben an Befreiungsminister Binder vom 17. Mai stellte er alarmiert fest:

„Es wurde mir berichtet, dass von 92 Personen, die bis zum 27. April 1948 vor die Neustädter Spruchkammer kamen, 66 als entlastet hervorgegangen sind. Das bedeutet, dass 66 Anti-Nazis waren, die nach bestem Können dem Nazismus Widerstand entgegengesetzt haben. Diese Anzahl ist in der Tat alarmierend [...]. Ich stelle in Zweifel, dass eine gewöhnliche Spruchkammer eine derartige ,Leistung' hätte vollbringen können. “203

Da er überzeugt war, dass viele ehemalige Offiziere in eine höhere Kategorie hätten eingestuft werden müssen, ordnete Teitelbaum zunächst eine Überprüfung

199 Vgl. hierzu Halbmonatliche Arbeitsberichte der hessischen Lagerspruchkammer in Neustadt, 1.3. bis 30.4. 1948, in: HHStAW, Abt. 501/1404.

200 Alfred Toppe, Wegweiser durch die Kriegsgeschichtsschreibung in Allendorf und Neustadt, November 1948, in: BArch, ZA 1/2553.

201 Zum Stand der hessischen Entnazifizierung zum 15. April 1948 vgl. die Abbildung in Schuster, Entnazifizierung in Hessen, S. 168.

202 Groppe, Schreiben an Günther Draub, 17.1.1948, in: HHStAW, Abt.501/3; Draub, Schreiben an den hessischen Befreiungsminister Gottlob Binder, 19.1.1948, in: HHStAW, Abt. 501/3.

203 Hubert Teitelbaum, Schreiben an den hessischen Befreiungsminister Gottlob Binder: Situation im Neustädter Lager, 17. 5. 1948, in: HHStAW, Abt. 501/1220. 
aller Neustädter Sprüche durch die Rechtsaufsichtsabteilung des Befreiungsministeriums an. ${ }^{204}$ Wenig später rückte er allerdings von dieser Forderung ab, da eine Wiederaufnahme der Verfahren in der Mehrheit der Fälle de facto keine Änderung der Ergebnisse erbracht hätte: Selbst im Falle einer höheren Einstufung hätten die Betroffenen vermutlich keine Restriktionen auferlegt bekommen. ${ }^{205}$

\section{Entnazifizierung Franz Halders}

Auch Franz Halder sollte durch die Lagerspruchkammer Neustadt entnazifiziert werden. Der bayerische Ankläger Frey erhob daher am 6. April 1948 Klage gegen Halder und beantragte seine Einreihung in die Gruppe I der „Hauptschuldigen“206 In der Anklageschrift wies Frey Halders apologetische Argumentation, er habe als Generalstabschef nicht das Regime, sondern die Wehrmacht repräsentiert und stets unpolitisch gehandelt, als unhaltbar zurück. Nachdem die Umsturzpläne der Militärs um Generaloberst Ludwig Beck im September 1938 gescheitert seien, habe Halder bewusst entschieden, sich in den Dienst der Hitlerschen Politik zu stellen. Die oberste Führung der Wehrmacht habe sich willfährig und „mit Haut und Haaren“ den verbrecherischen Plänen des Nationalsozialismus verschrieben, und „insbesondere der Chef des Generalstabes“ habe es unterlassen, „sein Veto dagegen einzulegen. Er ha[be] bis zum Oktober 1942 an maßgeblicher Stelle seine Arbeitskraft und seine Fähigkeit dem Regime zur Verfügung gestellt und die militärischen und politischen Pläne Hitlers verwirklichen“ geholfen. Als Stabschef des wichtigsten Wehrmachtsteiles trage Halder zweifellos „Mitverantwortung für all das unsägliche Elend, das der Krieg und seine Folgen über diese Generation gebracht" habe. ${ }^{207}$

Da Franz Halder im April 1948 als Zeuge in Nürnberg erscheinen musste, wurde seine Verhandlung vor der Lagerspruchkammer, die eigentlich am 22. April hätte beginnen sollen, verschoben. Durch die bald darauf folgende Auflösung der Spruchkammern wurde Halders Fall schließlich nicht mehr in Neustadt abgewickelt, sondern im Juli 1948 nach München an die Spruchkammer X überwiesen und kam dort Mitte September 1948 zur Verhandlung. ${ }^{208}$ Noch vor dem Beginn des Verfahrens wies Harold E. Potter die amerikanische Landesmilitärregierung in Bayern darauf hin, dass im Falle einer Verurteilung zu Arbeitslager ein Aufschub der Urteilsvollstreckung erfolgen sollte, um Halders andauernde Tätigkeit für die Historical Division sicherzustellen. ${ }^{209}$

204 Ebd.; Memo for the Record, 27. 5. 1948, in: NARA, RG 549, Box 3172, Folder 2; Joachim Oppenheimer, Aktennotiz betr. Spruchkammer Neustadt-Lager, 26. 5. 1948, in: HHStAW, Abt. 501/1220.

205 Hubert Teitelbaum, Schreiben an das hessische Befreiungsministerium: Trials by Neustadt Tribunal, 27. 5. 1948, in: HHStAW, Abt. 501/1220.

206 Manfred Frey, Klageschrift gegen Franz Halder, 6. 4. 1948, in: BHStAM, MSo 2399; Hans Lehmann, Schreiben an Regierungsrat Gustav Hünninger, 10.4.1948, in: HHStAW, Abt. 501/3.

207 Frey, Klageschrift Halder, in: BHStAM, MSo 2399.

208 Vgl. hierzu auch Ueberschär, Halder, S. 88-89.

${ }^{209}$ Harold E. Potter, Schreiben an den Director, Office of Military Government of Greater Bavaria: Employment of Former German Commanders and Staff Officers on Historical Project, 13. 9. 1948, in: NARA, RG 549, Box 3143, Folder 4. 
Die mündliche Verhandlung begann am 15. September 1948. In seiner Verteidigung betonte Franz Halder, dass er die Position des Generalstabschefs mit der Absicht übernommen habe, ,jede Möglichkeit zum Kampf gegen Hitler,, auszunutzen. ${ }^{210}$ Hinsichtlich der Einsatzgruppen sagte er aus, er habe davon nichts gewusst und erst in Nürnberg von deren Aktivitäten erfahren. ${ }^{211}$ Der öffentliche Kläger beantragte schließlich in seinem Abschlussplädoyer Halders Einreihung in die Gruppe der „Hauptschuldigen“, drei Jahre Arbeitslager und die Einziehung von 30 Prozent seines Vermögens. Die Kammer entschied jedoch anders. In der Urteilsverkündigung vom 26. Oktober 1948 befand die Spruchkammer, dass Halder „überhaupt nicht“ belastet und das Verfahren daher einzustellen sei. In der Begründung ging die Kammer ausführlich auf Halders „militärische Qualität“, seine „gewissenhafte Pflichttreue“ und sein „theoretisches Können“ ein. ${ }^{212}$

Gegen diesen umfassenden Freispruch legte der bayerische Generalkläger im November 1948 Berufung ein. Dieser hatte Halders Kriegstagebuch gründlich geprüft und war dabei zu Recht zu dem Schluss gekommen, dass Halder durchaus am Zustandekommen völkerrechtswidriger Befehle beim Überfall auf die Sowjetunion 1941, konkret dem Kriegsgerichtsbarkeitserlass und dem Kommissarbefehl, beteiligt gewesen war. ${ }^{213}$ Daraufhin wurde das Entlastungsurteil der ersten Instanz Ende November 1948 aufgehoben. ${ }^{214}$ Allerdings traf das bayerische Sonderministerium für Entnazifizierung bei der Ansetzung eines Berufungsverfahrens auf den Widerstand der Historical Division. So teilte Franz Halder dem Sonderministerium zunächst mit, dass er seine kriegsgeschichtliche Arbeit nicht unterbrechen und deshalb zu dem festgesetzten Termin nicht erscheinen könne. ${ }^{215}$ Als das Ministerium im Februar 1949 erneut Halders Anwesenheit vor der Berufungskammer forderte, teilte der geschäftsführende Leiter der Historical Division, Harry C. Larter, der Kammer mit, dass Halder unabkömmlich sei. ${ }^{216}$ Das Sonderministerium wandte sich daraufhin an die Denazifizierungsabteilung der bayerischen Landesmilitärregierung. Diese reagierte verschnupft, dass die Historical Division den üblicherweise über sie laufenden Dienstweg umgangen und sich direkt an die Münchner Berufungskammer gewandt hatte, und schaltete die Civil

210 Sitzungsprotokoll B. der Spruchkammerverhandlung gegen Franz Halder vor der Spruchkammer X, München, 15. 9. 1948, in: BArch, N 220/64.

211 Ebd.

212 Spruch und Begründung im Verfahren gegen Franz Halder, 26. 10. 1948, in: BArch, N 220/65; vgl. auch Ueberschär, Halder, S. 89.

213 Vgl. u. a. Hartmann, Halder, S. 14, S. 245; Deist, Einführende Bemerkungen, in: Müller/ Volkmann (Hg.), Die Wehrmacht, S. 45; Streit, Die Behandlung der sowjetischen Kriegsgefangenen und völkerrechtliche Probleme des Krieges gegen die Sowjetunion, in: Ueberschär (Hg.), „Unternehmen Barbarossa“, S. 201; Krausnick, Kommissarbefehl und "Gerichtsbarkeitserlass Barbarossa" in neuer Sicht, in: Vierteljahrshefte für Zeitgeschichte (1977), S. 710-711.

214 Ueberschär, Halder, S. 90.

215 Curtis H. Shell, Schreiben des Denazification Advisers, OMGB an Director, Civil Administration Division, OMGUS, 19.4. 1949, in: HHStAW, OMGUS, Shipment 17, Box 261-3, Folder 18.

216 Harry C. Larter, Schreiben an den Präsidenten der Berufungskammer München 22 betr. Franz Halder, 23. 2. 1949, in: NARA, RG 549, Box 3144, Folder 13. 
Administration Division von OMGUS ein. ${ }^{217}$ Diese empfahl daraufhin dem OMGUS Chief of Staff, Brigadier General Charles K. Gailey, dass er die Historical Division anweisen solle, Halder für das Berufungsverfahren freizugeben und darüber hinaus künftig den korrekten Dienstweg einzuhalten. ${ }^{218}$ Die Historical Division ignorierte jedoch zunächst die Aufforderung, Halder für die Verhandlung zur Verfügung zu stellen. ${ }^{219}$ Erst Mitte Juni 1949 erklärte sie sich bereit, den ehemaligen Generalstabschef für seine Verhandlung nach München zu beurlauben. ${ }^{220}$ Dennoch kam es nie zu einer Berufungsverhandlung. Die Verzögerungstaktik Halders und der Historical Division war aufgegangen: Die politische Entwicklung war mittlerweile über die Entnazifizierungsbemühungen der Alliierten hinweggegangen; am 6. September 1950 entschied das bayerische Befreiungsministerium, die Berufung zurückzuziehen, da es aufgrund des Gesetzes zum Abschluss der politischen Befreiung vom 27. Juli 1950 unwahrscheinlich war, dass Halder bei einer erneuten Verhandlung als „Hauptschuldiger“ oder „Aktivist“ eingereiht werden würde. Damit wurde der ursprüngliche Spruch vom Oktober 1948 rechtskräftig und Franz Halder galt fortan als nicht belastet. ${ }^{221}$

„Ein großer Aufwand schmählich ward vertan“ - so fasste Günther Draub die mehr oder weniger gescheiterte Arbeit der Neustädter Sonderspruchkammer nach deren unrühmlichem Ende im Mai 1948 verbittert zusammen. ${ }^{22}$ Draub selbst hatte die Problematik und Fallstricke, die mit der Entnazifizierung der ehemaligen Wehrmachtselite einhergingen, treffend erkannt; er war sich der Gefahr bewusst gewesen, dass die Mehrzahl der ehemaligen Generäle und Generalstabsoffiziere von der relativen Unwissenheit der Spruchkammern in militärischen Fragen und gegenseitigen entlastenden Zeugenaussagen profitieren und letztlich mangels Beweisen als nicht belastet eingestuft werden würde. Deshalb hatte sich der Kläger der Neustädter Spruchkammer wiederholt für eine Spezialisierung seiner Kammer auf alle in der amerikanischen Zone zu verhandelnden Generalsfälle ausgesprochen, um somit eine Kammer mit Expertise und Erfahrung in der

217 Shell, Schreiben des Denazification Advisers, OMGB an Director, Civil Administration Division, OMGUS, 19.4. 1949, in: NARA, RG 260, OMGUS, Shipment 17, Box 261-3, Folder 18.

218 Edward H. Lichtfield, Schreiben an den Chief of Staff, OMGUS betr. Appeal Trial of Franz Halder, 5. 5. 1949, in: HHStAW, OMGUS, Shipment 17, Box 261-3, Folder 18; Frederick A. Sturm, Schreiben des Acting Adjutant General an den Commander-inChief, European Command, betr. Appeal Trial of Franz Halder, 11.5.1949, in: HHStAW, OMGUS, Shipment 17, Box 261-3, Folder 18.

219 Edward H. Lichtfield, Schreiben an den Chief of Staff, OMGUS betr. Appeal Trial of Franz Halder, 1.6. 1949, in: HHStAW, OMGUS, Shipment 17, Box 261-3, Folder 18.

220 Chief Public Safety Branch OMGUS Theo E. Hall, Schreiben an den Chief of Staff, OMGUS betr. Appeal Trial of Franz Halder, 14. 6. 1949, in: HHStAW, OMGUS, Shipment 17, Box 261-3, Folder 18.

221 Ueberschär, Halder, S. 90-91.

222 Günther Draub, Schreiben an das hessische Befreiungsministerium betr. Auflösung der Spruchkammer Neustadt-Lager, 4. 6. 1948, in: HHStAW, Abt. 501/2. 
Handhabung und Beurteilung dieser speziellen Fälle zu schaffen und die Wahrscheinlichkeit von Fehlurteilen zu minimieren.

Dabei hatte Draub jedoch übersehen, dass die Neustädter Spruchkammer für eine so heikle Aufgabe denkbar ungeeignet war. Von Anfang an waren die drei Lagerspruchkammern ein Spielball unterschiedlicher und widerstreitender Interessen. Sowohl die hessische Denazification Division als auch das hessische Befreiungsministerium waren wenig begeistert von der Idee, eine Sonderspruchkammer in Neustadt einzurichten, mussten sich aber der Anweisung des Militärgouverneurs Lucius D. Clay beugen, der selbst erst nach monatelangem Konflikt mit der Historical Division schließlich nachgegeben und einer entsprechenden Regelung zugestimmt hatte. ${ }^{223}$ Hubert I. Teitelbaum und Gottlob Binder hegten deshalb von Beginn an erhebliche Zweifel an der Neutralität der Historical Division in der Entnazifizierungsfrage und befürchteten gar eine Einflussnahme zugunsten der deutschen Offiziere. Tatsächlich hatten die Offiziere der Operational History (German) Branch ein nicht unerhebliches Interesse an einer zügigen und diskreten Abwicklung der Verfahren und waren zumindest nicht unglücklich über die relativ milden Urteilssprüche. In den Quellen weist jedoch nichts darauf hin, dass die Historical Division tatsächlich versuchte, aktiv Einfluss auf die Urteilsfindung zu nehmen.

Allerdings herrschte im Lager Neustadt eine ganz besondere Atmosphäre, der sich die Spruchkammerangehörigen kaum entziehen konnten. In den vielen Monaten der kriegsgeschichtlichen Zusammenarbeit hatte sich ein kollegialer Umgang zwischen den deutschen Internierten und den amerikanischen Offizieren der Historical Division herausgebildet. Die deutschen und amerikanischen Militärs begegneten sich auf einer professionellen Ebene und identifizierten sowohl die detaillierte kriegsgeschichtliche Niederschrift der zurückliegenden Kriegsereignisse als auch die Informationsweitergabe über die Sowjetunion für einen zukünftigen Konflikt zwischen der UdSSR und den Vereinigten Staaten als gemeinsame Mission. Die Anwesenheit und Tätigkeit der Spruchkammern im Lager muss auf diese Gemeinschaft störend gewirkt haben; zumindest fühlten sich die Spruchkammerangehörigen rasch als kaum geduldete Außenseiter und sahen sich im Gerichtssaal einem zum Teil offen feindlich gesinnten Publikum deutscher Lagerinsassen gegenüber. Es ist wenig überraschend, dass die zumindest unangebrachte und überdies wochenlang ungeklärte Frage der Verpflegung des Spruchkammerpersonals in dieser Atmosphäre als Einmischungsversuch seitens der Historical Division interpretiert wurde.

Während die Angst vor der Ausbreitung des Kommunismus die deutschen und amerikanischen Offiziere in Neustadt einte, wurde die hessische Spruchkammer von einer im Rückblick hysterisch anmutenden und wohl unbegründeten Angst vor kommunistischer Infiltrierung und Agitation in den eigenen Reihen zerrüttet. Anstatt sich auf die Entnazifizierung der ehemaligen Wehrmachtselite zu konzentrieren, bot die hessische Kammer im Frühjahr 1948 ein unwürdiges und letztlich selbstzerstörerisches Schauspiel gegenseitiger Verdächtigungen und Anschuldi- 
gungen, das dem hessischen Befreiungsministerium und der Denazification Division schließlich einen willkommenen Anlass bot, die Sonderspruchkammer aufzulösen. Geleitet von persönlichen Animositäten, hatte sich der ambitionierte Günther Draub selbst ein Bein gestellt. Seine Vision, Neustadt zur Entnazifizierungszentrale für Generalsfälle zu machen, war damit endgültig gescheitert. Profiteure der Entnazifizierung in Neustadt waren schwer belastete Militärs wie Franz Halder und die Historical Division - deren fortgesetzter Kooperation stand nun, nachdem die deutschen Offiziere erfolgreich, d.h. mit keinen oder minimalen Bußauflagen, durch die Entnazifizierungsmühle gedreht worden waren, nichts mehr im Wege.

\subsection{Zusammenarbeit mit verurteilten Kriegsverbrechern}

Wie bereits gezeigt wurde, hatte die Historical Division keine Bedenken, mit mutmaßlichen Kriegsverbrechern zusammenzuarbeiten, und trug in einigen Fällen sogar aktiv dazu bei, dass deutsche Offiziere nicht an andere Staaten ausgeliefert wurden oder unterstützte im Prozessfall deren Verteidigung. Darüber hinaus arbeitete die kriegsgeschichtliche Abteilung der U.S. Armee in einer Reihe von Fällen auch mit verurteilten Kriegsverbrechern zusammen, die in den Kriegsverbrechergefängnissen im bayerischen Landsberg beziehungsweise im niedersächsischen Werl inhaftiert waren.

\section{Werl}

In Werl arbeiteten zum Beispiel der ehemalige General der Artillerie Curt Gallenkamp, Albert Kesselring, der ehemalige Generaloberst Eberhard von Mackensen und der ehemalige Generalleutnant der Waffen-SS Max Simon für die Historical Division. ${ }^{224}$ Da das Gefängnis in Werl im Gegensatz zur Haftanstalt in Landsberg nicht den Amerikanern, sondern den britischen Besatzungsbehörden unterstand, war die Historical Division verstärkt auf die Kooperationsbereitschaft der zuständigen britischen Penal Branch Legal Division und der britischen Gefängnisleitung unter Lieutenant Colonel E. R. Vickers (1946 bis 1954) angewiesen. Glücklicherweise zeigte sich dieser aus Sicht der Historical Division durchaus verständnisvoll und kooperativ. ${ }^{225}$

Der weitaus wichtigste Mitarbeiter der Historical Division in Werl war Albert Kesselring, den ein britisches Militärgericht im Mai 1947 in Venedig zunächst zum Tode durch Erschießen verurteilt hatte, dessen Urteil dann aber Ende Juni 1947 in eine lebenslängliche Haftstrafe umgewandelt worden war. ${ }^{226}$ Kesselring war daraufhin zunächst im Lager Wolfsberg in Österreich interniert worden,

224 James F. Scoggin, Memorandum betr. Operations at Werl, 14.7. 1948, in: NARA, RG 549, Box 2, Folder 3/6.

225 Ebd.; Ders., Werl Trip Report, 25. 11. 1947, in: NARA, RG 549, Box 3139, Folder 1; Harold E. Potter, Schreiben an Colonel Morgan, British Governor, Allied National Prison, Werl, 29. 12. 1947, in: NARA, RG 549, Box 12, Folder: Kesselring, Albert.

226 Von Lingen, Kesselrings letzte Schlacht, S. 119 und S. 134. 
bevor er im Oktober 1947 nach Werl überstellt wurde.227 Wenige Wochen später besuchte James F. Scoggin von der Historical Division Kesselring in seinem neuen Gefängnis, um die Möglichkeiten einer weiteren Zusammenarbeit auszuloten. Dabei wirkte der Generalfeldmarschall, der bei den Offizieren der Historical Division wegen seiner stets guten Laune und optimistischen Art als „Smiling Al“ bekannt war, ${ }^{228}$ auf Scoggin so „müde und verbraucht“ wie nie zuvor - auch wenn er sich wohl bemühte, einen heiteren Eindruck zu machen. ${ }^{229}$ Tatsächlich fragte sich Kesselring bang, wie das Gefängnisleben wohl werden würde. Das Gebäude wirkte dunkel auf ihn und die Aufseher machten „unfreundliche Gesichter“. Die Uniformität, die den Häftlingen aufgezwungen wurde, belastete den ehemaligen Generalfeldmarschall, der sich plötzlich als „Mensch ohne eigenen Willen“ empfand und die „Nivellierung mit dem Zuchthäusler“ für eine Zumutung hielt. ${ }^{230}$

Trotz seines Missfallens über die Bedingungen und die Behandlung in Werl ${ }^{231}$ hatte Kesselring seine kooperative Einstellung der Historical Division gegenüber nicht geändert. ${ }^{232}$ Nachdem er zunächst zum Tütenkleben eingeteilt worden war, durfte er bald seine kriegsgeschichtlichen Arbeiten fortsetzen und wurde dafür zunächst halbtags, später sogar ganz von der regulären Arbeit freigestellt. Darüber hinaus erhielten Kesselring und die anderen Mitarbeiter der Historical Division Stühle und große Tische und mussten das Licht erst um 22.00 Uhr statt um 20.00 Uhr löschen. ${ }^{233}$ Kesselring war nicht nur der produktivste unter den Werler Häftlingen, sondern wurde von der Historical Division auch mit der Anleitung und Beaufsichtigung der anderen kriegsgeschichtlich tätigen Offiziere beauftragt und fungierte zudem als deren Sprecher gegenüber der Historical Division. ${ }^{234}$

Offiziere der Historical Division besuchten die Gefangenen in Werl in regelmäßigen Abständen, um den Gang der Arbeiten zu besprechen und Materialien auszutauschen. ${ }^{235}$ Dabei hatten die Amerikaner meist den Eindruck, dass diese

227 Ebd., S. 143; vgl. auch Albert Kesselring, Notizen aus der Zeit der Gefangenschaft in Werl 1947/48, S. 1, in: BArch, N 750/15.

228 Mahin, Schreiben an S.L.A. Marshall, 1. 12.1953, in: UTEP, MS 186, Box 83, Folder 1409. Originalzitat: „Kesselring seemed more tired and worn on this occasion than I have ever seen him before. Although he made a brave attempt to be his usual cheerful self, he somehow could not make his eyes smile."

229 Scoggin, Werl Trip Report, 25. 11. 1947, in: NARA, RG 549, Box 3139, Folder 1.

230 Kesselring, Notizen aus der Zeit in Werl, Blatt 1-2, in: BArch, N 750/15.

231 Vgl. hierzu ebd.

${ }^{232} \mathrm{Zu}$ Kesselrings früherer Zusammenarbeit mit der Historical Division in Allendorf vgl. oben, Teil II, Kapitel 2.2.

${ }^{233}$ Kesselring, Notizen aus der Zeit in Werl, S. 2 und S. 6, in: BArch, N 750/15; Scoggin, Werl Trip Report, 25.11. 1947, in: NARA, RG 549, Box 3139, Folder 1.

234 Scoggin, Memorandum betr. Operations at Werl, 14. 7. 1948, in: NARA, RG 549, Box 2, Folder 3/6; Ders., Werl Trip Report, 25. 11. 1947, in: NARA, RG 549, Box 3139, Folder 1.

235 Vgl. beispielsweise Scoggin, Werl Trip Report, 25. 11.1947, in: NARA, RG 549, Box 3139, Folder 1; Daniel T. Murphy, Operational History Branch Weekly Reports No. 58 \& 59, 2. 3. 1949, in: NARA, RG 319, Box 7, Folder 4; Ders., Operational History Branch Weekly Reports No. 64 \& 65, 13.4.1949, in: NARA, RG 319, Box 7, Folder 4; Ders., Operational History Branch Weekly Reports No. 81 und 82, 8. 8.1949, in: NARA, RG 319, Box 7, Folder 3; Ders., Operational History Branch Weekly Reports No. 99 and 100, 15. 12. 1949, in: NARA, RG 319, Box 7, Folder 3. 
Zusammenkünfte den Gefangenen, die sonst nur alle sechs Wochen Besuch empfangen durften, ${ }^{236}$ viel bedeuteten. ${ }^{237}$ Außerdem setzte sich die Historical Division auch für kleinere Verbesserungen der Haftbedingungen ihrer Mitarbeiter ein und erreichte zum Beispiel, dass die Häftlinge Zigaretten und Schokolade erhielten. ${ }^{238}$ Abgesehen von diesen kleinen Annehmlichkeiten für die Häftlinge unterstützte die Historical Division auch die Angehörigen ihrer inhaftierten Mitarbeiter mit Paketen, darunter zum Beispiel die Ehefrauen von Albert Kesselring und Max Simon sowie die Frauen der Landsberger Gefangenen Georg von Küchler und Walter Warlimont. ${ }^{239}$

\section{Landsberg}

Das amerikanische Äquivalent zum britischen Kriegsverbrechergefängnis in Werl bildete die Strafanstalt in Landsberg am Lech, die der amerikanischen Besatzungsmacht seit 1946 als zentrales Kriegsverbrechergefängnis (War Criminal Prison No. 1) diente. Dort waren unter anderem die Verurteilten aus den zwölf Nürnberger Nachfolgeprozessen inhaftiert ${ }^{240}$ - darunter auch eine Reihe von Männern, die bereits vor ihrer Verurteilung mit der Historical Division kooperiert hatten und auch in der Haft weiter an kriegsgeschichtlichen Studien arbeiteten. Zum Landsberger Mitarbeiterkreis der kriegsgeschichtlichen Abteilung gehörten neben Warlimont und Küchler zum Beispiel der ehemalige Generalmajor der Waffen-SS Fritz Krämer, der ehemalige Generaloberst Wilhelm List, Generalfeldmarschall Erhard Milch, der ehemalige Oberst der Waffen-SS Joachim Peiper sowie der ehemalige Generaloberst Lothar Rendulic. ${ }^{241}$

Ähnlich wie Kesselring in Werl, war in Landsberg Walter Warlimont der weitaus wichtigste Mitarbeiter der Historical Division. Zunächst zum Dienst im Garten der Haftanstalt eingeteilt, wurde sein Arbeitspensum ab November 1949 halbiert, so dass er nachmittags an seinen kriegshistorischen Studien arbeiten konnte. ${ }^{242}$ Um seine Schreibarbeiten zu erleichtern, erhielt er neben einem Stuhl und Tisch

236 Kesselring, Notizen aus der Zeit in Werl, S. 3, in: BArch, N 750/15.

237 Report on Trip to Northern Germany 26.11.-1. 12.1951, in: NARA, RG 319, Box 62, Folder 5 .

238 Ders., Notizen aus der Zeit in Werl, in: BArch, N 750/15.

239 Daniel T. Murphy, Memorandum for Colonel Potter, 3. 6. 1949, in: NARA, RG 549, Box 3142, Folder 2; Allen V. Enfinger, Memorandum for Colonel Potter, 24. 6. 1949, in: NARA, RG 549, Box 3142, Folder 2.

240 Raithel, Die Strafanstalt Landsberg am Lech und der Spöttinger Friedhof (1944-1958), S. 51, S. 54 und S. 57-58. Die in den Nürnberger Prozessen verurteilten Häftlinge unterstanden bis 1949 dem Office of Military Government for Germany (U.S). Nach der Gründung der Bundesrepublik 1949 ging die Zuständigkeit für diese Häftlinge auf den amerikanischen Hochkommissar (HICOG) über. Als die Bundesrepublik schließlich 1955 weitgehend souverän wurde, übernahm der amerikanische Botschafter die Zuständigkeit für die verbliebenen Verurteilten der Nürnberger Prozesse.

241 List of former officers in Landsberg, who have assisted the Historical Division EUCOM, United States Army [ohne Datum, aber vermutlich 1951 verfasst], in: NARA, RG 549, Box 3160, Folder 4.

242 Vgl. Special Permit for Walter Warlimont, 3. 11. 1949, in: NARA, RG 466, Box 17, Folder: Warlimont, Walter - Prison Record; $1^{\text {st }}$ Lieutenant Sidney P. Dane, Special Status for Walter Warlimont, 10.2. 1950, in: NARA, RG 466, Box 17, Folder: Warlimont, Walter 
außerdem eine tragbare Schreibmaschine und durfte die von der Historical Division zur Verfügung gestellten Karten und Dokumente ${ }^{243}$ in seiner Zelle aufbewahren. ${ }^{244}$ Warlimont stand außerdem in regem brieflichen Kontakt mit der Historical Division und mit der Control Group sowie mit einer Reihe ehemaliger Wehrmachtsoffiziere, die er für seine Ausführungen konsultierte. ${ }^{245}$ Außerdem wurden er und die anderen beteiligten Gefangenen ebenfalls regelmäßig, etwa alle vier bis sechs Wochen, von Mitarbeitern der Historical Division besucht. ${ }^{246}$ Als Gegenleistung für seine Arbeit erhielt Warlimont zunächst ein monatliches Gehalt von 450 DM, ab September 1953 von 600 DM, das die Historical Division direkt an seine Frau überwies. ${ }^{247}$

Die kriegsgeschichtliche Abteilung entschädigte Warlimont jedoch nicht nur finanziell für seine Mitarbeit, sondern setzte sich Anfang der 1950er Jahre auch wiederholt für seine vorzeitige Entlassung aus dem Gefängnis ein und knüpfte damit an frühere Bemühungen an, ein milderes Urteil für diesen wichtigen Mitarbeiter zu erreichen. ${ }^{248}$ Nachdem mehrere Petitionen seines Anwalts Paul Leverkuehn auf Strafminderung ohne Ergebnis geblieben waren, ${ }^{249}$ wandte sich Warlimont Anfang Februar 1951 hilfesuchend an die Historical Division. ${ }^{250}$ Der

- Prison Record; Captain William M. Jones, Special Status for Walter Warlimont, 8. 4. 1952, in: NARA, RG 466, Box 17, Folder: Warlimont, Walter - Prison Record.

243 Vgl. z. B. Hans W. Helm, Schreiben an Walter Warlimont, 5. 1.1954, in: NARA, RG 466, Box 17, Folder: Warlimont, Walter - Prison Record; Verne E. Pate, Schreiben an Walter Warlimont, 9. 4. 1954, in: NARA, RG 466, Box 17, Folder: Warlimont, Walter Prison Record.

244 Vgl. Walter Warlimont, Receipt [for one portable typewriter], 29.9.1949, in: NARA, RG 466, Box 17, Folder: Warlimont, Walter - Prison Record; Special Permit, 4. 4. 1952, in: NARA, RG 466, Box 17, Folder: Warlimont, Walter - Prison Record; $1^{\text {st }}$ Lieutenant Thomas Large, Special Permit, 27. 6. 1952, in: NARA, RG 466, Box 17, Folder: Warlimont, Walter - Prison Record; Ders., Special Permit, 7.7. 1953, in: NARA, RG 466, Box 17, Folder: Warlimont, Walter - Prison Record; Special Permit, 7.4. 1953, in: NARA, RG 466, Box 17, Folder: Warlimont, Walter - Prison Record.

245 Vgl. hierzu Correspondence Register, Walter Warlimont, in: NARA, RG 466, Box 17, Folder: Warlimont, Walter - Prison Record.

246 Siehe zum Beispiel Daniel T. Murphy, Operational History Branch Weekly Reports No. 60 \& 61, 15.3. 1949, in: NARA, RG 319, Box 7, Folder 4; Murphy, Operational History Branch Weekly Reports No. 64 \& 65, 13. 4. 1949, in: NARA, RG 319, Box 7, Folder 4; Daniel T. Murphy, Operational History Branch Weekly Reports No. 83 and 84, 1.9. 1949, in: NARA, RG 319, Box 7, Folder 3; Ders., Operational History Branch Weekly Reports No. 96 and 97, 22.11. 1949, in: NARA, RG 319, Box 7, Folder 3; Tab „A“ to Report of Monthly Inspection, War Criminal Prison No. 1, for May 1950: Visitors to Landsberg Prison, in: NARA, RG 549, Box 3; Tab „A“ to Report of Monthly Inspection, War Criminal Prison No. 1 for February 1950, in: NARA, RG 549, Box 3; Tab "A“ to report of Monthly Inspection, War Criminal Prison No. 1, July 1950, in: NARA, RG 549, Box 6, Folder: Landsberg 201, 1949-50, War Crimes Gen. Administration.

${ }^{247}$ Hans W. Helm, Schreiben an Walter Warlimont, 8. 9. 1953, in: NARA, RG 466, Box 17, Folder: Warlimont, Walter - Prison Record.

248 Vgl. hierzu oben, Teil III, Kapitel 1.1.

249 Die Petitionen befinden sich in Warlimont, Walter - Petitions, Folder 1-3, in: NARA, RG 466, Box 38.

250 Wilbur S. Nye, Schreiben an Walter Warlimont, 16. 2. 1951, in: NARA, RG 549, Box 3154, Folder 4. 
amerikanische Hochkommissar John J. McCloy, in dessen Zuständigkeit die Verurteilten der Nürnberger Prozesse fielen, hatte kurz zuvor seine Entscheidung über die Gnadengesuche zahlreicher anderer Landsberger Häftlinge bekannt gegeben. In der großen Mehrheit der Fälle veranlasste der Hochkommissar eine Verringerung der Strafen, was bei 30 Häftlingen unter Anrechnung der Untersuchungshaft sowie guter Führung zur sofortigen Entlassung führte. ${ }^{251} \mathrm{Im}$ Fall von Walter Warlimont hatte McCloy die lebenslängliche Haftstrafe auf 18 Jahre reduziert. ${ }^{252}$

Enttäuscht, dass er nicht zu denjenigen gehörte, die sofort zur Entlassung anstanden, bat Warlimont den Chef der Historical Division, Wilbur S. Nye, nun also Anfang Februar 1951, sich für seine baldige Freilassung einzusetzen. Nye, der sich der öffentlichen Kontroverse um die Begnadigungen wohl bewusst war, reagierte zunächst verhalten auf Warlimonts Bitte. Angesichts der scharfen Kritik an den Freilassungen, ließ er den Deutschen wissen, sei der Zeitpunkt für einen solchen Vorstoß ungünstig. Dennoch versprach er, in der Angelegenheit bei seinen Kontakten in Heidelberg vorzufühlen. ${ }^{253}$ Tatsächlich hatte die Historical Division selbst großes Interesse daran, dass Walter Warlimont so bald wie möglich frei kommen würde. Zum einen würde die Expertise des ehemaligen OKW-Generals der Operational History (German) Section dann uneingeschränkt zur Verfügung stehen. Zum anderen erhoffte sich Wilbur S. Nye wie schon im Fall von Wilhelm Bittrich, dass Warlimont als Kontaktmann zu einer Reihe bislang unzugänglicher ehemaliger SS-Offiziere dienen würde, die man gerne zur Füllung einiger Lücken in der offiziellen amerikanischen Kriegsgeschichte herangezogen hätte. ${ }^{254}$ Hier zeigte sich wieder einmal die utilitaristische Einstellung führender Offiziere der Historical Division gegenüber ihren deutschen Mitarbeitern. So begründete Nye seinen Einsatz für Warlimonts Freilassung allein mit einem angeblichen „nationalen Interesse“ an der größtmöglichen Ausnutzung des Deutschen als Informationsquelle. An den juristischen Einzelheiten von Warlimonts Fall war der Amerikaner ausdrücklich nicht interessiert. Er informierte sich deshalb erst gar nicht über die Faktenlage. 255

251 Die umstrittene Entscheidung McCloys war als Geste der Versöhnung angelegt und signalisierte das Ende der alliierten „Bestrafungspolitik“ gegenüber Deutschland. Da die Vereinigten Staaten nur wenige Monate zuvor die Wiederbewaffnung Westdeutschlands vorgeschlagen hatten, warfen Kritiker dem Hochkommissar allerdings vor, er würde vor dem Hintergrund des Kalten Krieges, und konkreter des Koreakrieges, eine zweckrationale Appeasement-Politik gegenüber Deutschland betreiben, die in der $\mathrm{Zu}$ rücknahme der Nürnberger Prozesse resultiere. Vgl. Schwartz, Die Begnadigung deutscher Kriegsverbrecher, in: Vierteljahrshefte für Zeitgeschichte 38 (1990), S. 375-376; vgl. auch Office of the U.S. High Commissioner for Germany, Landsberg. A Documentary Report, 1951, in: NARA, RG 466, Box 51, Folder: Landsberg Prison.

252 United States High Commissioner for Germany John J. McCloy, Order with Respect to Sentence of Walter Warlimont, 31.1.1951, in: NARA, RG 466, Box 17, Folder: Warlimont, Walter - Prison Record.

${ }^{253}$ Nye, Schreiben an Walter Warlimont, 16. 2. 1951, in: NARA, RG 549, Box 3154, Folder 4.

254 Wilbur S. Nye, Schreiben an Orlando Ward, 1. 3. 1951, in: NARA, RG 319, Box 8, Folder 5 .

255 Ebd. 
Sein Versprechen Warlimont gegenüber erfüllend, sandte Nye am 27. Februar ein Memorandum an den politischen Berater von EUCOM, Corrigan. In diesem Dokument betonte er die hohe Bedeutung Warlimonts für die Historical Division, der als einziger verfügbarer Informant zum Oberkommando der Wehrmacht „eine Quelle von unschätzbarem Wert, insbesondere für Studien zu Planung und Strategie" der deutschen Führung sei. ${ }^{256}$ Anschließend ging Nye auf die Schwierigkeiten ein, die Warlimonts Inhaftierung in Landsberg für die kriegsgeschichtliche Kooperation bedeute. Zum einen erschwere die räumliche Entfernung von einer Tagesreise zwischen Karlsruhe und Landsberg die Kommunikation, zum anderen sei Warlimont wegen seiner fortdauernden Haft einigermaßen deprimiert - was sich wiederum negativ auf seine Arbeit auswirke. Schließlich brachte Nye die Möglichkeit ins Spiel, Warlimont unter Auflagen zu entlassen und für den Rest seiner Haftstrafe unter die Aufsicht der Historical Division zu stellen, die den Deutschen dann täglich konsultieren könnte. ${ }^{257}$ Die Reaktionen auf diesen Vorschlag scheinen negativ gewesen zu sein. Jedenfalls zog die Historical Division das Memorandum Mitte März zurück und verfolgte die Idee nicht weiter. ${ }^{258}$

Warlimont zeigte sich enttäuscht darüber, dass Nyes Bemühungen ins Leere liefen und wandte sich deshalb im Mai 1951 erneut an den Chef der Historical Division. Da einige der Landsberger Häftlinge ihre Entlassung aus medizinischen Gründen beantragten, ${ }^{259}$ hoffte Warlimont, er könnte ebenfalls auf diesem Wege frühzeitig entlassen werden. Er bat Nye außerdem, den Hochkommissar noch einmal über Art, Umfang und Qualität seiner Arbeit für die Historical Division in Kenntnis zu setzen. Ein solches offizielles Statement, glaubte Warlimont, würde bei der Entscheidung über seine Entlassung aus medizinischen Gründen vielleicht

256 Ders., Memorandum for Mr. Corrigan, betr.: Walter Warlimont, 27. 2. 1951, in: NARA, RG 549, Box 3154, Folder 4.

257 Ebd.

258 Warlimont, 16.3. 1951, in: NARA, RG 466, Box 39, Folder: Warlimont, Walter - Landsberg.

259 Der zu einer lebenslänglichen Freiheitsstrafe verurteilte Wilhelm List wurde zum Beispiel am 24. Dezember 1954 aus medizinischen Gründen auf Bewährung entlassen, da er an Arteriosklerose, Lungenemphysem und chronischer Bronchitis sowie einem vergrößerten Herzen litt. Am 25. April 1955 wurde das Urteil außerdem von lebenslänglich auf 25 Jahre reduziert. Siehe Colonel Howard C. Curtis, Morning Report, War Criminal Prison No.1, Landsberg, 24.12.1952, in: NARA, RG 549, Box 1, Folder: Morning Reports, Oct-Dec 1952; F. Dr. Puhr, Medical Report on List, Wilhelm, Criminal Prison No. 1 Hospital, 22.9. 1952, in: NARA, RG 466, Box 11, Folder: Classified. War Criminals - 1953. Georg Küchler, der u. a. an Arteriosklerose, altersbedingtem Emphysem und einer vergrößerten Prostata litt, wurde am 18. Februar 1953 ebenfalls aus medizinischen Gründen vorzeitig entlassen. Zehn Monate später, am 15. Dezember 1953, wurde Küchler unter Anrechnung guter Führung offiziell auch aus der Bewährung entlassen. F. Dr. Puhr, Medical Report on Küchler, Georg v., Criminal Prison No. 1 Hospital, 22.9. 1952, in: NARA, RG 466, Box 11, Folder: Classified. War Criminals - 1953; Colonel Howard C. Curtis, Morning Report, War Criminal Prison No. 1, Landsberg, 18. 2. 1953, in: NARA, RG 549, Box 1, Folder: Morning Reports, Jan-Mar 1953; Major Carter W. Spear, Morning Report, War Criminal Prison No. 1, Landsberg, 15. 12. 1953, in: NARA, RG 549, Box 1, Folder: Morning Reports, Oct-Dec 1953. 
positiv berücksichtigt werden. ${ }^{260}$ Erneut griff die Historical Division Warlimonts Anregung auf. Am 21. Juni 1951 sandte Thomas H. Young ein Schreiben an den Vorsitzenden des HICOG Extradition Board, R. C. Hagen, in dem er noch einmal das große Interesse der Historical Division an einer baldigen Freilassung Warlimonts unterstrich und in diesem Zusammenhang auf die Möglichkeit einer Entlassung aus medizinischen Gründen verwies. ${ }^{261}$ Schließlich bat er Hagan, die Interessen der Historical Division bei einer möglichen zukünftigen Entscheidung

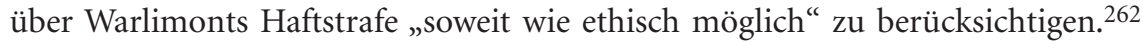
Da Warlimont trotz seiner wiederholten Klagen über Kreislaufbeschwerden, Schlaflosigkeit und einer Neigung zu Erkältungen eine für sein Alter gute gesundheitliche Verfassung bescheinigt wurde, erwies sich jedoch auch eine Entlassung aus medizinischen Gründen schließlich als Sackgasse. ${ }^{263}$ Tatsächlich war der amerikanische Hochkommissar wenig geneigt, Warlimonts Haftstrafe in irgendeiner Weise weiter zu reduzieren. Als Reaktion auf einen weiteren dementsprechenden Antrag von Warlimonts Rechtsanwalt, Dr. Paul Leverkuehn, machte John J. McCloy Ende 1951 deutlich, dass es keine neuen Beweise oder Fakten gäbe, auf deren Grundlage eine erneute Revision des Urteils basieren könne. Zudem sei die bereits reduzierte Strafe keineswegs überhöht, sondern sei angesichts der Faktenlage voll gerechtfertigt. ${ }^{264}$ In den folgenden zwei Jahren kam daher keine Bewegung in Warlimonts Fall.

Nachdem die Frage der noch inhaftierten Kriegsverbrecher im Zuge des Bundestagswahlkampfes 1953 verstärkt diskutiert wurde, schufen der neue amerikanische Hochkommissar James B. Conant und der Commander in Chief der amerikanischen Streitkräfte in Europa, General Charles L. Bolte, am 31. August 1953 den Interim Mixed Parole and Clemency Board, der sich mit den noch in Haft befindlichen Kriegsverbrechern befassen und die Möglichkeit von deren Begnadigung oder Entlassung auf Bewährung prüfen sollte. ${ }^{265}$ Der Ausschuss setzte sich aus fünf Amerikanern sowie zwei Vertretern der Bundesregierung zusammen. ${ }^{266}$ Die Aufgabe des Gremiums war heikel: Zum einen sollte die Kriegsverbrecherfrage, welche die Beziehungen zwischen der Bundesrepublik und den westlichen

260 Walter Warlimont, Schreiben an Wilbur S. Nye, 17.5.1951, in: NARA, RG 549, Box 3154, Folder 4.

261 Young, Schreiben an R. C. Hagen, 21.6. 1951. Darin heißt es: „Although he is a prisoner, Warlimont, to date, has not only shown himself to be one of the most cooperative contributors to our program from the ex-German general officers group, but in our estimation, is the most competent and capable of them all in writing on questions pertaining to the problems of higher command. In fact, he is the only key OKW supreme staff officer still alive."

262 Ebd.

263 Medical Report on Walter Warlimont [ohne Datum, vermutlich Oktober 1952], in: NARA, RG 466, Box 17, Folder: Warlimont, Walter - Medical Record.

264 United States High Commissioner for Germany John J. McCloy, Schreiben an Paul Leverkühn [ohne Datum, aber mit Sicherheit nach dem 22.12.1951 verfasst], in: NARA, RG 466, Box 39, Folder: Warlimont, Walter - Landsberg.

265 Shattuck, The Interim Mixed Parole and Clemency Board, in: Proceedings of the Massachusetts Historical Society 76 (1964), S. 69. Shattuck war Vorsitzender des Gremiums.

266 Raithel, Die Strafanstalt Landsberg am Lech, S. 75; vgl. auch Sigel, Gnadengesuche und Gnadenerlasse, in: Dachauer Hefte 10 (1994), S. 223. 
Alliierten belastete, ausgeräumt werden, um Deutschland im Kalten Krieg als westliche „Bastion gegen russische Aggression“ zu stärken. Andererseits musste auf die öffentliche Meinung in den Vereinigten Staaten Rücksicht genommen werden, die in der Vergangenheit empfindlich auf die Freilassung verurteilter Kriegsverbrecher reagiert hatte. ${ }^{267}$

Neben einer vollumfänglichen Begnadigung der Häftlinge konnte der Ausschuss auch eine sogenannte Parole - also eine Freilassung auf Ehrenwort oder Bewährung - empfehlen. Dies bedeutete keineswegs eine Reduzierung oder gar Aufhebung des Urteils, sondern erlaubte dem Häftling lediglich, den Rest seiner Strafe außerhalb des Gefängnisses, aber innerhalb eines klar definierten und limitierten Umkreises um seinen Wohnort abzuleisten. Der Verurteilte blieb rechtlich unter der Aufsicht der Besatzungsmacht und musste bestimmte Auflagen erfüllen. Für die Empfehlung des Ausschusses war neben der Wiedereingliederungsprognose vor allem die Frage ausschlaggebend, ob der jeweilige Häftling sich an die auferlegten Restriktionen halten würde. Die den ursprünglichen Urteilen zugrunde liegenden Verbrechen wurden vom Ausschuss zwar berücksichtigt, spielten aber bei der Beurteilung der Fälle nur eine sekundäre Rolle. ${ }^{268}$ Wurde ein Häftling auf Parole entlassen, so stand er unter der Aufsicht eines von der deutschen Regierung ernannten und von HICOG bestätigten Parole Supervisors sowie eines amerikanischen Parole Officers. ${ }^{269}$

Nachdem er von der Gründung des Mixed Interim Board for Clemency and Parole erfahren hatte, wandte sich Walter Warlimont im September 1953 wieder an die Historical Division und bat um eine Bescheinigung, die seine langjährige Mitarbeit und deren hohe Qualität belegen sollte. Er hoffte, dass die Mitglieder des Ausschusses aus einer solchen Bescheinigung positive Rückschlüsse auf seine „fundamentalen persönlichen Qualitäten“ ziehen würden. ${ }^{270}$ Tatsächlich stellte ihm der damalige Chief of Military History, Albert C. Smith, im Oktober eine solche Bescheinigung aus. Darin hieß es:

„General Warlimont has materially assisted this Office in closing gaps in existing captured German records and in commenting on the writings of other former German officers. The professional standard of his work has been such that it can be called a unique contribution to the writing of military history in the national interest. [...] The Chief, Historical Division, USAREUR, informs me that General Warlimont has at all times been a cheerful and willing contributor to our historical effort in the production of factual history of World War II.“ 271

Ursprünglich hatte Smiths Schreiben noch einen zweiten Absatz enthalten, in dem der Chief of Military History sich zu Warlimonts militärischer Vergangenheit äußerte:

267 Shattuck, The Interim Mixed Parole and Clemency Board, S. 70.

268 Ebd., S. 74; Sigel, Gnadengesuche und Gnadenerlasse, S. 223-224.

269 Shattuck, The Interim Mixed Parole and Clemency Board, S. 73; Raithel, Die Strafanstalt Landsberg am Lech, S. 75.

270 Walter Warlimont, Schreiben an Hans W. Helm, 14. 9. 1953, in: NARA, RG 549, Box 1149, Folder 2.

271 A. C. Smith, Schreiben an das Mixed Interim Board, betr. Appraisal of General Warlimont's Contribution to the writing of U.S. Army in World War II, 20.10.1953, in: NARA, RG 466, Box 39, Folder: Warlimont, Walter. 
„The matter of General Warlimont's position in the German High Command - he was Deputy Chief of the Armed Forces Operations Staff - has been studied very carefully in this Office for the past seven years. So far as the Office of Military History has been able to determine from strictly military records available to it, General Warlimont seems merely to have fulfilled the duties of a senior staff officer in the routine conduct of conventional type warfare." 272

Auf Anweisung des Büros des Judge Advocate General, das Aussagen zu Warlimonts Stellung und Haltung während des Krieges für „höchst unerwünscht“ hielt, musste Smith diesen Absatz jedoch streichen. ${ }^{273}$

Wenig später, am 30. Oktober 1953, reichte Walter Warlimont seinen Antrag auf Parole beim Interim Mixed Parole and Clemency Board ein. ${ }^{274}$ Da der Ausschuss sich aus politischen Gründen aber zunächst mit den weniger prominenten Fällen befasste, ${ }^{275}$ dauerte es mehrere Monate, bis sich das Gremium dem Antrag des ehemaligen OKW-Generals annahm. Dass Warlimont mit der Historical Division bereits ein mehrjähriges Arbeitsverhältnis unterhielt und dieses auch in Zukunft aufrechterhalten werden sollte, kam seiner Bewerbung sicherlich zugute. Darüber hinaus unterstützte auch der Landsberger Gefängnisdirektor E. C. Moore die Genehmigung von Warlimonts Antrag. Seine Haltung gegenüber dem Gefängnispersonal und den anderen Gefangenen sei „exzellent“ gewesen. Zudem verfüge Warlimont über die „mentalen, physischen und kulturellen“ Voraussetzungen, um einen hervorragenden Staatsbürger abzugeben, und werde sich sicher an die Auflagen und Bedingungen der Parole halten. ${ }^{276}$ Angesichts der positiven Prognose für Walter Warlimont empfahl der Interim Mixed Parole and Clemency Board dem amerikanischen Hochkommissar am 2. Juni 1954 schließlich einstimmig dessen Freisetzung auf Parole. ${ }^{277}$ Eine Woche später, am 9. Juni 1954, wurde er aus der Haftanstalt Landsberg nach Rottach-Egern im Landkreis Miesbach, dem Wohnort seiner Frau, entlassen. ${ }^{278}$

Seine Bewährungsbedingungen beschränkten Warlimonts Bewegungsfreiheit auf den Landkreis Miesbach. Er durfte weiter für die Historical Division arbeiten, allerdings war es ihm verboten, über seine Tätigkeit für die Historical Division hinaus Memoiren, Artikel oder sonstige Beiträge mit persönlichem, militärischem oder politischem Inhalt zu veröffentlichen. Der Kontakt zu anderen verurteilten

272 Entwurf, o. D., in: NARA, RG 319, Box 5, Folder 1.

273 Deputy A. C. of S. BG Mark McClure, G-2, Schreiben an OCMH, betr. „Request for Concurrence“, 15. 10. 1953, in: NARA, RG 319, Box 5, Folder 1.

274 Walter Warlimont, Application for Parole, 30.10. 1953, in: NARA, RG 466, Box 17, Folder: Warlimont, Walter.

275 Shattuck, The Interim Mixed Parole and Clemency Board, S. 72.

276 Colonel E. C. Moore, Parole-Application of Walter Warlimont, WCPL No. 1528. Institutional Records, 31. 10. 1953, in: NARA, RG 466, Box 17, Folder: Warlimont, Walter.

277 Chairman Henry Lee Shattuck, Interim Mixed Parole and Clemency Board, Schreiben an James B. Conant, U.S. High Commissioner to Germany betr. Case of Walter Warlimont Petition for Parole, 2. 6. 1954, in: NARA, RG 466, Box 39, Folder: Walter Warlimont.

278 United States High Commissioner for Germany James B. Conant, Order of Parole, 8. 6. 1954, in: NARA, RG 466, Box 17, Folder: Warlimont, Walter - Prison Record; Colonel E. C. Moore, Certificate of Release, 9. 6. 1954, in: NARA, RG 466, Box 17, Folder: Warlimont, Walter - Prison Record. 
Kriegsverbrechern war ihm streng untersagt. In den ersten vier Monaten nach seiner Entlassung musste er alle zwei Wochen einen schriftlichen Bericht bei seinem Parole Supervisor einreichen, der diesen dann an den amerikanischen Parole Officer weiterleitete. Auch danach musste er einmal pro Monat einen entsprechenden Bericht abfassen. ${ }^{279}$ Um Warlimonts Bewegungsfreiheit weiter zu vergrößern und dienstliche Besuche bei anderen ehemaligen Offizieren zu ermöglichen, richtete die Historical Division wiederholt die Bitte an den Interim Mixed Parole and Clemency Board, die Reisebeschränkungen zu lockern - jedoch ohne nennenswerten Erfolg. ${ }^{280}$ Auch nach einer Erweiterung seines Aufenthaltsgebietes im Mai 1955 durfte sich Warlimont außer im Landkreis Miesbach nur in den Stadt- und Landkreisen München, Bad Aibling und Ebersberg bewegen. ${ }^{281}$

Auch nach seiner Entlassung auf Bewährung versuchte Walter Warlimont weiterhin, eine vollständige Begnadigung zu erreichen. Zu diesem Zweck richtete er am 3. November 1955 ein Gnadengesuch an den amerikanischen Botschafter, das jedoch abschlägig beschieden wurde. ${ }^{282}$ Mitte Mai 1957 beantragte schließlich das Auswärtige Amt beim Gemischten Gemeinsamen Gnadenausschuss (Mixed Board) - einem Gremium aus Vertretern der westlichen Siegermächte USA, Großbritannien und Frankreich sowie Vertretern der Bundesrepublik, das 1955 an die Stelle des Interim Mixed Parole and Clemency Board getreten war ${ }^{283}$ - eine Reduzierung von Warlimonts Strafmaß. ${ }^{284}$ Nachdem auch der damalige Parole Officer, Deforest A. Barton, Warlimonts Verhalten während der Bewährung als hervorragend und seine Reintegration in die deutsche Zivilgesellschaft als erfolgreich eingeschätzt hatte 285 und auch Warlimonts Parole Supervisor und sein Bürge die Aussetzung des Urteils unterstützt hatten, ${ }^{286}$ empfahl das Mixed Board am 8. Juli

279 United States High Commissioner for Germany James B. Conant, Terms and Conditions of Parole, 8.6.1954, in: NARA, RG 466, Box 17, Folder: Warlimont, Walter Prison Record; Henry Lee Shattuck, Schreiben an James B. Conant, U.S. High Commissioner to Germany, betr. Case of Walter Warlimont Petition for Parole, 2. 6. 1954, in: NARA, RG 466, Box 39, Folder: Walter Warlimont.

280 U.S. Parole Officer P. J. Gernert, Office Memorandum für R. C. Hagan, betr.: Visits of Parolee Walter Warlimont, Historical Division, 1.2. 1955, in: NARA, RG 466, Box 39, Folder: Warlimont, Walter; Richard C. Hagan, Schreiben an den Interim Mixed Parole and Clemency Board, 2. 2. 1955, in: NARA, RG 466, Box 39, Folder: Warlimont, Walter; Chairman Interim Mixed Parole and Clemency Board Edwin A. Pitt, Schreiben an Richard C. Hagan, betr.: Travel Restrictions in Parole Conditions of Parolee Walter Warlimont, 2.3. 1955, in: NARA, RG 466, Box 39, Folder: Warlimont, Walter; Richard C. Hagan, Schreiben an die Historical Division, 4.3. 1955, in: NARA, RG 466, Box 39, Folder: Warlimont, Walter.

281 United States High Commissioner for Germany James B. Conant, Amendment to Order of Parole, 2. 5. 1955, in: NARA, RG 466, Box 39, Folder: Warlimont, Walter.

282 U.S. Parole Officer Deforest A. Barton, Schreiben an Walter Warlimont, 25. 9. 1956, in: NARA, RG 466, Box 39, Folder: Warlimont, Walter.

283 Sigel, Gnadengesuche und Gnadenerlasse, S. 224.

284 Auswärtiges Amt, Schreiben an das Mixed Board, 14. 5. 1957, in: NARA, RG 466, Box 39, Folder: Warlimont, Walter.

285 U.S. Parole Officer Deforest A. Barton, Schreiben an den Chairman, Mixed Board, 5. 6. 1957, in: NARA, RG 466, Box 39, Folder: Warlimont, Walter.

286 Toni Schmidhuber, Statement to be attached to the Request of the Federal Government for Reduction of the Sentence of Walter Warlimont (Übersetzung), 15.5.1957, in: 
1957 einstimmig, dass Warlimonts Urteil auf die bereits verbüßte Zeit reduziert werden sollte. 287 Am 19. Juli 1957 folgte der amerikanische Botschafter David Bruce dem Antrag und setzte die Haftstrafe auf die bereits verbüßte Zeit herab. ${ }^{288}$

Mitglieder der Historical Division setzten sich nicht nur für Walter Warlimont ein. Auch der ehemalige Generalmajor der Waffen-SS Fritz Krämer erfuhr Unterstützung. Krämer hatte zu den wenigen deutschen Offizieren gehört, die die Historical Division im Herbst 1945 in ihr damaliges Europa-Hauptquartier im Chateau Hennemont bei Paris gebracht hatte, um die dortige kriegsgeschichtliche Arbeit zu unterstützen. ${ }^{289}$ Dabei war er dem damaligen Theater Historian, S.L.A. Marshall, besonders positiv aufgefallen und dieser erinnerte sich noch zehn Jahre später an die gute Zusammenarbeit mit Krämer, den er für einen „anständigen und freimütigen Soldaten“ mit „solidem Charakter“ hielt. ${ }^{290}$ Nachdem Krämer im Juli 1946 im Malmedy-Prozess zu zehn Jahren Haft verurteilt und dann im Gefängnis in Landsberg inhaftiert worden war, fühlte sich Marshall dem „sympathischen und vornehmen“ Deutschen „in gewisser Weise verpflichtet“.291 Da er außerdem von Krämers Unschuld überzeugt war, wandte der ehemalige Theater Historian sich nur zehn Tage nach der Urteilsverkündung an den Chief of Staff der amerikanischen Streitkräfte in Europa, Major General Harold R. Bull, und bat um Nachsicht für Krämer. Bull leitete den Brief an den Theater Judge Advocate weiter, der versprach Marshalls Aussagen bei der Prüfung des Falls angemessen zu berücksichtigen. ${ }^{292}$

Auch wenn Marshalls Fürsprache keine unmittelbare Wirkung hatte, wusste Krämer den Einsatz des Amerikaners in seiner Sache sehr zu schätzen. Im Frühjahr 1950 bat er Daniel T. Murphy um Marshalls Anschrift. Anfang April wandte er sich unter Berufung auf dessen frühere Parteinahme an den Amerikaner und bat ihn, sich erneut für ihn einzusetzen. Anlass für Krämers Schreiben war die Einrichtung des War Crimes Modification Board im November 1949. Dieser Begnadigungsauschuss war für die Behandlung der Urteile verantwortlich, die in den Dachauer Prozessen gefällt worden waren und die in die Zuständigkeit des Commander-in-Chief der U.S. Streitkräfte in Europa, General Thomas T. Handy,

NARA, RG 466, Box 39, Folder: Warlimont, Walter; Ludwig Wirnhier, Statement to be attached to the Request of the Federal Government for Reduction of the Sentence of Walter Warlimont (Übersetzung), 21.5. 1957, in: NARA, RG 466, Box 39, Folder: Warlimont, Walter.

287 Prof. Dr. v. Weber, Schreiben an den amerikanischen Botschafter David K. E. Bruce, 8. 7. 1957, in: NARA, RG 466, Box 39, Folder: Warlimont, Walter.

288 David Bruce, Order with Respect to Sentence of Walter Warlimont, 19.7. 1957, in: NARA, RG 466, Box 39, Folder: Warlimont, Walter.

289 Vgl. oben, Teil II, Kapitel 1.4.

290 S.L.A. Marshall, Echos of Malmedy [o. D.], S. 2, in: UTEP, MS 186, Box 39, Folder 330. Dort heißt es in Bezug auf Krämer: „A decent and forthright soldier, he joined me in France as one of the first six Germans to co-operate with the Historical Division. Because of his solid character, he became the main influence in the early organization of the work."

291 Ebd. Originalzitat: „Thus I was under some obligation to him, and besides that, we found him a likeable and gentle man."

292 Major General H. R. Bull, Schreiben an S.L.A. Marshall, 26. 7. 1946, in: UTEP, MS 186, Box 87, Folder 1444. 
fielen. ${ }^{293}$ Der ehemalige Waffen-SS-General beteuerte eindringlich seine Unschuld: „I declare solemnly, that I am completely innocent and that I never committed any act which would violate the laws of warfare." 294 Schließlich bat er Marshall, noch einmal ein Gnadengesuch für ihn bei General Handy einzureichen. ${ }^{295}$ Marshall kam der Bitte am 18. April 1951 nach und unterstrich in seinem Schreiben an Handy erneut den seiner Meinung nach soliden Charakter des Deutschen. ${ }^{296}$ Wie wirkungsvoll Marshalls Fürsprache für Krämer letztendlich war, ist schwer abzuschätzen. Es ist jedoch nicht auszuschließen, dass der Einsatz des Amerikaners zugunsten des ehemaligen Waffen-SS-Generals zu dessen vorzeitiger Entlassung mindestens beitrug. Jedenfalls gehörte Fritz Krämer wenige Monate später zu einer Gruppe von 88 Landsberger Häftlingen, deren Entlassung Thomas T. Handy im Rahmen einer Weihnachtsamnestie anordnete. ${ }^{297}$

\section{Von Gegnern zu Waffenbrüdern: Zur Nutzbarmachung deutscher militärischer Erfahrung im Kalten Krieg}

\subsection{Hintergrund: Die Amerikanische Militärstrategie nach 1945 und ihre Auswirkungen auf die U.S. Armee}

\section{Demobilisierung nach 1945}

Der kriegsentscheidende Einsatz der beiden amerikanischen Atombomben in Hiroshima und Nagasaki stärkte die militärische und weltpolitische Position der Vereinigten Staaten und führte zu einer kompromissloseren Haltung gegenüber dem ungeliebten und zunehmend mit Argwohn betrachteten Verbündeten UdSSR. ${ }^{298}$ Vor dem Hintergurnd der vermeintlichen Sicherheit des Atomwaffenmonopols gab die amerikanische Regierung den vehementen Forderungen von

293 Fritz Krämer, Schreiben an S.L.A. Marshall, 3. 4. 1950, in: UTEP, MS 186, Box 82, Folder 1401; zur Einrichtung des War Crimes Modification Board vgl. Schwartz, Begnadigung deutscher Kriegsverbrecher, S. 387; Buscher, The U.S. High Commission and German Nationalism, 1949-52, in: Central European History 23 (1990), S. 67.

${ }^{294}$ Krämer, Schreiben an S.L.A. Marshall, 3.4.1950, in: UTEP, MS 186, Box 82, Folder 1401.

295 Ebd.

296 Zit. nach General Thomas T. Handy, Schreiben an S.L.A. Marshall, 28.4.1950, in: UTEP, MS 186, Box 87, Folder 1444.

297 Colonel Howard C. Curtis, Morning Report, War Criminal Prison No. 1, Landsberg, 21. 12. 1951, in: NARA, RG 549, Box 1, Folder: Morning Reports, Oct-Dec 1951; vgl. auch Buscher, Bestrafen und erziehen, in: Frei (Hg.), Transatlantische Vergangenheitspolitik: der Umgang mit deutschen Kriegsverbrechern in Europa nach dem Zweiten Weltkrieg, S. 132.

298 Vgl. zum sich wandelnden Verhältnis der USA und der Sowjetunion während des Zweiten Weltkriegs und der unmittelbaren Nachkriegszeit Sherry, Preparing for the Next War; Gaddis, Strategies of Containment; Yergin, Shattered Peace; Leffler, The Specter of Communism; Bernstein, Secrets and Threats; Herken, „A Most Deadly Illusion“, in: Pacific Historical Review 49 (1980), S. 51-76; Wiggershaus, Von Potsdam zum PlevenPlan, in: Forster (Hg.), Von der Kapitulation bis zum Pleven-Plan, S. 1-118. 
Parlament und Öffentlichkeit nach baldiger Rückführung der Truppen in die Heimat nach und leitete bereits im Herbst 1945 eine schnelle Demobilisierung der amerikanischen Streitkräfte ein. ${ }^{299}$ Schließlich schien es, als hätten sich konventionelle Bodentruppen endgültig überlebt und würden in künftigen Konflikten nur noch äußerst begrenzt zum Einsatz kommen. In Zukunft, so glaubten viele Amerikaner, gewährleiste das Atomwaffenarsenal das notwendige Maß an militärischer Bereitschaft und Sicherheit, ohne den amerikanischen Steuerzahler und die U.S. Wirtschaft mit den hohen Unterhaltskosten einer großen Armee zu belasten. ${ }^{300}$ In der Folge wurde die U.S. Armee rasch und drastisch reduziert: Ende 1945 hatte sie bereits die Hälfte ihrer Kriegsstärke von rund acht Millionen Mann abgebaut, im Juni 1946 belief sich die Truppenstärke auf knapp 1,9 Millionen Mann und bis Mitte 1947 sank die Zahl der Bodentruppen auf knapp $700000 .^{301}$ Während das amerikanische Heer also mit einer starken Reduzierung seiner Größe wie auch Bedeutung konfrontiert war, avancierte die Luftwaffe nach dem Zweiten Weltkrieg zur wichtigsten Komponente des amerikanischen Militärs. Im Sommer 1947 wurde sie aus dem Heer ausgegliedert und als eigene Teilstreitkraft etabliert. Aus der Army Air Force wurde die Air Force. ${ }^{302}$ Da nur die Luftwaffe in der Lage war, atomare Sprengköpfe im Falle eines Krieges ins feindliche Zielgebiet zu bringen, kam ihr in den „Kriegsplänen“ der späten 1940er Jahre die größte Bedeutung zu. ${ }^{303}$

299 Stewart, The United States Army in a Global Era, 1917-2003, S. 201; Weigley, The American Way of War, S. 368; Gersdorff, Die Gründung der Nordatlantischen Allianz, S. 23.

300 Trauschweizer, The Cold War U.S. Army, S. 18; Lewis, The American Culture of War, S. 63; Weigley, The American Way of War, S. 501; Stewart, The United States Army in a Global Era, S. 210-211. Die Sicherheit des Atomwaffenmonopols war allerdings trügerisch: In den ersten Nachkriegsjahren klaffte eine durchaus beträchtliche Lücke zwischen dem theoretischen nuklearen Potential der USA und der tatsächlichen Fähigkeit, dieses im Notfall auch einzusetzen. Denn das Atomwaffenarsenal der Amerikaner wuchs nur sehr langsam: Im Juli 1946 verfügten die USA gerade einmal über sechs nukleare Sprengköpfe, ein Jahr später waren es 13 und im Juli 1948 schließlich 50. Außerdem war keine dieser Bomben unmittelbar einsatzbereit und es hätte im Bedarfsfall zwei Tage gedauert, die Einzelteile zusammenzusetzen. Auch die Möglichkeiten, die Bomben zu transportieren, waren begrenzt - 1948 waren gerade einmal 30 Flugzeuge der amerikanischen Luftwaffe überhaupt in der Lage, die schweren Sprengköpfe zu laden. Vgl. hierzu ausführlicher Borowski, Air Force Atomic Capability from V-J Day to the Berlin Blockade - Potential or Real?, in: Military Affairs 44 (1980), S. 105-110; Rosenberg, The Origins of Overkill, in: International Security 7 (1983), S. 3-71.

301 Stewart, The United States Army in a Global Era, S. 201; Weigley, The American Way of War, S. 368.

302 Stewart, The United States Army in a Global Era, S. 202; Greiner, Die alliierten militärstrategischen Planungen zur Verteidigung Westeuropas, 1947-1950, in: Foerster (Hg.), Von der Kapitulation bis zum Pleven-Plan, S. 163.

303 HALFMOON und TROJAN 1948 sowie OFFTACKLE 1949. Dabei ging man davon aus, dass ein Krieg mit einem sowjetischen Angriff auf Westeuropa beginnen würde. $\mathrm{Da}$ die schwachen amerikanischen Bodentruppen in Westdeutschland einer sowjetischen Offensive nichts würden entgegensetzen können, sahen die Planungen des U.S. Militärs vor, den Sowjets Mitteleuropa zunächst mehr oder weniger kampflos zu überlassen und die eigenen Truppen nach Großbritannien oder an die europäische Peripherie (Spanien, Dänemark, Norwegen und Italien) zurückzuziehen. Dort wollte man 
Die Degradierung der Landstreitkräfte zur Hilfstruppe der Air Force wurde in Armee-Kreisen äußerst kritisch gesehen und führende Militärs wie General Omar N. Bradley vertraten die Meinung, dass ein Sieg letztendlich nur durch traditionelle Bodenoperationen und die Besetzung des feindlichen Territoriums durch die Armee erreicht werden würde. ${ }^{304}$ Auch S.L.A. Marshall betrachtete die Entwicklung mit Sorge. Der selbsternannte Militärexperte glaubte nicht, dass militärische Konflikte in Zukunft nur durch den Einsatz nuklearer Waffen entschieden werden würden. In seinen Augen blieb die traditionelle Rolle der Landstreitkräfte als Entscheidungsfaktor trotz der technologischen Entwicklung bestehen. ${ }^{305} \mathrm{Im}$ April 1948 warnte er in einem Memorandum an das für die Außenwirkung und das Image der U.S. Armee zuständige Information Office, dass sich die Vorstellung vom Heer als zweitrangiger Teilstreitkraft auf keinen Fall in der Öffentlichkeit festsetzen dürfe. ${ }^{306}$ Marshall hielt die Vorstellung, dass der Einsatz der Air Force im Kriegsfall allein ausschlaggebend sein würde, für trügerisch. ${ }^{307}$ Darüber hinaus fürchtete er, dass die Degradierung der Armee zu einer Hilfstruppe und der Glaube, dass Kriege in Zukunft unter geringeren Opfern zu gewinnen seien, negative Auswirkungen auf die Moral der Truppe, aber auch der amerikanischen Nation als solcher haben würde:

„The [...] results will be a continuing loss of moral fiber within the body of the Army and the withering away of all that is required within a people to keep its spirit equal to the test of war. It is a wholly mistaken and unrealistic appreciation of moral values which would have us believe that there can be any gain to the national capacity for survival by encouraging the growth of the idea that the strain upon field forces in the future may be less, and they may require less of the will to endure great hardship and severe losses, than in times past. The Army of the United States, traditionally, and by its size and nature, is a reflection of the image of the political body, far more than is the case with the other services. That fact is as unalterable as is the certainty that they cannot profit morally at the expense of the Army, without working ultimate injury to themselves and to the noblest instincts of our

dann schwer einzunehmende Verteidigungslinien aufbauen, die vor allem dazu dienen sollten, strategisch wichtige Luftwaffenstützpunkte zu schützen. Von diesen aus würden die Vereinigten Staaten dann in der zweiten Phase des Krieges eine strategische Luftoffensive gegen die UdSSR beginnen und dabei dutzende Atombomben auf militärische und industrielle Ziele in Osteuropa abwerfen, um die sowjetischen Kriegsanstrengungen zu behindern und Zeit für die Mobilisierung der alliierten Truppen zu gewinnen. Erst nach dem Erfolg der Luftoffensive würden schließlich Bodentruppen zum Einsatz kommen. In dieser dritten Phase sollte die Sowjetunion dann endgültig geschlagen und zu einem Frieden nach amerikanischen Bedingungen gezwungen werden. Vgl. Rosenberg, The Origins of Overkill, in: International Security 7 (1983), S. 16; Greiner, Die alliierten militärstrategischen Planungen zur Verteidigung Westeuropas, 1947-1950, S. 166; Soutor, To Stem the Red Tide, S. 661-662; Doughty, The Evolution of US Army Tactical Doctrine, 1946-1976, S. 3.

304 Doughty, The Evolution of US Army Tactical Doctrine, 1946-1976, S. 2.

305 S.L.A. Marshall, Memorandum for the Chief of Information, betr.: Present Doctrine of the Army, 9. 4. 1948, S. 7-8, in: UTEP, MS 186, Box 89, Folder 1475; Ders., Schreiben an den Chairman, House Foreign Affairs Committee, 10.8. 1949, in: UTEP, MS 186, Box 89, Folder 1476.

306 S.L.A. Marshall, Memorandum for the Chief of Information, betr.: Present Doctrine of the Army, 9. 4. 1948, S. 1, in: UTEP, MS 186, Box 89, Folder 1475.

307 Ebd., S. 3. 
people. Because of its symbolic importance, the Army cannot be given a secondary character without lowering the prospects of all services. “308

Abgesehen von den negativen Auswirkungen auf die Moral der Amerikaner warnte Marshall außerdem davor, dass der starke Abbau der amerikanischen Bodentruppen die Verteidigungsmoral der Europäer gegen eine sowjetische Aggression schwächen würde. Falls die Amerikaner Europa im Falle eines sowjetischen Angriffs zunächst aufgeben müssten, könne dies die „endgültige Bolschewisierung des europäischen Kontinents“ bedeuten. Auch wenn der Westen den Krieg letztlich durch den Einsatz amerikanischer Atomwaffen gewinne, sei damit zu rechnen, dass Europa aufgrund des durch die sowjetische Besatzung entstehenden politischen und wirtschaftlichen Chaos' verloren bleiben würde. ${ }^{309}$ Statt sich auf die spätere Befreiung der von den Sowjets eroberten Gebiete zu beschränken, mussten die Amerikaner in Marshalls Augen ihre gesamte bewaffnete Macht für die Verteidigung der bedrohten Gebiete aufbieten. ${ }^{310}$

Nachdem sich die wirtschaftliche Lage in Westeuropa gebessert und die Europäer mit dem Brüsseler Pakt vom März 1948 damit begonnen hatten, eine eigene militärische Verteidigungsorganisation gegen eine mögliche sowjetische Aggression aufzubauen, modifizierten die Amerikaner ihre Planungen für Europa. Im Falle eines russischen Angriffs sollte Westeuropa nun nicht mehr nach vorübergehender Aufgabe zurückerobert, sondern nach Möglichkeit am Rhein verteidigt werden - d.h., der sowjetische Vormarsch nach Westen musste so lange wie möglich verzögert und der Widerstandswillen der europäischen Völker gestärkt werden. Allerdings blieben diese Pläne einer Vorwärtsverteidigung zunächst reine Theorie, da die Europäer nicht über die für diese Strategie notwendigen eigenen Truppen verfügten und die Amerikaner ihre Bodentruppen in Europa nicht im erforderlichen Ausmaß aufstocken wollten. ${ }^{311}$ Das weiterhin bestehende, eklatante Kräfteungleichgewicht gegenüber der Roten Armee bedeutete de facto, dass Kontinentaleuropa im Kriegsfall auch weiterhin zunächst aufgegeben werden und zu einem späteren Zeitpunkt zurückerobert werden müsste. ${ }^{312}$ In ihrer Anfangsphase war die NATO daher trotz anders lautender Verlautbarungen und Planungen nicht wirklich eine militärische, sondern eher eine politische Allianz. Im Falle

308 Ebd., S. 5.

309 Ebd., S. 6.

310 Ders., Schreiben an den Chief of Information, betr.: Future Role of the Army [o. D., zwischen April 1948 und August 1949, vermutlich Sommer 1948], S. 6, in: UTEP, MS 186, Box 89, Folder 1475. Dort heißt es: „In the event of an aggression against the free states of Western Europe, [...] the total armed strength of the United States will be directed toward the defense of the areas threatened by aggression, rather than toward an ultimate liberation of territories conquered by the enemy."

311 Thoß, NATO-Strategie und nationale Verteidigungsplanung, S. 19; Greiner, Die alliierten militärstrategischen Planungen zur Verteidigung Westeuropas, 1947-1950, in: Foerster (Hg.), Von der Kapitulation bis zum Pleven-Plan, S. 170-171; Soutor, To Stem the Red Tide, S. 662-663.

312 Heuser, The Development of NATO's Nuclear Strategy, in: Contemporary European History 4 (1995), S. 42; Greiner, Die alliierten militärstrategischen Planungen zur Verteidigung Westeuropas, 1947-1950, in: Foerster (Hg.), Von der Kapitulation bis zum Pleven-Plan, S. 172-173. 
eines Krieges versprach nur die atomar bestückte Luftflotte der USA einen gewissen Schutz. ${ }^{313}$

\section{Auswirkungen des Koreakrieges}

Der Verlust des Atomwaffenmonopols im August 1949 sowie der Ausbruch und Verlauf des Koreakrieges (1950-1953) schärften das Bewusstsein für die Bedeutung konventioneller Streitkräfte wieder. ${ }^{314}$ In der Folge kam es zu einer Revision der amerikanischen Militärstrategie und einer Erhöhung der Verteidigungsausgaben im konventionellen Bereich. ${ }^{315}$ Angesichts der nun plötzlich um ein Vielfaches realer wirkenden kommunistischen Bedrohung verabschiedete sich die Truman-Administration von ihren militärischen Haushaltsbeschränkungen: ${ }^{316}$ Im ersten Jahr des Koreakrieges stiegen die Verteidigungsausgaben von 13,7 Milliarden (Haushaltsjahr 1950) ${ }^{317}$ auf 23,6 Milliarden (1951); im zweiten Kriegsjahr (Haushaltsjahr 1952) verdoppelte sich der Verteidigungsetat dann auf rund 46 Milliarden. Im Haushaltsjahr 1953 kletterten die Ausgaben schließlich auf ein Rekordhoch $^{318}$ von 52,8 Milliarden Dollar und machten damit knapp 70 Prozent des Gesamthaushaltes aus. ${ }^{319}$

Allerdings floss nur ein vergleichsweise geringer Teil dieser Mittel an die U.S. Armee. Denn obwohl zunächst ein gleichmäßiger Aufbau sowohl der nuklearen Bewaffnung als auch der konventionellen Streitkräfte vorgesehen war, argumentierte die Air Force im Kampf um die Mittel erneut erfolgreich, dass nur sie in der Lage wäre, die Atomwaffen im feindlichen Gebiet zum Einsatz zu bringen. Obwohl der Krieg in Korea ja eigentlich bewies, dass konventionelle Bodentruppen auch im Atomzeitalter durchaus gebraucht wurden, konnte die U.S. Armee kein politisches Kapital aus ihrem Einsatz in Asien schlagen. Im Gegenteil. ${ }^{320}$ Die Luft-

313 Trauschweizer, Creating Deterrence for Limited War, S. 71; Thoß, NATO-Strategie und nationale Verteidigungsplanung, S. 19.

314 Vgl. Herken, „A Most Deadly Illusion“, in: Pacific Historical Review 49 (1980), S. 5158; Gaddis, Strategies of Containment, S. 77-83, S. 89-98 und S. 107-108; Jervis, The Impact of the Korean War on the Cold War, in: The Journal of Conflict Resolution 24 (1980), S. 563-592; May, Introduction: NSC 68: The Theory and Politics of Strategy, in: May (Hg.), American Cold War Strategy, S. 1-14; Trauschweizer, The Cold War U.S. Army, S. 20; Thoß, NATO-Strategie und nationale Verteidigungsplanung, S. 23; Stewart, The United States Army in a Global Era, S. 222-246.

315 Für eine ausführlichere Analyse der Auswirkungen auf die amerikanische Außen- und Sicherheitspolitik sowie die Instrumentalisierung des Konfliktes zur Durchsetzung bereits früher angedachter, aber bislang nicht opportun erscheinender Maßnahmen wie zum Beispiel der Aufstockung des Verteidigungsbudgets oder der deutschen Wiederbewaffnung, siehe Jervis, The Impact of the Korean War on the Cold War.

316 Ebd., S. 579-580.

317 Das Haushaltsjahr endete im Juni 1950. Der Koreakrieg wirkte sich also erst auf die folgenden Haushalte der Jahre 1951 bis 1954 aus.

318 Lediglich in den Kriegsjahren 1943-1945 hatten die USA mehr für Verteidigung ausgegeben.

319 Vgl. Executive Office of the President of the United States. Office of Management and Budget (Hg.), Historical Tables. Budget of the United States Government. FY 2009, Washington D.C. 2008, Tab. 3.1: Outlays by Subfunction and Function 1940-2013, S. 48.

320 Trauschweizer, Creating Deterrence for Limited War, S. 62; Bacevich, The Pentomic Era, S. 9-10. 
waffe erhielt auch weiterhin Priorität bei den Verteidigungsausgaben. Ein großer Teil der Investitionen floss außerdem in die Weiterentwicklung militärischer Technologie, insbesondere die Herstellung kleinerer und leichterer Atombomben sowie thermonuklearer Waffen mit enormer Zerstörungskraft. ${ }^{321}$ Zwar nahm die Anzahl der konventionellen Truppen durch den Krieg in Korea zu - von knapp 600000 Mann im Sommer 1950 auf rund 1,5 Millionen im Juli 1951;322 nachdem der Krieg im Sommer 1951 jedoch zum Stellungskrieg erstarrt war, wurde die Armee nicht weiter aufgestockt und die finanziellen Mittel sogar gekürzt. ${ }^{323}$ Auch die in Deutschland stationierten Einheiten, die Mitte 1952 eigentlich ein recht hohes Bereitschaftsniveau erreicht hatten, waren von Kürzungen bei Training und Ausrüstung betroffen. ${ }^{324}$ Trotz der erneuten Mittelkürzungen blieb die Mission der Landstreitkräfte unverändert anspruchsvoll: Neben der erfolgreichen Beendigung der Kampfhandlungen in Asien sollte die Armee außerdem eine einsatzfähige Armee in Westdeutschland aufbauen. ${ }^{325}$ Denn im Zusammenhang mit dem Versuch, die NATO von einem Papiertiger mit vorwiegend politischem Symbolcharakter zu einer ernstzunehmenden militärischen Organisation auszubauen, erklärten sich die Vereinigten Staaten bereit, in Zukunft sechs amerikanische Divisionen in Europa zu stationieren, und drängten nun auch die Verbündeten in Westeuropa zu größeren Investitionen in den Aufbau einer angemessenen konventionellen Streitmacht. ${ }^{326}$ Die Aufstockung der Bodentruppen sollte die Westeuropäer befähigen, eine sowjetische Aggression in Zentraleuropa und nicht erst am Kanal oder in Gibraltar zu stoppen. Die Hoffnung war, das Konzept der Vorwärtsverteidigung zu einer realistischen Alternative zur Evakuierung des Kontinents zu machen. ${ }^{327}$

Die Hoffnung erfüllte sich nicht. Denn obwohl die USA Wort hielten und ihre Streitkräfte in Europa aufstockten, wuchs die Anzahl der westlichen Truppen zu langsam. Denn die Stärke der alliierten Bodentruppen blieb weit von den für eine erfolgreiche Vorwärtsverteidigung als notwendig erachteten 90 Divisionen entfernt. Als Dwight D. Eisenhower im April 1951 als erster Supreme Allied Commander Europe (SACEUR) das Oberkommando der NATO in Europa (Supreme Headquarters Allied Powers Europe - SHAPE) übernahm, ${ }^{328}$ verfügte er lediglich über 18 Divisionen, elf weitere hätten bei Bedarf mobilisiert werden können. ${ }^{329}$ Einem Angriff der Roten Armee mit ihren geschätzten 175 Divisionen hätten die NATO-

${ }^{321}$ Rosenberg, The Origins of Overkill, S. 22; Trachtenberg, A Constructed Peace, S. 156158; Trauschweizer, Creating Deterrence for Limited War, S. 46-48.

322 Donelly, „The Best Army that Can be Put in the Field in the Circumstances“, in: The Journal of Military History 71 (2007), S. 815-816.

323 Die für den Koreakrieg genehmigten zusätzlichen Haushaltsmittel für die U.S. Armee sanken von rund 19 Milliarden Dollar 1951 auf rund 13 Milliarden Dollar 1953. Ebd., S. 814.

324 Ebd., S. 829-831.

325 Donelly, ,The Best Army that Can be Put in the Field in the Circumstances“, S. 810 und S. 819-820.

326 Thoß, NATO-Strategie und nationale Verteidigungsplanung, S. 24.

327 Heuser, The Development of NATO's Nuclear Strategy, S. 42-43.

328 Jervis, The Impact of the Korean War on the Cold War, S. 580-581.

329 Trauschweizer, Creating Deterrence for Limited War, S. 49-50 und S. 72. 
Partner also auch weiterhin kaum etwas entgegensetzen können. Um die erforderliche Truppenstärke zu erreichen, hätten die Verbündeten ihre Militärausgaben daher drastisch erhöhen müssen. ${ }^{330}$ Dem standen jedoch die begrenzten finanziellen und wirtschaftlichen Ressourcen der NATO-Mitglieder entgegen. Europäische und amerikanische Politiker und Strategen waren überzeugt, dass der Westen nicht gleichzeitig große konventionelle Streitkräfte unterhalten und seinen hohen Lebensstandard würde halten können - Letzteres schien im ideologischen Ringen mit dem Kommunismus jedoch unbedingt notwendig. ${ }^{331}$ Da es angesichts dieses Dilemmas unmöglich war, die konventionellen Streitkräfte so weit aufzustocken, dass sie denen der Sowjetunion hätten Paroli bieten können, sahen sich die NATO-Mitgliedsstaaten bald gezwungen, auch weiterhin vorrangig auf eine Strategie der nuklearen Abschreckung zu setzen. ${ }^{332}$

\section{Eisenhowers "New Look"-Strategie}

Auch unter Präsident Dwight D. Eisenhower (1953-1961) änderte sich die Einschätzung der Sowjetunion als Gegner der Vereinigten Staaten kaum. Wie schon die Vorgängerregierung schrieben auch Eisenhower und seine wichtigsten Berater den Herrschern in Moskau ein ideologisch motiviertes expansionistisches Streben nach Weltherrschaft zu. ${ }^{333}$ Auch wenn Eisenhower grundsätzlich die Außenpolitik der Truman-Administration fortführte, betrachtete er die seit 1951 stark angestiegenen Verteidigungsausgaben äußerst kritisch. ${ }^{334}$ Vor allem die hohe Staatsverschuldung von rund 266 Milliarden Dollar ${ }^{335}$ machte dem neuen Präsidenten Sorgen. Eisenhower war überzeugt, dass ein Kollaps der amerikanischen Wirtschaft durch „eine überzogene Sicherheitsbefriedigung“ und daraus resultierenden überhöhten Staatsschulden eine ebenso große Gefahr für das amerikanische

330 Ebd., S. 74.

331 Heuser, NATO's Nuclear Strategy, S. 38.

332 Trauschweizer, Creating Deterrence for Limited War, S. 52.

333 Garthoff, Assessing the Adversary, S. 1; vgl. auch NSC 162/2. A Report to the National Security Council by the Executive Secretary on Basic National Security Policy, 30. 10. 1953, Washington, S. 1-2. Dort heißt es: „The Soviet rulers can be expected to continue to base their policy on the conviction of irreconcilable hostility between the bloc and the non-communist world. This conviction is the compound product of Marxist belief in their historically determined conflict with, and inevitable triumph over, ,world capitalism 'led by the United States, of fear for the security of the regime and the USSR, especially in the face of a hostile coalition, of distrust of U.S. aims and intentions, and of long-established reliance on techniques of conspiracy and subversion. Accordingly, the basic Soviet objectives continue to be consolidation and expansion of their own sphere of power and the eventual domination of the non-communist world."

334 Seit Ausbruch des Koreakrieges war die Truppenstärke des U.S. Militärs von knapp 1,6 Millionen Mann auf über drei Millionen angestiegen. Vgl. Tabelle in Dockrill, Eisenhower's New Look, S. 281.

335 Stand: Haushaltsjahr 1953. Dies entsprach rund 71 Prozent des Bruttoinlandsproduktes. Vgl. Executive Office of the President of the United States. Office of Management and Budget (Hg.), Historical Tables, Tab. 7.1: Federal Debt at the End of Fiscal Year: 1940-2013, S. 127. 
politische System darstellte wie die äußere Bedrohung durch die Sowjetunion. ${ }^{336}$ Da der Präsident die hohe Verschuldung für untragbar hielt, machte er es sich zum Ziel, die unkontrolliert steigenden Militärausgaben, die 1953 knapp 70 Prozent des Gesamthaushaltes ausmachten, ${ }^{337}$ deutlich zurückzufahren und eine „Synthese aus allgemeinem Haushaltsausgleich und realisierbarer Streitkräftestruktur“ zu erreichen. ${ }^{338} \mathrm{Zu}$ diesem Zweck sollten Atomwaffen und deren Trägersysteme erneut zum primären Verteidigungsinstrument der USA werden. ${ }^{339}$ Die Rolle der U.S. Armee für die nationale Sicherheit wurde nicht genauer definiert. Allerdings schien klar, dass die Landstreitkräfte vor allem für den Schutz des amerikanischen Territoriums und die Aufrechterhaltung von Ruhe und Ordnung im Falle eines sowjetischen Angriffs auf die Vereinigten Staaten vorgesehen waren. Größere Kampfeinsätze wurden dagegen als unwahrscheinlich erachtet; außerhalb der USA waren allenfalls Aufgaben als Okkupationsarmee im Falle der Eroberung feindlichen Territoriums nach erfolgreichen atomaren Luftschlägen vorgesehen. ${ }^{340}$ Das Primat der nuklearen Abschreckung stellte somit eine existenzielle Bedrohung für die amerikanischen Landstreitkräfte dar, indem es die traditionelle militärische Verteidigung und Eroberung von Territorium durch Bodentruppen als bevorzugtes Mittel der Kriegführung negierte. ${ }^{341}$

Die Proteste der Armee-Führung gegen diese Politik bewirkten zumindest während der Eisenhower-Administration wenig. Die einseitige Konzentration auf den Aufbau einer strategischen Luftstreitmacht erlaubte es der Regierung, die Verteidigungsausgaben bis 1955 um 20 Prozent zu senken und gleichzeitig die Zahl der nuklearen Sprengköpfe (und deren Zerstörungskraft) von 150 im Jahr 1953 auf 19000 im Jahr 1960 zu erhöhen. ${ }^{342}$ Für die U.S. Armee bedeutete dies, dass ihr Budget erneut zugunsten der Luftwaffe gekürzt wurde. In den Haushaltsjahren 1954 bis 1957 entfielen auf die Armee durchschnittlich nur rund 22 Prozent der Militärausgaben, während die Navy 29 Prozent und die Air Force etwa 47 Prozent der Mittel erhielten. ${ }^{343}$ Parallel mit der finanziellen Ausstattung der Armee sank auch deren Truppenstärke von rund 1,4 Millionen Mann 1954 auf

336 Thoß, NATO-Strategie und nationale Verteidigungsplanung, S. 36; Clarfield, Security with Solvency, S. 1; Gaddis, Strategies of Containment, S. 132.

337 Vgl. Executive Office of the President of the United States. Office of Management and Budget (Hg.), Historical Tables, Tab 3.1: Outlays by Superfunction and Function: 19402013, S. 48.

338 Thoß, NATO-Strategie und nationale Verteidigungsplanung, S. 35; Rosenberg, The Origins of Overkill, S. 28; Trauschweizer, Creating Deterrence for Limited War, S. 53-54; vgl. auch allgemein Kinnard, President Eisenhower and the Defense Budget, in: The Journal of Politics 39 (1977), S. 596-623.

339 Vgl. National Security Council Paper No. 162/2 (NSC-162/2) Promotes Atomic Power, 1953, in: Merrill/Paterson (Hg.), Major Problems in American Foreign Relations, Volume II, S. 291-292.

340 Trauschweizer, Creating Deterrence for Limited War, S. 55-56; Bacevich, The Pentomic Era, S. 16.

341 Trauschweizer, Creating Deterrence for Limited War, S. 33.

342 Sherry, Eisenhower's Heroic but Failed Crusade against Militarization, in: Merrill/ Paterson (Hg.), Major Problems in American Foreign Relations, Volume II, S. 306.

343 Trauschweizer, Creating Deterrence for Limited War, S. 56; Rosenberg, The Origins of Overkill, S. 29; Bacevich, The Pentomic Era, S. 16. 
knapp 900000 im Jahr 1958. Am Ende von Eisenhowers Präsidentschaft verfügte die U.S. Armee nur noch über 14 Divisionen, von denen lediglich elf einsatzbereit waren. ${ }^{344}$ Langfristig machte sich der hartnäckige Widerstand der Armeeführung gegen den New Look dann allerdings doch bemerkbar und einer der schärfsten Kritiker von Eisenhowers Strategie der massiven Vergeltung, Maxwell D. Taylor, wurde in den 1960er Jahren zum Architekten einer neuen Strategie der Flexible Response, in der auch den Landstreitkräften wieder eine zentralere Rolle beigemessen wurde. ${ }^{345}$

\subsection{Auswirkungen auf die Historical Division}

Da die Historical Division Teil der U.S. Armee war, bekam auch sie die Mittel- und Personalkürzungen zu spüren. Schon kurz nach Ende des Zweiten Weltkrieges machte sich die rasche Demobilisierung der Streitkräfte auch bei der Personalstärke der kriegsgeschichtlichen Abteilung bemerkbar. ${ }^{346}$ Bereits im Juli 1945 schickte sich das War Department an, das Stellenkontingent der Historical Division in Washington von 56 auf 46 zu reduzieren. ${ }^{347}$ Nur dank der beherzten Hilfe des Advisory Committee und des damaligen Assistant Secretary of War, John McCloy, gelang es schließlich, die Stellenstreichungen abzuwenden. ${ }^{348}$ Schon 1947 war die kriegsgeschichtliche Abteilung jedoch erneut mit einer zehnprozentigen Kürzung ihres (zivilen) Personals konfrontiert. ${ }^{349}$ Der geplante Stellenabbau drohte vor allem die Arbeit an der offiziellen Geschichte des Zweiten Weltkrieges zu behindern, die in erster Linie von professionellen Historikern bearbeitet werden sollte. Da die Beschäftigung dieser zivilen Historiker jedes Jahr aufs Neue von der Bewilligung entsprechender Haushaltsmittel abhängig war, konnte die Historical Division diesen Autoren keine längerfristige Arbeitsplatzgarantie bieten. Die meisten Historiker zogen deshalb die Stellensicherheit an den Universitäten der befristeten Arbeit für das War Department vor. ${ }^{350}$

Um zivilen Historikern zumindest die Anstellung bis zur Fertigstellung ihres jeweiligen Bandes in der World War II-Reihe zusichern zu können und eine ge-

344 Sherry, Eisenhower's Heroic but Failed Crusade against Militarization, S. 304; Trauschweizer, Creating Deterrence for Limited War, S. 56-57 und S. 67; Bacevich, The Pentomic Era, S. 19-20.

345 Bacevich, The Pentomic Era, S. 48.

346 Edwin B. Kerr, The Army Historical Program since 1942 - A History, S. 5, in: NARA, RG 319, Box 11, Folder 3.

347 Louis Morton, The Establishment of the Historical Division, WDSS. The Struggle for Survival, S. 4, in: NARA, RG 319, Box 82, Folder 1.

348 Vgl. ebd., S. 5-8.

349 Kent Roberts Greenfield, The U.S. Army's Historical Program since 1942 - A Memoir, 18. 10. 1952, in: NARA, RG 319, Box 2, Folder 2.

350 Vgl. hierzu Ders., Memorandum for the Chief, Historical Division. Report of Activities, 13.8. 1946, in: NARA, RG 319, Box 9, Folder 5; außerdem Chief World War II Branch Colonel A. R. Hartman, Memorandum for the Record, betr.: My Service with the Historical Division since November 1946, 13.2. 1950, S. 2, in: NARA, RG 319, Box 16, Folder 11. 
wisse Sicherheit vor Budgetkürzungen ${ }^{351}$ zu erreichen, bemühte sich der damalige Leiter der Historical Division, Colonel Allen F. Clark, 1947 um die Zusicherung eines haushaltsunabhängigen und nicht zweckgebundenden Fonds aus Mitteln des Kriegsministeriums in Höhe von vier Millionen Dollar. ${ }^{352}$ Dieser Betrag, so hoffte Clark, würde ausreichen, um die World War II-Reihe innerhalb von fünf Jahren abzuschließen. Tatsächlich erklärte sich der scheidende Kriegsminister Patterson, der dem historischen Programm ohnehin von Anfang an positiv gegenübergestanden hatte, ${ }^{353}$ im Juni 1947 bereit, aus Mitteln des War Department einen Sonderfonds - den sogenannten War Department Historical Fund - in der geforderten Höhe einzurichten und damit die Forschung der U.S. Armee zum Zweiten Weltkrieg unabhängig von der jährlichen Budgetplanung zu machen. ${ }^{354}$

Entgegen dem allgemeinen Trend in der U.S. Armee erlebte die Historical Division mit den Mitteln des Sonderfonds im Rücken in den folgenden Jahren einen regelrechten Wachstumsschub. Die Personalstärke der Abteilung in Washington kletterte von 130 im Juli 1947 über 193 im Jahr 1948 auf 210 im Jahr 1949 und erreichte mit 230 Mitarbeitern 1950 ihren Höhepunkt. Dabei machten die zivilen Mitarbeiter den Großteil des Personals aus: Im Jahr 1948 arbeiteten 158 Zivilisten für die Abteilung; 1950 waren es sogar 176. Allerdings blieb die Zahl der promovierten Mitarbeiter relativ gering; sie lag 1948 bei 21, 1950 bei 22 und 1951 bei 29. Trotz guter Bezahlung und der Aussicht auf mehrjährige Beschäftigung sowie der steigenden Reputation der Historical Division in geschichtswissenschaftlichen Kreisen fanden sich noch immer kaum Historiker bereit, ihr akademisches Umfeld für einen Regierungsjob in Washington aufzugeben. ${ }^{355}$ Die Frage, wie mehr professionelle Historiker für die Arbeit an der World War II-Serie gewonnen werden könnten, blieb letztlich ein ungelöstes Dauerthema in der Historical Division. ${ }^{356}$

351 Budgetkürzungen hatten bis 1947 bereits zur Einstellung der historischen Programme des Signal Corps und Transportation Corps geführt, was in der Historical Division "große Besorgnis" hervorrief. Siehe Kent Roberts Greenfield, Memorandum for Chief, Historical Division: Report of Activities, 9.-23. 6. 1947, 24.6. 1947, in: NARA, RG 319, Box 9, Folder 6.

352 Colonel A. R. Hartman, My Service with the Historical Division, S. 2 und S. 14, in: NARA, RG 319, Box 16, Folder 11.

353 Vgl. oben, Teil II, Kapitel 1.2.

354 Greenfield, Memorandum for Chief, Historical Division: Report of Activities, 9.23. 6. 1947, 24. 6. 1947, in: NARA, RG 319, Box 9; vgl. auch Office of the Chief of Military History, Accomplishments First Half FY 1952. Presentation for General Taylor, 7.2. 1952, in: NARA, RG 319, Box 2, Folder 2; Melvin C. Helfers, The United States Army's History of World War II, in: Military Affairs 19 (1955), S. 32; siehe außerdem Conn, Historical Work in the United States Army, 1862-1954, S. 138-152; Jessup/Coakley, A Century of Army Historical Work, in: Jessup/Coakley (Hg.), A Guide to the Study and Use of Military History, S. 291.

355 Kent Roberts Greenfield, Memorandum for the Chief, Historical Division. Report of Activities for the Period 8.12.1947-2.1.1948, 7.1.1948, in: NARA, RG 319, Box 9, Folder 7.

356 Vgl. hierzu die Debatten im Advisory Committee: Closed Session Meeting of Members of the Historical Division with the Advisory Committee, 5. 2. 1948, in: NARA, RG 319, Box 33, Folder 10; Minutes of Closed Session of Historical Advisory Committee, 12. 4. 1952, in: NARA, RG 319, Box 16, Folder 3; außerdem Colonel A. R. Hartman, My Service with the Historical Division, S. 2, in: NARA, RG 319, Box 16, Folder 11. 
Nachdem die kriegsgeschichtliche Abteilung in Washington also dank der Einrichtung des haushaltsunabhängigen Sonderfonds Ende der 1940er Jahre eine rasche Expansion durchlaufen hatte, geriet sie Anfang der 1950er Jahre erneut unter Druck. Schon Mitte 1949 hatte sich die Hoffnung, die World War II-Reihe bis 1952 zum Abschluss zu bringen, als unrealistisch erwiesen. Abgesehen vom Mangel an zivilen Historikern hatte sich außerdem gezeigt, dass die vorhandenen Autoren für Recherche und Verschriftlichung wesentlich mehr Zeit benötigten als zunächst angenommen. Darüber hinaus hatte sich die Drucklegung der Manuskripte, die über das Büro des Adjutant General mit dem Government Printing Office abgewickelt werden musste, als äußerst langwierig erwiesen. Nicht selten vergingen zwischen der Fertigstellung des Manuskripts und der Veröffentlichung rund zwei Jahre. ${ }^{357}$ Deshalb und wegen stark steigender Druckkosten lagen die Produktionskosten für einen Band bald wesentlich höher als ursprünglich von der Historical Division veranschlagt. ${ }^{358}$ Als der Sonderfonds Anfang 1952 langsam zur Neige ging, waren deshalb erst elf Bände der auf rund 90 Bände ausgelegten Weltkriegs-Serie erschienen. Um die Reihe fertig stellen zu können, mussten in den nächsten Jahren Sparmaßnahmen getroffen und zusätzliche Gelder in Höhe von knapp 1,3 Millionen Dollar aufgetan werden. ${ }^{359}$

Unter dem Druck des zur Neige gehenden Sonderbudgets und vor dem Hintergrund des Eisenhower'schen Sparprogramms verschlechterte sich die personelle Situation der Historical Division in Washington Anfang der 1950er Jahre zusehends: 1951 ging die Zahl der Stellen zunächst auf 210 zurück und sank dann bis 1953 auf 159. Vor allem die Anzahl der promovierten Mitarbeiter hatte sich von 29 im Jahr 1951 auf nur noch 14 im Jahr 1953 mehr als halbiert. Damit hatte das historische Programm der U.S. Armee nach Meinung von Chief Historian Kent Roberts Greenfield eine „kritische Phase“ erreicht. ${ }^{360}$ In einer ausführlichen Analyse der Lage stellte Greenfield im Frühjahr 1954 fest, dass sich das bis dato in der Historical Division herrschende personelle Gleichgewicht durch das dramatische Absinken der Zahl der zivilen Historiker tiefgreifend verändert habe. Falls nicht auch in Zukunft erstklassige Wissenschaftler für das Programm gewonnen werden könnten, sei es unmöglich, die Qualität der Publikationen noch länger zu garantieren und damit auch das Prestige der Historical Division aufrechtzuerhalten. ${ }^{361}$ Um das Programm vor dem Verfall zu bewahren, wandte sich Greenfield Anfang April 1954 an den Vice Chief of Staff der U.S. Armee, General Charles L. Bolte, und warnte eindringlich vor weiteren Kürzungen:

357 Kent Roberts Greenfield, Schreiben an S.L.A. Marshall, 26. 9. 1947, in: UTEP, MS 186, Box 81, Folder 1390.

358 Vgl. Conn, Historical Work in the United States Army, 1982-1954, S. 153-155.

359 Office of the Chief of Military History, Accomplishments First Half FY 1952. Presentation for General Taylor, 7. 2. 1952, in: NARA, RG 319, Box 2, Folder 2. Der erste Band der Reihe, „Organization of Ground Combat Troops“ wurde im Oktober 1947 veröffentlicht.

360 Kent Roberts Greenfield, Some Reflections on the Situation and Outlook of the Office of the Chief of Military History, 16.3. 1954, S. 1, in: NARA, RG 319, Box 16, Folder 11.

361 Ebd., S. 2. 
„The question now is whether the Army wants to continue its historical work at the same high level. I believe that it can do this only by measures that will keep alive and flourishing the activity and spirit that the World War II program generated. The danger, as I see it, is that in the present squeeze this may get damaged beyond repair." ${ }^{\text {"362 }}$

Die Rettung kam wenig später ausgerechnet von dem Mann, der die U.S. Armee so sehr schröpfte: U.S. Präsident Dwight D. Eisenhower. Anfang Mai hatten der damalige Chief of Military History, Albert C. Smith, und Kent Roberts Greenfield Gelegenheit, dem Regierungschef in einer persönlichen Audienz den neuesten Band der World War II-Reihe ${ }^{363}$ zu präsentieren. Glaubt man Greenfields Bericht, dann muss das Treffen in entspannter und informeller Atmosphäre stattgefunden haben. Wie schon in den Jahren zuvor zeigte sich Eisenhower scheinbar auch bei dieser Gelegenheit sehr interessiert am Programm der Historical Division und sagte trotz seines ansonsten rigorosen Sparkurses seine Unterstützung bei der Requirierung weiterer finanzieller Mittel zu. ${ }^{364}$ Tatsächlich scheint Eisenhower sein Versprechen wahr gemacht und für eine Aufstockung des Sonderbudgets gesorgt zu haben. Zwar sank die Zahl der zivilen wie auch der militärischen Planstellen in der kriegsgeschichtlichen Abteilung auch in den nächsten Jahren weiter ab; allerdings konnte die Historical Division in der zweiten Hälfte der 1950er Jahre die Personalkosten zahlreicher ziviler Historiker aus diesem Sonderfonds decken und somit noch dramatischere Personalkürzungen auffangen. ${ }^{365}$

Auch in Europa war die Historical Division mehrfach mit Stellenstreichungen konfrontiert und Harold E. Potter beklagte sich wiederholt, dass Truppenreduzierungen und Versetzungen zu einem Mangel an qualifizierten Offizieren in seiner Abteilung führten. ${ }^{366}$ Nachdem die Abteilung im Januar 1946 mit einem Personalbestand von insgesamt 86 Mitarbeitern an die Arbeit gegangen war, hatte sich deren Anzahl im Mai 1946 bereits auf 52 und im Januar 1947 auf 47 reduziert. Die Einrichtung des Lagers in Garmisch Ende 1946 ließ die Personalstärke der Historical Division im ersten Halbjahr 1947 noch einmal auf insgesamt 166 Personen nach oben schnellen, bevor dann ein kontinuierlicher Stellenrückgang einsetzte, bis die Abteilung schließlich im Juli 1957 über nur noch 30 Mitarbeiter

362 Kent Robert Greenfield., Schreiben an Vice Chief of Staff, U.S. Army, General C. L. Bolte, 1. 4. 1954, in: NARA, RG 319, Box 2, Folder 1.

363 Forrest C. Pogue, The Supreme Command.

${ }^{364}$ Kent Roberts Greenfield, Account of the Interview with the President on May 7, 9. 5. 1954, in: NARA, RG 319, Box 16, Folder 11.

365 OCMH - Personnel. Strength as of 1 February 1956, in: NARA, RG 319, Box 57, Folder 10. Ende 1958 wurden die unter dem Sonderfonds laufenden Stellen in Civil ServiceStellen umgewandelt. S. W. Foote, Summary of Activities for Month Ending 31 December, 22.1.1959, in: NARA, RG 319, Box 13, Folder 3. 1956 wurden beispielsweise 19 der insgesamt 81 zivilen Stellen über den Sonderfonds finanziert.

366 Harold E. Potter, Schreiben an Allen F. Clark, 11. 6. 1946, in: NARA, RG 549, Box 3142, Folder 7; Ders., Schreiben an Allen F. Clark, 6.3. 1947, in: NARA, RG 549, Box 3142, Folder 7; Ders., Schreiben an Allen F. Clark, 1.7. 1947, in: NARA, RG 549, Box 3142, Folder 7; vgl. Ders., Schreiben an Allen F. Clark, 10.6. 1948, in: NARA, RG 549, Box 3142, Folder 7. 
verfügte. ${ }^{367}$ Vor allem das militärische Personal wurde stark abgebaut: Von den 47 Offiziersstellen, die der Historical Division Anfang 1947 zur Verfügung standen, blieben nach der Konsolidierung des deutsch-amerikanischen Geschichtsprojektes im Sommer 1947 noch 17 Stellen übrig. Anfang 1951 waren nur noch acht Offiziere in der Historical Division tätig. Bis Mitte 1957 sank die Zahl der Offiziersstellen sogar auf vier. Auch die Zahl der einfachen Soldaten reduzierte sich zwischen 1946 und 1957 von 45 im Januar 1946 auf vier im Juli 1957. Die Zahl der amerikanischen und deutschen Zivilisten ${ }^{368}$, die als Übersetzer, Kartographen, Sekretärinnen, Fahrer und ähnliches für die Historical Division arbeiteten, sank im selben Zeitraum von 92 auf 22.

\subsection{Werbung für die deutschen Studien als Werbung für die Historical Division}

Die massiven Einsparungen bei den konventionellen Landstreitkräften machten sich bei der Historical Division nicht nur finanziell und personell bemerkbar. Die starke Fokussierung der U.S. Regierung auf modernste Nuklearwaffen als bevorzugtes Mittel der Abschreckung im Kalten Krieg zwang die Militärhistoriker auBerdem dazu, die andauernde Nützlichkeit und Notwendigkeit ihrer historischen Forschung für die Streitkräfte zu begründen und so das Fortbestehen des historischen Programms zu rechtfertigen. Das Studium der Vergangenheit hatte in den amerikanischen Streitkräften von jeher eine untergeordnete Rolle gespielt ${ }^{369}$ und nun befürchtete die Historical Division nicht zu Unrecht, dass die Führungsebene der U.S. Armee Militärgeschichte angesichts der raschen technischen Entwicklung seit dem letzten Krieg als altmodisch und wenig nützlich für die künftige Planung erachten könnte. In diesem Sinne stellte einer der Offiziere in der Historical Division in Washington pessimistisch fest:

„Perhaps the dawning of the atomic age seems to relegate everything which has gone before to a limbo of darkness. Or it may seem that the pace of history has become so fast that there is no time for examination of lessons which were learned yesterday. " ${ }^{370}$

Da den Lektionen der Geschichte innerhalb der U.S. Armee tatsächlich wenig Wert zugeschrieben wurde, ${ }^{371}$ musste in der Historical Division die Sorge entstehen, dass die Abteilung angesichts der Sparzwänge bald als entbehrlich betrachtet

367 Die Control Group-Mitglieder und „Heimarbeiter“ sind in diesen Zahlenangaben nicht enthalten, da sie aus anderen Mitteln bezahlt wurden als das militärische und zivile Personal der Historical Division.

368 Diese Zahlen beziehen sich ausdrücklich nicht auf die kriegsgeschichtlich tätigen ehemaligen Wehrmachtsoffiziere.

369 Vgl. Sinnreich, Awkward Partners, in: Murray/Sinnreich (Hg.), The Past as Prologue. The Importance of History to the Military Profession, S. 56.

370 Colonel Carl I. Hutton, Memorandum for General Ward, betr.: What should be the place and the role of the Office of the Chief of Military History. Tab C: Military History, 30.3. 1951, in: NARA, RG 319, Box 16, Folder 11.

371 Ebd.; vgl. auch Coffman, The Course of Military History in the United States Since World War II, in: The Journal of Military History 61 (1997), S. 765; Sinnreich, Awkward Partners, S. 59. 
werden könnte. Die Mitarbeiter bemühten sich deshalb, die grundlegende Notwendigkeit kriegsgeschichtlicher Forschung für die Weiterentwicklung militärischer Doktrin und die praktische Umsetzung von Erfahrungen aus der Vergangenheit in Handlungen der Gegenwart stärker zu betonen. ${ }^{372}$ Dabei verwies man darauf, dass die Armeen anderer Staaten kriegsgeschichtliche Auswertungen schon seit langem systematisch für die Entwicklung von Leitlinien, Trainingsmaterialien und Operationsplänen nutzbar machten. So habe zum Beispiel die kriegsgeschichtliche Abteilung des berühmten deutschen Generalstabes eine maßgebliche Rolle bei der Entstehung der deutschen Militärmacht der 1930er und frühen 1940er Jahre gespielt. Und auch die Rote Armee nutze ihre Kriegsgeschichte gezielt für die Weiterentwicklung ihrer Operationsdoktrin. ${ }^{373}$ In der U.S. Armee, so die Klage der Historical Division, habe die Kriegsgeschichte dagegen einen zu geringen Stellenwert:

"There has never existed in the Department of the Army an organized plan which would give assurance from an overall standpoint for the integration of research on past experiences with consideration of determining current policy, doctrine, planning or operations. The historical services of the U.S. Army have been looked upon as an archival agency to collect, index, and preserve records with little or no consideration to the utilization of such services. ${ }^{374}$

Die Historical Division bemühte sich nach Kräften, diesen Zustand zu ändern. Schließlich erschien es angesichts der neuen Rolle der Vereinigten Staaten als Weltmacht noch wichtiger, militärische Erfahrungen der Vergangenheit für die Erstellung künftiger Operationspläne, die Anpassung von Taktik und Strategie sowie das Training und die Ausbildung von Soldaten und Zivilisten heranzuziehen. ${ }^{375}$ In einem internen Memorandum versuchte deshalb Colonel Carl I. Hutton, die kriegsgeschichtliche Abteilung im Gefüge der U.S. Armee zu verorten:

„First there must be experience. Next, there must be military history. Then, by study and deduction the lessons which are contained in the history must be stated. In the next step,

372 NARA, RG 319, Box 16, Folder 11; siehe auch Hutton, What should be the place and the role of the Office of the Chief of Military History. Tab C: Military History, 30.3. 1951, S. 1, in: NARA, RG 319, Box 16, Folder 11. Dort heißt es: „Actually, the soldier uses some form of military history every minute of his working day. Each problem he faces, each action he takes, has a historical basis, whether he is the Chief of Staff of the Army or a corporal in charge of an outpost in Korea, he relies consciously or sub-consciously upon what he has learned from the past. He cannot escape military history because it surrounds him as the air he breathes. When he digs a foxhole for a perimeter defense, he is performing an action in conference with a doctrine which is based upon lessons learned from military history." Hervorhebung im Original.

373 The Long-Range Objective and Role of the Office of Military History during Peace [o. D., vermutlich Ende 1950/Anfang 1951], in: NARA, RG 319, Box 2, Folder 1.

374 Ebd.

375 Ebd. Originalzitat: „[I]n view of our currently accepted place in world power, politics, and economy, and the need for combining practical experiences with theoretical study, it becomes increasingly important that steps be taken at this time to insure that maximum utilization be made by the Army of our past military experiences in the preparation of current and future operational plans, the modification of tactical and strategic doctrine, and in the training and education of the soldier and civilian." 
doctrine is developed to take advantage of the lessons. Finally, the actions which are taken daily throughout the Army are governed by the doctrine." 376

Diese Verkettung von Erfahrung, kriegsgeschichtlicher Aufbereitung, Schlussfolgerung, Doktrinbildung und schließlich Handlung bilde den geistigen Beitrag des Militärs zur Verteidigung des Landes. Wenn die Kette jedoch irgendeine Schwachstelle aufweise, könne das Militär seiner Verantwortung gegenüber der Nation nicht gerecht werden. ${ }^{377} \mathrm{Da}$ die U.S. Armee es jedoch so lange versäumt habe, ihre Kriege planmäßig und umfassend kriegsgeschichtlich auszuwerten, habe sich das amerikanische Militär bis 1945 vor allem auf die nur bedingt verlässlichen und notwendigerweise beschränkten individuellen Erfahrungen ihrer Offiziere stützen müssen. Dieser Mangel an einer Synthese der Erfahrungen durch eine amtliche Kriegsgeschichtsschreibung habe es in der Vergangenheit enorm erschwert, Lehren aus früheren Kriegen zu ziehen. ${ }^{378}$ Das Versäumnis des General Staff, nach 1918 den Einsatz von Panzern im Ersten Weltkrieg systematisch zu analysieren, habe so zum Beispiel dazu geführt, dass die amerikanischen Streitkräfte bis 1939 keine fundierte Doktrin für ihre Panzerwaffe entwickelt hätten. ${ }^{379}$ Die kriegsgeschichtliche Schwachstelle im geistigen Kreislauf der U.S. Armee, so die Argumentation der Historical Division, ziehe also zwangsläufig Schwächen in anderen Bereichen, wie beispielsweise der Doktrinbildung, nach sich und entscheide damit letztlich mit über den künftigen Erfolg oder Misserfolg der Truppen auf dem Schlachtfeld. ${ }^{380}$

Über diese theoretischen Überlegungen hinaus bemühten sich die Mitarbeiter der Historical Division auch darum, ihre Abteilung durch gezielte Werbemaßnahmen bekannter zu machen. In den späten 1940er und in den 1950er Jahren hielten Offiziere der Abteilung häufig Vorträge an Militärschulen und verfassten Aufsätze für die einschlägigen militärischen Fachzeitschriften. In mehreren Vorlesungen vor angehenden Stabsoffizieren warb zum Beispiel der Chief of Military History General Orlando Ward darum, ein größeres Bewusstsein für die Nützlichkeit von Kriegsgeschichte zu entwickeln und pries in diesem Zusammenhang natürlich vor allem die Dienste der Historical Division an. Seine Mitarbeiter, so Ward, besäßen eine Fülle von Wissen und könnten den Kriegsakademien und den Planungs- und Operationsstäben des Department of the Army jederzeit sachdienliche Informationen zu allen möglichen Themen zur Verfügung stellen. ${ }^{381}$

Auch der langjährige Leiter der Special Studies Section, Paul M. Robinett, rührte die Werbetrommel für die kriegsgeschichtliche Abteilung. In den 1950er Jahren veröffentlichte er mehrere Artikel in Fachzeitschriften der U.S. Armee wie Military Affairs und Military Review. Darin betonte er stets, dass kein Berufsstand

376 Hutton, What should be the place and the role of the Office of the Chief of Military History. Tab C: Military History, 30.3. 1951, S. 1, in: NARA, RG 319, Box 16, Folder 11.

377 Ebd.

378 Ebd., S. 3.

379 Ebd., S. 2.

380 Ebd., S. 3.

381 Orlando Ward, Military History - The Staff Officer and the Soldier. Office of the Chief of Military History, 29. 2. 1952, S. 4, in: NARA, RG 319, Box 25, Folder 2. 
mehr vom Studium der Geschichte profitieren könne als das Militär. ${ }^{382}$ Trotz der raschen technologischen Entwicklung seit dem Zweiten Weltkrieg sei der Wert kriegsgeschichtlicher Forschung unverändert geblieben, denn unabhängig von Verbesserungen in der Waffentechnologie reagierten Soldaten in der Schlacht weiterhin, wie sie es immer getan hätten und vermutlich auch immer tun würden. ${ }^{383}$ Und auch wenn sich aus früheren Kriegen aufgrund der radikalen technischen Veränderungen nicht mehr unbedingt Lehren für kleinere taktische Operationen ziehen ließen, bleibe die Geschichte der größeren taktischen und strategischen Entscheidungen vergangener Kriege so nützlich wie zuvor. ${ }^{384}$

Im Ringen der Historical Division um ihr organisatorisches Überleben spielte die kriegsgeschichtliche Kooperation mit der ehemaligen Wehrmachtselite eine wichtige Rolle. Dass die Mitarbeiter der Historical Division, die ja in erster Linie mit der Erstellung der offiziellen Geschichte der U.S. Armee beauftragt und deshalb vor allem an deutschen Studien zur Westfront interessiert waren, die Anregung des militärischen Nachrichtendienstes zur Ausdehnung des Projektes auf die Ostfront bereitwillig aufgriffen, muss auch in diesem Kontext gesehen werden. Sicherlich waren viele der beteiligten Offiziere vom faktischen Nutzen der deutschen Studien für die Verteidigung der Nation überzeugt. Davon abgesehen hatte die Bereitschaft der Historical Division, zusätzlich zu ihren eigentlichen Aufgaben der Kriegsgeschichtsschreibung und Dokumentation auch als Vermittlungsagentur zwischen den Dienststellen und Stäben der U.S. Armee einerseits und der ehemaligen Wehrmachtselite andererseits zu fungieren, aber auch damit zu tun, dass die historische Abteilung in Zeiten der drastischen Mittelkürzungen nach jedem Strohhalm griff, um ihre Existenz zu rechtfertigen.

Wie gerade beschrieben führten die Mitarbeiter der Historical Division im Kampf um finanzielle Mittel und Personal als Argument für die Aufrechterhaltung ihres Programms immer wieder den praktischen Nutzen ihrer Arbeit für die U.S. Armee ins Feld. Dabei ließ sich die Nützlichkeit kriegsgeschichtlicher Forschung in der von Unsicherheit gekennzeichneten Anfangsphase des Kalten Krieges besonders gut am Beispiel der deutsch-amerikanischen kriegsgeschichtlichen Kooperation vermarkten. Schließlich verfügte die Abteilung durch die Zusammenarbeit mit der ehemaligen Wehrmachtselite über einen einzigartigen Zugang $\mathrm{zu}$ wertvollen Informationen über den wahrscheinlichsten nächsten Gegner der Vereinigten Staaten. Die deutschen Studien, so glaubte man in der Historical Division, waren besonders geeignet, der Armeeführung „den Wert historischer Information und einer Abteilung zu demonstrieren, die diese Information zusammentragen, aufbereiten und auswerten" könne. ${ }^{385}$ Ende der 1940er und Anfang der 1950er Jahre stilisierten die Mitarbeiter der Historical Division das

\footnotetext{
382 Paul M. Robinett, The Study of Military History, in: Military Affairs 18 (1954), S. 27.

383 Ebd., S. 28.

384 Ders., Observations on Military History, in: Military Review 36 (1956), S. 34.

385 Kent Roberts Greenfield, Memorandum for the Chief, Historical Division. Report of Activities for the Period 4.-15. 10. 1948, in: NARA, RG 319, Box 9, Folder 7. Originalzitat: „[The activities] of the Foreign Studies Section [...] are contributing directly to one of the primary missions of the [Applied Studies] Group and the Division, namely to pump the precious information which the Division possesses directly into the blood-
} 
Foreign Studies-Programm deshalb zum Flaggschiff der Abteilung ${ }^{386}$ und argumentierten immer wieder, dass die Ostfront-Erfahrung der ehemaligen Wehrmacht eine wertvolle und unentbehrliche Informationsquelle für die Vorbereitung der U.S. Armee auf eine mögliche Auseinandersetzung mit der Sowjetunion sei. 387

In der Hoffnung, dass das Interesse an den deutschen Studien sich letztlich positiv auf die Historical Division als Ganzes auswirken würde, ${ }^{388}$ bemühten sich die Offiziere der beiden Foreign Studies-Abteilungen in Deutschland und den USA seit den späten 1940er Jahren intensiv darum, den Bekanntheitsgrad und die Verbreitung dieser Materialien in der U.S. Armee und an den Service Schools zu erhöhen. ${ }^{389}$ Im Juli 1948 präsentierte die Foreign Studies Section zum Beispiel dem damaligen Army Chief of Staff, General Omar N. Bradley, und seinem Stab eine Auswahl deutscher Studien. ${ }^{390}$ Im November 1949 pries Frank C. Mahin bei einem Vortrag am Command and General Staff College in Fort Leavenworth die deutschen Studien als Basis für die Weiterentwicklung der amerikanischen Militärdoktrin an. Die in den Studien kondensierte deutsche Erfahrung könne zum Beispiel als „ein Referenzrahmen“ oder „Ausgangspunkt“ für die Formulierung operativer Lehrsätze für große Rückzugsoperationen, die Verteidigung befestigter Strände, oder den Schutz von Kommunikationslinien in Partisanengebieten dienen. ${ }^{391}$ Damit bewarb Mahin die deutschen Studien als eine „Erfahrungsbank“, die der in derartigen Operationen unerfahrenen U.S. Armee nun über die Historical Division zur Verfügung stehe. ${ }^{392}$

Ab Frühjahr 1948 konnten Armee-Dienststellen und Militärschulen auf Grundlage der German Manuscript Accession List Kopien deutscher Studien bei der Historical Division bestellen. Um die Materialen noch weiter zu verbreiten, gab die Historical Division ab April 1948 außerdem ausgewählte deutsche Studien in der German Report Series heraus. ${ }^{393} 1950$ entschied man sich schließlich, besonders gefragte Manuskripte redaktionell aufzubereiten und sie als Broschüren des Department of the Army - sogenannte DA-Pamphlets - herauszugeben. Sie

stream of the Army, demonstrating to the Army the usefulness of historical information, and of a Division which can compile, prepare, and evaluate it."

386 So bemerkte zum Beispiel Chief Historian Kent Roberts Greenfield im August 1948 mit Blick auf die Bemühungen von Frank C. Mahin, die Bekanntheit der Foreign Studies zu steigern: „The pay-off in advertising within in the Department of the Army the importance of the work being done in the Division would be hard to overestimate." Kent Roberts Greenfield, Memorandum for the Chief, Historical Division. Report of activities for the Biweekly Period 20. 8.-3.9. 1948, in: NARA, RG 319, Box 9, Folder 7.

387 Orlando Ward, Military History - The Staff Officer and the Soldier. Office of the Chief of Military History, 29. 2. 1952, S. 5, in: NARA, RG 319, Box 25, Folder 2.

388 Vgl. Greenfield, Memorandum for the Chief, Historical Division. Report of activities for the Biweekly Period 20. 8.-3. 9. 1948, in: NARA, RG 319, Box 9, Folder 7.

389 Vgl. hierzu oben, Teil II, Kapitel 3.1.

390 Kent Roberts Greenfield, Memorandum for the Chief, Historical Division. Report of Activities for Period 12.7.-23. 7. 1948, in: NARA, RG 319, Box 9, Folder 7.

${ }^{391}$ Frank C. Mahin, Speech delivered to Faculty, Command and General Staff College, Fort Leavenworth, Kansas, 23. 11. 1949, in: NARA, RG 319, Box 62, Folder 5.

392 Ebd.

393 Vgl. oben, Teil II, Kapitel 3.1. 
wurden durch das Büro des Adjutant General vertrieben und in der gesamten Armee verbreitet. ${ }^{394}$ Bis 1956 veröffentlichte die Historical Division auf diesem Wege 18 Broschüren, von denen die meisten Themen des Russlandfeldzuges behandelten (vgl. Liste der DA-Pamphlets im Anhang, Tab. 8). ${ }^{395}$

Der unerwartete Krieg in Korea schien die Position der Historical Division zu stärken. Schließlich bewiesen die Kämpfe in Asien eindrücklich, dass es auch im Atomzeitalter durchaus lokal begrenzte, konventionell geführte Kriege geben konnte. Vor dem Hintergrund der gestiegenen Ängste vor einem sowjetischen Angriff auf Westeuropa glaubte die kriegsgeschichtliche Abteilung deshalb Anfang der 1950er Jahre, mehr Geld für die deutsch-amerikanische Kooperation fordern zu können. Der stellvertretende Leiter der Historical Division in Europa, Thomas H. Young, schlug deshalb seinem Vorgesetzten, Wilbur S. Nye, im August 1951 vor, die Bedeutung der kriegsgeschichtlichen Kooperation mit der ehemaligen Wehrmachtselite für die Verteidigung Westeuropas noch stärker als bisher herauszustellen. Da ein solcher Krieg zumindest teilweise auf den Schlachtfeldern des deutsch-russischen Krieges von 1941 bis 1945 stattfinden werde, könne man gar nicht genug über diesen Kriegsschauplatz und die Rote Armee wissen. ${ }^{396}$ Und wer wäre besser geeignet, diese Informationen zusammenzutragen, als die Historical Division mit ihren ausgezeichneten Kontakten zur ehemaligen Wehrmachtselite, ohne deren Kooperation die Operationsgeschichte des deutsch-russischen Krieges niemals umfassend geschrieben werden könne? Für Young jedenfalls stand fest:

„[T]he Historical Division occupies a uniquely favorable position which no other agency will probably ever again be able to duplicate. The sum involved is insignificantly small when compared to the solid basis of facts acquired and the actual need for this information. “397

Wilbur S. Nye griff Youngs Vorschlag ohne zu zögern auf und sandte nur einen Tag später eine dienstliche Mitteilung an den Chief of Staff von EUCOM, Major General Daniel C. Noce, in der er eine vermehrte Nutzbarmachung der historischen Abteilung im Sinne der Feindaufklärung anregte und zu diesem Zweck eine Aufstockung der Personaldecke vorschlug. Unter Verweis auf die mangelnden Kenntnisse der Truppen über das chinesische Militär im Koreakrieg warb Nye für die verstärkte Verwendung der bei der Historical Division verfügbaren deutschen militärischen Studien zur Informationsgewinnung über die Sowjetunion: Das europäische Oberkommando der U.S. Armee könne sich glücklich schätzen, dass ihm durch die Kooperation der Historical Division mit zahlreichen kompetenten und erfahrenen ehemaligen Wehrmachtsoffizieren eine Fülle von Informationen über den wohl wahrscheinlichsten nächsten Kampfraum und künftigen Feind zur Verfügung stehe. Allerdings seien diese Informationen bislang noch nicht genü-

394 Melvin C. Helfers, Memorandum for the Record, betr.: FSB Publications Program, 25. 8. 1951, in: NARA, RG 319, Box 63, Folder 5.

395 Foreign Studies Branch. Department of the Army Pamphlet Program.

396 Thomas H. Young, Memorandum für den Chief, Historical Division, EUCOM, 16. 8. 1951, in: NARA, RG 319, Box 30, Folder 5.

397 Ebd. 
gend für Planung und Training der amerikanischen Streitkräfte in Europa genutzt worden. Er schlug deshalb eine Aufstockung der Schreibkräfte in der Historical Division vor, um die Reproduktion der deutschen Studien zu beschleunigen, und argumentierte dabei, dass der Wert des Materials die relativ geringen zusätzlichen Kosten rechtfertige. ${ }^{398}$

Als die Abteilung im Juli des darauffolgenden Jahres der Obergrenze ihres Budgets „gefährlich nahe“ kam und Gefahr lief, ihr Programm zurückfahren zu müssen, ${ }^{399}$ führte Nye erneut den andauernden Krieg in Korea ins Feld, um für das gerade beginnende Haushaltsjahr 1953 eine Aufstockung der Mittel für das Foreign Studies-Programm durchzusetzen. „Die internationale Situation“, schrieb Nye an den Deputy Chief of Staff, EUCOM, „und insbesondere die gegenwärtigen Kampfhandlungen in Asien, erfordern die möglichst frühzeitige Beschaffung aller verfügbaren Daten über das kommunistische Militärpotential." 400 Wie bereits im Jahr zuvor betonte Nye die Schlüsselrolle der Historical Division bei der Beschaffung solcher Informationen:

„The Historical Division is one of the most lucrative channels for securing such information, and possesses carefully fostered sources of unparalleled value. They should be exploited now while they are still available. [...] The material should be purchased while the cost is low and funds are available. This cost is exceedingly low in comparison with the value received [...].“401

Mit diesem Argument beantragte Nye eine Aufstockung des Budgets um mehrere zehntausend DM. ${ }^{402}$ Die Kostenstelle von EUCOM sagte schließlich, wenn auch unter Vorbehalt der tatsächlichen Verfügbarkeit der Mittel, eine Bereitstellung der geforderten Summe aus dem Budget der Intelligence Division zu. ${ }^{403}$ Nur wenige

398 W. S. Nye, Internal Route Slip an den Chief of Staff, EUCOM betr.: Increased Utilization of Historical Division, 17. 8. 1951, in: NARA, RG 549, Box 3160, Folder 2. Originalzitat: „The European Command is fortunate in having a wealth of information concerning its most probable battlegrounds and enemy. This material has been supplied by numerous able and experienced former German leaders working for this division. [...] So far, this material has been little exploited except for historical purposes. The reason is that, as it was obtained for the Office of the Chief of Military History, as a part of that agency's program, only a file copy of each manuscript has been retained here. As a result much material of great present interest and value to planning and training agencies in EUCOM has been virtually nonavailable."

399 Wilbur S. Nye, Schreiben an Orlando Ward, 1.7.1952, in: NARA, RG 319, Box 30, Folder 3.

400 Ders., IRS an den Deputy Chief of Staff, EUCOM, through Comptroller, betr.: Additional Deutsch Marks for Foreign Studies, 2.7.1952, in: NARA, RG 549, Box 1141, Folder 3. Originalzitat: „The present international situation, with hostilities already in progress in Asia, demands that all available data concerning Communist military potential be obtained at the earliest possible moment."

401 Ebd.

402 Ebd.

403 Chief Lieutenant Colonel D. W. Glenn, Control Branch, IRS: Intelligence Division to Comptroller, betr.: Additional Deutsche Marks for Foreign Studies, 16.7.1952, in: NARA, RG 549, Box 1141, Folder 3; Deputy Comptroller Colonel C. R. Hutchison, IRS: Comptroller of Historical Division, betr.: Additional Deutsche Marks for Foreign Studies, 17.7. 1952, in: NARA, RG 549, Box 1141, Folder 3. 
Monate später, im Dezember 1952, forderte Nye erneut zusätzliche Mittel für die Foreign Studies Branch, wobei er die Latte dieses Mal mit knapp 480000 DM wesentlich höher legte. Das Geld sollte zur Anfertigung weiterer deutscher Studien, unter anderem zur sowjetischen Taktik, dienen. Auch dieses Mal begründete er seinen Antrag mit dem zu erwartenden wesentlichen Beitrag der deutschen Studien zur „nationalen Verteidigung“ und deren Bedeutung als „einer der wichtigsten [...] Informationsquellen hinsichtlich des wahrscheinlichsten Feindes der Vereinigten Staaten“" 404

\subsection{Verwendung der deutschen Studien als Trainingsmaterial}

Durch die Kombination aus massiv beworbenem Angebot und der steigenden Nachfrage nach Informationen über die Sowjetunion erlebten die deutschen Materialien der Historical Division ab 1948 eine deutliche Konjunktur. So gaben 1948 unter anderem die Personnel and Administration Division des Heeres-Generalstabs, das Office of the Chief of Engineers, das Antiaircraft and Guided Missiles Center sowie der Chief of Transportation und der Chief, Chemical Corps Studien in Auftrag, die sich zum Beispiel mit den Anforderungen von Winteroperationen in Osteuropa an Training und Ausrüstung einer Armee befassen sollten. ${ }^{405}$ Auch an den Militärschulen erlebten die deutschen Studien um 1950 einen Boom: ${ }^{406} \mathrm{Be}-$ reits im Frühjahr 1948 hatte die Veröffentlichung der ersten German Manuscript Accession List eine rege Nachfrage nach deutschen Studien ausgelöst; ${ }^{407}$ und nachdem Ende Juni 1951 eine zweite, erweiterte und aktualisierte Liste deutscher Manuskripte (German Manuscript Accession List \#2) herauskam, trafen erneut innerhalb kürzester Zeit hunderte Bestellungen bei der Foreign Studies Section ein. 408 Ende der 1940er und Anfang der 1950er Jahre lieferte die Historical Division tausende Kopien deutscher Studien an die Service Schools. ${ }^{409}$

Die deutschen Materialien kamen an den Service Schools offensichtlich ausgesprochen gut an. Im Dezember 1951 zeigte sich zum Beispiel der Kommandant

404 Wilbur S. Nye, Schreiben an den Comptroller, EUCOM, betr.: Allocation of Funds, 3. 12. 1952, in: NARA, RG 549, Box 1141, Folder 3. Originalzitat: „It is believed that the projects and information paid for from funds as requested will contribute materially to National Defense. The foreign studies now being produced and projected are one of the most important, single sources of information concerning the most probable enemy of the United States."

405 Schreiben des Adjutant General an den Commander in Chief, European Command, 3. 5. 1948, in: NARA, RG 549, Box 3141, Folder 12; Harold E. Potter, Schreiben an den Chief of Staff, EUCOM betr. German Operational History, 14. 6. 1948, in: NARA, RG 549, Box 2465.

406 Vgl. Orlando Ward, German Army Experience Manuscripts, in: NARA, RG 319, Box 7, Folder 6.

407 Vgl. oben, Teil II, Kapitel 3.1.

408 Melvin C. Helfers, Report of Activities, Foreign Studies Section (1.-31.7.1951), 2. 8. 1951, in: NARA, RG 319, Box 20. Monthly Progress Reports 1950-51. Zwischen August 1948 und Dezember 1953 erreichten die Foreign Studies Section so insgesamt knapp 5800 Bestellungen für deutsche Studien; im gleichen Zeitraum brachte die Abteilung etwas mehr als 15000 Kopien deutscher Studien in Umlauf.

${ }^{409}$ Vgl. auch oben, Teil III, Kapitel 3.1. 
des Army War College, Lieutenant General Edward M. Almond, äußerst beeindruckt von den kriegsgeschichtlichen Studien und teilte der Historical Division im Namen seines Lehrpersonals mit:

"[I]t is the consensus [among the faculty and students of the AWC] that these publications have been invaluable references throughout our curriculum. Many of the pamphlets have been listed in published references as accompanying problem directives. Others have arrived only recently, but nevertheless have been made available to student committees and used to great advantage. In future courses this year and in future years these pamphlets will undoubtedly be studied extensively.

I feel that your Historical Division has been farsighted in taking advantage of former German officers in furthering knowledge of Russian terrain and Russian warfare. The compilation of this valuable information into small and readable pamphlets provides a useful medium of instruction. “410

Tatsächlich führten die Service Schools über die 1950er Jahre hinweg immer wieder ausgewählte deutsche Studien als Referenzmaterial in ihren Curricula auf. In einem Kurs des AWC mit dem Titel Special Problems Related to Future War empfahl der Dozent seinen Studenten im Frühjahr 1951 zum Beispiel unter anderem Hasso Neitzels Studie Rear Area Security in Russia ${ }^{411}$ sowie Haunted Forests. Russian Partisans Behind the Front ${ }^{412}$ von Gustav Höhne und The War Behind the Front: Guerilla Warfare ${ }^{413}$ von Albert Kesselring zur Lektüre. ${ }^{414}$ Auch die Psychological Warfare School in Fort Bragg, North Carolina, listete im Oktober 1952 in ihrem Lehrplan für einen achtwöchigen Special Forces Course die DA-Pamphlets Russian Combat Methods in WW II ${ }^{415}$ und Rear Area Security in Russia auf. ${ }^{416}$ Im akademischen Jahr 1955/56 bot das Command and General Staff College ein Seminar zu Spezialoperationen an, in dem unter anderem die Operationsführung „in Gebieten mit tiefem Schnee und extremer Kälte, dichtem Wald und ausgedehnten Sümpfen und Seen " thematisiert werden sollte. Als Hintergrundmaterial führte der Seminarplan unter anderem vier deutsche Studien an: The German Campaign

410 Edward M. Almond, Schreiben an Orlando Ward, 20. 12. 1951, in: NARA, RG 549, Box 1143 , Folder 2.

411 Hasso Neitzel, DA-Pamphlet 20-240: Rear Area Security in Russia. The Soviet Second Front Behind the German Lines, Washington 1951.

412 Gustav Höhne, MS \# C-037. „Haunted Forests“: Enemy Partisans behind the Front, 1948, in: NARA, Mikrofiche Publication M 1035: Foreign Military Studies.

413 Albert Kesselring, MS \# C-032. The War Behind the Front: Guerilla Warfare, in: NARA, Mikrofiche Publication M 1035: Foreign Military Studies.

414 Army War College, Fort Leavenworth, Kansas, Military Doctrines and Techniques. General Directive and Problem Directive for Courses 5, 6 and 7, Phase II 1950-51 Curriculum, 4. 1. 1951, Course 7: Partisan Warfare, in: NARA, RG 337, Box 336, Folder 352/26. Auch das Command and General Staff College empfahl 1960/61 in einem thematisch verwandten Kurs Neitzels Studie sowie eine Studie von Alexander Ratcliffe mit dem Titel German Antiguerilla Operations in the Balkans. Franz Halder, Schreiben an Siewert, 28. 10. 1955, in: BArch, N 220/79.

415 Department of the Army (Hg.), DA-Pamphlet 20-230: Russian Combat Methods in World War II, Washington 1950.

416 The Psychological Warfare School, Fort Bragg, NC. Program of Instruction, Special Forces Course, 31. 10. 1952, in: NARA, RG 319, Box 62, Folder 12. 
in the Balkans ${ }^{417}$ von Burkhart Müller-Hillebrand, Combat in Russian Forests and Swamps ${ }^{418}$ von Hans von Greiffenberg, Terrain Factors in the Russian Campaigns von Karl Allmendinger sowie Warfare in the Far North ${ }^{419}$ von Waldemar Erfurth. ${ }^{420}$

Die deutschen Studien waren jedoch nicht nur an den Service Schools in den Vereinigten Staaten gefragt. Auch das Oberkommando der amerikanischen Streitkräfte in Europa griff für das Training seiner Truppen vermehrt auf Erfahrungen der Wehrmacht zurück. So forderte zum Beispiel der stellvertretende Kommandeur von USAREUR, Lieutenant General Frank W. Milburn, Anfang 1950 mehrere deutsche Studien zur Ostfront als Trainingsmaterial an. ${ }^{421}$ Wenig später befahl Milburns Vorgesetzter, der Oberbefehlshaber der U.S. Streitkräfte in Europa, Lieutenant General Clarence R. Huebner, der Operations, Plans, Organization \& Training Division (OPOT), die Studie Experience Gained in Combat with Soviet Infantry ${ }^{422}$ des ehemaligen Waffen-SS Generals Max Simon für die Ausbildung und das Training von amerikanischen Truppen in Europa auszuwerten. ${ }^{423}$

Ein Jahr später, Anfang April 1951, gab die Intelligence Division von SHAPE, des gerade erst etablierten Europa-Hauptquartiers der NATO, eine Studie mit brandaktuellem Bezug in Auftrag: Die Control Group sollte ihre Einschätzung der voraussichtlichen sowjetischen Strategie im Falle eines Angriffs auf Westeuropa erörtern. Ein solcher Angriff erschien den amerikanischen Militärs durchaus nicht ganz unwahrscheinlich. Seit 1948 hatte die im konventionellen Bereich zahlenmäßig und materiell ohnehin weit überlegene Sowjetunion ${ }^{424}$ ihre Streitkräfte auf dem Gebiet der DDR, in Österreich sowie an der sowjetischen Grenze zu Polen weiter verstärkt. Darüber hinaus hatten die amerikanischen Geheimdienste 1949/50 großangelegte Manöver der Roten Armee auf Divisionsebene registriert. Auch die Reputation der zuvor als schlecht ausgerüstet und hinsichtlich ihrer Kampfmoral als fragwürdig geltenden Streitkräfte der Satellitenstaaten hatte sich seit 1948 verbessert. Vor dem Hintergrund dieser Entwicklung hatten die Joint Chiefs of Staff die amerikanische Regierung bereits im Februar 1950 gewarnt, dass die Sowjetunion nun in der Lage sei, Westeuropa ohne großen Vorlauf anzugreifen. ${ }^{425}$ Der Ausbruch des Korea-

417 Department of the Army (Hg.), DA-Pamphlet 20-260: The German Campaign in the Balkan 1941, Washington 1953.

418 Department of the Army (Hg.), DA-Pamphlet 20-231: Combat in Russian Forests and Swamps, Washington 1951.

419 Department of the Army (Hg.), DA-Pamphlet 20-292: Warfare in the Far North, Washington 1951.

420 Command and General Staff College 1955-56. Program of Instruction for Regular Course (250-0-1), in: CARL, Book 4. File 6072/6: Special Operations.

${ }^{421}$ Harold E. Potter, Schreiben an E. M. Harris, Historical Division, Special Staff U.S. Army, 9. 3. 1950, in: NARA, RG 319, Box 7, Folder 7.

422 Max Simon, MS \# C-058. Erfahrungen aus dem Kampf mit russischer Infanterie, in: BArch, ZA 1/1257.

423 Potter, Schreiben an E. M. Harris, Historical Division, Special Staff U.S. Army, 9.3. 1950, in: NARA, RG 319, Box 7, Folder 7.

424 Siehe hierzu Karber/Combs, The United States, NATO, and the Soviet Threat to Western Europe, in: Diplomatic History 22 (1998), S. 399-429.

425 Ebd., S. 414-416. 
krieges im Juni 1950 schien den angenommenen Expansionswillen der Sowjetunion zu bestätigen und verstärkte das Bedrohungsgefühl in Westeuropa. ${ }^{426}$

Im Frühjahr 1951 wandte sich SHAPE nun also an die Historical Division und bat darum, dass qualifizierte ehemalige Wehrmachtsgeneräle das Szenario eines solchen sowjetischen Angriffs durchdenken sollten. Dabei waren die NATO-Strategen besonders an den voraussichtlichen Vorstoßrouten, der geschätzten Größe der russischen Streitkräfte, der voraussichtlichen Geschwindigkeit ihres Vorrückens sowie ihren möglichen Schwächen interessiert. ${ }^{427}$ Hocherfreut über diesen prestigeträchtigen Auftrag machten sich Franz Halder, Hans von Greiffenberg, Alfred Toppe, Hellmuth Reinhardt und Burkhart Müller-Hillebrand an die Arbeit. ${ }^{428}$ Da Halder und seinen Kollegen bei ihren Überlegungen keine internen Informationen der NATO zur Verfügung standen, beruhten ihre Ausführungen ausschließlich auf „Annahmen und Schätzungen“, die sich hauptsächlich auf Angaben in der internationalen Presse sowie die eigenen Erfahrungen der Autoren aus dem Zweiten Weltkrieg stützten. ${ }^{429}$ Dabei kamen die fünf ehemaligen Generalstäbler den Annahmen der NATO-Strategen, wie sie im mittelfristigen Verteidigungsplan des Bündnisses vom März 1950 (DC 13) dargelegt waren, recht nahe. ${ }^{430}$ Ebenso wie die NATO gingen die Deutschen davon aus, dass die Sowjetunion einen Angriff auf Westeuropa nur bei Aussicht auf Erfolg riskieren würde. ${ }^{431}$ Für den aus ihrer Sicht unwahrscheinlichen Fall eines Angriffs, so die fünf Autoren, stünde die Sowjetunion unter dem Druck, so schnell wie möglich Westeuropa bis zu den Pyrenäen unter ihre Kontrolle zu bringen, da längere Verzögerungen die Gefahr böten, dass die westlichen Alliierten Minenfelder und andere Hindernisse anlegen sowie zusätzliche Truppen von Übersee heranschaffen und so wichtige Brückenköpfe für eine Gegenoffensive besetzen könnten. Deshalb erwarteten die Autoren der Studie, dass die Rote Armee, unterstützt von den Streitkräften der sowjetischen Satellitenstaaten, mit stark bewaffneten Keilen vorrücken würde, die sich aus Panzer-, Schützen- und von schweren Panzern begleiteten, motorisierten Infanteriedivisionen zusammensetzen würden. Die Sowjets würden folglich in Gebieten angreifen, die den Einsatz konzentrierter Panzerverbände zuließen und in denen keine unnötigen Zeitverluste durch Kämpfe in Wald- und Bergregionen zu erwarten wären. ${ }^{432}$

426 Jervis, The Impact of the Korean War on the Cold War, in: The Journal of Conflict Resolution 24 (1980), S. 579.

427 Deputy Asst. C/S Col. Robert A. Schow, Intelligence, SHAPE, Schreiben an W. S. Nye, Chief, Historical Division, EUCOM, 9. 4. 1951, in: NARA, RG 549, Box 3160, Folder 2.

428 W. S. Nye, Schreiben an Col. Robert Schow, Deputy Asst. C/S, Intelligence, SHAPE, 19. 4. 1951, in: NARA, RG 549, Box 3160, Folder 2.

429 Vgl. das Vorwort in Franz Halder u. a., MS \# P-104. An Assumed Plan of Attack by the USSR on Western Europe, 1951, in: NARA, RG 549, Box 144.

430 DC 13 - North Atlantic Treaty Organization. Medium Term Defense Plan, 28. 3. 1950, http://www.nato.int/docu/stratdoc/eng/a500328d.pdf (letzter Zugriff: 23. 2. 2015).

431 Ebd.; Halder u. a., MS \# P-104. An Assumed Plan of Attack by the USSR on Western Europe, 1951, S. 8, in: NARA, RG 549, Box 144.

432 Halder u. a., MS \# P-104. An Assumed Plan of Attack by the USSR on Western Europe, 1951, S. 9, in: NARA, RG 549, Box 144. 
Wahrscheinlich sei die Bildung zweier Heeresgruppen, wobei die nördliche Heeresgruppe den Hauptangriff führen und dabei durch das Flachland von Hannover und Westfalen, dann weiter durch die belgischen Regionen Brabant und Flandern vorrücken würde, um so schnell wie möglich die deutsche, niederländische und belgische Nordseeküste $\mathrm{zu}$ erreichen und dann die französische Kanalküste sowie die Normandie zu besetzen. Die Heeresgruppe Süd würde sich ihrerseits die Niederungen nördlich der Vogesen sowie im Süden zwischen den Vogesen und dem Schweizer Jura zu Nutze machen und dann entlang der Loire und der Rhône in Richtung der französischen Mittelmeerküste vorrücken. Schließlich würden sich die beiden Heeresgruppen vereinigen und ganz Frankreich bis zu den Pyrenäen besetzen. Zur Absicherung ihrer nördlichen bzw. südlichen Flanke würde die Rote Armee außerdem bei Beginn der Offensive in Dänemark und Norditalien einmarschieren. ${ }^{43}$

Nennenswerter alliierter Widerstand war nach Einschätzung der ehemaligen Wehrmachtsoffiziere erst im Bereich der schwäbischen Alb und um Ulm herum zu erwarten, auch dieser würde jedoch durch die numerische Überlegenheit der Roten Armee rasch gebrochen werden. Auch die Überquerung des Rheins, den beide sowjetischen Heeresgruppen bei einem Vorrücken von etwa 40 Kilometern täglich in etwa acht Tagen erreicht haben würden, stelle für die zahlenmäßig überlegenen Sowjets lediglich eine technische Frage dar. Hinter den Rhein zurückgeworfen könnten alliierte Kräfte das rasche Vorrücken der Sowjets dann nur noch durch örtlichen Widerstand und gelegentliche Straßenblockaden behindern. ${ }^{434}$ Die Deutschen gingen davon aus, dass die sowjetische Regierung angesichts der gegenwärtig begrenzten konventionellen Streitkräfte der westlichen Alliierten ihr strategisches Ziel, Westeuropa bis zu den Pyrenäen zu besetzen, ohne ernsthafte Schwierigkeiten erreichen würde. ${ }^{435}$ Wie auch die Verfasser des NATO-StrategiePapiers (DC-13, 1950), hielten Franz Halder und seine Kollegen deshalb den großflächigen und massiven Einsatz defensiver atomarer Luftschläge angesichts der gegebenen konventionellen Unterlegenheit der Alliierten für die aussichtsreichste Abwehrstrategie. Nur so könnten die Nachschublinien der Roten Armee unterbrochen und die Offensive schließlich zum Stillstand gebracht werden. ${ }^{436}$

Mitte Juli 1951 wurde die Studie unter dem Titel An Assumed Plan of Attack by the USSR on Western Europe $e^{437}$ - zusammen mit einem Katalog der anderen historischen Studien - an SHAPE ausgeliefert. ${ }^{438}$ Wilbur S. Nye sandte außerdem

433 Ebd., S.9-12; vgl. auch ähnliche Ausführungen in: DC 13 - North Atlantic Treaty Organization. Medium Term Defense Plan, 28.3.1950, http://www.nato.int/docu/ stratdoc/eng/a500328d.pdf (letzter Zugriff: 23. 2. 2015).

${ }^{434}$ Halder u. a., MS \# P-104. An Assumed Plan of Attack by the USSR on Western Europe, 1951, S. 15-16 und S. 24-25 sowie S. 32, in: NARA, RG 549, Box 144.

435 Ebd., S. 31.

436 Ebd., S. 32; vgl. DC 13 - North Atlantic Treaty Organization. Medium Term Defense Plan, 28. 3. 1950, http://www.nato.int/docu/stratdoc/eng/a500328d.pdf (letzter Zugriff: 23. 2. 2015).

437 Halder u. a., MS \# P-104. An Assumed Plan of Attack by the USSR on Western Europe, 1951, in: NARA, RG 549, Box 144.

438 W. S. Nye, Schreiben an Col. Robert A. Schow, Deputy Ass. C/S, Intelligence, SHAPE, 12. 7. 1951, in: NARA, RG 549, Box 3160, Folder 2. 
ein Exemplar der Studie an das EUCOM-Hauptquartier und wies in seinem Begleitschreiben darauf hin, dass sich der Wert der Studie noch steigern ließe, falls sie als Grundlage eines Kriegsspieles verwendet würde. ${ }^{439}$ Tatsächlich entschied die OPOT-Abteilung von EUCOM im August 1951, die Studie als Basis eines zweiseitigen Karten-Manövers zu verwenden. ${ }^{440}$ Dass die Studie von der U.S. Armee durchaus als interessant und hilfreich eingeschätzt wurde, zeigte sich auch daran, dass die Engineering Division beauftragt wurde, 100 Kopien der Studie anzufertigen. ${ }^{441}$ Das Manuskript erreichte schließlich auch die nachrichtendienstliche Abteilung der U.S. Armee im Pentagon. Deren Leiter, Major General Alexander R. Bolling, hielt die Annahmen der Studie für „sehr interessant und wertvoll“ und empfahl sie sowohl der G-2 als auch der G-3 Abteilung zur weiteren Prüfung. ${ }^{42}$ Eine weitere Folge der Studie war, dass die Kooperation zwischen der Historical Division und der Operations- und Trainingsabteilung von USAREUR intensiver wurde. ${ }^{43}$ Sichtbarstes Ergebnis dieser Zusammenarbeit war schließlich die Etablierung der Publikationsreihe Foreign Studies Series unter dem Dach von USAREUR, die quasi als Pendant zu den in Washington veröffentlichen DA-Pamphlets fungierte und den amerikanischen Truppen in Europa ausgewählte deutsche Studien in größerer Auflage zugänglich machte (vgl. Tab. 9 im Tabellenanhang). 444

Es ist nicht das Ziel dieser Arbeit, eine systematische Inhaltsanalyse aller Studien vorzulegen, die im Rahmen der kriegsgeschichtlichen Kooperation entstanden sind. Stattdessen sollen lediglich einige ausgewählte Studien stichprobenartig untersucht und so zumindest ein Eindruck vom Ton der Arbeiten vermittelt

439 W. S. Nye, Schreiben an den Chief of Staff, EUCOM, 12.7. 1951, in: NARA, RG 549, Box 3160, Folder 2.

440 W. S. Nye, Chief, Historical Division, EUCOM, Schreiben an Major General Orlando Ward, Chief of Military History, SSUSA, 13.8.1951, in: NARA, RG 549, Box 3160, Folder 2.

${ }^{441}$ Major Urcel L. Bell, Schreiben an OCMH: Assumed Plan of Attack by the USSR on Western Europe, in: NARA, RG 549, Box 3160, Folder 2.

442 A. R. Bolling, Summary Sheet, betr. Brief on ,An Assumed Plan of Attack by the USSR on Western Europe', 31.8.1951, in: NARA, RG 319, Box 30, Folder: An Assumed Attack by USSR on Western Europe.

${ }^{443}$ Louis M. Nawrocky, Foreign Military Studies Branch - Weekly Report No. 150, 4.9. 1951, in: NARA, RG 549, Box 3160, Folder 4; Thomas H. Young, Report of Progress for Week ending 25. 11. 1951, in: NARA, RG 549, Box 3160, Folder 4. So gab der Direktor der OPOT-Division, EUCOM, Major General R. M. Montague zum Beispiel unter Berufung auf die für SHAPE angefertigte Studie im September 1951 eine weitere Studie bei der Control Group in Auftrag, in der die deutschen Offiziere die Möglichkeit erörtern sollten, einen sowjetischen Angriff auf Westeuropa „durch die Errichtung von Befestigungsanlagen, Hindernissen und Landminen entlang der innerdeutschen Grenze abzubremsen und zu kanalisieren". Vgl. Director R. M. Montague, OPOT, EUCOM, Internal Route Slip von Major General R. M. Montague, Director of OPOT, EUCOM an den Chief, Historical Division, EUCOM. Subject: Proposed study by Ex-German Officers, 6. 9. 1951, in: NARA, RG 549, Box 3160, Folder 2.

${ }^{444}$ Historical Division, United States Army Europe, Guide to Foreign Military Studies 1945-54. Catalog and Index, S. 116, in: CARL, N 17500; vgl. auch Nye, Internal Route Slip an den Chief of Staff, EUCOM betr.: Increased Utilization of Historical Division, 17. 8. 1951, in: NARA, RG 549, Box 3160, Folder 2. 
werden. Dabei werden vor allem solche Studien näher betrachtet, die besonders häufig von verschiedenen Heeres-Dienststellen bestellt wurden, regelmäßig auf Lehrplänen der Militärschulen auftauchten oder als DA-Pamphlet weite Verbreitung in der U.S. Armee fanden. Dazu wurden drei Studien ausgewählt, die repräsentativ für die thematische Bandbreite der am meisten verwendeten Studien sind: Die Studie Peculiarities of Russian Warfare (MS \# T-22 bzw. DA-Pamphlet 20-230) bediente das Interesse der U.S. Armee, möglichst viel über die Methoden und den vermeintlich besonders aggressiven Charakter der sowjetischen Kriegsführung und die Eigenschaften der sowjetischen Truppen zu erfahren; die Studie Terrain Factors in the Russian Campaign (MS \# T-34 bzw. DA-Pamphlet 20-290) lieferte Informationen, die eine wichtige Rolle spielen würden, wenn die U.S. Armee die Rote Armee entsprechend der alliierten Kriegsplanungen in der letzten Phase des Dritten Weltkrieges auf ihr eigenes Territorium zurückdrängen und dort schlagen würde; und das Manuskript Rear Area Security in Russia (MS \# T-19 bzw. DA-Pamphlet 20-240) versprach, Anregungen dafür zu liefern, wie die U.S. Armee ihre dann zwangsläufig überlangen Nachschublinien auf sowjetischem Gebiet vor Partisanenangriffen schützen könnte. ${ }^{445}$

Die Studie T-22, die den deutschen Titel Besonderheiten der russischen Kampfführung trug und 1947/48 unter der Federführung des ehemaligen Generaloberst Erhard Raus entstanden war, war eine der am stärksten nachgefragten deutschen Studien überhaupt. ${ }^{446}$ Aufgrund der German Manuscript Accession List bestellten im Oktober 1948 zum Beispiel der militärische Nachrichtendienst, die Ausrüstungsabteilung und das Armed Forces Staff College Kopien des Manuskriptes. ${ }^{447}$ Da die Studie offensichtlich sehr gut ankam, ließ die Historical Division im Juni 1949 gleich 1000 Exemplare in der German Report Series drucken, von denen 700 Stück innerhalb weniger Tage in Umlauf gebracht wurden. ${ }^{448}$ Abnehmer war unter anderem die Intelligence Division. ${ }^{449}$ Auch die Plans and Operations Division zeigte sich interessiert und die Strategic Intelligence School orderte gleich zwanzig

445 Dass diese Themen besonders gefragt waren, belegt neben den Lehrplänen und der Liste der DA-Pamphlets auch die Missionsbeschreibung der Historical Division aus dem Jahr 1951: Hqs. EUCOM Historical Division, Memorandum for the Chief of Staff, betr. Mission of Historical Division for 1951, in: NARA, RG 549, Box 3160, Folder 4. Dort heißt es: „No essential change in the type of product, which consists of studies prepared by German military writers on specially assigned topics relating to combat during World War II, and lessons to be derived there from. Increased emphasis to be placed on activities of small units; and in combat on the Russian front, together with characteristics of Russian methods, equipment, and influence of climate and terrain."

446 Der Österreicher Erhard Raus (1889-1956) war im März 1938 in die Wehrmacht übernommen worden. Im Zweiten Weltkrieg wurde er fast ausschließlich als Truppenkommandeur an der Ostfront verwendet. Raus befehligte u.a. die 6. Panzer-Division (1942/43), das Generalkommando des XI. Armeekorps (1943), die 4. Panzerarmee (1943/44), die 1. Panzerarmee (1944) und die 3. Panzerarmee (1944/45).

447 Frank C. Mahin, Report of Activities, Foreign Studies Section, 4.-18. 10. 1948, 18. 10. 1948, in: NARA, RG 319, Box 23, Folder: Progress Reports, Foreign Studies 1948.

448 James F. Scoggin, Report of Activities, Foreign Studies Section (25.7.-15. 8. 1949), 15. 8. 1949, in: NARA, RG 319, Box 23, Progress Reports, Foreign Sudies 1949.

449 Ebd. 
Exemplare der Studie. ${ }^{450}$ Bestellungen kamen außerdem vom Büro des Secretary of Defense, Louis Arthur Johnson, dem Research and Development Board des Verteidigungsministeriums, der nachrichtendienstlichen Abteilung der Joint Chiefs of Staff, der CIA, dem Office of Naval Intelligence, der Air Force und dem Marine Corps. ${ }^{451}$ Das State Department bestellte Anfang 1950 weitere 30 Exemplare der Studie. ${ }^{452}$ In Europa ging die Studie außerdem an den Commander in Chief und den Chief of Staff von EUCOM; den Commanding General und den Deputy Commanding General von USAREUR; die Leiter der P\&A Division, Intelligence Division, OPOT Division, und Logistics Division; sowie die kommandierenden Offiziere der in Deutschland und Österreich stationierten Infanterie-Divisionen. ${ }^{453}$ Bereits 1949 erreichte die Studie indirekt auch ein größeres Publikum außerhalb der U.S. Armee, als der ehemalige Leiter der Intelligence Division, Colonel Louis B. Ely, ein Buch mit dem Titel The Red Army Today veröffentlichte, in dem er sich in großen Teile auf Raus' Studie stützte. ${ }^{454}$

Worum ging es? Die rund 150-seitige Studie gliederte sich abgesehen von Einleitung und Schluss in vier Hauptteile. Das erste Kapitel behandelte die „Charakteristik des russischen Soldaten und der [russischen] Kampfführung“; das zweite Kapitel ging auf „Besonderheiten der russischen Taktik“ ein; im dritten Kapitel diskutierte Raus die sowjetische Luftwaffe; und im vierten Teil thematisierte er schließlich den Partisanenkrieg. ${ }^{455}$ In der Einleitung betonte der Autor, dass russische Kampfmethoden angesichts der internationalen Situation mehr und mehr $\mathrm{zu}$,einem Thema von lebenswichtigem Interesse“ würden. Denn auch wenn der technologische Fortschritt die äußeren Aspekte der Kriegführung verändert habe und weiter verändern werde, blieben „der Charakter und die Besonderheiten des russischen Soldaten und seine eigene Art zu kämpfen von solchen Neuerungen

450 Ebd.

451 Frank C. Mahin, Report of Activities, Foreign Studies Section (15.-29.8. 1949), 29. 8. 1949, in: NARA, RG 319, Box 23, Progress Reports, Foreign Studies 1949; Ders., Report of Activities, Foreign Studies Section (29.8.-12.9. 1949), 12.9. 1949, in: NARA, RG 319, Box 23, Progress Reports, Foreign Sudies 1949; Ders., Report of Activities, Foreign Studies Section (12.-26.9. 1949), 26.9. 1949, in: NARA, RG 319, Box 23, Progress Reports, Foreign Sudies 1949.

452 John R. Ulmer, Report of Activities, Foreign Studies Section (5.12.1949-9.1. 1950), 9. 1. 1950, in: NARA, RG 319, Box 23, Progress Reports, Foreign Sudies 1950.

453 Distribution List of German Manuscript \# T-22 ,Peculiarities of Russian Warfare', in: NARA, RG 319, Box 7, Folder 3.

454 Ely, The Red Army Today.

455 Die im Folgenden angegebenen Seitenzahlen und Zitate beziehen sich auf die Neuauflage der Studie von 1950, die jedoch mit dem Original fast identisch ist: Department of the Army (Hg.), DA-Pamphlet 20-230: Russian Combat Methods in World War II. Ein Durchschlag des deutschen Originalmanuskriptes liegt im Bundesarchiv in Freiburg: Erhard Raus, MS \# T-22. Besonderheiten der russischen Kampfführung, in: BArch, ZA 1/2371. Wie die meisten Studien entstand auch T-22 unter Beteiligung eines Kreises mehrerer ehemaliger Wehrmachtsoffiziere; da sich jedoch nicht mehr ermitteln lässt, wer genau diesem Kreis angehörte, wird im Folgenden ausschließlich Erhard Raus als Autor genannt, da dieser die Federführung innehatte und mit an Sicherheit grenzender Wahrscheinlichkeit der maßgebliche Verfasser des Textes ist. 
unbeeinflusst“. Die deutschen Erfahrungen im Kampf gegen die Rote Armee seien deshalb nach wie vor voll gültig. ${ }^{456}$

Raus ging dementsprechend ausführlich auf die „Charakteristika des russischen Soldaten“ und die Besonderheiten von dessen Kampfführung ein. Dabei vermittelte er über die gesamte Studie hinweg den Eindruck, dass eine fundamentale Wesensverschiedenheit zwischen westlichen und sowjetischen Soldaten bestehe und führte dies vor allem auf angeborene - d.h. rassische - Eigenschaften zurück. So beschrieb er die „halb-asiatischen“ sowjetischen Soldaten zum Beispiel als „primitiv“, „anspruchslos“ und als „unfähig, selbständig zu denken“. Sie seien „von Stimmungen abhängig“ und handelten „instinktiv“. Auch wenn der einzelne Soldat „tapfer“ sei, so bliebe die Masse der sowjetischen Truppen vor allem „passiv“ und von einem „Herdeninstinkt“ geleitet. Außerdem, so betonte Raus an mehrere Stellen, zeichne den russischen Soldaten eine „Menschen- und Todesverachtung “ aus, die westlichen Völkern unverständlich sei. ${ }^{457}$ Einerseits hätten die russischen Soldaten dank ihrer technischen Begabung rasch gelernt, mit neuen Waffen umzugehen und hätten während des Zweiten Weltkrieges vor allem im Bereich der Kommunikation großes Geschick und Lernfähigkeit bewiesen; ${ }^{458}$ allerdings hätten die Deutschen auch häufig Eigenschaften wie „Dumpfheit“, „mangelnde Flexibilität“ und „Apathie“ beobachtet, die die sowjetischen Streitkräfte wohl auch in Zukunft prägen würden. ${ }^{459}$

Die Offiziere der höheren Befehlsebene beurteilte Raus etwas positiver als die Mannschaften. Das sowjetische Militär habe sich in der Zwischenkriegszeit so sehr weiterentwickelt und verbessert, dass auch die Säuberungen der 1930er Jahre nicht $\mathrm{zu}$ einer grundsätzlichen Verschlechterung geführt hätten. Das russische Oberkommando sei „im Großen und Ganzen kompetent“ gewesen und hätte ein Auge für die strategischen und taktischen Schwachstellen des Feindes gehabt. Allerdings hätten die unteren und mittleren Kommandobehörden weit weniger Flexibilität an den Tag gelegt; außerdem sei es ihnen nicht gelungen, die Masse der russischen Soldaten zu beleben. Letztlich hätten vor allem die enormen Ressourcen des Landes und die hohe Zahl verfügbarer Truppen den Sowjets einen deutlichen Vorteil gegenüber den Deutschen verschafft. ${ }^{460}$ Als maßgeblichste russische Kampfmethode identifizierte Raus daher den Einsatz einer Masse von Soldaten und Material auf der Grundlage des scheinbar endlosen sowjetischen Nachschubes. Dieser Einsatz der Masse sei zwar in der Regel unintelligent und ohne Variation erfolgt, sei aber unter den gegebenen Bedingungen immer effektiv gewesen - wenn auch kostspielig. Raus war überzeugt, dass eine natürliche Geringschätzung menschlichen Lebens, die durch den Kommunismus weiter verstärkt worden sei, diese Praxis begünstigt hätte:

456 Department of the Army (Hg.), DA-Pamphlet 20-230: Russian Combat Methods in World War II, S. 1-2.

457 Ebd., S. 3 und S. 7.

458 Ebd., S. 6-7.

459 Ebd., S. 7.

${ }^{460}$ Ebd., S. 8-11; vgl. auch Fritz Wenzell, MS \# B-266. Kampferfahrungen aus dem Osten, S. 3, in: BArch, ZA 1/617. 
„A Russian attack which had been twice repulsed with unheard-of losses would be repeated a third and a fourth time at the same place and in the same fashion. Unimpressed by previous failures and losses, new waves always came on. An unusual inflexibility of mind and unimaginative obstinacy lay in this use of masses, and was dearly paid for. [...] This inflexible method of warfare, with the objective of accomplishing everything through the use of human masses, is the most inhuman and costly possible." 461

Neben dem rücksichtslosen Einsatz von Mensch und Material machte Raus vor allem die geographischen und klimatischen Bedingungen in Osteuropa und deren effektive Ausnutzung durch die Rote Armee für die Niederlage der Wehrmacht verantwortlich. ${ }^{462}$ Dank ihrer "primitiven Instinkte“ seien die russischen Soldaten zum Beispiel in der Lage gewesen, sich ausgezeichnet zu tarnen und Wetter und Vegetation für ihre Zwecke auszunutzen. Darüber hinaus seien sie wesentlich anspruchsloser als die deutschen Soldaten gewesen und hätten sich in Ermangelung von Nachschub tage- und wochenlang von Wurzeln und Ähnlichem ernähren können. ${ }^{463}$

Trotz der besonderen militärischen Vorteile, die sich seiner Meinung nach aus Geographie und Klima, den schier unerschöpflichen menschlichen und materiellen Ressourcen und der Mentalität der russischen Soldaten ergaben, hielt Raus einen Krieg gegen die Sowjetunion nicht von vorneherein für ein vergebliches Unterfangen - auch die Deutschen hätten einen Sieg „trotz Russland und den Russen, trotz Kälte und Schlamm, trotz unzulänglicher Ausrüstung und einer geradezu lächerlichen numerischen Unterlegenheit [...] in Reichweite gehabt“ ${ }^{4}{ }^{4} 4$ Allerdings könne ein solcher Krieg gegen die Sowjetunion auf deren eigenem Territorium nur bei akribischer und systematischer Vorbereitung und einer auf die geographischen und klimatischen Gegebenheiten ausgelegten und im Umfang ausreichenden Ausrüstung gewonnen werden. Von diesen materiellen Gesichtspunkten abgesehen, die Raus angesichts der amerikanischen Wirtschaftskraft für unproblematisch hielt, betonte er außerdem die Bedeutung der Ausbildung der westlichen Truppen. Um den Charaktereigenschaften der russischen Soldaten etwas entgegensetzen zu können, müssten vor allem die Härte und Belastbarkeit der westlichen Soldaten, ihre Selbständigkeit und ihr Verantwortungsbewusstsein gestärkt werden. Letztlich, daran ließ Raus keinen Zweifel, müssten die Soldaten jedoch vor allem eine innere Überzeugung entwickeln „einen unbezwingbaren Willen, zu verhindern, dass der russische Moloch die Welt" verschlinge. ${ }^{465}$

461 Department of the Army (Hg.), DA-Pamphlet 20-230: Russian Combat Methods in World War II, S.24. Raus betonte auch an anderen Stellen der Studie immer wieder, wie brutal die sowjetischen Truppen sowohl gegen die deutschen Truppen - er erwähnte explizit die Erschießung von deutschen Kriegsgefangenen - als auch gegen die Zivilbevölkerung und die eigene Truppe gewesen seien. Deutsche Kriegsverbrechen erwähnte Raus natürlich mit keiner Silbe.

462 Ebd., S. 76.

463 Ebd., S. 17-18.

464 Ebd., S. 116.

465 Ebd. 
Glaubt man Frank C. Mahin, dann waren die Kommentare zu Raus' Studie "außerordentlich positiv“.466 Laut eines Informanten der Historical Division wurde die Studie in den Büros der Intelligence Division intensiv studiert. ${ }^{467} \mathrm{Als}$ schließlich von Seiten des National Security Resources Board ${ }^{468}$ die Studie dann doch als „unausgewogen in einigen Analysen der russischen Psyche und Soziologie“ kritisiert wurde, teilte der Leiter der Historical Division lediglich lapidar mit, der Leser werde ja in der Einleitung darauf hingewiesen, dass es sich um „nicht mehr und nicht weniger als eine gewissenhafte Darstellung der Ansichten des deutschen Autors" handle. ${ }^{469}$ Da das National Security Resources Board mit seiner Kritik in der Minderheit blieb, bereitete die Historical Division im Januar 1950 auf Anregung der Organization and Training Division eine Neuauflage der Studie vor, die einer geringeren Geheimhaltungsstufe unterliegen und somit einem noch größeren Kreis amerikanischer Offiziere zugänglich sein sollte. Als erste deutsche Studie erschien Raus' Arbeit schließlich im November 1950 leicht überarbeitet unter dem Titel Russian Combat Methods in World War II als DA-Pamphlet No. 20230. Die Broschüre erhielt die niedrigste Sicherheitsklassifizierung (Restricted) und konnte damit von allen Angehörigen der Streitkräfte und der Regierung eingesehen werden. ${ }^{470}$

Abgesehen von den Kampfeigenschaften der sowjetischen Truppen interessierte sich die U.S. Armee in Vorbereitung auf eine mögliche eigene Konfrontation mit der Roten Armee auch für die Auswirkungen der besonderen geographischen und klimatischen Bedingungen im Falle eines amerikanischen Vordringens auf sowjetisches Territorium. Eine der zahlreichen Studien, die diese Faktoren behandelten, stammte von dem ehemaligen General der Infanterie Karl Allmendinger. ${ }^{471}$ In der Studie Terrain Factors in the Russian Campaign, die im Juli 1951 als DA-Pamphlet 20-290 veröffentlicht wurde, beschrieb er detailliert, welche natürlichen Hindernisse einem von Westen aus angreifenden Heer in der Sowjetunion entgegenstünden. ${ }^{472}$ Dabei ging er vor allem auf die vielen in Nord-Süd-Richtung verlaufenden Flüsse, wie den Dnepr, den Don und die Wolga ein, thematisierte aber auch die Bedeutung der russischen Wälder und Sümpfe für militärische Operationen.

466 Mahin, Report of Activities, Foreign Studies Section (15.-29. 8. 1949), 29. 8. 1949, in: NARA, RG 319, Box 23, Folder: Progress Reports, Foreign studies 1949.

467 Scoggin, Report of Activities, Foreign Studies Section (25.7.-15. 8. 1949), 15. 8.1949, in: NARA, RG 319, Box 23, Folder: Progress Reports, Foreign Studies 1949.

468 Das NSRB war durch den National Security Act von 1947 geschaffen worden und hatte die Aufgabe, den U.S. Präsidenten im Falle eines Krieges in allen Fragen der militärischen, industriellen und zivilen Mobilisierung zu beraten.

469 Scoggin, Report of Activities, Foreign Studies Section (25.7.-15. 8. 1949), 15. 8. 1949, in: NARA, RG 319, Box 23, Folder: Progress Reports, Foreign Studies 1949.

470 Ulmer, Report of Activities, Foreign Studies Section (5.12.1949-9. 1. 1950), 9. 1. 1950, in: NARA, RG 319, Box 23, Folder: Progress Reporst, Foreign Studies 1950.

471 Allmendinger hatte im Ostfeldzug zunächst die 5. Infanterie-Division (1941-1943) und später das 5. Armeekorps (1943/44) kommandiert.

472 Die Seitenzahlen beziehen sich auf die englische Version: Department of the Army (Hg.), DA-Pamphlet 20-290: Terrain Factors in the Russian Campaign; das deutsche Original liegt in Freiburg: Karl Allmendinger, MS \# T-34. Die Bedeutung von Flußund Waldgebieten, Sümpfen und Steppen im Rußland-Feldzug, 1951, in: BArch, ZA $1 / 2381-2382$. 
Wie bei Raus stand auch bei Allmendinger die Frage nach den Gründen für das Scheitern des deutschen Russlandfeldzuges immer im Hintergrund. ${ }^{473}$ Allmendinger argumentierte, dass die deutsche Blitzkriegstrategie angesichts der enormen Dimensionen des sowjetischen Territoriums und der numerischen Überlegenheit der Bevölkerung und damit des Militärs im Grunde von vorneherein zum Scheitern verurteilt gewesen sei. Fehler bei der Planung des Feldzuges hätten die ohnehin schwierige Ausgangslage noch weiter verschlechtert. Dem Unternehmen, so der Autor, habe es an einem strategischen Endziel gemangelt: Nachdem die Erwartung, dass die Sowjetunion nach den deutschen Anfangserfolgen von innen heraus zusammenbrechen würde, sich nicht erfüllt und sich stattdessen ein längerer Krieg entwickelt habe, seien alle folgenden deutschen Operationen reine Improvisation ohne übergreifende Planungen oder Ziele gewesen. In der Folge hätten die Sowjets die Initiative übernommen und das deutsche Heer hätte nur noch reagieren können. ${ }^{474}$

Die Schwäche der deutschen Planungen machte Allmendinger vor allem auch an der Ignoranz der deutschen Führung gegenüber den Kampf- und Widerstandsfähigkeiten des sowjetischen Volkes sowie den besonderen Eigenschaften des Landes fest. So habe man zum Beispiel die Bedeutung der zweimal jährlich einsetzenden Schlammperiode völlig unterschätzt, die die schweren deutschen Fahrzeuge wochenlang fast völlig bewegungsunfähig gemacht habe. Indem die Schlammperiode eine konventionelle Kriegführung auf bestimmte Jahreszeiten beschränke, habe sie enormen Einfluss auf die Planung und Operationsführung in Russland. ${ }^{475}$ Auch wirtschaftlich sei das Deutsche Reich nicht ausreichend auf den Krieg gegen die Sowjetunion vorbereitet gewesen und hätte zum Beispiel die enormen Verluste an Material nicht ausgleichen und beispielsweise nicht genügend geländegängige Fahrzeuge herstellen können. ${ }^{476}$ Einen weiteren Schwachpunkt der deutschen Feldzugsplanung sah Allmendinger in der mangelnden praktischen Vorbereitung des Ostheeres auf die bevorstehende Aufgabe, die einerseits der langen Geheimhaltung der Angriffspläne selbst vor der eigenen Truppe, andererseits einem Mangel an geographisch und klimatisch geeignetem Trainingsgelände in Mittel- und Westeuropa geschuldet gewesen sei. ${ }^{477}$ Durch die großen Verluste und die zunehmenden Schwierigkeiten, diese zu ersetzen, seien die Qualität und der Trainingsstand der Truppe im Laufe des Krieges dann immer weiter gesunken. ${ }^{478}$

Allmendinger kam letztlich zu dem Schluss, dass das russische Terrain einen tiefgreifenden Einfluss auf das deutsche Heer gehabt habe - vor allem im Hin-

473 Department of the Army (Hg.), DA-Pamphlet 20-290: Terrain Factors in the Russian Campaign, S. 6.

474 Ebd., S. 8-9.

475 Ebd., S. 9-10.

476 Ebd., S. 15.

477 Ebd.

478 Ebd., S. 24. Dort heißt es: „The longer the war lasted and the higher the toll of casualties mounted, the smaller became the portion of well-trained, professional soldiers in the German fighting machine. This fact cannot be ignored in looking at the later stages of the campaign when the tide turned and the enemy seized the initiative." 
blick auf die schweren Materialverluste: „Heat, dust, poor roads, marshy terrain, and too few stops for repairs wreaked such havoc with German armored and motorized equipment that no amount of subsequent effort could undo the damage. “479 Das schwierige Gelände in der Sowjetunion, so Allmendinger, beeinträchtige die Leistungsfähigkeit von Panzern und anderen motorisierten Fahrzeugen, die ständig überholt und ersetzt werden müssten. Da die deutsche Industrie nicht in der Lage gewesen sei, die ausfallenden Maschinen in vollem Umfang zu ersetzen, habe das deutsche Heer zunehmend an Schlagkraft und Mobilität eingebüßt. ${ }^{480}$ Ohne die geographischen und klimatischen Faktoren bei der deutschen Niederlage gegen die Sowjetunion überbewerten zu wollen, schloss der Autor mit dem Statement, dass „der letzte Krieg zumindest eine Tatsache bestätigt“ habe: Bei einem einseitigen Angriff auf die Sowjetunion von Westen würden selbst die besten militärischen Kräfte große Schwierigkeiten haben, die UdSSR zum Einsturz zu bringen. ${ }^{481}$

Eine weitere Studie, die sich häufig auf den Leselisten der amerikanischen Militärschulen fand und auch in der renommierten Fachzeitschrift Military Review zitiert wurde, war Hasso Neitzels Studie über die Sicherung der rückwärtigen Verbindungen im Osten (T-19). ${ }^{482}$ In der Studie, die 1951 als DA-Pamphlet No. 20-240 veröffentlicht wurde, beschrieb Neitzel die Versuche der Wehrmacht, das rückwärtige Heeresgebiet hinter der Ostfront zu befrieden und die wichtigen Nachschub- und Kommunikationslinien, insbesondere die Eisenbahnlinien, gegen Sabotage durch Partisanen zu schützen. Um die vitale Bedeutung der rückwärtigen Verbindungslinien zu unterstreichen, verglich Neitzel diese mit den Adern des menschlichen Körpers: Das fähigste Gehirn, der mächtigste Arm, das stärkste Herz [könne] seine Funktionen nicht mehr voll ausführen, wenn das Blut nicht seinem vorgeschriebenen Weg durch die Arterien folgen [könne]. ${ }^{483}$

Neitzel bezog sich in erster Linie auf die Pazifizierungsbemühungen im rückwärtigen Gebiet der Heeresgruppe Mitte und ging zunächst ausführlich auf die Planungen und Vorbereitungen der Heersführung zur Nachschubversorgung des Ostheeres durch spezielle Sicherungsdivisionen in den zu diesem Zweck gebildeten rückwärtigen Heeresgebieten ein. ${ }^{484}$ Der Autor unterschied zwischen aktiven und passiven Sicherungsmaßnahmen: Während die Sicherungsdivisionen für den aktiven Schutz des Nachschubes zuständig waren, sollten die Nachschubeinheiten selbst ihre Sicherheit zum Beispiel durch „schnelles und reibungsloses Fahren“ in

479 Ebd., S. 59.

480 Ebd.

481 Ebd., S. 60. Dort heißt es: „The recent war has reaffirmed only one fact: In any one-sided assault from the west, even the best of military forces will find it more than difficult to bring about the collapse of Russia."

482 Department of the Army (Hg.), DA-Pamphlet 20-240. Rear Area Security in Russia. The Soviet Second Front Behind the German Lines; das Original befindet sich in Freiburg: Hasso Neitzel, MS \# T-19, Sicherung der rückwärtigen Verbindungen (Osten), in: BArch, ZA 1/2366.

483 Department of the Army (Hg.), DA-Pamphlet 20-240. Rear Area Security in Russia. The Soviet Second Front Behind the German Lines, S. 2.

484 Ebd., S. 5-7. 
langen Versorgungskolonnen gewährleisten; Fahrzeuge sollten bekannte Partisanengebiete nach Möglichkeit nicht einzeln durchqueren; LKWs sollten in Konvois von Sicherungsposten zu Sicherungsposten fahren; und entladene Nachschubgüter sollten großflächig verteilt und eventuell unterirdisch aufbewahrt werden, um sie vor Luftangriffen zu schützen. ${ }^{485}$ Besonders ausführlich beschrieb Neitzel die deutschen Planungen zum Schutz der wichtigen Bahnlinien. So habe man zum Beispiel rechts und links der Gleise knapp 300 Meter Wald gerodet, um die Annäherung von Partisanen frühzeitig sehen zu können; den eigentlichen Nachschubzügen habe man mit Steinen beladene Waggons vorausgeschickt, um eventuell versteckte Minen auszulösen; außerdem seien mobile Bautrupps entlang der Strecke verteilt worden, um Schäden so schnell wie möglich zu beheben. ${ }^{486}$

Im zweiten Teil der Studie ging Neitzel dann anhand mehrerer Beispiele ausführlich auf die Aktivitäten der Partisanen im rückwärtigen Gebiet der Heeresgruppe Mitte ein. ${ }^{487}$ Dass die Partisanenbewegung ab dem Spätherbst 1941 spürbar anwuchs, schrieb Neitzel der verfehlten Politik gegenüber der Zivilbevölkerung durch die Befehlshaber der rückwärtigen Heeresgebiete und der militärischen Besatzungsgebiete zu. ${ }^{488}$ Schließlich seien die Kampftruppen im Juni und Juli 1941 zum Beispiel in der Gegend von Bobruysk zunächst von der Zivilbevölkerung als „Befreier“ begrüßt worden und hätten in der Regel gut mit den deutschen Truppen kooperiert, die sich bemüht hätten, die Bevölkerung korrekt zu behandeln. So seien zum Beispiel die Kirchen geöffnet und die lokale Wirtschaft wieder in Gang gebracht worden. Die Zusammenarbeit mit den Einwohnern der Gegend sei so gut gewesen, dass die deutschen Truppen aus der lokalen Produktion hätten mitversorgt werden können, ohne die Bevölkerung zu belasten. Erst als die Kampftruppen weiter nach Osten vorgerückt seien und die rückwärtigen Besatzungstruppen das Kommando übernommen hätten, habe sich die Situation verschlechtert und die Gegend um Bobruysk sei allmählich zu einem der größten und gefährlichsten Partisanengebiete des gesamten Krieges geworden. Neitzel führte diese Entwicklung vor allem auf die harte Behandlung der Zivilbevölkerung zurück, die das Vertrauen in die deutschen Besatzer verloren und sich stattdessen den Partisanen zugewendet habe. ${ }^{489}$

Die Lehren, die Neitzel schließlich aus den deutschen Erfahrungen zog, betonten daher die Bedeutung einer friedlichen Haltung gegenüber der Zivilbevölkerung in besetzten Gebieten. Falls sich dennoch eine Partisanenbewegung entwickle, müsse jedoch eine umfassende aktive Verteidigung unternommen werden. Dabei sei die Qualität der Sicherungstruppen und deren Ausrüstung besonders wichtig: Kein Partisanengebiet könne auf Dauer von einer Truppe alter Männer

485 Ebd., S. 9.

486 Ebd., S. 10.

487 Vgl. zum Beispiel ebd., S. 13-14.

488 Siehe zu diesem Themenkomplex ausführlich Hartmann, Wehrmacht im Ostkrieg.

489 Department of the Army (Hg.), DA-Pamphlet 20-240. Rear Area Security in Russia. The Soviet Second Front Behind the German Lines, S. 14-17, vgl. auch ebd., S. 18-20; vgl. auch Fritz Wenzell, MS \# B-266. Kampferfahrungen aus dem Osten, 1946, S. 7, in: BArch, ZA 1/617. 
mit schlechten Waffen und zu wenig Munition befriedet werden. ${ }^{490}$ Denn im Falle eines Partisanenkrieges seien die rückwärtigen Gebiete ein vollwertiger Kriegsschauplatz und die Kämpfe gegen die Partisanen würden oftmals mehr Opfer fordern als die Operationen an der Front. Die Bekämpfung der Partisanen erfordere daher den Einsatz regulärer Truppen. ${ }^{491}$ Eine dauerhafte Befriedung sei letztlich jedoch nur zu erreichen, indem man die Bevölkerung durch Propaganda und vor allem durch eine gute Behandlung auf seine Seit bringe. ${ }^{492}$

\subsection{Vorträge ehemaliger Wehrmachtsoffiziere in Ausbildungs- und Trainingseinrichtungen der U.S. Armee in Europa und den USA}

Wie die eben erläuterten Beispiele zeigen, war die Zusammenarbeit der Historical Division mit zahlreichen ehemaligen Wehrmachtsoffizieren seit Ende der 1940er Jahre für die U.S. Armee, aber auch das Außenministerium und die CIA, zu einem gerne und vielfach genutzten Instrument der Informations- und Lehrmittelbeschaffung geworden. Die deutschen Militärs genossen innerhalb der amerikanischen Streitkräfte zweifellos eine hohe Reputation. Dies wird auch daran deutlich, dass ehemalige deutsche Offiziere zwischen 1952 und 1958 regelmäßig als Gastdozenten an Militärschulen und Fortbildungseinrichtungen der U.S. Armee in Deutschland, aber auch in die Vereinigten Staaten, eingeladen wurden.

Im November 1950 beantragte das Army War College erstmals, deutsche Offiziere für Vorträge in die USA zu bringen. Allerdings sprach sich das Department of State damals gegen den Vorschlag aus, da angesichts der gerade beginnenden Verhandlungen um eine deutsche Wiederbewaffnung negative öffentliche Reaktionen befürchtet wurden. ${ }^{493}$ Obwohl die Historical Division dennoch im Januar 1951 eine Liste möglicher deutscher Gastdozenten zusammenstellte, ${ }^{494}$ kam die Sache erst ein Jahr später, im Oktober 1951, ins Rollen. ${ }^{495}$ Damals fragte der Kommandant des Army War College, Lieutenant General Edward M. Almond, bei der Geheimdienstabteilung im Generalstab an, ob einer ihrer Offiziere im Dezember einen Vortrag am AWC zum Thema Logistic Operations on the Eastern Front halten könne. Gleichzeitig bat er darum, dass auch der ehemalige Oberstleutnant i.G. der deutschen 35. Infanterie Division, Ernst Schultes, der sich zu

490 Department of the Army (Hg.), DA-Pamphlet 20-240. Rear Area Security in Russia. The Soviet Second Front Behind the German Lines, S. 34 .

491 Ebd., S. 34-35.

492 Ebd., S. 36-39.

493 A. R. Bolling, Memorandum for Deputy Chief of Staff for Administration, betr. Lecture on Battle of Stalingrad at the Army War College, 17.11. 1950, in: NARA, RG 549, Box 9, Folder: v. Greiffenberg, Hans.

494 Frank C. Mahin, Memorandum for Chief, Special Studies Division, betr. Nominations for German Lecturer Program, 4. 1. 1951, in: NARA, RG 549, Box 9, Folder: v. Greiffenberg, Hans.

495 Paul M. Robinett, Memorandum for Chief of Military History. Progress Report of Special Studies Division, 3. 10.-2.11. 1951, 2. 11. 1951, in: NARA, RG 319, Box 20, Folder: Monthly Progress Reports 1950-51; Memo for Record, Oktober 1951, in: NARA, RG 319, Box 56, Folder 9. 
diesem Zeitpunkt bei der nachrichtendienstlichen Abteilung im Pentagon aufhielt, bei der Vorlesung anwesend sein könne, um Fragen der Studenten aus erster Hand zu beantworten. ${ }^{496}$

Major General Alexander R. Bolling, Assistant Chief of Staff, G-2, kam Almonds Bitte gerne nach und sandte am 10. Dezember neben Colonel William R. Frederick und Lieutenant Colonel Arthur L. Dean auch Schultes ans AWC. ${ }^{497}$ Der ehemalige deutsche Offizier, der an einer Podiumsdiskussion teilnahm und verschiedenen studentischen Arbeitsgruppen im kleineren Kreise für Fragen zur Verfügung stand, hinterließ einen äußerst guten Eindruck. Mit seiner „freimütige[n], informative[n] und direkte[n] Art", schrieb Almond später an Bolling, habe Schultes „ein[en] wertvoll[en] Beitrag“ zu der Veranstaltung geleistet. Er hoffte deshalb, dass in Zukunft mehr deutsche Offiziere als Gastdozenten zum Einsatz kommen würden. 498 Tatsächlich hatte die nachrichtendienstliche Abteilung des Department of the Army bereits selbst in diese Richtung gedacht und Anfang Dezember 1951 Anton von Bechtolsheim über die Historical Division zu einer Vortragsreise in die Vereinigten Staaten eingeladen. Dabei sollte Bechtolsheim von Mitte Januar bis Mitte Februar 1952 unter anderem am Army War College, am National War College, am Command and General Staff College und am Armed Forces Staff College über die deutsche Strategie gegen die Sowjetunion während des Zweiten Weltkrieges referieren. Abgesehen von der Kostenübernahme für Flug, Unterbringung und Mahlzeiten bot die Armee dem Deutschen eine Aufwandsentschädigung von bis zu neun Dollar pro Tag sowie ein Honorar von je rund 50 Dollar pro Vortrag. 499

In Europa zeigte sich Wilbur S. Nye durchaus angetan von der Idee, einen ehemaligen deutschen Offizier für Vorträge in die USA zu schicken - schließlich würde eine solche Reise eine gute Werbung für das Foreign Studies Program sein. Allerdings hielt er Bechtolsheim nicht für den idealen Kandidaten für eine solche Aufgabe. Er sei zwar hinsichtlich seiner Englischkenntnisse, seines Intellekts sowie seiner Persönlichkeit durchaus geeignet; als Divisionskommandeur bzw. Generalstabschef eines Korps habe er jedoch während des Russlandfeldzuges keine ausgesprochen hochrangige Position innegehabt und verfüge somit nur über begrenzte Erfahrungen und Perspektiven. Nye hätte es deshalb vorgezogen, den erfahreneren (und zweifelsohne bekannteren) Heinz Guderian nach Amerika zu schicken - eine Idee, die sich allerdings aufgrund von Guderians allgemein bekannter Nähe zum Nationalsozialismus als nicht opportun erwies. ${ }^{500}$ Wilbur S. Nye blieb

496 Ebd.

497 A. R. Bolling, Schreiben an Lieutenant Genral Edward M. Almond, 23. 10. 1951, in: NARA, RG 319, Box 56, Folder 9.

498 Edward M. Almond, Schreiben an A. R. Bolling, 17. 12. 1951, in: NARA, RG 319, Box 56, Folder 9.

499 Cable from State Department to HICOG, Berlin, 10. 12. 1951, in: NARA, RG 549, Box 3160, Folder 3; Cable from Chief of Staff, U.S. Army, AC/S G2 to CINCEUR, 23. 12. 1951, in: NARA, RG 549, Box 3160, Folder 3. Umgerechnet in D-Mark sollte von Bechtolsheim eine Aufwandsentschädigung von etwa $37,80 \mathrm{DM}$ pro Tag sowie ein Honorar von 210 DM pro Vortrag erhalten.

500 W. S. Nye, Schreiben an Paul M. Robinett, 4. 1. 1952, in: NARA, RG 319, Box 8, Folder 8. 
deshalb nichts anderes übrig als zu hoffen, dass Bechtolsheim an den Service Schools einen guten Eindruck machen und so „das Eis für weitere Besuche dieser Art brechen" würde. ${ }^{501}$

Auch der Leiter der Special Studies Section Paul M. Robinett war sich über Bechtolsheims Defizite durchaus im Klaren. Dennoch war er überzeugt, dass er zu diesem Zeitpunkt die richtige Wahl für die geplante Vortragsreise war. Vor allem die Tatsache, dass Bechtolsheim Anfang der 1930er Jahre für ein Jahr die Artillery School in Fort Sill, Oklahoma besucht hatte, machte ihn in Robinetts Augen zu einem geeigneten Kandidaten. Immerhin verfügte er somit über eigene Erfahrungen mit dem Lehrstil an amerikanischen Militärschulen. Außerdem erwartete Robinett, dass die Ehre, Vorträge an den renommiertesten Militärschulen halten zu dürfen, zusammen mit einem freundschaftlichen Empfang durch alte Kommilitonen dafür sorgen würde, dass Bechtolsheim nach seiner Rückkehr nach Deutschland auch andere, schwergewichtigere ehemalige Wehrmachtsgeneräle für derartige Vortragsreisen gewinnen würde. ${ }^{502}$

In Unwissenheit über die amerikanischen Bedenken seine fachliche Qualifikation betreffend nahm Anton von Bechtolsheim das Angebot ohne zu zögern an. Nachdem er wochenlang „Tag und Nacht“ an seinem Manuskript gearbeitet hatte, brach er am 11. Januar 1952 schließlich in die Vereinigten Staaten auf. ${ }^{503}$ Die Vortragsreise wurde ein voller Erfolg. So lobte Edward M. Almond beispielsweise Bechtolsheims Vortrag gegenüber Alexander R. Bolling als „herausragend“:504

„As you know, our students have been studying the German campaign in Russia, but no amount of study of historical records can take the place of firsthand reports by a person who participated in many of the events and who has since had the opportunity to devote considerable thought and mature judgment to those experiences. ${ }^{\text {"505 }}$

Orlando Ward, dem Chef der Historical Division in Washington, gefiel Bechtolsheims Vortrag sogar so gut, dass er ihn sich gleich zwei Mal anhörte. ${ }^{506}$

Tatsächlich bildeten Bechtolsheims Vorträge in Washington, Carlisle und Fort Leavenworth den Auftakt zu einer ganzen Reihe weiterer Vortragsreisen. So reiste Bechtolsheim in den nächsten Jahren jeweils im Frühjahr für mehrere Wochen durch die USA und trug an den Service Schools vor. ${ }^{507}$ Dabei erweiterte er sein

501 Ders., Schreiben an Orlando Ward, 9. 1. 1952, in: NARA, RG 319, Box 8, Folder 8.

502 Paul M. Robinett, Schreiben an Wilbur S. Nye, 11.1.1952, in: NARA, RG 319, Box 8, Folder 8 .

${ }^{503}$ Nye, Schreiben an Orlando Ward, 9. 1. 1952, in: NARA, RG 319, Box 8, Folder 8.

504 Edward M. Almond, Schreiben an A. R. Bolling, 31. 1. 1952, in: NARA, RG 319, Box 56 , Folder 9.

505 Ebd.

506 Orlando Ward, Schreiben an Wilbur S. Nye, 8. 2. 1952, in: NARA, RG 319, Box 8, Folder 8.

507 Melvin C. Helfers, Report of Activities, Foreign Studies Branch (1.-31.1.1954), in: NARA, RG 319, Box 10, Monthly Progress Reports OCMH 1954; Robert M. Kennedy, Report of Activities, Foreign Studies Branch (1.-31.1.1955), in: NARA, RG 319, Box 11, Monthly Progress Reports 1955; Paul M. Robinett, Progress Report for Special Studies Division (3.1.-3.2. 1955), in: NARA, RG 319, Box 11, Monthly Progress Reports 1955; Ders., Progress Report for the Special Studies Division (3.3.-1.4. 1956), in: NARA, RG 319, Box 12, Monthly Progress Reports 1956; Edward J. Barta, Schreiben 
Vortragsrepertoire um einen Vortrag zur Schlacht um Kahrkov 1942 und ein Referat zum Blitzkrieg im Osten: Von Kleists Panzerarmee in der Ukraine, Juni bis Dezember $1941 .{ }^{508}$ Wie von der Historical Division erhofft, blieb Bechtolsheim nicht der einzige deutsche Gastdozent an amerikanischen Militärschulen: Bis 1957 vergrößerte sich der Kreis der deutschen Vortragenden, die regelmäßig in die Vereinigten Staaten reisten, um Friedrich von Boetticher, Ulrich Lise, Günther Reichhelm, Hasso Freiherr von Puttkamer, Hellmut Schultze und Frido von Senger und Etterlin. ${ }^{509}$

Nicht nur die amerikanische Leitung der Historical Division, sondern auch die deutsche Control Group um Franz Halder maß diesen Vorträgen „große Bedeutung“ $z u,{ }^{510}$ trugen sie doch maßgeblich zur Verbreitung der deutschen Erfahrungen in den USA und damit zur Nutzbarmachung „deutsche[r] Erfahrung und deutsche[n] soldatische[n] Denken[s]“ für „den militärischen Aufbau des Westens" bei. ${ }^{511}$ Die Control Group nahm deshalb bewusst Einfluss auf die Auswahl der Referenten und bestellte diese vor der Abreise zu Besprechungen ein, um die Gliederung der Vorträge sowie die fertigen Texte zu prüfen. ${ }^{512}$

Wie die nachgefragtesten Studien spiegelten auch die Vortragsthemen die maßgeblichen Interessen der U.S. Armee an den deutschen Ostfront-Erfahrungen wieder: Hellmut Schultze referierte beispielsweise zum Thema Russian Partisans. Their Operations and German Countermeasures. ${ }^{513}$ Günther Reichhelm hielt

an den Commanding General, Continental Army Command, Fort Monroe, VA, betr: German Lecturers for Army Service Schools in Fiscal Year 1957, 23. 4. 1956, in: NARA, RG 319, Box 5, Folder 7.

508 Barta, German Lecturers for Army Service Schools in Fiscal Year 1957, 23. 4. 1956, in: NARA, RG 319, Box 5, Folder 7.

${ }^{509}$ Robert M. Kennedy, Report of Activity, Foreign Studies Branch (1.-30.4.1955), in: NARA, RG 319, Box 11, Monthly Progress Reports 1955; Paul M. Robinett, Progress Report for Special Studies Division (2.3.-3.4.1955), in: NARA, RG 319, Box 11, Monthly Progress Reports 1955; William F. Hintz, Report of Activities, Foreign Studies Branch, 1.-30.9. 1956, in: NARA, RG 319, Box 12, Monthly Progress Reports 1956; Ders., Report of Activities for Foreign Studies Branch (1.-31.12. 1956), in: NARA, RG 319, Box 12, Monthly Progress Reports 1956; Barta, German Lecturers for Army Service Schools in Fiscal Year 1957, 23.4. 1956, in: NARA, RG 319, Box 5, Folder 7; Guest Lecture Program for Fiscal Year 1958 [o. D.], in: NARA, RG 319, Box 6, Folder 1; vgl. auch Franz Halder, Halbjahresbericht der Control Group für die Zeit vom 1. Juli bis 31. Dezember 1953, in: BArch, ZA 1/1842; Halbjahresbericht der Control Group für die Zeit vom 1. Januar bis 30. Juni 1955, in: BArch, ZA 1/1845; Halbjahresbericht der Control Group für die Zeit vom 1. Januar bis 30. Juni 1956, in: BArch, ZA 1/1847.

${ }^{510}$ Halder, Halbjahresbericht der Control Group für die Zeit vom 1. Juli bis 31. Dezember 1953, in: BArch, ZA 1/1842.

511 Franz Halder, Schreiben an Alfred Toppe, 9. 3. 1953, in: BArch, N 220/203.

512 Halder, Halbjahresbericht der Control Group für die Zeit vom 1. Juli bis 31. Dezember 1953, in: BArch, ZA 1/1842; vgl. auch Franz Halder, Tagesnotizen aus der Zeit der Control Group, August 1954 bis September 1955, in: BArch, N 220/110; Ders., Tagesnotizen aus der Zeit der Control Group, Oktober 1955 bis Oktober 1956, in: BArch, N 220/111; Ders., Tagesnotizen aus der Zeit der Control Group, Oktober 1956-Oktober 1957, in: BArch, N 220/112; Ders., Tagesnotizen aus der Zeit der Control Group, Oktober 1957-Juni 1958, in: BArch, N 220/113.

513 Barta, German Lecturers for Army Service Schools in Fiscal Year 1957, 23. 4. 1956, in: NARA, RG 319, Box 5, Folder 7. 
wiederholt Vorträge zum Thema The Russian Soldier, in dem er auf „die geschichtliche und geistige Entwicklung des russischen Volkes“ einging, dessen „ethnologische Struktur" analysierte und basierend auf seiner persönlichen Erfahrung und Berichten ehemaliger Kriegsgefangener die „russischen Charaktereigenschaften“ beschrieb, bevor er auf die „Kampfqualitäten des russischen Soldaten“ zu sprechen kam. ${ }^{514}$ Im Falle von Frido von Senger und Etterlin konnten die Service Schools aus drei Vorträgen wählen: Der Deutsche referierte entweder zum Scheitern von Entlastungsoperationen, Rückzugsgefechten während des Rückzugs von Stalingrad oder Panzerdivisionen im Übergang von Rückzug zu Gegenoffensive. ${ }^{515}$ Hasso Freiherr von Puttkamer, der erst im Herbst 1955 aus sowjetischer Gefangenschaft freigekommen war, hielt Vorträge zu russischen Verhörmethoden und Techniken zur ideologischen Indoktrinierung von Kriegsgefangenen. ${ }^{516}$ Friedrich von Boetticher schließlich bot einen Vortrag zum Stellenwert des Bodenkrieges in der nationalen Strategie an, den er auch an Einrichtungen der U.S. Air Force hielt. ${ }^{517}$

Die Deutschen kamen in der Regel mit einem guten Gefühl aus den Vereinigten Staaten zurück. Hellmuth Schultze berichtete Franz Halder nach einer seiner Vortragsreisen im März 1955 zum Beispiel, dass die Aufnahme „überall sehr herzlich“ gewesen sei; man scheine „die Leistungen des deutschen Soldaten und vor allem Methode, Kenntnisse und Überlegenheit des deutschen Generalstabs [in den USA] sehr zu schätzen“.518 Schultze hatte den Eindruck, dass sein „Vortrag bei allen neuen Waffenschulen gut gefallen ha[be und] das Interesse [...] groß“ gewesen sei, denn in der anschließenden Diskussion hätten die amerikanischen Offiziere „eifrig gefragt“.519 Auch die Vorlesungen von Frido von Senger und Etterlin kamen offensichtlich gut bei den U.S. Militärs an. Zumindest schrieb der Kommandeur der Armored School in Fort Knox, Major General John L. Ryan, im Januar 1957 an den Deutschen:

„I wish to express my appreciation for your fine presentation [...]. The students and members of the Staff and Faculty [of the U.S. Army Armored School] who attended your lecture received a thought-provoking and interesting discourse which I am certain contributed to their professional growth. ${ }^{" 520}$

Nachdem sich die ersten Vorträge ehemaliger deutscher Offiziere in den Vereinigten Staaten als Erfolg erwiesen hatten, zog die Historical Division in Europa nach

514 Ebd.; Robinett, Progress Report for Special Studies Division (2.3.-3.4. 1955), in: NARA, RG 319, Box 11, Folder: Monthly Progress reports 1955; Kennedy, Report of Activity, Foreign Studies Branch (1.-30.4.1955), in: NARA, RG 319, Box 11, Folder: Monthly Progress Reports 1955.

515 Guest Lecture Program for Fiscal Year 1958, [o. D.], in: NARA, RG 319, Box 6, Folder 1; Barta, German Lecturers for Army Service Schools in Fiscal Year 1957, 23.4. 1956, in: NARA, RG 319, Box 5, Folder 7.

516 Barta, German Lecturers for Army Service Schools in Fiscal Year 1957, 23. 4. 1956, in: NARA, RG 319, Box 5, Folder 7.

517 Guest Lecture Program for Fiscal Year 1958 [o. D.], in: NARA, RG 319, Box 6, Folder 1.

518 Hellmuth Schultze, Schreiben an Franz Halder, 12.3. 1955, in: BArch, N 220/79.

519 Ebd.

520 Commanding General Fort Knox Major General John L. Ryan Jr., Schreiben an Frido von Senger und Etterlin, 13.2. 1957, in: NARA, RG 549, Box 1155, Folder 3. 
und bot den in Deutschland stationierten U.S. Truppen ab Oktober 1952 ähnliche Vorträge an. ${ }^{521}$ Im Dezember 1952 referierte als erster der ehemalige Generalleutnant Fritz Bayerlein vor Offizieren und Unteroffizieren der $2^{\text {nd }}$ Armored Division in Bad Kreuznach über den Strategische[n] Einsatz von Panzern und taktische Erfahrung der 3. Panzerdivision in Russland 1943. Ihm folgte im Januar 1953 Frido von Senger und Etterlin; und auch im Februar und März sollten ehemalige Wehrmachtsoffiziere in Bad Kreuznach sprechen. ${ }^{522}$ Die Offiziere der $2^{\text {nd }}$ Armored Division nahmen die Vorlesungsreihe „enthusiastisch“ auf. ${ }^{523}$ Gegenüber dem Commander in Chief der U.S. Armee in Europa stellte die Führung der Division fest:

„These lectures are of great value to the commanders of this Division at all echelons. The professional competence of speakers added to [the] significance of the subjects to personnel of this Division makes these presentations invaluable. Our knowledge of Russian tactics and military concepts is neither thorough nor extensive. In effect, these talkers are a live training aid and as such have far more impact than all the available literature in subjects combined. There is no better way for the junior officers and NCOs of this division to understand characteristics of their counterparts in the Russian Army, how they function, how they think, and how they fight." ${ }^{24}$

Angesichts des „wesentlichen“ Gewinns, den die Hörer aus den Ausführungen der Deutschen ziehen könnten, ${ }^{525}$ schlug Colonel L. C. Shea, Chief of Staff der Division, vor, die Vortragsreihe zu institutionalisieren. ${ }^{526}$ Nicht nur die $2^{\text {nd }}$ Armorded Division, sondern auch zahlreiche weitere Trainings- und Fortbildungseinrichtungen der U.S. Armee machten in den folgenden Monaten vom Vortragsangebot der ehemaligen Wehrmachtselite Gebrauch. So hielten beispielsweise Frido von Senger und Etterlin und Anton von Bechtolsheim im März bzw. April 1953 Vorträge vor 400 Offizieren der Officers' School in Kaiserslautern. ${ }^{527}$ Auch die amerikanische 7. Armee sowie das Tank Training Center, die Intelligence and Military

${ }^{521}$ Rudolf Hofmann, Schreiben an Hans W. Helm, 7. 10. 1952, in: NARA, RG 549, Box 1143, Folder 1.

522 Ebd.; Hans W. Helm, Schreiben an die G-2 Section, $2^{\text {nd }}$ Armored Division, 13. 10. 1952, in: NARA, RG 549, Box 1143, Folder 1; AC of S Lieutenant Colonel Haymond G. Jones, Hq. $2^{\text {nd }}$ Armd Div, Schreiben an Hans W. Helm, 17. 10. 1952, in: NARA, RG 549, Box 1143 , Folder 1.

523 Schreiben des Hq. ${ }^{\text {nd }}$ Armored Division an CINCUSAREUR [o. D., vermutlich Sommer 1953], in: NARA, RG 549, Box 1149, Folder 2.

524 Ebd.

525 Colonel L. C. Shea, Schreiben an den Commander in Chief, USAREUR betr.: Guest Speaker Program, 29.4.1953 in: NARA, RG 549, Box 1149, Folder 3. Originalzitat: "There is no doubt that members of the 2nd Armored Div[ision] who attended lectures of this series benefited materially and that the project was worthy done."

526 Ebd.

527 Ass. Adjutant R. B. Peacock, Hq. Western Area Command, Schreiben an den Commander-in-Chief, Hq. USAREUR, Historical Division, 12.2. 1953, in: NARA, RG 549, Box 1149, Folder 3; Hans W. Helm, Schreiben an Major Nash, Hq. Western Area Command, 18. 2. 1953, in: NARA, RG 549, Box 1149, Folder 3; Ders., Schreiben an Hq. Western Area Command, 17.3. 1953, in: NARA, RG 549, Box 1149, Folder 3. Von Senger und Etterlin referierte über Panzeroperationen in Russland, Bechtolsheims Vortrag trug den Titel „Joint and Combined Planning and Operations with Examples from Axis Strategy in World War II“. 
Police School und die USAREUR Engeneer School engagierten deutsche Gastdozenten. ${ }^{528}$

Die europäische Historical Division reagierte auf die große Nachfrage nach deutschen Gastreferaten und stellte im Laufe des Frühjahrs und Sommers 1953 ein rasch wachsendes Vortragsprogramm zusammen, aus dem die amerikanischen Trainingseinrichtungen je nach Bedarf auswählen konnten. Neun ehemalige deutsche Offiziere, darunter Anton von Bechtolsheim, Frido von Senger und Etterlin und Leopold Bürkner, boten Vorträge zur Partisanenbekämpfung, zum Nachtkampf, der Koalitionskriegführung, zu Kesselschlachten, zur Entwicklung der russischen Artillerie- und Panzertaktik sowie zum Einfluss von Wetter und Terrain auf die Operationsführung in der Sowjetunion an. ${ }^{529}$

Wie das Beispiel der $2^{\text {nd }}$ Armored Division zeigt, waren die Reaktionen der Amerikaner auf die deutschen Vorträge in der Regel sehr positiv. ${ }^{530}$ Und als die Direktive für das historische Programm der U.S. Armee in Europa im November 1955 aktualisiert wurde, fand die Bereitstellung ehemaliger deutscher Offiziere für Gastvorträge an Trainingseinrichtungen und Schulen der U.S. Armee in den Vereinigten Staaten und Europa sogar Eingang in die Missionsbeschreibung des Foreign Military Studies Program. ${ }^{531}$ Dennoch gab es gelegentlich auch Kritik an einzelnen Vorträgen und Dozenten. So beurteilte der Kommandant der USAREUR Intelligence and Military Police School in Oberammergau, Colonel C. H. Ott, im September 1953 einen Vortrag von Anton von Bechtolsheim zwar ins-

528 Verne E. Pate, Schreiben an Commanding General, Hq. Seventh Army, 19. 3. 1953, in: NARA, RG 549, Box 1149, Folder 3; Captain Edwin S. Harrison, Adjutant Hq. Tank Training Center, Schreiben an Commanding General USAREUR, attn. Historical Division, Col. H. W. Helm, 4. 4. 1953, in: NARA, RG 549, Box 1140, Folder 3; Schreiben der Historical Division an das Hq. Tank Training Center, 10.4.1953, in: NARA, RG 549, Box 1140, Folder 3; Verne E. Pate, Schreiben an die Intelligence and Military Police School, Hq. USAREUR, 12.5. 1953, in: NARA, RG 549, Box 1149, Folder 3; Captain Edward L. Wright, Schreiben an den Chief, Historical Division, USAREUR, betr. Lectures by Former German Officers, 31.7. 1953, in: NARA, RG 549, Box 1149, Folder 2.

529 Verne E. Pate, Schreiben an Commanding General, Hq. Seventh Army, att. Mr. Kelly, Historical Section: Lectures by former German Officers, 17.6.1953, in: NARA, RG 549, Box 1149, Folder 3; Ders., Schreiben an die Engineer School, attn. Captain Stapula: Lectures by former German Officers, 8. 7. 1953, in: NARA, RG 549, Box 1149, Folder 2 .

530 Als weiteres Beispiel der positiven Reaktion auf die deutschen Vorträge sei hier die Beurteilung eines Vortrags des ehemaligen Oberstleutnants Schwerdtfeger zu sowjetischen Kampftaktiken genannt: „It was objective, factual, and illustrated with pertinent examples. The subject matter was timely and interesting and shed additional light on the Soviet soldier, the Soviet High Command, Soviet Tactics, and the evolution of Soviet concepts in military operations. The speaker had a good command of English, and his manner of delivery of the presentation was excellent. Many students commented on the talk, and the staff felt that Colonel Schwerdtfeger was one of the best speakers we have had from the Historical Division." Siehe Colonel C. H. Ott, Schreiben an Commanding General, U.S. Army Europe, attn. Historical Division, betr. Critique of Guest Speaker, 23. 11. 1953, in: NARA, RG 549, Box 1149, Folder 2.

531 Schreiben des Department of the Army, Office of the Adjutant General to Commander-in-Chief, U.S. Army Europe, betr. Historical Program, United States Army Europe, 22. 11. 1955, in: NARA, RG 319, Box 10, Folder 9. 
gesamt als „interessant und wertvoll für die Studenten“, wies aber gleichzeitig darauf hin, dass Bechtolsheim „einige Tendenzen zeigte, Hitlers militärische Fehler zu entschuldigen“.532 Darüber hinaus habe er „mehrmals versucht, bestimmte politische Maßnahmen der Nazi-Führung zu rechtfertigen".533

Als Hasso Neitzel Ende Oktober 1953 in Oberammergau zum Thema German Military Government in the USSR dozierte, fiel Otts Kritik sogar noch deutlicher aus: Er hielt den Vortrag für „unbefriedigend“, da Neitzel „viele wesentliche Aspekte“ wie „die generellen Ziele der [deutschen] Militärregierung und Besatzung, die Misshandlung von Kriegsgefangenen [und] die Vernichtung der Juden und Slaven" ausgelassen habe. Auch eine Erklärung für das Scheitern der deutschen Besatzungspolitik habe gefehlt. ${ }^{534}$ Zudem seien mehrere von Neitzels Aussagen, wie zum Beispiel jene, dass „die deutsche Militärregierung internationales Recht befolgt" habe oder dass „der Bevölkerung materielle Hilfe geleistet“ worden sei, irreführend gewesen. ${ }^{535}$ Trotz dieser Kritik stellte aber auch Ott die Vorträge ehemaliger Wehrmachtsgeneräle an amerikanischen Militärschulen nicht grundsätzlich in Frage, sondern sprach sich für eine Fortsetzung der Vortragsreihe aus. ${ }^{536}$

\subsection{Einfluss auf die operative Doktrin der U.S. Armee}

Die in den vorangegangenen Absätzen erläuterten Beispiele haben gezeigt, dass die Expertise der ehemaligen Wehrmachtselite in Form ihrer kriegsgeschichtlichen Studien und Vorträge an den Militärschulen des amerikanischen Heeres in den USA und bei den Trainingseinrichtungen der U.S. Armee in Europa in der ersten Hälfte der 1950er Jahre gerne genutzt wurde. Spielte die deutsche OstfrontErfahrung jedoch auch eine Rolle bei der Weiterentwicklung der amerikanischen Operationsgrundsätze? Die Beantwortung dieser Frage erfordert es, ein wenig auszuholen und näher auf die Entwicklung der Verteidigungsdoktrin des amerikanischen Heeres nach 1945 einzugehen.

Die Tatsache, dass die Vereinigten Staaten und die Sowjetunion als die zwei verbliebenen und zunehmend antagonistischen Weltmächte aus dem Zweiten

532 Ders., Schreiben an den Kommandierenden General von USAREUR, attn. Historical Dvision, betr. Critique of Guest Speaker, 29. 10. 1953, in: NARA, RG 549, Box 1149, Folder 2. Originalzitat: The presentation ,was of definite interest and value to the students of the course. [...] He showed some tendency to be apologetic for Hitler's military failures."

533 Ebd. Originalzitat: „In several instances he also tried to justify certain political measures on the part of the Nazi leadership."

534 Ders., Schreiben an den Kommandierenden General von USAREUR ber. Critique of Guest Speaker, 10. 11. 1953, in: NARA, RG 549, Box 1149, Folder 2. Originalzitat: „[T] he presentation was considered unsatisfactory for the following reasons: Many vital topics were omitted; the general aims of the Military Government and the occupation; mistreatment of prisoners of war; extermination of Jews and Slavs; and the explanation for the failure of the occupation policy."

535 Ebd. Originalzitat: „A number of statements were misleading; the assertion that the German Military Government abided by the International Law; $[. .$.$] and that material$ aid was rendered to the population."

536 Ebd. 
Weltkrieg hervorgegangen waren, schlug sich nach 1945 zunehmend auch in der offiziellen Operationsdoktrin der U.S. Armee nieder. Die technologische Entwicklung und der sich verschärfende Wettbewerb mit der UdSSR um die globale Vorherrschaft bedeuteten, dass die Amerikaner sich in Zukunft nicht mehr sorglos auf ihren eigenen Kontinent zurückziehen konnten. Anders als noch nach dem Ersten Weltkrieg war die Sicherheit und machtpolitische Position der USA nun aufs Engste mit dem Schicksal Europas verbunden. Die Eroberung Westeuropas durch die Sowjetunion hätte auch die Amerikaner schwer getroffen, die auf die europäischen Luftwaffenstützpunkte angewiesen waren, um ihre Atomwaffen gegen die Sowjetunion zum Einsatz zu bringen. Die Verteidigung Westeuropas gegen jegliche sowjetische Aggression wurde somit zur wichtigsten strategischen Herausforderung der U.S. Armee. ${ }^{537}$

Allerdings stellte dieser Umstand die Strategen der U.S. Armee vor ein nicht unerhebliches Problem. Da die Operationen der U.S. Truppen im Zweiten Weltkrieg vor allem offensiv angelegt gewesen waren, hatte die Verteidigung in der allgemeinen operativen Doktrin der Landstreitkräfte, die in den Field Service Regulations: Operations (FM 100-5) niedergelegt waren, keine große Rolle gespielt. Die 1944 erschienene und bis 1949 gültige Version dieser Operationsgrundsätze behandelte Defensivoperationen deshalb recht stiefmütterlich und sah für den Verteidigungsfall lediglich die Bildung befestigter Kampfpositionen vor, die mit allen Mitteln gehalten werden sollten; außerdem sollten Infanterieeinheiten im Vorfeld dieser festen Verteidigungsareale den Vormarsch des Gegners verzögern. ${ }^{538}$ Tatsächlich orientierten sich die Amerikaner in ihren strategischen Planungen bis 1948 an Szenarien, die denen des Zweiten Weltkrieges sehr ähnelten. Demnach würden Mittel- und Westeuropa zunächst weitgehend der Roten Armee überlassen und erst nach einer atomwaffengestützten strategischen Luftoffensive gegen sowjetische Ziele in einer dritten Kriegsphase zurückerobert werden. Erst ab 1948 modifizierten die Amerikaner ihre Verteidigungsstrategie in Bezug auf Europa und wollten nun versuchen, Westeuropa entlang des Rheins zu verteidigen und den sowjetischen Vormarsch so lange wie möglich hinauszuzögern. ${ }^{539}$

Da der amerikanische Strategiewechsel hin zu einer solchen Vorwärtsverteidigung wohl zu spät kam, um Eingang in die 1949 erschienene Überarbeitung von FM 100-5 zu finden, betonte die Operationsdoktrin der U.S. Armee zunächst weiterhin vor allem die Offensive. Defensive Operationen dienten demnach vor allem dazu, „Zeit zu gewinnen, bis sich günstigere Bedingungen für eine Offensive“ ergäben, oder dazu, die Truppen an einer Stelle der Front zu reduzieren, um sie an anderer Stelle für wichtigere (Offensiv-) Operationen einsetzen zu können. ${ }^{540}$ Wie bisher setzte man weiterhin auf die Verteidigung gut ausgebauter taktischer

537 Soutor, To Stem the Red Tide, S. 660-661.

538 Walters, Mobile Defense, S. 5-6.

539 Vgl. zur amerikanischen Militärstrategie ausführlicher oben, Teil III, Kapitel 2.1.

540 Department of the Army (Hg.), FM 100-5, Field Service Regulations: Operations, 1949, S. 120. Originalzitat: „The general objective of defensive combat is to gain time pending the development of more favorable conditions for undertaking the offensive, or to economize forces on one front for the purpose of concentrating superior forces for a decisive action elsewhere." 
Positionen entlang einer klar definierten Hauptverteidigungslinie. ${ }^{541}$ Eine mobile und flexible, auf Panzerkräften fußende Verteidigung fand sich - nicht zuletzt aufgrund des haushaltsbedingten Mangels an gut ausgerüsteten motorisierten Verbänden - in dem Dokument nicht. ${ }^{542}$

Das Festhalten an dieser recht starren Verteidigungsstrategie war Ausdruck der relativen Unerfahrenheit der U.S. Armee mit langfristig angelegten Defensivoperationen. Ohne über entsprechende Erfahrungen aus dem letzten Krieg zu verfügen, sahen sich die amerikanischen Strategen vor die Aufgabe gestellt, Pläne zu entwickeln, um die numerisch weit überlegene Rote Armee so lange wie möglich aufzuhalten und den NATO-Staaten somit Gelegenheit zu geben, ihr militärisches und wirtschaftliches Potential voll zu mobilisieren. ${ }^{543}$ In dieser Situation kam die von Frank C. Mahin beworbene „Erfahrungsbank“ der Historical Division ins Spiel - schließlich stand der U.S. Armee über die deutschen kriegsgeschichtlichen Studien die Expertise der Wehrmacht zur Verfügung, die sich erst jüngst gegenüber der Roten Armee in der Defensive gesehen und den Vormarsch der Sowjets nach Westen ab 1943 immerhin über zwei Jahre hinweg hinausgezögert hatte. Tatsächlich stieg ab 1948 die Nachfrage der U.S. Armee nach deutschen Studien zur Ostfront. Wie ein Blick auf die Liste der als DA-Pamphlets und Foreign Military Studies veröffentlichten Manuskripte zeigt, fanden vor allem solche Studien weite Verbreitung, die Beispiele für Defensivoperationen gegen die Rote Armee lieferten. Die DA-Pamphlets behandelten zum Beispiel Deutsche Maßnahmen gegen russische Durchbrüche (MS \# T-10 bzw. DA-Pamphlet 20-233); das Zurückkämpfen eingekesselter Verbände zur eigenen Front (MS \# T-12 bzw. DA-Pamphlet 20-234); und die Improvisation als Mittel der Führung im Russlandfeldzug (MS \# T-21 bzw. DA-Pamphlet 20-201). ${ }^{54}$

Sowohl Christian Greiner als auch Kevin Soutor sind überzeugt, dass die deutschen Studien einen nicht unbedeutenden Einfluss auf die Verbreitung des Konzeptes einer beweglichen Verteidigung in der U.S. Armee gehabt haben. ${ }^{545}$ Tatsächlich betonten die deutschen Offiziere in ihren Studien immer wieder die Notwendigkeit, den numerisch überlegenen sowjetischen Truppen durch eine mobile Verteidigung zu begegnen. Mit Blick auf den militärischen Charakter eines künftigen Krieges machte zum Beispiel Günther Blumentritt deutlich, dass das starre Festhalten an dünn besetzten Linien sinnlos sei. Der Zweite Weltkrieg, so Blumentritt, habe gezeigt, dass eine weitgestreckte und somit nur dünn be-

${ }^{541}$ Ebd., S. 127-128. Dort heißt es wörtlich: „The defense is built around a series of organized and occupied tactical localities. These tactical localities are selected with consideration for their observation and natural defense strength so that their retention will insure the integrity of the position. The main battle position comprises a zone of resistance consisting of a number of mutually supporting defense areas disposed irregularly in width and depth, each organizes for all around defense with trenches, fox holes, obstacles, and emplacements. Tactical unity is maintained in each defensive area."

542 Vgl. auch Soutor, To Stem the Red Tide, S. 666-667.

543 Ebd., S. 669.

544 Vgl. ebd., S. 674-675.

545 Greiner, „Operational History (German) Section“ und „Naval Historical Team“, S. 422; Soutor, To Stem the Red Tide, S. 658, S. 663-664, S. 669-670 und S. 672. 
setzte Verteidigungslinie - wie die Deutschen versucht hatten, sie von Leningrad bis auf die Krim zu spannen - nicht gehalten werden könne. Für eine solche Verteidigung bedürfe es einer enormen Anzahl an Soldaten - eine Masse, die den Westmächten schlicht nicht zur Verfügung stehe. Deshalb müsse man in Zukunft auf eine mobile Verteidigung im großen Raum setzten. Moderne Verteidigung, da war sich Blumentritt sicher, zeichne sich nicht durch durchgehende Verteidigungslinien, sondern durch mobile Kräfte aus. ${ }^{546}$

Auch wenn sich die Wirkungsweise der Studien auf die Entwicklung der amerikanischen Verteidigungsstrategie letztlich nicht exakt bestimmen lässt, scheint die Annahme, dass die Strategen der U.S. Armee sich bei der Anpassung ihrer Verteidigungsstrategie an die Gegebenheiten des Kalten Krieges auch an den in den kriegsgeschichtlichen Studien niedergelegten Empfehlungen der ehemaligen Wehrmachtselite orientierten, durchaus plausibel. Der sich ab Ende 1949 allmählich abzeichnende Wandel in der amerikanischen Verteidigungsdoktrin basierte wohl nicht zuletzt auf der Grundlage der deutschen Erfahrungen im Zweiten Weltkrieg. Nachdem FM 100-5 (1949) noch die althergebrachte Verteidigung von Befestigungsanlagen propagiert hatte, war in der nur wenige Monate später erschienenen Operationsdoktrin für Panzerdivisionen (FM 17-100, Dez. 1949) erstmals auch von der Möglichkeit einer mobilen Verteidigung die Rede, die darauf abzielen sollte, die große Feuerkraft und Beweglichkeit der Panzerverbände auszunutzen. ${ }^{547} \mathrm{Da}$ sicher schien, dass die numerische und ausrüstungstechnische Unterlegenheit der konventionellen amerikanischen und europäischen Bodentruppen angesichts der finanziellen Bevorzugung der Luftwaffe auch in absehbarer Zukunft bestehen bleiben würde, eigneten sich die Strategen der U.S. Armee dann Anfang der 1950er Jahre das Konzept der mobilen Verteidigung mehr und mehr an. Immerhin schien eine solche Strategie wenigstens die Chance zu bieten, im Kriegsfall den Vormarsch der Roten Armee und ihrer Verbündeten zumindest zu verlangsamen. ${ }^{548}$

Amerikanische Offiziere betonten deshalb immer wieder die Bedeutung einer mobilen Verteidigungsstrategie für Europa. In einem Artikel aus dem Military Review vom Mai 1951 hieß es zum Beispiel: „Because of inadequate ,forces in being‘, Phase I of any future war will find us, initially, on the defensive. To contain any

546 Günther Blumentritt, MS \# B-681. The Military Aspect of a Future War, 29. 10. 1947, S. 17-18, in: NARA, RG 549, Box 50, Folder: B-681; vgl. auch Ders., MS \# B-647. Gedanken eines ehemaligen Soldaten: über die Strategie, die Politik und Psychologie des Krieges 1939-1945, S. 35, in: NARA, RG 549, Box 48, Folder: B-647; siehe zur Bedeutung mobiler Verteidigung auch Bodo Zimmermann, MS \# C-040. Ideas on the Defense of the Rhine and Western Germany as an Outpost Area of Western Europe, 10. 12. 1948, in: NARA, RG 549, Box 65.

547 Soutor, To Stem the Red Tide, S. 668-669.

548 Robert J. Hoffman, Mobile Defense, in: Military Review 31 (1951), S. 47; vgl. auch DeReus, The Defense of Tomorrow?, in: Military Review 34 (1954), S. 8-12. DeReus schreibt auf S. 9: „It is accepted that we must plan for provision of a force operating under defensive missions to gain time to permit starting the wheels of industry and to crystallize the thinking of a people to support an all-out war. This defensive mission must be carried out with limited troops in broad frontages. The time gained will govern the continued stand or fall of a nation and an ideal." 
aggressor, therefore, we must be familiar with the techniques of conducting a mobile defense. " 549 Die Existenz der westlichen Alliierten, so der Autor weiter, könne von der erfolgreichen Anwendung einer mobilen Verteidigungsstrategie abhängen. Es liege daher in der Verantwortung des Militärs, sich mit dieser Strategie vertraut $\mathrm{zu}$ machen und entsprechende Methoden und Techniken zu entwickeln. ${ }^{550}$

Auch der Kommandant der Infantery School machte sich für die Adaption einer mobilen Verteidigungsstrategie stark. In einem Schreiben an den Leiter des Command and General Staff College machte er seine Position folgendermaßen deutlich:

„A need exists for a different concept of defense in the infantry. Virtually all analyses of future warfare agree on two points. First, that the United States and its allies will be forced, in any future war, on the defensive. Secondly, an attempt to man any projected defensive line across Europe, using the position-type defense concept, will be impossible because of the large number of troops required for such an undertaking. Sufficient troops are not available now, and probably will not be available in the future for a position defense. Wider sectors need to be defended with the troops available." 551

Um die Notwendigkeit einer mobilen Verteidigungsstrategie im Kampf gegen die Rote Armee zu unterstreichen, griffen die Lehrbeauftragten am CGSC immer wieder auch auf Beispiele aus den deutschen Studien zur Ostfront zurück. So fasste beispielsweise der Dozent für Infanterie-Taktik, Colonel Lloyd M. Marr, Hasso Neitzels Studie Rear Area Security 1951 in einem kompakten Artikel im Military Review zusammen. ${ }^{552}$ Einen Monat später veröffentlichte die Zeitschrift einen Aufsatz des Dozenten für Artillerie-Taktik, Colonel Henry D. Lind, in dem dieser versuchte, eine vorläufige Doktrin für den Ausbruch eingekesselter Truppen zu entwickeln. Als Beispiel führte er unter anderem zwei Fälle an, die Oldwig von Natzmer in seiner Studie Operations of Encircled Forces: German Experiences in Russia erläutert hatte: die Kesselschlacht der deutschen 1. Panzer-Armee bei Kamenez-Podolski in der Westukraine im März/April 1944 und der Ausbruch des XI. und des XLII. Armeekorps aus dem Kessel westlich der ukrainischen Stadt Tscherkassy im Februar 1944. ${ }^{553}$ Im Juli 1952 zitierte Colonel William H. Bed-

549 Hoffman, Mobile Defense, S. 47.

550 Ebd., S. 56. Originalzitat: „The very existence of the Western Allies may be dependent upon the successful application of the principles of conducting a mobile defense. It is incumbent upon us, the military, to become familiar with this application, and to be alert to the possibility of developing methods or techniques by which it may be improved."

551 U.S. Army Mobile Defense, Position Paper from the Infantry School Commandant to the Commandant of CGSC, Ft. Benning, GA, 1.9. 1954, zit. nach Walters, Mobile Defense, S. 8.

552 Lloyd M. Marr, Rear Area Security, in: Military Review 31 (1951), S. 57-62.

553 Henry D. Lind, Break-Out from Encirclement, in: Military Review 31 (1951), zur Kesselschlacht bei Kamenets-Podolskiy siehe S. 51-53, zum Ausbruch bei Cherkassy S. 5356; siehe im Vergleich zu Lind Department of the Army (Hg.), DA-Pamphlet 20-234: Operations of Encircled Forces: German Experiences in Russia, S. 43-53 (Beispiel Kamenets-Podolskiy) und S. 15-42 (Beispiel Cherkassy); das deutsche Original liegt in Freiburg: Oldwig von Natzmer u. a., MS \# T-12. Das Zurückkämpfen eingekesselter Verbände zur eigenen Front, in: BArch, ZA 1/2346. 
ford, ebenfalls Dozent für Artillerie-Taktik am CGSC, in einem weiteren Artikel im Military Review mehrere Seiten aus Erhard Raus' Studie German Defense Tactics against Russian Break-Throughs und argumentierte auf dieser Grundlage für frontale Gegenangriffe als Alternative zu den von der amerikanischen Doktrin favorisierten Gegenangriffen auf die Flanken des Feindes. ${ }^{554}$ Im November 1952 zitierte der Dozent für Panzer-Taktik am CGSC, Lieutenant Colonel William R. Desobry, ebenfalls aus Raus' Studie. ${ }^{555}$

Wie sehr die Expertise der ehemaligen Wehrmachtselite Anfang der 1950er Jahre in der Frage der Weiterentwicklung der amerikanischen Operationsdoktrin gefragt war, zeigte sich, als die Control Group schließlich im Februar 1952 gebeten wurde, im Rahmen der anstehenden Revision von FM 100-5 die bis dahin gültige Version der operativen Doktrin (FM 100-5, 1949) zu evaluieren und Verbesserungsvorschläge zu unterbreiten. Der Gedanke, die Deutschen an der Revision von FM 100-5 zu beteiligen, war während des ersten Besuches von Anton von Bechtolsheim in den Vereinigten Staaten vom damaligen Chief of Military History, Orlando Ward, an die Deutschen herangetragen worden. ${ }^{556}$ Ward kontaktierte dann den Deputy Chief of Staff for Operations and Administration in der Angelegenheit, der ein solches Projekt ebenfalls für lohnenswert hielt. Die als geheim eingestufte Operationsdoktrin sollte für ausgewählte Deutsche zugänglich gemacht werden, die das Dokument dann vor dem Hintergrund der früheren deutschen Doktrin und auf Grundlage ihrer eigenen Erfahrung sorgfältig prüfen und Änderungen, Streichungen oder Ergänzungen vorschlagen sollten. ${ }^{557}$ Anfang März 1952 besprach schließlich der Chef der europäischen Historical Division, Wilbur S. Nye, das Projekt mit Franz Halder. Glaubt man Nyes Worten, so fühlte sich der ehemalige Generalstabschef so geehrt von dem Auftrag, dass er sogar „ein wenig schluchzte“;558 und tatsächlich erfüllte es Halder „mit einer gewissen Befriedigung “, dass die U.S. Armee den deutsche Generalstab offensichtlich als „unerreichten Sachverständigen“ betrachtete. ${ }^{559}$ Halder fühlte sich nicht zu Unrecht geehrt - denn indem sie die deutschen Offiziere beauftragten, die Operationsdoktrin der U.S. Armee zu evaluieren, gaben die Amerikaner Franz Halder und seinen Mitarbeitern die Möglichkeit, direkten Einfluss auf die operative Ausrichtung der U.S. Armee zu nehmen. ${ }^{560}$

554 William H. Bedford, Counterattack - Flanks or Nose?, in: Military Review 32 (1952), S. 24-31; vgl. Department of the Army (Hg.), DA-Pamphlet No. 20-233: German Defense Tactics against Russian Break-Throughs, S.3-8; siehe auch Soutor, To Stem the Red Tide, S. 675-676.

555 William R. Desobry, Spoiling Attack, in: Military Review 32 (1952), S. 11-15; vgl. Department of the Army (Hg.), German Defense Tactics against Russian Break-Throughs, S. 15-19.

556 Orlando Ward, Schreiben an Wilbur S. Nye, 15.2.1952, in: NARA, RG 319, Box 8, Folder 8 .

557 Ders., Schreiben an den Deputy Chief of Staff for Operations and Administration, 14. 2. 1952, in: NARA, RG 319, Box 8, Folder 8; Ders., Schreiben an Wilbur S. Nye, 28. 2. 1952, in: NARA, RG 319, Box 8, Folder 8 .

558 W. S. Nye, Schreiben an Orlando Ward, 7. 3. 1952, in: NARA, RG 319, Box 8, Folder 8.

559 Franz Halder, Schreiben an Günther Blumentritt, 19. 4. 1952, in: BArch, N 252/8.

560 Soutor, To Stem the Red Tide, S. 676-677. 
Neben sich selbst wählte Halder schließlich Anton von Bechtolsheim, Alfred Zerbel, Hellmuth Schultze, die beiden ehemaligen Generäle der Infanterie Otto Stapf und Edgar Röhricht sowie den ehemaligen Generalleutnant Alfred Kretschmer für die Revision von FM 100-5 aus. In den kommenden 12 Monaten unterzogen sie die operative Doktrin der U.S. Armee einer umfassenden Prüfung und erarbeiteten einen ausführlichen Bericht mit zahlreichen detaillierten Kommentaren und Änderungsvorschlägen, den sie schließlich im April 1953 bei der Historical Division einreichten. Einer der Hauptkritikpunkte der Deutschen betraf die Tendenz der bisherigen amerikanischen Operationsdoktrin, alle Entwicklungen auf dem Schlachtfeld bis ins Detail vorhersehen und die Reaktion der kommandierenden Offiziere durch entsprechend detaillierte Vorschriften vorherbestimmen zu wollen. Jede einzelne Entscheidung, wie zum Beispiel das Zurückweichen in einem bestimmten Frontabschnitt, von der Genehmigung des direkten Vorgesetzten abhängig $\mathrm{zu}$ machen, sei nicht $\mathrm{zu}$ rechtfertigen und fördere nur die Unentschlossenheit der Truppenkommandeure: ${ }^{561}$

„The understandable effort to obtain as complete as possible a picture of the enemy and his intentions must not impair the ability to act boldly in situations which have not been clarified. What matters is the mission and the will to carry it out successfully. Flexibility in the selection of means and in execution is often necessary. " 562

Davon abgesehen bemängelten die Deutschen vor allem die starke Betonung, ja „Überbewertung“ der Offensive. ${ }^{563}$ In den Augen der Kommissionsmitglieder unterschätzte FM 100-5 die Verteidigung als eigenständige Kampfform, obwohl diese unter bestimmten Umständen durchaus einen Selbstzweck haben könne. Die vereinfachte Definition der Verteidigung als „passive“ und des Angriffs als „aktive“ Kampfform sei unzutreffend, schließlich zwinge man dem Feind auch durch defensive Operationen zumindest indirekt seinen Willen auf, indem man ihn zum Beispiel an der Erfüllung seiner Mission hindere:564

„To regard defense as merely an expedient to be resorted to in time of need is to underestimate its importance. Although the defender to a large extend surrenders the initiative, the defensive nevertheless is an independent form of combat. It is a method of conducting operations which can even be deliberately selected to break the spirit of an opponent greatly superior in strength and to force him, under the pressure of well-organized defensive force, to expend his striking power in men and material in terrain unfavorable for his purpose. ${ }^{\circ 565}$

Schließlich merkten die ehemaligen Wehrmachtsoffiziere in diesem Zusammenhang auch an, dass die amerikanische Doktrin sich zu sehr auf die Infanterie beschränke und die - vor allem für eine mobile Verteidigung so wichtige - Panzerwaffe kaum berücksichtige. Es sei „frappierend, dass die taktische Verwendung

561 Vgl. zum Beispiel Franz Halder u. a., Analysis of US Field Service Regulations, April 1953, S. 7, S. 9 und S. 31, in: CARL, MS \# P-133.

562 Ebd., S. 9.

563 Ebd., S. 9 und S. 16.

564 Ebd., S. 10.

565 Ebd., S. 67. 
von Panzereinheiten nicht erwähnt [werde], obwohl diese das schlagkräftigste und direkteste Angriffsmittel“ darstellten. ${ }^{566}$

Nachdem der knapp 150-seitige Bericht der deutschen „Expertenkommission“ ins Englische übersetzt worden war, sandte ihn die Historical Division Anfang November 1953 mit der Bitte um Stellungnahme an Brigadier General Einar Bernard Gjelsteen, den Chief of Staff der 7. U.S. Armee. ${ }^{567}$ Gjelsteen war an der Formulierung früherer Versionen von FM 100-5 beteiligt gewesen und konnte die Analyse und Anregungen der Deutschen deshalb besonders gut einschätzen. Außerdem bat die Historical Division auch Brigadier General Douglas V. Johnson, den Chef der Operations- und Planungsabteilung (G-3) im Generalstab der U.S. Armee in Europa (USAREUR) um seine Meinung. ${ }^{568}$ Die beiden amerikanischen Offiziere zeigten sich von der Analyse der deutschen Offiziere beeindruckt und waren überzeugt, dass sie wichtige Anregungen für die anstehende Revision von FM 100-5 liefere. ${ }^{569}$ Gjelsteen griff insbesondere den Hinweis auf die mangelnde Beachtung der Panzerwaffe auf und schloss sich der Meinung der Deutschen an, dass dieser Waffengattung in Zukunft mehr Raum in der Operationsdoktrin eingeräumt werden solle. ${ }^{570}$

Als die U.S. Armee 1954 eine aktualisierte Version von FM 100-5 veröffentlichte, schlug sich das in den vorangegangenen Jahren auch auf der Grundlage der deutschen Studien zunehmend salonfähig gewordene und von Halder und seinen Kollegen in ihrer Revision der Dienstvorschrift propagierte Konzept der mobilen Verteidigung schließlich in der offiziellen Operationsdoktrin nieder: Es erhielt nun einen gleichberechtigten Platz neben der Doktrin der Verteidigung ausgebauter Stellungen. ${ }^{571}$ Bewegliche Verteidigung, so das Handbuch, sei eine

„Verteidigungsmethode, bei der die vorgelagerten Verteidigungspositionen von möglichst wenigen Truppen besetzt werden, deren Aufgabe es ist, einen bevorstehenden Angriff zu melden und die angreifenden Truppen in für sie weniger günstiges Gelände zu kanalisie-

566 Ebd., S. 38, S. 43, S. 47 und S. 50, Zitat S. 38. Originalzitat: „It is striking that no mention is made of the tactical employment of armor, although this is the most powerful and direct means of attack."

567 Hans W. Helm, Schreiben an BG E. B. Gjelsteen, 4.11. 1953, in: NARA, RG 549, Box 1149, Folder: Correspondence 1953.

568 Ders., Internal Route Slip an ACofS G3, USAREUR, 4.11.1953, in: NARA, RG 549, Box 1149, Folder: Correspondence 1953.

569 E. B. Gjelsteen, Schreiben an Wilbur S. Nye, 27. 11. 1953, in: NARA, RG 549, Box 1149, Folder: Correspondence 1953; Douglass V. Johnson, Internal Route Slip an die Historical Division, USAREUR, 4.11.1953, in: NARA, RG 549, Box 1149, Folder: Correspondence 1953. Gjelsteen schrieb: „I am deeply impressed with the sound analysis which the authors have made. Our present FM 100-5 was written by officers who were fresh from the battle field. I personally believe that a revision of the field service regulations at this time would be very valuable. The Study MS \# P-133 should be a valuable source of material for the authors at Fort Leavenworth.“ Bei Johnson hieß es: „I have reviewed this document with interest. [...] I think the comments and suggestions made by the Germans may well be of value to those making the revision [of FM 100-5]."

570 Gjelsteen, Schreiben an Wilbur S. Nye, 27.11.1953, in: NARA, RG 549, Box 1149, Folder: Correspondence 1953.

571 Department of the Army (Hg.), FM 100-5. Field Service Regulations: Operations, 1954, S. 113; vgl. auch Walters, Mobile Defense, S. 11; Soutor, To Stem the Red Tide, S. 678. 
ren, während die Masse der verteidigenden Truppen in offensiven Aktionen eingesetzt wird, um den Feind zu einem Zeitpunkt und an einem Ort zu zerstören, der für die Verteidiger besonders günstig ist. " ${ }^{572}$

Schließlich wurden auch die Panzertruppen nun im Zusammenhang mit der mobilen Verteidigung explizit erwähnt. ${ }^{573}$

Wie die Verweise auf erfolgreiche mobile Verteidigungsoperationen der Wehrmacht gegen die Rote Armee im Military Review zeigen, fanden die deutschen Studien zum Krieg im Osten unter den Lehrbeauftragten des Command and General Staff College ein interessiertes Publikum. Dabei wurden vor allem Studien aufgegriffen, die Beispiele für bewegliche Verteidigung lieferten. Dass die Control Group mit einer Evaluation von FM 100-5 beauftragt wurde, ist ein weiterer deutlicher Hinweis darauf, dass die Erfahrungen der ehemaligen Wehrmacht Anfang der 1950er Jahre durchaus eine Rolle bei der Weiterentwicklung der amerikanischen Operationsdoktrin spielten. ${ }^{574} 1954$ hatte sich das Konzept der beweglichen Verteidigung schließlich so weit durchgesetzt, dass es einen festen Platz in den Field Service Regulations: Operations erhielt. Allerdings blieb dies ein theoretischer Triumph - denn die zur praktischen Umsetzung einer mobilen Verteidigung notwendigen Veränderungen in der Struktur der amerikanischen Bodentruppen blieb aus. Die Haushaltsbeschränkungen des New Look verhinderten den Auf- und Ausbau der Panzertruppen, die für die mobile Verteidigung so grundlegend waren. Angesichts knapper Finanzmittel einer- und der Forderung, zum Beispiel in Deutschland mehr Truppen zu stationieren, andererseits, entschied sich die U.S. Armee dafür, statt kostenintensiver Panzerdivisionen lieber mehr Infanterie-Divisionen aufzustellen. Die Kommandeure der U.S. Streitkräfte in Europa verfügten damit schlicht nicht über die entsprechenden Mittel, um eine bewegliche Verteidigung im Bedarfsfalls auch wirklich umsetzen zu können. Die Strategie der mobilen Verteidigung hatte es damit Mitte der 1950er Jahre zwar in die theorielastige Militärliteratur am Command and General Staff College und sogar in die Operationsdoktrin geschafft, in der praktischen Planung der europäischen Verteidigung blieb sie jedoch weitgehend ohne Relevanz. Denn zur gleichen Zeit, als mobile Verteidigung schließlich in FM 100-5 auftauchte, verlegte sich die Eisenhower-Administration mit dem New Look ganz auf eine Strategie der luftwaffengestützten massiven nuklearen Vergeltung, in der die Verteidigung Europas mit konventionellen Bodentruppen - mobil oder nicht - so gut wie keine Rolle

572 Department of the Army (Hg.), FM 100-5. Field Service Regulations: Operations, 1954, S. 120. Originalzitat: „Mobile defense is that method of defense in which forward defensive positions are occupied by the minimum forces necessary to warn of impending attack, canalize the attacking forces into less favorable terrain, and block or impede the attacking forces, while the bulk of the defending forces is employed in offensive action to destroy the enemy at the time and place most favorable to the defender."

573 Ebd.

574 Soutor, To Stem the Red Tide, S. 676. Wie groß die Bedeutung der deutschen Studien im Vergleich zu möglichen anderen Einflussfaktoren tatsächlich war, muss allerdings hier dahingestellt bleiben. Nur die Analyse der entsprechenden Akten am CGSC, an dem FM 100-5 überarbeitet wurde, kann Aufschluss darüber liefern. Eine solche Untersuchung kann im Rahmen dieser Arbeit jedoch nicht geleistet werden. 
spielte. Die U.S. Armee konzentrierte sich ab Mitte der 1950er Jahre vor allem auf die Entwicklung taktischer Atomwaffen. Zur Verteidigung gegen einen ebenfalls mit taktischen Atomwaffen ausgerüsteten Feind etablierte man anstelle der beweglichen Verteidigung die Verteidigung bestimmter strategisch wichtiger Räume, die jeweils von einzelnen, voneinander unabhängigen Kampfgruppen gehalten werden sollten. ${ }^{575}$ Die Einführung taktischer Atomwaffen relativierte damit die Bedeutung der beweglichen Verteidigung; gleichzeitig erlahmte das Interesse der U.S. Armee an den deutschen Erfahrungen im Zweiten Weltkrieg, die nun als obsolet für die amerikanischen Planungen erschienen. ${ }^{576}$

In der Folge sank die Bedeutung der kriegsgeschichtlichen Kooperation ab Mitte der 1950er Jahre: Bei den U.S. Truppen in Deutschland wurde das Vortragsprogramm ehemaliger Wehrmachtsoffiziere Mitte 1955 eingestellt, ${ }^{577}$ ab 1956 wurden keine deutschen Studien mehr als DA-Pamphlets veröffentlicht; und Ende 1957 stellten die Amerikaner auch die deutschen Vorträge in den USA ein. ${ }^{578}$ Das nachlassende Interesse bei der Truppe führte schließlich in Kombination mit den anhaltenden Haushaltszwängen dazu, dass die Historical Division Ende 1958 zunächst die Control Group auflöste und die Zusammenarbeit mit der ehemaligen Wehrmachtselite dann bis 1961 nach und nach vollständig auslaufen ließ.579

\section{Politik der Kriegserinnerung}

\section{1 „Für die Verteidigung der freien Welt ..." 580 gegen den "Todfeind unserer Kultur" :581 Zum neuen Selbstverständnis der ehemaligen Wehrmachtselite nach 1945}

\section{Hinwendung zum Westen}

Das Ende des Zweiten Weltkrieges bedeutete eine tiefe Zäsur für die deutsche Gesellschaft. Nach zwölf Jahren nationalsozialistischer Herrschaft und knapp sechs Jahren Krieg war Deutschland besiegt, besetzt und zerstört. Der deutsche Staat hatte vorübergehend aufgehört zu existieren. Während die Opfer des Nationalsozialismus, die in Konzentrationslagern, Zuchthäusern und Zwangsarbeiterlagern

575 Ebd., S. 682-683; Trauschweizer, Creating Deterrence for Limited War, S. 94; Bacevich, The Pentomic Era, S. 115-117.

576 Soutor, To Stem the Red Tide, S.681-682; siehe auch Bacevich, The Pentomic Era, S. 54-55.

577 Halbjahresbericht der Control Group für die Zeit vom 1. Januar bis 30. Juni 1955, in: BArch, ZA 1/1845.

578 Adjutant General Colonel T. J. Marnane, Discontinuance of Annual Program of German Lecturers for Army Service Schools, 12.11. 1957, in: NARA, RG 549, Box 1155, Folder 3.

579 Soutor, To Stem the Red Tide, S. 683. Vgl. zur Abwicklung der kriegsgeschichtlichen Kooperation oben, Teil II, Kapitel 3.2.

580 Franz Halder, Schreiben an Wilbur S. Nye, 12. 1. 1952, in: BArch, N 220/202.

581 Günther Blumentritt, MS \# B-635. Persönliche Gedanken über die Weltlage, Februar 1947, S. 8, in: NARA, RG 549, Box 47. 
den Sieg der Alliierten herbeigesehnt hatten, sich befreit fühlen konnten, wurde die Mehrheit der deutschen Bevölkerung, die das nationalsozialistische Regime bis zum Schluss unterstützt hatte, angesichts des Zusammenbruchs von tiefer Niedergeschlagenheit erfasst. ${ }^{582}$ Die Niederlage mit all ihren Konsequenzen und die ungewissen Zukunftsaussichten stellten das Selbstverständnis dieser Deutschen fundamental infrage. Die Traditionen, Wertvorstellungen, Leit- und Geschichtsbilder des deutschen Nationalstaats Bismarck'scher Prägung waren durch die Verbrechens- und Kriegspolitik des Dritten Reiches, durch den Sieg der Alliierten, den Souveränitätsverlust und die sich abzeichnende Teilung der Nation schwer erschüttert worden. Aus dem totalen Krieg folgte die totale Niederlage sie zwang die deutsche Gesellschaft, sich unter den veränderten Bedingungen auf neue Traditionsbestände $\mathrm{zu}$ einigen und ein neues politisches und nationales Selbstverständnis zu entwickeln. ${ }^{583}$

Die Notwendigkeit zur Neuorientierung galt insbesondere für die militärische Elite des Dritten Reichs, deren Selbstverständnis und gesellschaftliche Stellung durch die Niederlage besonders tief erschüttert war. Denn 1945 war nicht 1918. Damals waren die deutschen Streitkräfte zwar drastisch verringert und mit strengen Rüstungsbeschränkungen belegt, jedoch nicht gänzlich aufgelöst worden, und hatten schnell wieder an gesellschaftlichem und politischem Einfluss gewonnen. ${ }^{584} 1945$ war die Situation eine gänzlich andere. Um eine erneute deutsche Aggression auszuschließen, hatten sich die Siegermächte dieses Mal zu einer vollständigen und dauerhaften Entmilitarisierung Deutschlands verpflichtet. Im August 1946 verfügten die Alliierten im Kontrollratsgesetz Nr. 34 die faktisch bereits weitgehend vollzogene Auflösung aller deutschen Streitkräfte und erklärten alle militärischen Vereine und Vereinigungen für ungesetzlich. Darüber hinaus hob das Gesetz die Ansprüche der Berufssoldaten auf Gehälter und Pensionen auf und machte damit die ehemaligen Berufssoldaten und ihre Angehörigen, soweit sie nicht über entsprechendes Privatvermögen verfügten oder Anspruch auf Kriegsbeschädigtenrente hatten, von den Leistungen der Fürsorge abhängig. Darüber hinaus waren alle höheren Generalstabsoffiziere, wenn sie sich nicht ohnehin in Kriegsgefangenschaft befanden, vom automatischen Arrest betroffen und mussten unter Umständen mit einer Anklage wegen Kriegsverbrechen rechnen. ${ }^{585}$ Niederlage, Kapitulation und Besatzung bedeuteten also für die hochrangigen und bisher hochangesehenen deutschen Generäle und Generalstabsoffiziere nicht nur das schlagartige Karriereende, sondern darüber hinaus drastischen gesellschaftlichen Abstieg, wirtschaftliche Deklassierung und öffentliche

582 Vgl. Schildt/Siegfried, Deutsche Kulturgeschichte, S. 21-22; Echternkamp, Nach dem Krieg, S. 8; vgl. auch Ders., Im Schlagschatten des Krieges, in: Müller (Hg.), Der Zusammenbruch des Deutschen Reiches 1945, Zweiter Halbband, S. 695-696.

583 Bock/Wolfrum, Einleitung, in: Bock/Wolfrum (Hg.), Umkämpfte Vergangenheit, S. 7; Wolfrum, Geschichtspolitik in der Bundesrepublik Deutschland 1949-1989, in: Bock/ Wolfrum (Hg.), Umkämpfte Vergangenheit, S. 60; Ders., Geschichte als Waffe, S. 59.

584 Wette, Militarismus in Deutschland, S. 137-138; Gordon, Die Reichswehr und die Weimarer Republik 1919-1926, S. 193.

585 Vgl. Endfassung der amerikanischen Besatzungsdirektive JCS 1067 vom 26. April 1945 (Auszug), in: Vollnhals (Hg.), Entnazifierung, S. 100. 
Anklage. ${ }^{586}$ In dieser Situation mussten die ehemaligen Berufsoffiziere ein neues Selbstverständnis entwickeln, das sowohl ihre Vergangenheit und ihre Rolle im Zweiten Weltkrieg erklärte, als auch neue Perspektiven für eine Zukunft aufzeigte, in der es auf absehbare Zeit keine deutschen Streitkräfte geben würde.

Wie für die Westdeutschen insgesamt, gaben die westlichen Siegermächte, vor allem die Vereinigten Staaten, auch für die ehemalige Wehrmachtselite den Rahmen für die politische, gesellschaftliche und weltanschauliche Neuorientierung vor. ${ }^{587}$ Angesichts von Niederlage, Besatzung und deutscher Teilung im Zuge des sich verstärkenden Kalten Krieges richteten die deutschen Spitzenmilitärs ihr Selbstverständnis in relativ kurzer Zeit auf den Westen und seine politischen, wirtschaftlichen und ideologischen Paradigmen aus. Über ihre kriegsgeschichtlichen Studien und die Kommunikation mit den amerikanischen Offizieren partizipierten die ehemaligen Offiziere an der gesamtgesellschaftlich stattfindenden Einbindung der westlichen Besatzungszonen bzw. ab 1949 der Bundesrepublik in die westliche Wertegemeinschaft. Dabei bedienten sie sich einer okzidentalen Rhetorik und betonten in ihren Arbeiten, aber auch in der Korrespondenz, persönlichen Aufzeichnungen und öffentlichen Äußerungen immer wieder, dass Deutschland seiner Geschichte, seiner Kultur und seinen Werten nach zum Westen gehöre. Albert Kesselring notierte 1946 in sein Tagebuch, er sei „ein fanatischer Anhänger" des Westens; ${ }^{588}$ Bodo Zimmermann wollte durch seine kriegsgeschichtliche Tätigkeit das „gegenseitige Verständnis“ des Westens fördern; ${ }^{589}$ Kurt Brennecke sah in der kriegsgeschichtlichen Kooperation einen Beitrag „zum Schutz der westlichen Kultur".590

Auch Günther Blumentritt war überzeugt, dass die deutsche Kultur nur überleben würde, wenn die Deutschen mit dem Westen zusammenarbeiteten. In seinen Augen konnte Deutschland auf sich allein gestellt nicht viel länger existieren. ${ }^{591}$

586 Meyer, Zur Situation der deutschen militärischen Führungsschicht im Vorfeld des westdeutschen Verteidigungsbeitrages 1945-1950/51, in: Foerster (Hg.), Von der Kapitulation zum Pleven-Plan, S. 635-636; Ders., Soldaten ohne Armee, in: Broszat (Hg.), Von Stalingrad zur Währungsreform, S. 684; Wulfhorst, Der „Dank des Vaterlandes“ Sozialpolitik und -verwaltung zur Integration ehemaliger Wehrmachtsoldaten und ihrer Hinterbliebenen, in: Müller/Volkmann (Hg.), Die Wehrmacht, S. 1040-1041, S. 1055; Lockenour, Soldiers as Citizens, S. 4-6; Naumann, Sicherheitselite und außenpolitischer Stil, in: Mittelweg 3685 (1999), S. 6; vgl. auch Echternkamp, Wut auf die Wehrmacht? in: Müller/Volkmann (Hg.), Die Wehrmacht S. 1058-1080.

587 Doering-Manteuffel, Wie westlich sind die Deutschen?, S. 8-10.

588 Albert Kesselring, Tagebuchaufzeichnungen aus der Zeit der Kriegsgefangenschaft, Blatt 48, in: BArch, N 750/2.

589 Bodo Zimmermann, Schreiben an Frank C. Mahin, 8. 12. 1947, in: NARA, RG 549, Box 8, Folder 1.

590 Kurt Brennecke, Schreiben an Harold E. Potter, 8. 5. 1948, in: NARA, RG 549, Box 3143, Folder 4.

591 Günther Blumentritt, Thoughts on World War II, S. 10, in: CARL Digital Library, URL: http://cgsc.contentdm.oclc.org/cdm/ref/collection/p4013coll8/id/105 (letzter Zugriff: 4. 3. 2015). Originalzitat: „Our civilization, however, will continue only if it collaborates with the great western world. The remaining fragments of the continent cannot exist for long alone and by themselves. This calls for a determined change in thinking." Hervorhebung im Original. 
Er bekannte sich deshalb zu einer entschiedenen weltanschaulichen Neuorientierung und betrachtete es als seine „persönliche Pflicht“, das „westliche Ideal“ zu unterstützen. ${ }^{592}$ Und auf seine Weise tat er das auch: In seinen zahlreichen, größtenteils unaufgefordert angefertigten Studien und essayistischen Ausführungen ${ }^{593}$ beschwor Blumentritt historische, kulturelle, ethnische und ideologische Gemeinsamkeiten zwischen Deutschland und den Vereinigten Staaten, die geeignet schienen, die Differenzen der vergangenen Jahrzehnte zu überbrücken. ${ }^{594}$ Immer wieder betonte er, dass Deutschland „seit Jahrhunderten nach Geschichte und Kultur" zum Westen gehört habe, ${ }^{595}$ und unterstrich diese Behauptung durch den Rückgriff auf Allgemeinplätze aus dem westlichen Wertekanon, die eine ideologische Anschlussfähigkeit bei seinen amerikanischen Lesern versprachen. So stellte er zum Beispiel fest, dass die Deutschen „die persönliche Freiheit“ sowie „in irgendeiner Form den Liberalismus“ und die „Demokratie“ lieben und „das Individuum, den Einzelmenschen“ achten würden. Außerdem seien die Deutschen für „freie Meinungsäußerung, freie Aussprache, freien Gedankenaustausch, freie Presse, freien Film, freie Kunst [und] freies Theater".596

Wie Blumentritts Äußerungen zum drohenden Ende der deutschen Kultur andeuten, ergab sich die Notwendigkeit einer umfassenden Eingliederung der westlichen Besatzungszonen in die westliche Wertegemeinschaft für die ehemaligen Militärs nicht zuletzt aus der angenommenen Bedrohung Westeuropas - und insbesondere Westdeutschlands - durch die kommunistische Sowjetunion. Denn dass allein die Vereinigten Staaten militärisch und wirtschaftlich in der Lage waren, dem Expansionsstreben der UdSSR entgegenzutreten, stand für die deutschen Offiziere außer Frage. Nur die USA hätten „den Willen und die Macht [...], die Gefahr aus dem Osten zu bannen“597, weshalb das deutsche Volk nur als Teil des Westens ,am Leben bleiben“ "könne. ${ }^{598}$ Auch wenn die ehemalige Wehrmachtselite also die Vormachtstellung der USA anerkannte und zugab, dass Westdeutschland existenziell auf den Schutz der Amerikaner angewiesen war, war es ihnen doch auch wichtig, immer wieder zu betonen, dass der Westen seinerseits kaum auf das wirtschaftliche und militärische Potential der Westdeutschen verzichten könne. Schließlich, so äußerte zum Beispiel Georg von Sodenstern, verfüge kein anderes Volk des europäischen Festlandes „über gleich kräftige Lebensströme“ 599 Angesichts der momentanen Schwäche auch der anderen westeuropäischen Staa-

592 Ders., Schreiben an James F. Scoggin, 10. 12. 1947, in: NARA, RG 549, Box 8, Folder 1.

593 Die Historical Division fasste die über 50 Manuskripte unter der Nummer MS \# C-096 zusammen.

594 Günther Blumentritt, Gedanken über die angelsächsische Weltstellung, März 1947, S. 4, in: NARA, RG 549, Box 36, MS \# B-386.

595 Ders., MS \# B-338. Warum hat der deutsche Soldat in aussichtsloser Lage bis zum Schluss des Krieges 1939-45 gekämpft?, Februar 1947, S. 2, in: BArch, ZA 1/689.

596 Ders., MS \# C-096. Unsere Erfahrungen mit dem „Eisernen Vorhang“ im Osten, 19. 3. 1948, S. 1, in: NARA, RG 549, Box 74.

597 Franz Halder, Schreiben an Hermann Ochsner, 22. 3. 1948, in: BArch, N 220/202.

598 Blumentritt, MS \# B-338. Warum hat der deutsche Soldat bis zum Schluss gekämpft?, in: BArch, ZA 1/689.

599 Georg von Sodenstern, MS \# B-454. Gedanken zur Gegenwart, April 1947, in: NARA, RG 549, Box 39. 
ten stelle Deutschland deshalb mit der „wirtschaftlichen und geistigen Kraft“600 seiner „60 Millionen tüchtige[n[, tapfere[n] und fleißigen Menschen"601 einen „wertvoll[en] Faktor“ für die Verteidigung Europas und damit die Zukunft des Westens dar. ${ }^{602}$ Deutschland, da waren sich die ehemaligen Offiziere einig, war durchaus nicht bedingungslos von den Vereinigten Staaten abhängig, sondern bot sich dem Bündnis des Westens gegen den Osten als attraktiver und möglicherweise sogar unentbehrlicher Partner an.

\section{Fortdauernde Abgrenzung vom Osten}

Die aus dem Zweiten Weltkrieg resultierende internationale Mächtekonstellation und ein anhaltendes Gefühl der Bedrohung durch die Sowjetunion erzwang also in den Augen der ehemaligen deutschen Offiziere geradezu eine - zumindest verbale - Annäherung an die liberal-demokratischen Wertvorstellungen der Amerikaner. Wie tief dieser Wandel der politischen Überzeugungen beim Einzelnen ging, ist nur schwer zu sagen. Dass sich die ehemals überwiegend demokratiefeindlichen deutschen Militärs nach 1945 relativ rasch mit dem Westen versöhnen ließen, hatte allerdings wohl weniger mit der positiven Strahlkraft liberaldemokratischer Werte als mit der integrativen Wirkung der nach 1945 verstärkt auch international hervortretenden Kultur des Antikommunismus zu tun. Den für die Historical Division tätigen Wehrmachtsoffizieren fiel es auch deshalb so leicht, sich auf den Westen auszurichten, weil sich ihnen im Kontext des Kalten Krieges die Möglichkeit bot, weiterhin alte antibolschewistische, antislawische und antirussische Feindbilder zu pflegen und zu kultivieren. Dies wurde dadurch erleichtert, dass die Russen- und Russlandbilder der ehemaligen Wehrmachtsoffiziere und ihrer amerikanischen Kollegen erhebliche Schnittmengen aufwiesen. ${ }^{603}$ Obwohl antisemitische Elemente mit dem Ende des Nationalsozialismus weitgehend aus dem öffentlich kolportierten Russlandbild der ehemaligen Wehrmachtsoffiziere getilgt werden mussten, konnten so antibolschewistische und auch antislawische Akzente im Kalten Krieg fortbestehen und bildeten eine der wenigen ideologischen Kontinuitäten nach $1945 .{ }^{604}$

Die kriegsgeschichtlichen Studien, die die ehemaligen Wehrmachtsoffiziere im Auftrag der Historical Division zum Krieg im Osten verfassten, führten vor allem das in den letzten Kriegsjahren dominierende Bild von der „russischen Gefahr“ fort, transportierten aber auch Vorstellungen von der kulturellen Überlegenheit

600 Blumentritt, MS \# B-338. Warum hat der deutsche Soldat bis zum Schluss gekämpft?, S. 2, in: BArch, ZA 1/689.

601 Günther Blumentritt, MS \# B-582. Weltstrategische Betrachtungen, April 1947, S. 14, in: NARA, Mikrofiche Publication M 1035: Foreign Military Studies.

602 Blumentritt, MS \# B-338. Warum hat der deutsche Soldat bis zum Schluss gekämpft?, S. 2, in: BArch, ZA 1/689; Siehe auch Zimmermann, MS \# C-040. Ideas on the Defense of the Rhine and Western Germany as an Outpost Area of Western Europe, 10. 12. 1948, S. 1, in: NARA, RG 549, Box 65.

603 Vgl. ausführlicher oben, Teil I, Kapitel 2.2.

604 Wette, The Wehrmacht, S. 17; Jahn, Russlandbild und Antikommunismus in der bundesdeutschen Nachkriegszeit, in: Quinkert (Hg.), „Wir sind die Herren dieses Landes“, S. 231-232; vgl. auch Wippermann, Die Deutschen und der Osten, S. 83-91. 
der westlichen Völker. So beschrieben die deutschen Militärs „den Osten“ vor allem als unkultiviert, fremd und bedrohlich. Der ehemalige General der Infanterie Friedrich Fangohr warnte beispielsweise in seiner Studie Russland als Kampfraum, dass westliche Soldaten in der Sowjetunion angesichts der „,wesentlich niedrigeren Kulturstufe" der dort lebenden Menschen immer auf Schwierigkeiten stoßen würden. Als Beispiel nannte er Probleme bei der Quartiersuche, die sich aus der mangelnden „Wohnkultur“ im Osten ergeben würden: „Die kleine Lehmkate, in der jeder größere Mensch sich nur gebückt bewegen kann, strotzt von Ungeziefer und Schmutz."605 Auch Gustav Höhne warnte vor den Auswirkungen von Verschmutzung und Verlausung der russischen Wohnhäuser, die den Ausbruch von Typhus und anderen Krankheiten begünstigten. ${ }^{606}$

Die negativen Klischees bezogen sich nicht nur auf die Lebensumstände und hygienischen Bedingungen der sowjetischen Bevölkerung, sondern sie erstreckten sich auch auf die geographische Beschreibung Russlands, das wegen seiner großflächigen Wälder, Steppen, Sümpfe und Wüsten als überwiegend ungastlich, unwirtlich und trostlos galt. Die enorme Größe des Landes wirkte furchteinflößend, rief gleichzeitig aber auch staunende Bewunderung hervor. ${ }^{607}$ So erinnerte sich zum Beispiel Albert Kesselring an die Hilflosigkeit, die man angesichts der „allmächtigen Natur“ in Russland mit ihren „endlosen Steppen“ östlich der Wolga, in denen „man tagelang keinem Menschen begegnete“, und den „undurchdringlichen, riesigen Wäldern“ im Norden und Nordosten empfinde. ${ }^{608}$ Erhard Raus identifizierte den „russische[n] Raum selbst und sein Klima“ als „Waffen“. 609 Von der Natur des Landes zogen Kesselring und andere ehemalige Offiziere Rückschlüsse auf das Wesen seiner Bewohner, die ebenso „ungewöhnlich und voller Gegensätze“ seien. ${ }^{610}$

Tatsächlich hielten viele ehemalige Wehrmachtsoffiziere auch nach dem Krieg weiterhin am Bild der fundamentalen Wesensverschiedenheit der Menschen in West und Ost fest. „Kein Angehöriger des westlichen Kulturkreises“, davon war neben Friedrich Fangohr auch Erhard Raus fest überzeugt, würde „den Russen je ganz verstehen“611 oder „seinen Charakter und seine Seele voll ergründen können. “ 612 Der „Russe“ sei „im Allgemeinen unberechenbar“, meist lasse sich nicht sagen, „wie er sich schon in der nächsten Minute verhalten“ werde. Er schwanke

605 Friedrich Fangohr, MS \# P-071. Russland als Kampfraum. Gelände, Klima und Bevölkerung in ihren Einflüssen auf eine Kriegführung in der Union der Sozialistischen Sowjetrepubliken, 1950/1951, S. 24-25, in: NARA, RG 549, Box 138.

606 Gustav Höhne, In Snow and Mud: Thirty-one Days of attack under Seydlitz during the Early Spring of 1942 [C-034], in: Detwiler/Burdick/Rohwer (Hg.), World War Two German Military Studies, S. 5.

607 Lammich, Vom „Barbarenland“ zum „Weltstaat“, S. 167.

608 Curt Gallenkamp und Albert Kesselring, MS \# D-395. The Soviet Army and Air Force, März 1951, in: NARA, RG 549, Box 91.

609 Raus, MS \# T-22. Besonderheiten der russischen Kampfführung, S. 44, in: BArch, ZA $1 / 2371$.

610 Ebd., S. 9.

611 Ebd.

612 Fangohr, MS \# P-071. Russland als Kampfraum, in: NARA, RG 549, Box 138. 
„Zwischen grenzenloser Gutmütigkeit und barbarischer Grausamkeit“.613 Den Grund für dieses, dem „Westeuropäer“ unverständliche Verhalten sah Erhard Raus darin, dass man es mit „Asiaten“ zu tun habe, die „jenseits europäischer Grenzen aufgewachsen“ seien. ${ }^{614}$ Dieses Schlagwort vom „asiatischen Charakter“ des Ostens und seiner Bewohner, das sich nicht nur bei Raus findet, sondern in den kriegsgeschichtlichen Studien immer wieder auftaucht, ${ }^{615}$ war bereits im 16. Jahrhundert ${ }^{616}$ entstanden. In der Weimarer Republik war es zum Gemeingut fast aller Kritiker des russischen Bolschewismus geworden ${ }^{617}$ und hatte sich dann während des Zweiten Weltkrieges durch die Äußerungen führender deutscher Militärs gezogen. ${ }^{618}$ Es brachte den fundamentalen Unterschied auf den Punkt, der angeblich zwischen Slawen und Russen einer- und Europäern andererseits bestand. Die griffige Formel vom "asiatischen Osten“ unterstrich die angebliche Fremd- und Andersartigkeit der dortigen Völker und implizierte einen unüberbrückbaren Gegensatz zwischen Westeuropa als Träger des historischen Menschheitsfortschritts und Asien als Ort der Barbarei und Stagnation. ${ }^{619}$

Das Schlagwort vom „asiatischen Osten“ zog sich wie ein roter Faden durch die Nachkriegsstudien der ehemaligen Wehrmachtsoffiziere. So sprach beispielsweise Georg von Sodenstern in einer Studie vom April 1947 von einem zweitausendjährigen Antagonismus zwischen „Europa“ und dem „asiatischen“ Slawentum. Für Sodenstern war die gegenwärtige Spannung zwischen dem freiheitlich-demokratischen Westen und dem bolschewistischen Osten demnach auch kein politischer oder ideologischer, sondern ein grundsätzlicher kultureller (und in letzter Konsequenz rassischer) und damit ein dauerhaft unlösbarer Konflikt. ${ }^{620}$ Auch

613 Ebd.

614 Raus, MS \# T-22. Besonderheiten der russischen Kampfführung, S. 9, in: BArch, ZA $1 / 2371$.

615 Siehe zum Beispiel Zimmermann, MS \# C-040. Ideas on the Defense of the Rhine and Western Germany as an Outpost Area of Western Europe, 10. 12. 1948, S. 17, in: NARA, RG 549, Box 65.

616 Siehe hierzu ausführlich Klug, Das „Asiatische“ Russland, in: Historische Zeitschrift 245 (1987), S. 265-289.

617 Jahn, Russenfurcht und Antibolschewismus, S. 52.

618 So bezeichnete zum Beispiel Georg von Küchler die Sowjetunion als „asiatische[n] Staat" und warnte vor „asiatische[n] Horden“, die seit den Tagen von Tschingis Khan "gegen die rassisch höher stehenden Germanen vorzudrücken“ versuchten; und Günther Blumentritt sprach von der "halbasiatischen Sturheit" der russischen Soldaten. Dokument 6. Aus den handschriftlichen Notizen des Oberbefehlshabers der 18. Armee, Generaloberst von Küchler, für einen Vortrag vor seinen Divisionskommandeuren am 25. April 1941 (AOK 18/Ia Nr. 406/41 g.Kdos. Chefs., BArch, RH 20-18/71), in: Wilhelm (Hg.), Rassenpolitik und Kriegführung, S. 133; Ansprache Küchlers, 22.6. 1941, 7.30 Uhr an die Führungsabteilung, 9.00 Uhr an die O.Qu.-Abteilung, in: NARA, T 312/799, zit. nach Hürter, Hitlers Heerführer, S. 219; Denkschrift Blumentritts, damals Chef des Generalstabs der 4. Armee, vom 29.12. $1940 \mathrm{zu}$ „inneren Werten und Kampfkraft des russischen Gegners“, zit. nach Förster, Zum Russlandbild der Militärs 1941-1945, in: Volkmann (Hg.), Das Russlandbild im Dritten Reich, S. 144.

619 Jahn, „Zarendreck, Barbarendreck“, S. 233; Lammich, Vom „Barbarenland“ zum „Weltstaat", S. 167-168; Waschik, Metamorphosen des Bösen, S. 299.

620 Sodenstern, MS \# B-454. Gedanken zur Gegenwart, April 1947, S. 1-3, in: NARA, RG 549, Box 39. 
Günther Blumentritt war von der fundamentalen Wesensverschiedenheit der westlichen und der östlichen Völker überzeugt. Der langen Tradition negativer Russland-Stereotype folgend, zeichnete sich die „asiatisch-slawische Mentalität“ für ihn unter anderem durch „Dumpfheit“ und „Unterordnung“, ja ein Bedürfnis nach diktatorischer Führung aus. In seinen Augen wussten die Völker des Ostens mit innerer Freiheit und Individualismus nichts anzufangen, sondern lebten als amorphe Masse dumpf vor sich hin, ${ }^{621}$ - eine Charakterisierung, die eine klare Entgegensetzung zum Wesen des Westeuropäers bildete, das sich angeblich durch Freiheitsliebe und Individualismus auszeichnete. ${ }^{622}$ Während die „asiatisch-slawische“ Bevölkerung der Sowjetunion also qua ihrer Natur dem Kommunismus zugeneigt sei, bleibe dieser den westlichen Deutschen eine „unheimliche und fremde Welt".623

\section{Das Bild vom russischen Soldaten}

Naturgemäß befassten sich die ehemaligen deutschen Offiziere in ihren Studien und sonstigen Ausführungen über allgemeine Feststellungen hinaus vor allem mit den Eigenschaften und Charakteristika der russischen Soldaten und der Bewertung der russischen Kriegführung. Dabei konnten sich die ehemaligen Militärs nicht von ihrem stereotypen Russenbild frei machen, im Gegenteil. Das Bild, das sie in ihren Studien von "dem“ russischen Soldaten zeichneten, schwankte zwischen arroganter Verachtung und naiver Bewunderung und enthielt damit Elemente beider Seiten des janusköpfigen Russlandbildes. Dabei tauchten immer wieder drei Leitmotive auf, denen sich alle anderen beschriebenen Charakteristika zuordnen lassen: Da ist zunächst das Leitmotiv der „Naturverbundenheit“ zu nennen, das die deutschen Offiziere immer wieder als grundlegende Eigenschaft der russischen Soldaten hervorhoben. Auch wenn sie diese enge Verbundenheit mit der Natur als Zeichen der kulturellen Rückständigkeit werteten, konnten die deutschen Militärs eine gewisse Bewunderung für diese „Unverbildetheit“624 nicht verhehlen, schien sie doch gerade aus militärischer Sicht Vorteile zu bieten. So betonten die Deutschen immer wieder die Anspruchslosigkeit, Genügsamkeit und Anpassungsfähigkeit der russischen Soldaten und bewunderten deren Unempfindlichkeit gegen Witterungsverhältnisse. ${ }^{625}$ Außerdem verfügten sie angeb-

621 Blumentritt, MS \# C-096. Unsere Erfahrungen mit dem „Eisernen Vorhang“ im Osten, 19. 3. 1948, S. 2, in: NARA, RG 549, Box 74; Ders., MS \# B-635. Persönliche Gedanken über die Weltlage, Februar 1947, S. 7, in: NARA, RG 549, Box 47.

622 Blumentritt, MS \# C-096. Unsere Erfahrungen mit dem „Eisernen Vorhang" im Osten, 19.3. 1948, S. 1, in: NARA, RG 549, Box 74.

${ }^{623}$ Ders., Thoughts on World War II, S. 5-6, in: CARL Digital Library, URL: http://cgsc. contentdm.oclc.org/cdm/ref/collection/p4013coll8/id/105 (letzter Zugriff: 4. 3. 2015).

624 Raus, MS \# T-22. Besonderheiten der russischen Kampfführung, S. 10, in: BArch, ZA $1 / 2371$.

${ }^{625}$ Als Beispiele seien hier genannt: Fangohr, MS \# P-071. Russland als Kampfraum. Gelände, Klima und Bevölkerung in ihren Einflüssen auf eine Kriegführung in der Union der Sozialistischen Sowjetrepubliken, 1950/1951, in: NARA, RG 549, Box 138; Gallenkamp und Kesselring, MS \# D-395. The Soviet Army and Air Force, März 1951; Raus, MS \# T-22; Simon, MS \# C-058; Rudolf Sintzenich, MS \# D-103. 132d Infantry Division - Geo-military Description of the Western Ukraine - The Russian Soldier (1947), 
lich über ein „natürliches Orientierungsvermögen“ und einen „instinkthaften Scharfsinn“.626 Dank seiner Naturverbundenheit, stellte zum Beispiel Friedrich Fangohr fest, verhalte sich ein russischer Soldat „gegen Hitze und Kälte [...] ebenso gleichgültig wie gegenüber Hunger und Durst“.627 Außerdem falle es ihm „nicht schwer, tagelang von trockenem Brot, Blättern und Wurzeln zu leben“628 und so auch lang andauernde Versorgungsengpässe relativ leicht zu überstehen. ${ }^{629}$ Auch Erhard Raus zeigte sich von der Fähigkeit russischer Soldaten, sich selbst zu versorgen, und ihrem Gleichmut gegenüber „Frost und Hitze, Hunger und Durst, Nässe und Schlamm, Krankheit und Ungeziefer" beeindruckt. ${ }^{630}$ Schließlich schrieben die deutschen Offiziere den russischen Soldaten aufgrund ihrer angeblichen Naturverbundenheit auch eine besondere Begabung bei der Tarnung und der Ausnutzung des Geländes zu. ${ }^{631}$

All diese Eigenschaften machten die russischen Soldaten in den Augen der ehemaligen Wehrmachtselite zu vorzüglichen Kämpfern und gefährlichen Gegnern für westliche Streitkräfte, bei deren Soldaten eine derartige Abhärtung gegen die Unbill der Natur nicht zu erwarten sei. ${ }^{632}$ Ihre primitive Naturverbundenheit gebe den russischen Soldaten deshalb eine gewisse Überlegenheit gegenüber den Soldaten der „zivilisierten Westmächte“.633 Während die russische Militärführung über starke, robuste, leicht zu befriedigende Truppen verfüge, die natürliche Gegebenheiten ganz selbstverständlich für militärische Zwecke wie zum Beispiel Aufklärung, Tarnung und Nachtkampf zu nutzen wüssten, müssten derlei Fähigkeiten den westlichen Soldaten erst durch mühsames und zeitaufwendiges Training beigebracht werden. ${ }^{634}$

Ein weiteres Leitmotiv bei der Beschreibung des russischen Soldaten bildete dessen vermeintliche „Menschen- und Todesverachtung“, seine Gleichgültigkeit auch gegenüber dem eigenen Tod, die sich angeblich aus der Konfrontation mit der Allmacht der Natur ableitete. Demnach akzeptierte der russische Soldat Leben und Tod als gottgewollt und stelle sein Schicksal nicht in Frage. ${ }^{635}$ Aus dieser

in: NARA, Mikrofiche Publication M 1035: Foreign Military Studies; Fritz Wentzel, MS \# B-264. Erfahrungen im Waldkampf in Russland (Februar 1947) in: NARA, RG 549, Box 27.

626 Wentzel, MS \# B-264. Erfahrungen im Waldkampf in Russland (Februar 1947), S. 9-10, in: NARA, RG 549, Box 27.

627 Fangohr, MS \# P-071. Russland als Kampfraum, in: NARA, RG 549, Box 138.

628 Ebd.

629 Sintzenich, MS \# D-103. 132d Infantry Division, S.9, in: NARA, Mikrofiche Publication M 1035: Foreign Military Studies.

${ }^{630}$ Raus, MS \# T-22. Besonderheiten der russischen Kampfführung, S. 10 und S. 13, in: BArch, ZA 1/2371.

631 Ebd., S. 12-13; Wentzel, MS \# B-264. Erfahrungen im Waldkampf in Russland (Februar 1947), S. 9-10, in: NARA, RG 549, Box 27.

632 Fangohr, MS \# P-071. Russland als Kampfraum, in: NARA, RG 549, Box 138.

633 Gallenkamp und Kesselring, MS \# D-395. The Soviet Army and Air Force, März 1951, S. 2, in: NARA, RG 549, Box 91.

${ }^{634}$ Ebd., S. 4; Sintzenich, MS \# D-103. 132d Infantry Division, S. 9-10, in: NARA, Mikrofiche Publication M 1035: Foreign Military Studies.

635 Gallenkamp und Kesselring, MS \# D-395. The Soviet Army and Air Force, März 1951, in: NARA, RG 549, Box 91. 
Schicksalsergebenheit leite sich eine natürliche Tapferkeit der russischen Soldaten ab, ${ }^{636}$ aber auch eine "gewisse Unterbewertung des Lebens“. ${ }^{637}$ Als Beweis für die angebliche Verachtung der russischen Soldaten - wie der russischen Bevölkerung insgesamt - dem Leben gegenüber, führte Erhard Raus die „Ausschaltung jeden Totenkultes“ während des Zweiten Weltkrieges an. Das von Raus gewählte Beispiel für diese Behauptung könnte freilich nicht zynischer sein: In seiner Studie Besonderheiten der russischen Kampfführung beschrieb er, wie die Deutschen im September 1941 russische Kriegsgefangene und Zivilisten vor Leningrad bei der Bestattung von rund 300 russischen Gefallenen in drei Schachtgräbern eingesetzt hatten. Als diese Zwangsverpflichteten bemerkt hätten, „dass für die letzten dreißig bis vierzig Leichen kein Platz mehr vorhanden war“, seien sie „so lange mit Stiefeln auf den Leichen herum“getrampelt, „bis durch das Einstampfen der erforderliche Raum geschaffen war“.638

Als drittes Leitmotiv diente das Bild von den russischen Truppen als alles überflutender „Masse“, das sich eng an die alte Angst von einer Ausdehnung Russlands nach Westen anschloss. In seiner Studie zur russischen Kampfführung beschwor Erhard Raus dieses Bild besonders anschaulich:

„Im Handumdrehen war das Gelände vor der eigenen Front schwarz von russischen Soldaten. Sie schienen aus der Erde zu wachsen und konnten zunächst nicht aufgehalten werden. Lücken schlossen sich von selbst, die Masse quoll weiter, bis der Vorrat an Menschen aufgebraucht war und die Welle, stark gelichtet, wieder zurückflutete. [...] Eindrucksvoll und erstaunlich, wie oft aber auch flutete diese Masse nicht zurück, sondern schob sich unaufhaltsam vorwärts und vorwärts." ${ }^{639}$

Auch Albert Kesselring zeigte sich von der schieren Zahl anstürmender russischer Soldaten beeindruckt: Selbst wenn ein Schlachtfeld vor Beginn eines Angriffs leer erschienen sei, habe es sich mit Beginn der Kämpfe plötzlich mit Massen angreifender Männer gefüllt. „Das gesamte vordere Gebiet“, so Kesselring, werde im Handumdrehen „mit zahllosen, zu Gruppen zusammengeballten Truppen bedeckt." 640 Auch in den Studien von Günther Blumentritt trat das Motiv der Masse immer wieder auf. ${ }^{641}$ So gründete sich die Gefährlichkeit des Ostens seiner Meinung nach vor allem auf seine „fügsamen und apathischen Massen, die leicht zu lenken“ seien und von den kommunistischen Machthabern

636 Raus, MS \# T-22. Besonderheiten der russischen Kampfführung, S. 11, in: BArch, ZA $1 / 2371$.

637 Gallenkamp und Kesselring, MS \# D-395. The Soviet Army and Air Force, März 1951, S. 1, in: NARA, RG 549, Box 91.

638 Raus, MS \# T-22. Besonderheiten der russischen Kampfführung, S. 37, in: BArch, ZA $1 / 2371$.

639 Ebd., S. 39-40.

640 Gallenkamp und Kesselring, MS \# D-395. The Soviet Army and Air Force, März 1951, S. 18-19, in: NARA, RG 549, Box 91.

641 Siehe zum Beispiel Blumentritt, MS \# C-096. Unsere Erfahrungen mit dem „Eisernen Vorhang" im Osten, 19. 3. 1948, in: NARA, RG 549, Box 74; Ders., MS \# B-635. Persönliche Gedanken über die Weltlage, Februar 1947, in: NARA, RG 549, Box 47; Ders., MS \# B-582. Weltstrategische Betrachtungen, April 1947, in: NARA, Mikrofiche Publication M 1035: Foreign Military Studies. 
sowohl im Frieden als auch im Krieg in ihrer Gesamtheit eingesetzt werden könnten. ${ }^{642}$

Eng mit dem Leitmotiv der „Masse“ verbunden war eine Reihe negativer Schlagworte wie zum Beispiel „Dumpfheit“, „Trägheit“, „Starrheit“ und „Herdentrieb“" ${ }^{643}$ So ergäbe sich die massenhafte Konzentration der Truppen um ihre Anführer aus der Unfähigkeit der Soldaten, bewusst und selbständig zu denken oder gar eigene Entscheidungen zu treffen. Es handele sich um einen „in der Masse stumpf dahindämmernde[n] Soldat[en]“644, der immer „auf Weisung, Erlaubnis und Befehl“ warte und sich selbst „nur ungern zu irgend einer aktiven Handlung "645 entschließe. Er sei daher stark von seinen Vorgesetzten abhängig. ${ }^{646}$ Während zugestanden wurde, dass einzelne Russen durchaus zu „äußerster Gutmütigkeit" fähig und bisweilen "freundlich und hilfsbereit" seien, betonten die deutschen Offiziere unablässig, dass die russischen Soldaten ,in der Masse gehässig und grausam" ${ }^{647}$, ,gemein und hinterlistig"648 seien.

Das stereotype Russen- und Russlandbild der ehemaligen Wehrmachtselite deckte sich zumindest in Teilen mit den Vorstellungen ihrer amerikanischen Kollegen, die in der ersten Hälfte des 20. Jahrhunderts an den amerikanischen Militärschulen mit den Theorien zahlreicher Eugeniker sozialisiert worden waren. ${ }^{649}$ Auch nach 1945 änderte sich die traditionell negative Haltung vieler amerikanischer Militärs zu Osteuropäern nicht grundlegend, antikommunistische Tendenzen wurden durch den im Entstehen begriffenen Kalten Krieg sogar noch verstärkt. So charakterisierte der Militärattaché bei der U.S. Botschaft in Moskau den russischen Soldaten auf Anfrage des militärischen Nachrichtendienstes Anfang 1951 folgendermaßen:

„The Soviet soldier is physically fit, well disciplined and thoroughly indoctrinated in the justice of his cause and the superiority of his army. He trains under all extremes of weather and climate. [...] Limited observation indicates that the Soviet soldier will doggedly pursue his objective in exactly the manner in which he has been taught or directed, but that in general he lacks mental flexibility. [...] The soviet troops will fight desperately and stubbornly, without regard to losses, and cannot be expected to surrender easily. [...] Man for man, American troops can defeat Russians provided we are in excellent physical condition

642 Blumentritt, MS \# B-387. Thoughts on World War II, S. 6, in: CARL Digital Library, URL: http://cgsc.contentdm.oclc.org/cdm/ref/collection/p4013coll8/id/105 (letzter Zugriff: 4.3.2015).

643 Vgl. zum Beispiel Raus, MS \# T-22. Besonderheiten der russischen Kampfführung, S. 15 , in: BArch, ZA 1/2371.

644 Ebd., S. 10.

${ }^{645}$ Neitzel, MS \# T-19. Sicherung der rückwärtigen Verbindungen (Osten), S. 95, in: BArch, ZA 1/2366; vgl. auch Gallenkamp und Kesselring, MS \# D-395. The Soviet Army and Air Force, März 1951, S. 6, in: NARA, RG 549, Box 91.

646 Sintzenich, MS \# D-103. 132d Infantry Division, S. 10, in: NARA, Mikrofiche Publication M 1035: Foreign Military Studies.

${ }^{647}$ Raus, MS \# T-22. Besonderheiten der russischen Kampfführung, S. 10, in: BArch, ZA $1 / 2371$.

648 Fangohr, MS \# P-071. Russland als Kampfraum, in: NARA, RG 549, Box 138.

649 Vgl. ausführlich oben, Teil I, Kapitel 2.2. 
and thoroughly trained because the American is more alert, ingenious and full of initiative." 650

Diese Einschätzung entsprach dem Bild, das zum Beispiel Erhard Raus in seiner nur einige Monate zuvor als DA-Pamphlet veröffentlichten Studie zu den Besonderheiten der russischen Kampfführung gezeichnet hatte. Dort hieß es:

„[T] he Russian soldier [...] possesses neither the judgment nor the ability to think independently. He is subject to moods which to a Westerner are incomprehensible; he acts by instinct. As a soldier, the Russian is primitive and unassuming, innately brave but morosely passive when in a group." 651

Die weitestgehend übereinstimmende Bewertung der sowjetischen Bevölkerung nach rassischen Kriterien sowohl in Kreisen der ehemaligen Wehrmacht als auch innerhalb der U.S. Armee erklärt, weshalb die Mitarbeiter der Historical Division und die verantwortlichen Redakteure der DA-Pamphlets sich nicht an den zahlreichen rassistisch gefärbten Äußerungen in den kriegsgeschichtlichen deutschen Studien stießen. Denn schließlich redigierten die Amerikaner die zur Veröffentlichung als DA-Pamphlets oder in der Foreign Studies Series bestimmten Studien vor der Drucklegung, kürzten sie gegebenenfalls und veränderten zum Teil die Gliederung der Texte, um die Anordnung der Beispiele für den amerikanischen Leser einleuchtender zu machen. Interessanterweise wurden apologetische, aber auch pauschalisierende und diffamierende Äußerungen dabei im Zuge des Lektorats nicht etwa entfernt, sondern unverändert und unkommentiert übernommen. So finden sich in den veröffentlichten Studien immer wieder ganze Passagen mit rassistischen Vorurteilen und Stereotypen, die vor allem darauf abzielen, den Vernichtungskrieg der Wehrmacht in Osteuropa durch den Hinweis auf die angebliche Andersartigkeit und besondere Grausamkeit der dortigen Völker zu legitimieren. Dass die amerikanischen Lektoren diese Aussagen, die doch kaum Relevanz für die taktischen Lehrbeispiele besaßen, nicht aus den Manuskripten strichen, ist bezeichnend. Denn indem die Historical Division diffamierende und rassistische Äußerungen wie die von Erhard Raus unkritisch übernahm und ihnen durch die Veröffentlichung als DA-Pamphlet sogar den offiziellen Stempel des Armee-Ministeriums zugestand, verlieh sie den Rechtfertigungsstrategien der ehemaligen Wehrmachtsoffiziere ein besonderes Gewicht. Auch dass die Historical Division in den Vorworten zu den DA-Pamphlets gelegentlich ausdrücklich darauf verwies, dass die deutschen „Vorurteile“ unverändert übernommen worden seien, erscheint da eher als Versicherung gegen mögliche Kritik an dieser Praxis. Denn es stellt sich doch die Frage, weshalb diese Vorurteile - wenn sie denn schon als solche erkannt wurden - unkommentiert in einer offiziellen Publikation des amerikanischen Heeres-Ministeriums an die eigene Truppe weiterverbreitet werden sollten. Darüber hinaus erscheint es fraglich, ob die Mehrheit der Adressaten

650 Army Attache Major General R. W. Grow, Office of the Army Attache, American Embassy Moscow, USSR, Schreiben an den Assistant Chief of Staff, G-2, Department of the Army, 8. 1. 1951, in: NARA, RG 319, Box 56, Folder 9.

651 Department of the Army (Hg.), DA-Pamphlet 20-230. Russian Combat Methods in World War II, S. 3. 
solcher Broschüren sich überhaupt die Mühe machte, das Vorwort und damit die halbherzige Warnung vor eventuellen Vorurteilen im Text zu lesen.

\section{Experten im Kampf gegen die Sowjetunion}

Das antirussische Feindbild der ehemaligen Wehrmachtselite deckte sich nicht nur mit den Vorstellungen ihrer amerikanischen Kollegen, sondern fügte sich auch fast nahtlos in das Russen- und Russlandbild weiter Teile der westdeutschen Bevölkerung ein. Dieses basierte auf antirussischen Traditionen des 19. und frühen 20. Jahrhunderts und hatte durch den Zweiten Weltkrieg weitere Nahrung erfahren - denn in den 1940er Jahren waren Millionen Deutsche direkt oder zumindest indirekt über das Schicksal von Familienmitgliedern oder Bekannten mit Kriegs-, Vertreibungs- und Gefangenschaftserfahrungen konfrontiert gewesen. ${ }^{652}$ In den 1950er Jahren waren literarische, dokumentarische und autobiographische Verarbeitungen dieser Erfahrungen auch deshalb so beliebt, weil sich so viele Deutsche persönlich mit den darin angebotenen Interpretationen der jüngsten Ereignisse identifizieren konnten. Bücher wie Einen bessern findst du nicht ${ }^{653}$ von Andreas Engermann, Heinz Konsaliks Der Arzt von Stalingrad ${ }^{654}$ oder Es begann an der Weichsel ${ }^{655}$ von Jürgen Thorwald erreichten Millionen von Lesern. Die Autoren bedienten sich dabei derselben negativen Stereotype, auf die auch die ehemaligen Wehrmachtsoffiziere in ihren Studien zurückgriffen. ${ }^{656}$

Hier zeigte sich das Bedürfnis einer großen Mehrheit der westdeutschen Bevölkerung nach Kontinuität. Vor dem Hintergrund des Kalten Krieges konnte die Vorstellung von einer andauernden Bedrohung aus dem Osten über das Ende des Nationalsozialismus hinaus in Übereinstimmung mit den Siegermächten und der Bundesregierung aufrechterhalten werden. Die Kombination des Russlandfeindbildes mit dem Antikommunismus der westlichen Wertegemeinschaft erfüllte in der jungen Bundesrepublik, in der die Zustimmung zur parlamentarischen Demokratie noch keineswegs gefestigt war, eine wesentliche integrative Funktion und diente der Regierung Adenauer als ein wichtiges Herrschaftsinstrument, zum Beispiel zur Durchsetzung der Wiederbewaffnung. ${ }^{657}$

652 So waren etwa neun Millionen Deutsche als Soldaten und/oder Kriegsgefangene in der Sowjetunion gewesen, zehn bis zwölf Millionen Deutsche waren 1945 vor den sowjetischen Truppen geflohen oder vertrieben worden. Vgl. Jahn, Russlandbild und Antikommunismus in der bundesdeutschen Nachkriegszeit, S. 225-226 und S. 229.

${ }^{653}$ Engermann, Einen bessern findst du nicht.

${ }^{654}$ Konsalik, Der Arzt von Stalingrad.

655 Thorwald, Es begann an der Weichsel.

656 So beschreibt zum Beispiel Konsalik den Angriff sowjetischer Truppen mit den Worten: „[U]nd dann stürmten sie [...] wie Ameisen, erdbraun gefärbt, krochen sie aus den Löchern und Bunkern aus den Trümmern und verborgenen Stahlgerüsten. [...] Tataren und Mongolen, Kirgisen und Kalmücken [...] sie stürmten auf uns zu und schrien laut beim Laufen." Konsalik, Der Arzt von Stalingrad, S. 44. Und Thorwald charakterisiert das Vorrücken der Roten Armee so: „Es schien, als sei der Teufel leibhaftig auf Oberschlesien herniedergestiegen. Mit den sowjetischen Armeen war die ,Hunnenbarbarei der innerasiatischen Steppe' nicht nur in der Propaganda, sondern in vollster Wirklichkeit hereingebrochen." Thorwald, Es begann an der Weichsel, S. 118-119.

657 Jahn, Russlandbild und Antikommunismus in der bundesdeutschen Nachkriegszeit, S. 233-234. 
Diese sowohl von den westlichen Siegermächten als auch der neuen westdeutschen politischen Führungsschicht sanktionierte Aufrechterhaltung des Russlandfeindbildes kam den Bedürfnissen der ehemaligen Wehrmachtsoffiziere in besonderem Maße entgegen: Es erlaubte ihnen, eine klare Unterscheidung zwischen der Wehrmacht und dem nationalsozialistischen Herrschaftssystem vorzunehmen und dem Krieg gegen die Sowjetunion und den eigenen Handlungen während dieses Feldzuges einen tieferen, über die nationalsozialistischen Herrschaftsinteressen hinausgehenden Sinn zu verleihen. ${ }^{658}$ Die rhetorisch-ideologische Angliederung Deutschlands an den Westen einerseits und die fortdauernde radikale Abgrenzung vom kommunistischen Osten andererseits hatte deshalb für die ehemalige Wehrmachtselite eine wichtige Funktion bei der Neukonstruierung ihres Selbstverständnisses: Ihrer eigentlichen Aufgabe als Soldaten beraubt, fanden sie eine neue Berufung als Experten im Kampf des Westens gegen die Sowjetunion. ${ }^{659}$

Das zunehmende Interesse der Amerikaner an kriegsgeschichtlichen Studien zum östlichen Kriegsschauplatz kam diesem neuen Selbstverständnis entgegen und förderte es nachhaltig. Schließlich bot die Historical Division den ehemaligen Berufsoffizieren zu einer Zeit, in der sich ihre beruflichen Perspektiven vielfach auf Gelegenheits- und Aushilfstätigkeiten beschränkten, nicht nur ein recht attraktives wirtschaftliches Auskommen, sondern auch ein sinnstiftendes Betätigungsfeld, das den aus der Niederlage von 1945 resultierenden biographischen Bruch abmilderte. Dabei wog die Wertschätzung, welche die kriegsgeschichtlichen Studien von der U.S. Armee erfuhren, angesichts der als demütigend empfundenen allgemeinen Behandlung der ehemaligen Wehrmachtselite umso schwerer. In der Kooperation mit der Historical Division konnten die ehemaligen Generalstabsoffiziere mit ihrem „Können“, das in Deutschland „mehr als eine Belastung denn als ein Vorteil gewertet" 660 werde, wenigstens "noch etwas Nützliches leisten",661 und stellten ihr Wissen deshalb „gern den westlichen Alliierten"662 zur Verfügung.

Die Zusammenarbeit mit der Historical Division bot einen nahezu idealen Rahmen für die ehemaligen deutschen Militärs, um ihre Kriegserfahrungen als wertvolles Kapital im Ost-West-Konflikt zu vermarkten und sich den amerikanischen Streitkräften als kompetente Ratgeber anzubieten. Denn Franz Halder und seine Kollegen waren überzeugt, dass die Amerikaner bei der „militärische[n] Sicherung des freien europäischen Westens" auf die Ausnutzung der deutschen „Erfahrungen im Osten" angewiesen sein würden. ${ }^{663}$ Der ehemalige Generalstabschef wollte die Zusammenarbeit mit der Historical Division deshalb als einen „aus langer Berufserfahrung geschöpfte[n] Beitrag“ zu den Aufgaben der „U.S. Arm[ee] als Hüter des Friedens und als Kämpfer für den Geist wahrer Freiheit" verstanden

658 Ebd., S. 234.

659 Naumann, Sicherheitselite und außenpolitischer Stil, S. 8.

${ }^{660}$ Halder, Schreiben an Hermann Ochsner, 22. 3. 1948, in: BArch, N 220/202.

661 Ebd.

662 Günther Blumentritt, Gedanken über Kriegsgeschichtsschreibung, Dezember 1946, in: BArch, ZA 1/645. Hervorhebung im Original.

${ }^{663}$ Franz Halder, Zum 21. 11. 1955. Ansprache anlässlich des 10. Jahrestages der Kooperation mit der Historical Division, 15. 11. 1955, in: BArch, N 220/118. 
wissen. ${ }^{664}$ Indem sie „den Westmächten“ mittels ihrer Studien „all die Erfahrungen zugänglich“ machten, „die [diese] selbst nicht machen konnten“, 665 sollten „[d]eutsches Denken und deutsche Erfahrung“ für „den Aufbau des Westens [...] nutzbar“ gemacht ${ }^{666}$ und somit ein „wertvolle[r] Beitrag [für die] Verteidigung der freien Welt“667 vor einer drohenden „Zerstörung [...] durch den Kommunismus"668 geleistet werden.

Wie die steigende Nachfrage nach deutschen Studien - vor allem zwischen 1948 und 1954 - zeigt, ${ }^{669}$ nahmen die Amerikaner dieses Angebot gerne an. Führende U.S. Militärs betonten immer wieder, wie vorteilhaft die Expertise der Deutschen und vor allem ihre Erfahrungen im Kampf gegen das kommunistische Russland für die U.S. Armee seien. ${ }^{670}$ So schrieb zum Beispiel der Oberbefehlshaber der U.S. Streitkräfte in Europa, Henry Irving Hodes, im Rückblick auf mehr als zehn Jahre fruchtbarer Kooperation im März 1959 an Franz Halder:

„The product of your labor is much more than mere pages of military history. Already it has provided valuable material for the organization of our military forces to meet the threat of communist aggression [...]. Thus, your work has developed another area of alliance between our two great nations for the joint defense of our democratic ways of life."671

Wichtiger als solche schönen Worte war für die ehemalige Wehrmachtselite jedoch, dass sich die Anerkennung ihrer Kompetenzen ganz konkret in der vielfältigen Verwendung der kriegsgeschichtlichen Studien innerhalb der U.S. Armee, der Einladung zu Vorträgen an den Service Schools und der Konsultation der Control Group für aktuelle Fragestellungen zeigte. ${ }^{672}$

Die große Wertschätzung, die die ehemaligen deutschen Offiziere von Seiten der Amerikaner erfuhren, nährte ihre Hoffnung, über die kriegsgeschichtliche Kooperation die Werte ihrer Zunft bewahren und für die Zukunft nutzbar machen zu können. Angesichts der Bemühungen der Regierung Adenauer, mit den als militaristisch diskreditierten preußischen Militärtraditionen zu brechen und stattdessen eine Armee politisch informierter Bürgersoldaten zu schaffen, ${ }^{673}$ so-

${ }^{664}$ Ders., Schreiben an Orlando Ward, 22.3. 1950, in: BArch, N 220/202.

665 Kesselring, Tagebuchaufzeichnungen aus der Zeit der Kriegsgefangenschaft, Blatt 48, in: BArch, $N 750 / 2$.

666 Halder, Schreiben an Alfred Toppe, 9. 3. 1953, in: BArch, N 220/203.

667 Ders., Schreiben an Wilbur S. Nye, 12. 1. 1952, in: BArch, N 220/202.

668 Halders Rede wird zitiert in James F. Scoggin und Frank C. Mahin, Weekly Report Seventh Campaign Group, 8. 2. 1947-15. 3. 1947, in: NARA, RG 549, Box 3172.

${ }^{669}$ Vgl. hierzu ausführlich oben, Teil II, Kapitel 3.1 und Teil III, Kapitel 2.

670 So zum Beispiel Paul M. Robinett, Schreiben an Secretary of War, Wilber M. Brucker, 30. 3. 1958, in: George C. Marshall Research Library, Bestand 28, Box 14, Folder 9.

671 Henry Irving Hodes, Schreiben an Franz Halder, 18. 3. 1959, in: BArch, N 220/90.

672 Vgl. hierzu ausführlich oben, Teil III, Kapitel 2.

673 Vgl. hierzu Bald, Militärreform und Grundgesetz, in: Aus Politik und Zeitgeschichte (2005), S. 22-26. Allerdings gelang es den Traditionalisten unter den ehemaligen Wehrmachtsoffizieren, die ab 1950 am Aufbau der Bundeswehr beteiligt waren, zumindest teilweise, sich gegen die Versuche des Reformers Wolf Graf Baudissin durchzusetzen und an alte Traditionsmuster anzuknüpfen. Vgl. Bald, „Bürger in Uniform“, in: Schildt/ Sywottek (Hg.), Modernisierung im Wiederaufbau, S. 392-402; Ders., Alte Kameraden, in: Ulrich/Breymayer/Wieland (Hg.), Willensmenschen, S. 50-64; Ders., Kämpfe um 
wie dem Vorsatz der westeuropäischen Staaten, den Einfluss des „alten soldatischen Denkens“674 auf mögliche neue deutsche Streitkräfte „aufs äußerste zu beschneiden“"675, stand für Franz Halder Anfang der 1950er Jahre fest:

„Wenn man also deutsches Denken und deutsche Erfahrung für den militärischen Aufbau des Westens, auf den es uns unheilbaren Idealisten ankommt, nutzbar machen will, so darf man den Beitrag nicht in den Reißwolf der kleineuropäischen Eifersuchtsmaschine stecken, sondern muss ihn dahin geben, wo die geringeren Widerstände vorliegen und außerdem der Boden fruchtbarer ist." 676

Ausgehend von den guten Erfahrungen mit der Historical Division hielt Halder die Bedingungen für die Fortführung deutschen Generalstabsdenkens in der U.S. Armee für besonders günstig. Schließlich hatte die Historical Division „die Leistung der geschlagenen ehemaligen deutschen Armee“ in ihrer amtlichen Kriegsgeschichte nach Meinung der ehemaligen deutschen Offiziere bisher „in ritterlicher Weise gewürdigt“. 677 Während sich die Bundesregierung jahrelang nicht darum gekümmert habe, „der übermenschlichen Leistung des deutschen Soldaten im letzten Weltkrieg ein literarisches Denkmal“ zu setzen und es „ängstlich vermieden [habe], sich um die Sammlung militärischer Erfahrungen aus der fluchwürdigen Vergangenheit zu bekümmern“, hätten sich die Amerikaner der Nutzbarmachung eben dieser Erfahrungen angenommen. ${ }^{678}$ Die Control Group verlegte sich deshalb Anfang der 1950er Jahre darauf, ihr Wissen und ihre Werte zunächst an die Amerikaner weiterzugeben. Dabei bot die Kooperation mit der Historical Division einen guten Ansatzpunkt, deren Arbeit die ehemalige Wehrmachtselite „durch sachliche Vorschläge [...] in die richtigen Bahnen“ leiten wollte. ${ }^{679}$

\section{2 "Unseren Truppen ein Denkmal“ setzen680}

\section{Geschichtspolitische Ziele der ehemaligen Wehrmachtselite}

Wie bereits beschrieben bildete die rhetorische Westorientierung unter den Vorzeichen des Kalten Krieges eine wichtige Komponente bei den Versuchen der ehemaligen Wehrmachtsoffiziere, eine Sinnstiftung sowohl für ihre Rolle im Nationalsozialismus als auch ihre künftige Rolle im Gesamtkomplex der westlichen Verteidigungs- und Wertegemeinschaft zu betreiben. Die Fortführung des traditionellen deutschen Russlandfeindbildes in der Rhetorik von Deutschlands Zuge-

die Dominanz des Militärischen, in: Bald/Klotz/Wette (Hg.), Mythos Wehrmacht, S. 17-65; Ders., Die Wehrmacht als Vorbild, in: Geschichte, Politik und ihre Didaktik 29 (2001), S. 305-313. Zu Baudissin siehe zum Beispiel Schlaffer/Schmidt (Hg.), Wolf Graf von Baudissin 1907-1993.

674 Franz Halder, Schreiben an Alfred Toppe, 9. 3. 1953, in: BArch, N 220/203.

675 Ebd.

676 Ebd.

677 Halder, Schreiben an Orlando Ward, 22. 3. 1950, in: BArch, N 220/202.

678 Ders., Schreiben an Alfred Toppe, 9.3. 1953, in: BArch, N 220/203.

679 Franz Halder, Schreiben an Gotthard Heinrici, 25. 8. 1951, in: BArch, N 265/71.

680 Georg von Küchler, Richtlinien für die Kriegsgeschichtsschreibung in Garmisch, 7.3. 1947, in: BArch, ZA 1/70. 
hörigkeit zum Westen und die Verschmelzung des eigenen Feindbildes mit dem der Amerikaner eröffnete ihnen nicht nur eine Zukunftsperspektive als Experten im Konflikt mit der Sowjetunion, sondern half ihnen außerdem, ihre Vergangenheit zu rationalisieren und eine aktive Geschichtspolitik zu betreiben. Tatsächlich erkannte die ehemalige Wehrmachtselite von Anfang an, dass die kriegsgeschichtliche Kooperation mit den Amerikanern ihnen die Möglichkeit bot, ihre eigene Interpretation der Vergangenheit $\mathrm{zu}$ formulieren und $\mathrm{zu}$ artikulieren und so das künftige Bild von der Wehrmacht und ihrer Rolle im Zweiten Weltkrieg mitzubestimmen.

Nachdem sie Mitte Mai 1945 im Vernehmungslager der amerikanischen 7. Armee erstmals um die Beantwortung kriegsgeschichtlicher Fragen gebeten worden waren, diskutierten beispielsweise Wilhelm Ritter von Leeb, Leo Geyr von Schweppenburg und Heinz Guderian die Vor- und Nachteile einer kriegsgeschichtlichen Zusammenarbeit mit den Amerikanern. Das in englischer Übersetzung vorliegende Abhörprotokoll dieser Unterredung offenbart, wie sehr sich die deutschen Offiziere sorgten, dass die Wehrmachtsführung durch die Enthüllung eklatanter Fehlentscheidungen „zum Gespött der ganzen Welt“ werden würde.681 Die drei Generäle beschäftigten sich deshalb intensiv mit der Frage, in welchem Licht die deutsche Wehrmacht und insbesondere das Offizierskorps den Amerikanern gegenüber präsentiert werden sollten. ${ }^{682}$ Vor allem die Bewertung politischer Vorgänge und einzelner Persönlichkeiten sollte dabei unter allen Umständen unterbleiben, damit sich die Amerikaner keine „günstigen oder unvorteilhaften Vorurteile gegenüber bestimmten Personen“ bilden würden. ${ }^{683}$ In diesem Zusammenhang machte Leeb seine Haltung unmissverständlich klar:

„The German officer has done nothing but his duty in this war. Please emphasize that whenever possible, just as I have done whenever somebody broached the question. The German officer did not care whether his commander was National-Socialist or a Hindenburg. The lower the rank, the narrower the viewpoint. The German officer was content in confining his interests to his own narrow sphere. There can be no harm in saying this. "684

Neben den eindeutig apologetischen Absichten der drei Generäle verdeutlicht die Unterredung auch, dass hochrangige Wehrmachtsoffiziere über die Niederlage hinaus ihre Führungsfunktion gegenüber ihren ehemaligen Untergebenen beibehielten. Geyr von Schweppenburg und Guderian wandten sich an Leeb, weil dieser der dienstälteste Offizier im Lager war. Vor allem in den ersten drei Jahren der kriegsgeschichtlichen Kooperation, als sich die meisten der beteiligten Offiziere noch in Kriegsgefangenschaft beziehungsweise in Zivilinternierung befanden und damit von äußeren, zivilen Einflüssen weitgehend isoliert waren, konnten hochrangige und angesehene Offiziere wie Franz Halder in Allendorf bzw. Neustadt,

${ }^{681}$ Seventh Army Interrogation Center, Ref No SAIC/X/12, 26.7.1945, in: NARA, RG 498, Box 73, Folder 2. Das Abhörprotokoll ist falsch datiert und stammt nicht vom 26. Juli, sondern höchstwahrscheinlich vom 26. Mai 1945. Für den Hinweis danke ich Jens Brüggemann.

682 Ebd.

683 Ebd.

${ }^{684}$ Ebd. Hervorhebung im Original. 
Georg von Küchler in Garmisch und Albert Kesselring in Werl dank der weitgehenden Aufrechterhaltung der militärischen Hierarchien in den Lagern und Gefängnissen kraft ihrer andauernden Autorität den Interpretationsrahmen vorgeben, innerhalb dessen die ehemaligen Wehrmachtsoffiziere sich und ihre Rolle während des Zweiten Weltkrieges darstellten. ${ }^{685}$

Für die in Garmisch tätigen Militärs steckte Georg von Küchler diesen Interpretationsrahmen im März 1947 in einer Richtlinie für die Kriegsgeschichtsschreibung ab. Darin wies der ehemalige Generalfeldmarschall seine Kameraden ausdrücklich an, „nicht amerikanische, sondern deutsche Kriegsgeschichte“ zu schreiben und „die deutschen Taten, von deutschem Standpunkt [aus] gesehen“ darzustellen. ${ }^{686}$ Außerdem mahnte er seine Kameraden ausdrücklich zur Vorsicht. Anstatt Führungsgeheimnisse zu enthüllen, sollten sie in ihren Berichten ausschließlich die „Tatsachen, de[n] Verlauf der Kampfhandlungen und die Vorgänge auf deutscher Seite" schildern. ${ }^{687}$ Kritik durfte nicht geübt werden. Darüber hinaus sollten auf keinen Fall Kameraden belastet und stattdessen die positiven Leistungen der deutschen Truppen betont werden. ${ }^{688}$

Die Unterredung zwischen Guderian, Leeb und Geyr von Schweppenburg sowie Küchlers Dienstanweisung machen deutlich, dass eines der Hauptmotive der ehemaligen Wehrmachtselite für die Kooperation mit der Historical Division von Anfang an darin lag, die Zusammenarbeit für die Revision des negativen Images der deutschen Streitkräfte zu nutzen. In den kriegsgeschichtlichen Studien wollten die Autoren vor allem der „Ehre der deutschen Armee“689 gedenken, die militärischen Leistungen der „deutschen Truppen“690 gebührend würdigen und - je nach Ausprägung des elitären Selbstbewusstseins - den einfachen „Soldaten“691 oder der „heiligen Institution des Deutschen Generalstabs ein Denkmal“692 setzen. Um den Ruf der deutschen Streitkräfte wiederherzustellen, musste allerdings die öffentliche Assoziation der Wehrmacht mit Kriegsverbrechen und Völkermord aufgelöst und die alleinige Verantwortung für Ausbruch und Verlauf des Zweiten Weltkrieges auf nicht-militärische Stellen abgewälzt werden. Die wichtigsten Argumente in der Imagekampagne der ehemaligen Wehrmachtselite sind bereits angeklungen - der Mythos von der politischen Abstinenz der Wehrmacht, das Abwälzen der Verantwortung auf Hitler und seine Schergen und die Mär von der Verteidigung des Abendlandes gegen den vom Osten anbrandenden Bolschewismus. Im Folgenden sollen diese Argumentationsstrategien nun etwas ausführlicher dargestellt werden.

685 Vgl. zu den Mechanismen der kriegsgeschichtlichen Arbeit oben, Teil II, Kapitel 2 und 3. 686 Georg von Küchler, Memorandum, 7.3.1947, in: BArch, ZA 1/70. Hervorhebung im Original.

687 Ebd.

688 Ebd.

689 Alfred Toppe, Die Kriegsgeschichtsschreibung in Königstein/Taunus von Beginn bis April 1949, S. 28, in: BArch, ZA 1/1824.

690 Georg von Küchler, Memorandum, 7. 3. 1947, in: BArch, ZA 1/70.

${ }^{691}$ Kesselring, Tagebuchaufzeichnungen aus der Zeit der Kriegsgefangenschaft, Blatt 50, in: BArch, N 750/2.

${ }^{692}$ Franz Halder, Schreiben an Waldemar Erfurth, 26. 6. 1952, in: BArch, ZA 1/2651. 


\section{Argumentationsstrategien}

Eines der gängigsten Motive bei der Kolportage der Legende von der „sauberen“ Wehrmacht war das des „unpolitischen Soldaten“. Es portraitierte die Streitkräfte für die Zeit des Nationalsozialismus als un- und überpolitisch und behauptete, dass die Wehrmacht Distanz gegenüber dem Regime gewahrt habe. Statt um Politik hätten sich die Spitzenmilitärs ausschließlich um ihre militärischen Aufgaben gekümmert und dabei nicht etwa dem Führer, sondern Volk und Vaterland, ja indirekt sogar ganz Europa gedient. Von Verbrechen habe man entweder nichts gewusst - oder aber versucht, diese zu verhindern bzw. abzumildern. Die Wehrmacht war in dieser Darstellung ein Hort der soldatischen Tugend und Ritterlichkeit, ja gar ein Zufluchtsort all derjenigen, die sich dem Parteieinfluss entziehen wollten. ${ }^{693}$

Das Bild vom unpolitischen Wehrmachtsgeneral hatte jedoch wenig mit der Realität des nationalsozialistischen Staates zu tun. Auch wenn die ehemaligen Militärs es nach 1945 vehement bestritten, so hatte sich doch eine Mehrheit in der Zwischenkriegszeit und während des Zweiten Weltkrieges dezidiert politisch positioniert. Die Ablehnung der Weimarer Republik und die Anbiederung an die NSDAP waren Ausdruck einer politischen Grundeinstellung, die zum einen den autoritären Staat der Demokratie grundsätzlich vorzog, zum anderen den Krieg als positive, ja natürliche und letztlich unvermeidliche Kraft betrachtete und daher nach möglichst umfassender Aufrüstung strebte. ${ }^{694}$ Entgegen andersartiger Behauptungen war die Reichswehr und später die Wehrmacht ein enormer Machtfaktor und ihre Führer übten sowohl während der Weimarer Republik als auch in der Anfangsphase des Dritten Reiches durchaus maßgeblichen politischen Einfluss aus. ${ }^{695}$ Schon vor 1933 stand die Mehrheit des Offizierskorps dem politischen Programm der NSDAP und vor allem deren revisionistischen und revanchistischen außenpolitischen Zielen aufgeschlossen gegenüber. ${ }^{696} \mathrm{Nach}$ der Ernennung Hitlers zum Reichskanzler leistete die Reichswehr dem neuen Regime dann aktive Hilfestellung bei der Aushebelung der Demokratie, indem sie bei der Ausschaltung und Verfolgung der politischen Linken eine „wohlwollende

${ }^{693}$ Naumann, Die „saubere“ Wehrmacht, in: Mittelweg 367 (1998), S. 9; Bartov, Wem gehört die Geschichte?, in: Naumann (Hg.), Vernichtungskrieg. Verbrechen der Wehrmacht 1941-1944, S. 606; Hillmann, Der Mythos vom unpolitischen Soldaten, in: Epkenhans (Hg.), Die Suche nach Orientierung in deutschen Streitkräften 1871-1990, S. 41.

${ }^{694}$ Hillmann, Der Mythos vom unpolitischen Soldaten, S. 45-46; Wette, The Wehrmacht, S. 140-141; Graml, Wehrmacht im Dritten Reich, in: Vierteljahrshefte für Zeitgeschichte 45 (1997), S. 365-366.

695 Außenpolitisch setzte die Reichswehr in den 1920er Jahren zum Beispiel die Annäherung an die Sowjetunion und die, nach den Bestimmungen des Versailler Vertrages, illegale militärische Kooperation mit der Roten Armee durch und behinderte damit eine Annäherung zwischen Deutschland und Frankreich. Innenpolitisch hatte die Reichswehrführung zum Beispiel Anteil am Sturz des Kabinetts Müller und der Ernennung Heinrich Brünings zum Reichskanzler. Vgl. Graml, Wehrmacht im Dritten Reich, S. 367-368.

696 Volkmann, Von Blomberg zu Keitel - Die Wehrmachtführung und die Demontage des Rechtsstaates, in: Müller/Volkmann (Hg.), Die Wehrmacht, S. 48 und S. 53. 
Neutralität“ wahrte, die im Grunde einer „Mittäterschaft“ gleichkam und auf eine künftige „Partnerschaft“ mit dem neuen Regime ausgerichtet war. ${ }^{697}$ Wenig später leistete das Militär den Machthabern aktive Unterstützung bei der Ermordung zahlreicher SA-Führer und anderer unbeliebter Personen, unter denen bezeichnenderweise auch zwei Reichswehrgeneräle, Kurt von Schleicher und Ferdinand von Bredow, waren. Und als Hitler sich nach dem Tod Hindenburgs das Amt des Reichspräsidenten aneignete und die Wehrmacht statt auf die Verfassung künftig auf sich selbst als Staatsoberhaupt vereidigte, wurde auch dies von der Reichswehrführung hingenommen und unterstützt. ${ }^{698}$ Die deutsche Militärelite machte sich damit ganz bewusst zum Komplizen „bei der Liquidierung von Demokratie und Parlamentarismus "699 und trug in der instabilen Anfangsphase des Regimes „entscheidend zur Festigung und Etablierung des NS-Staates“ bei. 700

Tatsächlich identifizierte sich die Reichswehrführung stark mit diesem neuen Staat und beteiligte sich aktiv an der Politik des Regimes. Im Mai 1933 wurde das Reichsbeamtengesetz in der Weise geändert, dass Offiziere bei der Übernahme eines Ministeramtes künftig im aktiven Dienst verblieben. In der Folge traten sowohl Reichswehrminister Werner von Blomberg als auch Hermann Göring, Luftfahrtminister und Preußischer Innenminister, wieder in die Reichswehr ein d.h., die Reichswehrführung saß nun mit am Kabinettstisch und war damit für die Politik der Regierung nach innen wie nach außen direkt mitverantwortlich. Ab 1938 genossen auch die Oberbefehlshaber der Marine und des Heeres Kabinettsrang. Darüber hinaus hatten die Oberbefehlshaber der Teilstreitkräfte, später auch der Generalstabschef des Heeres, unmittelbares Vortragsrecht bei Hitler. ${ }^{701}$ Auch intern wurden die Streitkräfte konsequent auf die politische Linie des Regimes gebracht. Bereits im Juni 1933 hatte Reichswehrminister Blomberg erklärt, dass die Zeit des „unpolitisch seins“ nun vorbei sei, stattdessen gelte es, „der nationalen Bewegung mit aller Hingabe zu dienen".702 Zwei Jahre später schrieb das neue Wehrgesetz fest, „dass jeder, der in der Wehrmacht seinen Dienst für Führer und Volk leistet[e], zu einer Festigung des [nationalsozialistischen] Staatsgedankens" beizutragen habe. ${ }^{703}$ Nach dem gescheiterten Attentat auf Hitler vom 20. Juli 1944 wurde die politische Stellung der Wehrmachtsangehörigen sogar noch deutlicher formuliert: Sie hatten nun „die Pflicht, dienstlich und außerdienstlich im Sinne nationalsozialistischer Weltanschauung zu wirken und sich

697 Graml, Wehrmacht im Dritten Reich, S. 368.

698 Ebd., S. 369; Volkmann, Von Blomberg zu Keitel - Die Wehrmachtführung und die Demontage des Rechtsstaates, S. 58-60.

699 Graml, Wehrmacht im Dritten Reich, S. 369.

700 Volkmann, Von Blomberg zu Keitel - Die Wehrmachtführung und die Demontage des Rechtsstaates, S. 54.

${ }^{701}$ Ebd., S. 56-57; Volkmann, Zur Verantwortlichkeit der Wehrmacht, in: Müller/Volkmann (Hg.), Die Wehrmacht, S. 1197-1198.

702 Aufz. Liebmanns über Ausführungen Blombergs, 1.6.1933, BArch, MSg 1/1668, zit. nach Volkmann, Von Blomberg zu Keitel - Die Wehrmachtführung und die Demontage des Rechtsstaates, S. 56.

703 Hillmann, Der Mythos vom unpolitischen Soldaten, S. 39-40, Zitat S. 39. 
jederzeit für sie einzusetzen“. Vor allem den Offizieren fiel die Aufgabe zu, „ihre Untergebenen nationalsozialistisch zu erziehen und zu führen".704

Auch die in der Nachkriegszeit oft betonte Distanz zu Hitler entsprach meist nicht der Realität. Die Beziehung der Generalität zum Diktator war in der Regel durch Vertrauen, Anerkennung und Unterordnung geprägt; und selbst die Konflikte einzelner Offiziere mit Hitler bezogen sich häufig auf rein militärisch-taktische Fragen und waren kaum Ausdruck einer Ablehnung der generellen Politik oder Strategie des Führers. Die Wehrmachtsführung hatte denn auch kaum moralische Bedenken, die rassisch-ideologischen Vorstellungen der Regierung in konkrete militärische Befehle umzumünzen und so den Vernichtungskrieg mit vorzubereiten. ${ }^{705}$ Indem sie Hitler Hilfestellung bei der Ausschaltung jeglicher politischer Gegenkräfte gab und ihm den Weg zur Vervollkommnung seiner Macht ebneten beraubte sich die Reichswehr jedoch letztlich selbst jeglicher innenpolitischer Handlungsspielräume. ${ }^{706}$ Das entband sie jedoch nicht von einer Mitverantwortung für die Verbrechen des Regimes. Dass es sich beim Feldzug gegen die Sowjetunion um einen verbrecherischen Vernichtungskrieg handeln würde, musste der Wehrmachtsspitze klar sein, wurde sie doch von Hitler in eindeutiger Weise darauf eingestimmt. ${ }^{707}$ Die Formulierung der verbrecherischen Befehle, zum Teil in vorauseilendem Gehorsam, sowie deren Weitergabe und Durchführung zeigt darüber hinaus, in welchem Umfang die deutschen Spitzenmilitärs sich mit den Motiven der politischen Führung identifizierten und bereit waren, sich an deren Vernichtungsfeldzug zu beteiligen. Die Ermordung tausender politischer Kommissare auf Grundlage des Kommissarbefehls, die Tötung ungezählter Zivilisten im Rahmen des Partisanenkrieges und der Tod Millionen sowjetischer Kriegsgefangener gehen direkt auf das Konto der Wehrmacht. Darüber hinaus stimmte die Wehrmachtsspitze den Vernichtungsaktionen der SSEinsatzgruppen bereits im Vorfeld des Russlandfeldzuges $\mathrm{zu}$ und arbeitete schließlich auch bei der Durchführung des Holocaust eng mit diesen zusammen. ${ }^{708}$

Trotz oder gerade wegen dieser Verantwortung der Wehrmachtselite für Kriegsund NS-Verbrechen, bemühten sich zahlreiche ehemalige Militärs nach dem Zweiten Weltkrieg darum, ihre tragende Rolle im NS-Unrechtsstaat herunterzu-

704 Reichsgesetzblatt, Teil 1, Nr. 59/1944, S. 317: Erstes Gesetz zur Änderung und Ergänzung des Wehrgesetzes vom 24.9.1944, $\$ 26$ Abs. 1.

705 Wette, The Wehrmacht, S. 150 und S. 154.

706 Vgl. Graml, Wehrmacht im Dritten Reich, S. 370-371.

707 Siehe zum Beispiel Franz Halder, Kriegstagebuch, bearb. von Hans-Adolf Jacobsen, Bd. 2: Von der geplanten Landung in England bis um Beginn des Ostfeldzuges (1.7. 1940-21. 6. 1941), S. 336-337.

${ }^{708}$ Hier sei nur auf einen kleinen Teil der Literatur hingewiesen: Streim, Die Behandlung sowjetischer Kriegsgefangener im „Fall Barbarossa“; Streit, Die Behandlung der sowjetischen Kriegsgefangenen und völkerrechtliche Probleme des Krieges gegen die Sowjetunion, in: Ueberschär/Wette (Hg.), „Unternehmen Barbarossa“, S. 197-218; Ders., Keine Kameraden; Arnold, Die Wehrmacht und die Besatzungspolitik in den besetzten Gebieten der Sowjetunion; Hartmann, Wehrmacht im Ostkrieg; Hürter, Hitlers Heerführer; Heer, Killing Fields - Die Wehrmacht und der Holocaust, in: Heer (Hg.), Tote Zonen, S. 11-40. 
spielen und ein positives Bild der Wehrmacht zu schaffen. ${ }^{709}$ Neben den zahlreichen Memoiren, die in den späten 1940er und in den 1950er Jahren erschienen, wurden auch die unter dem Dach der Historical Division verfassten kriegsgeschichtlichen Studien und die Beziehungen zur U.S. Armee zum Medium dieser Legende von der „sauberen“ Wehrmacht. ${ }^{710}$ Darin betonten die deutschen Offiziere immer und immer wieder ihre unpolitische Haltung während des Dritten Reiches und stritten jegliche Verantwortung für Verbrechen rundheraus ab.

So wandte sich zum Beispiel Friedrich von Boetticher entschieden gegen die Vorstellung, dass „die Generale [...] zum Kriege getrieben“ hätten. ${ }^{711}$ Der Generalstab sei, ganz im Gegenteil, „ein entschiedener Gegner aller Kriegspolitik“ gewesen. ${ }^{712}$ Die Offiziere hätten entsprechend ihrer Erziehung, „sich von der Politik fernzuhalten“, nur ihre Pflicht getan. ${ }^{713}$ Boetticher zeichnete ein Bild, nach dem vor allem das Offizierskorps traditionell „über den Schwächen der Zeit“ gestanden und der „Allgemeinheit“ in „hingebender Selbstlosigkeit“ gedient hätte. ${ }^{714}$ Von „Tagesströmungen und Politik“ hätten Generalstabschefs wie Ludwig Beck sich ferngehalten und stattdessen „das Ideal des Beraters“ verkörpert, „der gehorchte und der Stunde harrte, wo seine Ansichten gefordert und erforderlich“ würden, um dann zu versuchen, „den Aufgaben, die die Staatsführung stellte“, Genüge zu tun. „Gehorsam gegenüber der politischen Führung, nicht Eingreifen in die Politik" - das sei die Maxime gewesen. ${ }^{715}$ Bei allem Gehorsam hätten die Offiziere letztlich jedoch „nicht Herrn Hitler und seiner Partei, sondern dem deutschen Volk“ gedient.

Und „[a]ls das Staatsschiff von Hitler in die Stürme eines Krieges hineingetrieben worden war, waren sie über ihre Pflichten nicht einen Augenblick im Zweifel. Wenn auch Entwicklung und Ausgang des Krieges ihnen Unrecht zu geben schienen, war doch ihr Verhalten sittlich richtig [...]." 716

Günther Blumentritt argumentierte ähnlich, wenn er behauptete, dass das deutsche Offizierskorps seit dem 19. Jahrhundert der Politik „gleichgültig“ gegenübergestanden und sogar „eine innere Abneigung gegen alles Politische“ empfunden habe. ${ }^{717}$ In der Weimarer Republik sei man stolz darauf gewesen, „nichts mit Politik zu tun zu haben"718, und zwischen 1933 und 1945 habe man ohnehin keinen

709 Siehe Wette, Das Bild der Wehrmacht-Elite nach 1945, in: Ueberschär (Hg.), Hitlers militärische Elite, S. 293-308; Ders., Die Wehrmacht, S. 197-244.

710 Zur Memoirenliteratur siehe Düsterberg, Soldat und Kriegserlebnis; Gerstenberger, Strategische Erinnerungen, in: Naumann/Heer (Hg.), Vernichtungskrieg, S. 620-628.

711 Friedrich von Boetticher, MS \# B-484. Eindrücke und Erfahrungen des Militär- und Luftattachés bei der Deutschen Botschaft in Washington, D.C. aus den Jahren 1933 bis 1941, 27.4.1947, S.36, in: NARA Mikrofiche Publication M 1035: Foreign Military Studies.

712 Ebd., S. 50.

713 Ebd., S. 37.

714 Ebd., S. 22.

715 Ebd., S. 22-23.

716 Ebd., S. 51.

717 Günther Blumentritt, Gedanken über „Soldat“ und „Politik“ in der Kriegsgeschichte, Februar 1947, S. 2, in: BArch, ZA 1/656.

718 Ebd., S. 4. 
„politischen Einfluss“ gehabt. ${ }^{719}$ Schließlich würde ein Soldat in einer Diktatur „nicht gefragt, ob er [...] politisch mit einem Krieg übereinstimm[e] oder aus politischen Gründen oder aufgrund des internationalen Rechts Einwände gegen einen Krieg“ habe. Der Soldat werde von den Staatsmännern nur hinsichtlich seiner militärischen Expertise und seiner Einschätzung der militärischen Lage angehört. ${ }^{720}$ Im Hinblick auf die politische Verantwortlichkeit des deutschen Militärs behauptete Blumentritt, dass die Wehrmachtsführung „niemals in die politischen, wahren Absichten" der Staatsführung eingeweiht worden sei. ${ }^{721}$ Gegen den Vorwurf von Kriegsverbrechen verwahrte sich der ehemalige General auf Schärfste: „Wir echten Soldaten alter Erziehung eines berühmten alten Heeres mit hohen Traditionen, haben niemals, gemordet' und niemals, gemeine' Handlungen begangen. Wir haben im Gegenteil geholfen!"722

Auch Franz Halder bestritt jegliche Beteiligung des Heeres an der verbrecherischen Politik des Regimes und ging sogar so weit, die aus den Akten hervorgehenden Beweise für die Beteiligung der Wehrmachtsführung an nationalsozialistischen Verbrechen, wie zum Beispiel die Formulierung der verbrecherischen Befehle und deren Durchführung, als „Zweckmeldungen, beschönigende Berichte, Scheinbefehle und bewusst doppelsinnige Anordnungen" darzustellen - man habe also nur zum Schein mitgemacht, um „Hitlers verhängnisvolle Eingriffe“ in die militärische Führung „abzuschwächen“ ${ }^{723}$

Trotz besseren Wissens versuchten die ehemaligen Militärs, die Verantwortung für den Krieg, seine Verbrechen und schließlich die Niederlage allein Hitler und einer kleinen, ihn umgebenden Gruppe zuzuschreiben. Guderian, Leeb und Geyr von Schweppenburg waren sich in ihrer Besprechung im Sommer 1945 einig, dass gegenüber den Amerikanern deutlich gemacht werden müsse, dass ein einzelnes, krankes „Gehirn für die Katastrophe verantwortlich sei, die über Deutschland, Europa und die ganze Welt gekommen sei“.724 Dass zur treuen Entourage des Diktators mit Wilhelm Keitel und Alfred Jodl auch die obersten Führer der Wehrmacht gezählt hatten, wurde mit dem Hinweis entkräftet, dass diese beiden „nicht Exponenten und Sprecher der deutschen Generale und der deutschen Wehrmacht, sondern Vertraute Hitlers" gewesen seien. ${ }^{725}$ Eines der wichtigsten Anliegen der ehemaligen Wehrmachtselite war zudem, „nicht die Legende entstehen zu

719 Ebd., S. 5.

720 Blumentritt, MS \# B-681. The Military Aspect of a Future War, 29. 10. 1947, S. 2, in: NARA, RG 549, Box 50, Folder: B-681.

721 Ders., MS \# B-647. Gedanken eines ehemaligen Soldaten, S. 1, NARA, RG 549, Box 48, Folder: B-647.

722 Günther Blumentritt, Meine militärische Dienstlaufbahn. Der „20. Juli 1944“, in: BArch, ZA 1/606. Hervorhebung im Original.

${ }^{723}$ Franz Halder, Ansprache des Generalsoberst Halder vor OCMH am 6. 12.1955 in Washington (Entwurf), in: BArch, N 220/118.

724 Seventh Army Interrogation Center, Ref No SAIC/X/12, 26.7. 1945, in: NARA, RG 498, Box 73, Folder 2.

725 Boetticher, MS \# B-484. Eindrücke und Erfahrungen des Militär- und Luftattachés bei der Deutschen Botschaft in Washington, D.C. aus den Jahren 1933 bis 1941, 27. 4. 1947, S. 42, in: NARA, Mikrofiche Publication M 1035: Foreign Military Studies; siehe auch Franz Halder, Schreiben an einen „Professor“, 29. 3. 1955, in: BArch, N 220/79. 
lassen, [...] dass Hitler ein Opfer unzureichender Beratung durch die berufenen Generäle oder des Versagens der Generäle geworden sei“.726 Die Verantwortung für den Krieg und dessen Ausgang liege in erster Linie beim Diktator, der schon lange vor dem Krieg die „Warnung“ der Generäle „vor dem unergründlichen Potential Russlands [...] geflissentlich überhört“ hätte. ${ }^{727}$ Unfähig, „die Gedanken anderer auf sich wirken zu lassen", habe sich Hitler dann während des Russlandfeldzuges der Meinung der Offiziere völlig verschlossen und wahnwitzige Operationen befohlen, um seine „Wunschträume“ zu erfüllen. ${ }^{728}$ Durch die immer stärkeren Eingriffe des sich zum Oberbefehlshaber des Heeres aufspielenden Diktators sei die „Stärke der deutschen Führung“ ab 1943 „getötet“ worden, weil die „bewährten oberen Führer“ des Heeres „nicht mehr [hätten] führen“ dürfen. ${ }^{729}$ Alle „Versuche [...], die Kunst der deutschen Führung [...] zur Geltung zu bringen“, seien aufgrund von Hitlers Unbelehrbarkeit und seiner „Unfähigkeit operativen Denkens“ letztlich „ein hoffnungsloses Beginnen“ gewesen. ${ }^{730}$ Hitler habe durch seine unsinnigen Haltebefehle „nach und nach die herausragende und erfolgreiche Wehrmacht [...] zusammengestutzt und so die unausweichliche Niederlage herbeigeführt. ${ }^{731}$ Als bloßes „Instrument der Politik“ sei die Wehrmacht diesen „Leidensweg“ im Osten dennoch gehorsam gegangen. ${ }^{732}$

Beim Versuch zu erklären, warum die Wehrmacht bis zum bitteren Ende weiterkämpfte, kam schließlich die wohl wirkmächtigste argumentative Strategie der ehemaligen Militärs zum Tragen: die Beschwörung der alten Metapher von Deutschland als schützendem Bollwerk gegen den „Osten“ ${ }^{733}$ Diese „Legende von der Rettungsmission des deutschen Ostheeres" passte sowohl in Westdeutschland als auch jenseits des Atlantiks in die „politische Konjunktur“ der Nachkriegszeit. $^{734}$ Denn die von den Amerikanern sanktionierte Aufrechterhaltung des antikommunistischen Russlandfeindbildes erlaubte den ehemaligen Wehrmachtsoffizieren, den deutschen Ostkrieg von 1941 bis 1945 rhetorisch mit der Frontstellung des Westens gegen die Sowjetunion im Kalten Krieg zu verknüpfen und so den Vernichtungskrieg der Wehrmacht in Osteuropa nachträglich als Akt der Verteidigung westlicher Kultur zu rechtfertigen. Vor allem Günther Blumentritt

726 Friedrich von Boetticher, MS \# B-484. Eindrücke und Erfahrungen des Militär- und Luftattachés bei der Deutschen Botschaft in Washington, D.C. aus den Jahren 1933 bis 1941, 27.4.1947, S.36, in: NARA Mikrofiche Publication M 1035: Foreign Military Studies.

${ }^{727}$ Franz Halder, Schreiben an Friedrich-Wilhelm Hauck, 25.1.1960, in: BArch, ZA $1 / 2548$.

728 Ebd.

729 Blumentritt, MS \# B-647. Gedanken eines ehemaligen Soldaten, S. 34, in: NARA, RG 549, Box 48, Folder: B-647.

730 Halder, Schreiben an Friedrich-Wilhelm Hauck, 25. 1. 1960, in: BArch, ZA 1/2548.

${ }^{731}$ Hqs. EUCOM Historical Division (Hg.), Foreign Military Studies, Vol. I, No. 10. Combat in the East, Karlsruhe 1952, S. 4.

732 Blumentritt, MS \# B-647. Gedanken eines ehemaligen Soldaten, S. 21, in: NARA, RG 549, Box 48, Folder: B-647.

733 Vgl. Wippermann, Die Deutschen und der Osten, S. 40.

734 Naumann, Die „saubere“ Wehrmacht, S. 11. 
betonte unablässig die vermeintlich historische „Mission“735 der Deutschen, Westeuropa vor dem Einfall „asiatischer Horden“ aus dem Osten zu schützen:

„Wir haben das große, viel zu wenig gewürdigte, Verdienst um den europäischen Westen, dass wir in 1000 Jahren deutscher Geschichte wiederholt Europa gerettet haben vor der fremden, östlichen Flut. [...] Hunnen, Avaren, Tartaren, Mongolen, Türken und Slawen. Alle wollten nach Westen und scheiterten vornehmlich an der deutschen Kraft. Das war eine Mission und Realpolitik der Vernunft, denn es ging in erster Linie um unser Dasein, als östlicher Vorposten Westeuropas."736

Dabei sei „[v]iel deutsches Blut geflossen“737 und die Deutschen hätten damit „indirekt für Europa“738 große „Opfer“"739 gebracht. In die Tradition dieser vermeintlichen deutschen Abwehrmission gegen den „Osten“ stellte Blumentritt unter anderem auch die Niederschlagung der kommunistischen Aufstände in Deutschland durch Freikorps und Reichswehr 1919.740 Von 1941 bis 1945 hätten die Deutschen dann erneut „unter unsäglichen Opfern [...] auf Leben und Tod“ gegen den „asiatisch-slawischen Bolschewismus“ gekämpft - dies sei zwar „politisch wahnsinnig - aber für Europa praktisch“ gewesen. ${ }^{741}$ Denn „das deutsche Volk und die deutsche Wehrmacht" hätten die Anders- und Fremdartigkeit des Kommunismus gespürt und deshalb „bis zur Selbstaufgabe verzweifelt dagegen angekämpft. "742 Aus der Perspektive des Westens, so Blumentritt, sei der deutsche Ostkrieg sogar „vorteilhaft“ gewesen, da „der Bolschewismus [...] 1941-1945 durch [Deutschland] erheblich geschwächt" worden sei. ${ }^{743}$ „So gesehen“ habe „die unglückliche Ostpolitik Hitlers 1941 der Westwelt einen großen Dienst erwiesen“, denn immerhin hätten die Deutschen „durch den ungeheuren Kampf 1941-45 im Osten den bolschewistischen Druck gegen Europa aufgehalten und geschwächt “ ${ }^{744}$

735 Günther Blumentritt, MS \# C-096. Der Aufbau Deutschlands, August 1946, S. 17, in: NARA, RG 549, Box 74; Blumentritt, MS \# B-635. Persönliche Gedanken über die Weltlage, Februar 1947, S. 41, in: NARA, RG 549, Box 47; Günther Blumentritt, MS \# C-096. Gedanken, Dezember 1947, S. 22-23, in: NARA, RG 549, Box 74.

736 Blumentritt, MS \# C-096. Der Aufbau Deutschlands, August 1946, S. 17, in: NARA, RG 549, Box 74; vgl. auch das fast wortgleiche Zitat in Ders., MS \# B-635. Persönliche Gedanken über die Weltlage, Februar 1947, S. 41, in: NARA, RG 549, Box 47. Dort heißt es: „Deutsche haben dem Druck aus dem Osten seit 1000 Jahren standgehalten, sich damit vor Europa gestellt. Mongolen und Hunnen, Türken und Slawen wurden auf deutschem Boden aufgehalten, zurückgeworfen. Das war eine Mission." Hervorhebung im Original.

737 Blumentritt, MS \# C-096. Gedanken, Dezember 1947, S. 10, in: NARA, RG 549, Box 74.

738 Ebd.

739 Ders., MS \# C-096. Der Aufbau Deutschlands, August 1946, S. 17, in: NARA, RG 549, Box 74.

740 Ebd., S. 38.

741 Ebd.

742 Ders., MS \# B-387. Thoughts on World War II, S. 5, in: CARL Digital Library, URL: http://cgsc.contentdm.oclc.org/cdm/ref/collection/p4013coll8/id/105 (letzter Zugriff: 4.3.2015).

743 Ders., MS \# B-647. Gedanken eines ehemaligen Soldaten, S. 20, in: NARA, RG 549, Box 48, Folder: B-647. Hervorhebung im Original.

744 Ebd., S. 21. Hervorhebung im Original. 
Ganz ähnlich argumentierte auch Bodo Zimmermann, der Deutschland ebenfalls als „Prellbock“745 gegen Invasionen aus dem Osten darstellte. So sei das deutsche Heer „den Russen“ in zwei Weltkriegen „bereitwillig und ergeben“ gegenübergetreten und habe dabei „in vielen blutigen Schlachten schwere Verluste „erlitten. ${ }^{746}$ Und auch Georg von Sodenstern kolportierte wiederholt das Bild von Deutschland als „Schutzwall Europas“. ${ }^{747}$ In dieser Erzählung wurde der verbrecherische Krieg gegen die Sowjetunion zu einem heroischen und selbstlosen Akt zum Schutze Europas, ja der ganzen westlichen Welt, vor der Bedrohung durch „bolschewistische Horden“ umgedeutet. Dass es bei diesem existenziellen Kampf „auf beiden Seiten so harte Kämpfe und so östliche Methoden“ gegeben habe, war in Günther Blumentritts Augen „im harten Osten, mit harten Menschen“ eben einfach unausweichlich gewesen. ${ }^{748}$ Aus der „Härte des Landes [und] der Menschen“ sei eben auch „die Härte des östlichen Kampfes“ gefolgt, der „ganz anders als im Westen" gewesen sei. ${ }^{749}$

Die deutschen Offiziere deuteten auch immer wieder an, dass der Zweite Weltkrieg im Grunde ein Krieg „mit verkehrten Fronten“ gewesen sei, sprich: Die Westmächte hätten sich gemeinsam mit den Deutschen gegen die UdSSR wenden sollen, anstatt das Deutsche Reich zu bekämpfen und so letztlich die Sowjetunion zu stärken. Als Resultat des verhängnisvollen, weil die eigentliche Gefahr verkennenden Konfliktes zwischen den Westmächten und Deutschland habe der Bolschewismus nun „das Tor des Abendlandes [...] aufgestoßen“750: Er sei „tief nach Westen hineingerutscht“751, sitze nun „bereits [...] in Eisenach im kerndeutschen Thüringen“752 und sei somit quasi der „Herr Mitteleuropas“753. Damit habe der Kreml das eigentliche Ziel seines vorübergehenden Bündnisses mit den Westmächten erreicht: ${ }^{754}$ Das „tapfere Deutschland“755 sei als „Mittelblock“756 und „Bollwerk“757 gegen den Bolschewismus ausgefallen. In der Folge würden sich

745 Zimmermann, MS \# C-040. Ideas on the Defense of the Rhine and Western Germany as an Outpost Area of Western Europe, 10. 12. 1948, S. 3, in: NARA, RG 549, Box 65.

746 Ebd.

747 Sodenstern, MS \# B-454. Gedanken zur Gegenwart, April 1947, S. 2, S. 7 und S. 16, in: NARA, RG 549, Box 39.

748 Blumentritt, MS \# C-096. Der Aufbau Deutschlands, August 1946, S. 38-39, in: NARA, RG 549, Box 74. Hervorhebung im Original.

749 Ders., MS \# B-647. Gedanken eines ehemaligen Soldaten, S. 25, in: NARA, RG 549, Box 48, Folder: B-647. Hervorhebung im Original.

750 Sodenstern, MS \# B-454. Gedanken zur Gegenwart, April 1947, S.3, in: NARA, RG 549, Box 39.

751 Blumentritt, MS \# C-096. Der Aufbau Deutschlands, August 1946, S. 42, in: NARA, RG 549 , Box 74.

752 Günther Blumentritt, MS \# B-582. Weltstrategische Lagebeurteilung 1947, Mai 1947, in: NARA, Mikrofiche Publication M 1035: Foreign Military Studies.

753 Blumentritt, MS \# B-635. Persönliche Gedanken über die Weltlage, Februar 1947, S. 28, in: NARA, RG 549, Box 47. Hervorhebung im Original.

754 Ders., MS \# B-582. Weltstrategische Lagebeurteilung 1947, Mai 1947, in: NARA, Mikrofiche Publication M 1035: Foreign Military Studies.

755 Ebd.

756 Ebd.

757 Ders., MS \# B-635. Persönliche Gedanken über die Weltlage, Februar 1947, S. 28, in: NARA, RG 549, Box 47. 
„die seit langem in der Entwicklung befindlichen Fronten der Zukunft“ in der „Auseinandersetzung zwischen Ost und West" umso deutlicher offenbaren. ${ }^{758} \mathrm{Al}-$ lerdings, auch das unterstrichen die ehemaligen Offiziere immer wieder, sei noch nicht alles verloren und Deutschland könne auch künftig ein wichtiger „Baustein“ in der Sicherheitsarchitektur des Westens sein. ${ }^{759}$ Schließlich hätten die Deutschen ein existenzielles Interesse daran, eine weitere Westexpansion des Bolschewismus zu verhindern und die Gefahr aus dem Osten zu bannen. ${ }^{760} \mathrm{Um}$ der Sowjetunion aber erfolgreich entgegentreten zu können, müssten die Westmächte nun endlich ihre „Bedenken, ihre Zweifel und ihr Misstrauen“ den Deutschen gegenüber aufgeben und auch militärisch mit ihnen zusammenarbeiten. ${ }^{761}$

Die deutschen Offiziere nutzten die kriegsgeschichtliche Kooperation also als einen von mehreren Kanälen, um sich als unpolitisch und gänzlich unverantwortlich für Vorbereitung und Verlauf des Zweiten Weltkrieges darzustellen. Eine wichtige Komponente des Arguments vom „unpolitischen Soldaten“ bildete dabei der Appell an die Vorstellung von der Existenz eines quasi übernationalen militärischen Berufsstandes, dessen Angehörige unabhängig vom jeweiligen politischen Regime den gleichen Prinzipien von Pflichterfüllung und Treue zu Volk und Vaterland folgen würden. Dahinter stand der Gedanke, dass die nachträgliche Bestrafung der Generalität für ihre Pflichterfüllung in einem von der politischen Führung begonnenen Krieg durch die jeweiligen Sieger die Rolle des Militärs fundamental und über den deutschen Fall hinaus infrage stelle.

Diese Argumentation verfing durchaus bei den amerikanischen Mitarbeitern der Historical Division. Viele von ihnen lehnten die Nachkriegsprozesse mit dem Argument ab, dass die Soldaten schließlich nur Befehle befolgt hätten und nicht für die politischen Verfehlungen des Regimes verantwortlich gemacht werden sollten. Selbst ein Intellektueller wie George N. Shuster, der schon während des Krieges den Holocaust angeprangert hatte, ${ }^{762}$ schenkte der Legende von der Unschuld der Wehrmacht Glauben und hielt es daher für falsch, „Generäle, die einen Krieg verloren hatten, vor einen Gerichtshof zu stellen " ${ }^{763}$ Schließlich sei ihnen nichts anderes übrig geblieben, als die Schlachten auszufechten, die ihnen von der politischen Führung aufgezwungen worden seien. ${ }^{764}$ Auch Paul M. Robinett lehn-

758 Sodenstern, MS \# B-454. Gedanken zur Gegenwart, April 1947, S. 2, in: NARA, RG 549, Box 39.

759 Blumentritt, MS \# C-096. Der Aufbau Deutschlands, August 1946, S. 44, in: NARA, RG 549, Box 74; vgl. auch Sodenstern, MS \# B-454. Gedanken zur Gegenwart, April 1947, S. 2, in: NARA, RG 549, Box 39.

760 Zimmermann, MS \# C-040. Ideas on the Defense of the Rhine and Western Germany as an Outpost Area of Western Europe, 10.12. 1948, S. 3, in: NARA, RG 549, Box 65; vgl. auch Blumentritt, MS \# B-635. Persönliche Gedanken über die Weltlage, Februar 1947, S. 41, in: NARA, RG 549, Box 47.

761 Zimmermann, MS \# C-040. Ideas on the Defense of the Rhine and Western Germany as an Outpost Area of Western Europe, 10. 12. 1948, S. 17, in: NARA, RG 549, Box 65.

762 Vgl. oben, Teil II, Kapitel 1.2.

763 Shuster, In Amerika und Deutschland, S. 252.

764 Ebd. 
te die Anklage und Verurteilung deutscher Offiziere ab. Für ihn stellten die alliierten Kriegsverbrechertribunale „eines der schwärzesten Kapitel der jüngeren Geschichte" dar. ${ }^{765}$ Ähnlich sah es Frank C. Mahin, der die Nürnberger Prozesse für eine Verunglimpfung des deutschen Militärs hielt und sie gar als „Hexenkessel des Rufmords“ bezeichnete. ${ }^{766}$ Selbst bei den überführten Kriegsverbrechern zweifelten die Mitarbeiter der Historical Division bisweilen an der Rechtmäßigkeit der Urteile. So glaubte der Chief of Military History, Albert C. Smith, dass Walter Warlimont in seiner Funktion als Chef des Wehrmachtsführungsstabes „lediglich die Pflichten eines höheren Stabsoffiziers bei der routinemäßigen Führung eines normalen Krieges erfüllt" habe. ${ }^{767}$ Und Paul M. Robinett „bezweifelte“ ebenfalls, dass Warlimont seine lebenslängliche Haftstrafe wirklich „verdient“ habe. ${ }^{768}$

Indem beide Seiten die politische Mitverantwortung der Wehrmachtsführung an den zwischen 1933 und 1945 begangenen Verbrechen ausklammerten, konnten deutsche und amerikanische Offiziere sich im Rahmen der kriegsgeschichtlichen Kooperation auf der Ebene eines internationalen Berufsoffizierstums quasi auf Augenhöhe treffen. Die deutschen Beteiligten wussten dieses Entgegenkommen angesichts der Politik der Demilitarisierung und der laufenden Kriegsverbrechertribunale sehr zu schätzen. Franz Halder bedankte sich deshalb 1950 beim Leiter der Historical Division in Europa, Colonel Harold E. Potter, für dessen kameradschaftliche Haltung gegenüber den deutschen Offizieren:

„Sie, Herr Oberst, haben damals uns geschlagenen und verfemten Kriegsgefangenen die Hand des Kameraden gereicht und damit an die Ideale echten Soldatentums appelliert, die den wahren Soldaten aller Kulturnationen gemeinsam sind. Sie haben Geduld gehabt mit den inneren Spannungen und Hemmungen, denen die deutschen Offiziere hinter Stacheldraht ausgesetzt waren. Sie haben sich für uns und für viele unserer Kameraden als persönlicher Freund bewährt und stets geholfen, wo Sie helfen konnten. Damit haben Sie uns inmitten der Schwierigkeiten und Unerfreulichkeiten des heutigen Deutschlands die innere Ruhe gegeben und die Freude an der gemeinsamen Berufsarbeit geweckt."769

Die Wertschätzung wurde auf amerikanischer Seite durchaus erwidert. In einem Brief an Leo Geyr von Schweppenburg blickte Potter 1959 auf seine Tätigkeit als Leiter der Historical Division in Europa zurück und betonte dabei, wie sehr er das „großartige Gefühl der Kameradschaft“ mit vielen der ehemaligen Wehrmachtsgeneräle genossen habe und wie dankbar er sei, „mit einigen der bedeutendsten Männer und besten Soldaten“ zusammengearbeitet zu haben, „die die Welt je gekannt“ habe. Amerikaner und Deutsche hätten vieles gemeinsam gehabt und er habe Deutschland mit einem Gefühl der „warmen Freundschaft“ für viele deutsche Offiziere verlassen. ${ }^{770}$ Auch Paul M. Robinett entwickelte eine auf gegenseiti-

765 Paul M. Robinett, German Participation in the U.S. Army Historical Program, S. 1, in: George C. Marshall Research Library, Bestand 28, Box 16, Folder 19.

766 Mahin, Schreiben an S.L.A. Marshall, 1. 12. 1953, in: UTEP, MS 186, Box 83, Folder 1409.

767 Entwurf, o. D., in: NARA, RG 319, Box 5, Folder 1.

768 Paul M. Robinett, Schreiben an George T. Keating, 1.5. 1965, in: George C. Marshall Research Library, Bestand 28, Box 5, Folder 30.

769 Franz Halder, Schreiben an Harold E. Potter, 22. 3. 1950, in: BArch, N 220/202.

770 Harold E. Potter, Schreiben an Leo Geyr von Schweppenburg [o. D., vermutlich 1959], in: IfZArch, ED 91/21. 
gem Respekt gegründete Beziehung zu Franz Halder, die weit über die kriegsgeschichtliche Kooperation hinausging und bis zum Tod des ehemaligen Generalstabschefs im Jahr 1974 andauerte. Der Amerikaner bewunderte Halder als einen „klugen Mann“771, ja einen „Philosophen“772 der Kriegsgeschichte und war sichtlich stolz, ihn als seinen „Freund“773 bezeichnen zu können. Der ehemalige Generalstabschef des deutschen Heeres erwiderte Robinetts wohlwollende Gefühle und hob vor allem dessen „ritterliche Einstellung zum deutschen Offiziertum [sic]" hervor. Dass Robinett sich von Anfang an für die Kooperation mit den Deutschen stark gemacht habe, beweise, dass er „ein Mann von weitem Blick, von hoher militärischer Erfahrung und von echtem soldatischen Denken " sei. ${ }^{774} \mathrm{Ob}$ wohl die „hohe Politik“, so Halder, Robinett und ihn selbst „einst in gegensätzliche Lager" gestellt habe, habe man sich nach dem Krieg auf der Grundlage gemeinsamer militärischer Ideale verständigt. ${ }^{775}$

Dass die vor allem auf dem östlichen Kriegsschauplatz begangenen Verbrechen der Wehrmacht bei den amerikanischen Militärs so wenig Beachtung fanden, lag auch daran, dass die Argumentationsstrategie von Deutschland als Bollwerk gegen den Osten auch bei ihnen an ein bereits seit langem etabliertes Weltbild anknüpfte, das zudem durch den Kalten Krieg aktualisiert wurde. Schon während des russischen Bürgerkrieges hatten amerikanische Offiziere immer wieder darauf hingewiesen, dass die Deutschen von jeher als „natürlicher Damm gegen den [...] Druck der Menschenmassen“ aus den „primitiven Weiten des eurasischen Kontinents" fungiert hätten und bedauerten, dass dieser "großartige teutonische Damm" durch den Ersten Weltkrieg zumindest vorübergehend zerstört worden sei. ${ }^{776}$ Nachdem der Zweite Weltkrieg zu einer vorübergehenden Annäherung zwischen den USA und der Sowjetunion geführt hatte, festigte sich in den Vereinigten Staaten nach 1945 erneut die Vorstellung vom fundamentalen Gegensatz zwischen West und Ost; gleichzeitig tauchte das Image von Deutschland als Bollwerk gegen „östliche Horden“ wieder auf. ${ }^{777}$ So postulierte S.L.A. Marshall 1946: „These hordes have come west and have conquered. "778 Diejenigen deutschen Offiziere, deren Apologien Anfang der 1950er Jahre in Buchform auch in den USA veröffentlicht wurden, erhielten immer wieder Zuschriften von bewundernden

${ }^{771}$ Paul M. Robinett, Schreiben an George T. Keating, 23. 12. 1971, in: George C. Marshall Research Library, Bestand 28, Box 5, Folder 31.

772 Ders., Schreiben an George T. Keating, 11.12. 1969, in: George C. Marshall Research Library, Bestand 28, Box 5, Folder 31.

773 Ders., Schreiben an George T. Keating, 14.4.1965, in: George C. Marshall Research Library, Bestand 28, Box 5, Folder 31.

${ }^{774}$ Franz Halder, Schreiben an Paul M. Robinett, 6. 11. 1957, in: George C. Marshall Research Library, Bestand 28, Box 14, Folder 12.

775 Ders., Schreiben an Paul M. Robinett, 24.7. 1957, in: George C. Marshall Research Library, Bestand 28, Box 14, Folder 15.

776 Malborough Churchill, Schreiben des Director, Military Intelligence Division, an den Secretary of War, 13.1.1919, S.3, in: NARA, RG 165, MID 10059-118 (4), zit. nach Bendersky, The „Jewish Threat“, S. 83.

777 Jackson, Civilizing the Enemy, S. 133-134.

778 S.L.A. Marshall, History and the Post-War Situation. Have We Learned Enough to Avert World War III?, in: Vital Speeches of the Day 12 (1946), S. 629. 
amerikanischen Lesern, die in dieselbe Richtung gingen. So brachte ein junger Weltkriegsveteran im Dezember 1951 in einem Brief an „seine Exzellenz“ Heinz Guderian nicht nur seine „starke Bewunderung für das deutsche Heer“ zum Ausdruck, sondern betonte auch, dass bereits während des Zweiten Weltkrieges „viele Amerikaner das Gefühl gehabt“ hätten, die Vereinigten Staaten „hätten besser auf der Seite Deutschlands gegen die Russen“ stehen sollen. Die „Ereignisse der letzten Jahre“ hätten letztlich „den Wahnwitz der Kooperation mit der Sowjetunion bewiesen".779

Auch auf politischer Ebene wurde die Bollwerk-Metapher beschworen: So zum Beispiel durch den demokratischen Senator James O. Eastland aus Mississippi, der Anfang Dezember 1945 in einer imposanten Rede vor dem Senat vehement gegen die harte Politik gegenüber dem besiegten Deutschen Reich protestierte und stattdessen einen schärferen Kurs gegenüber der Sowjetunion einforderte, die er als „räuberische Aggressor-Nation“ bezeichnete: ${ }^{780}$

„There is involved in the present predicament of Germany the whole question of the relation between the eastern and the western civilizations. Germany has served both as a neutralizing agent and as a barrier between the Oriental hordes and a western civilization 2000 years old [...]. Our treatment of Germany will decide this question of whether Germany is going to clamor for [annexation] to Moscow, or is to be reincorporated into our own civilization and culture $[\ldots] .{ }^{\text {“781 }}$

Diese Beispiele zeigen, dass die apologetische Argumentationsstrategie der ehemaligen Wehrmachtselite nicht nur in der deutschen Nachkriegsgesellschaft weitgehend unkritisch aufgenommen wurden, ${ }^{782}$ sondern auch im U.S. Militär, aber auch bei amerikanischen Politikern und Teilen der Bevölkerung auf positive Resonanz stieß. Dabei war die Historical Division jedoch nicht passiver Rezipient der Legende von der „sauberen“ Wehrmacht, sondern beteiligte sich aktiv an deren weiterer Verbreitung. Doch wie sah diese Komplizenschaft konkret aus? Um diese Frage zu beantworten, sollen im Folgenden Mechanismen und Umfang der geschichtspolitischen Hilfestellung betrachtet werden.

779 Harald Keith Thompson, Schreiben an Heinz Guderian, 5.12.1951, in: BArch, N 802/79. Originalzitat: „There were many Americans during the last war who felt that the United States should have more properly been on the side of Germany against the Russians. Surely the events of recent years have shown the folly of Soviet collaboration. I always opposed it." Auch in den Briefen anderer Amerikaner an Guderian schimmerte immer wieder die Ansicht durch, dass es für den Westen besser gewesen wäre, wenn die Deutschen den Krieg gegen die Sowjetunion gewonnen hätten. Siehe zum Beispiel Don Mahone Harlan, Schreiben an Heinz Guderian, 24. 10. 1952, in: BArch, N 802/79; William Leedom, Schreiben an Heinz Guderian, 13.11. 1952, in: BArch, N 802/79; Garrett Underhill, Schreiben an Heinz Guderian, 17. 4. 1953, in: BArch, N 802/79.

780 Zit. nach Schlauch, American Policy Towards Germany, 1945, in: Journal of Contemporary History 5 (1970), S. 124.

781 Congressional Record of the United States, 4. 12. 1945, S. 11376, zit. nach Jackson, Civilizing the Enemy, S. 134.

782 Vgl. Bald/Klotz/Wette (Hg.), Mythos Wehrmacht; Wette, Das Bild der Wehrmacht-Elite nach 1945. 


\subsection{Eine Agentur der Artikulation: Zur Bedeutung der kriegsgeschichtlichen Kooperation für die Geschichtspolitik der ehemaligen Wehrmachtselite}

Die Kooperation mit der Historical Division bot der ehemaligen Wehrmachtselite einen geeigneten Rahmen, um ihre geschichtspolitischen Ziele voranzutreiben. Schon die organisatorische Struktur der Zusammenarbeit erwies sich dafür als äußerst günstig: In ihren Lagern in Oberursel und Allendorf, in Garmisch und in Neustadt führten die Amerikaner hunderte ehemaliger Wehrmachtsoffiziere zusammen, die bis vor Kurzem als Truppenkommandeure und Generalstabsoffiziere in Divisionen und Korps, Armeen und Heeresgruppen an den maßgeblichen Operationen des Zweiten Weltkrieges an der Ostfront, im Westen, in Nordafrika und in Italien teilgenommen oder diese im OKH und im OKW geplant hatten. In den Campaign Groups ${ }^{783}$ konnten diese Offiziere ihre Erinnerungen austauschen und aufeinander abstimmen und so unter Berücksichtigung der veränderten politischen Realitäten eine apologetische Interpretation des Krieges konstruieren. Damit stellten die Amerikaner der ehemaligen Wehrmachtselite eine „Arena der Artikulation“784 zur Verfügung, einen „sozial-politischen Raum“785, innerhalb dessen die deutschen Militärs eine abgestimmte Geschichte ihrer Rolle im Zweiten Weltkrieg entwerfen konnten.

Die Historical Division stellte nicht nur den organisatorischen Rahmen sowie personelle Ressourcen wie Schreibkräfte, Kartographen und Übersetzer für diese koordinierte Erinnerungsarbeit zur Verfügung, sondern leistete auch darüber hinaus wichtige Hilfestellungen für den Erfolg der geschichtspolitischen Aktivitäten der ehemaligen Wehrmachtselite. Denn wie wirkmächtig Erinnerungsnarrative, wie sie eben auch die ehemalige Wehrmachtselite konstruierte, werden, hängt unter anderem davon ab, ob ihre Verfechter Zugang zu einflussreichen Institutionen des Staates oder der Zivilgesellschaft haben und über sie an der Erhaltung und Anpassung kultureller Erinnerung mitwirken können. ${ }^{786}$ Auch dabei leistete die Historical Division den deutschen Militärs wertvolle Dienste: Zum einen bot sie den ehemaligen Offizieren über Jahre hinweg privilegierten Zugang zu den beschlagnahmten deutschen Militärakten und damit einen wesentlichen Vorsprung vor der akademischen Geschichtswissenschaft; zum anderen ermöglichte die Historical Division den deutschen Offizieren schon frühzeitig, Aufsätze in amerikanischen Militärzeitschriften zu veröffentlichen und stellte außerdem den Kontakt zu zivilen Verlagshäusern, Historikern und Journalisten her. Schließlich gaben die Amerikaner die kriegsgeschichtlichen Studien in den 1950er Jahren nach und nach an die Bundeswehr ab und erlaubten den ehemaligen Wehrmachtsoffizieren, ihre Arbeiten in deutschen Verlagen zu veröffentlichen.

783 Zum System der Campaign Groups siehe oben, Teil II, Kapitel 2.2.

784 Zum Konzept der „Arena der Artikulation“ siehe Ashplant/Dawson/Roper, The Politics of War Memory and Commemoration, in: Dies. (Hg.), The Politics of War Memory and Commemoration, S. 17-25.

785 Ebd., S. 17.

786 Ashplant/Dawson/Roper, Politics of War Memory and Commemoration, S. 21. 


\section{Zugang zu den deutschen Militärakten}

Die wohl wichtigste Unterstützung bestand darin, dass die U.S. Armee den ehemaligen deutschen Offizieren Zugang zu den 1945 von den Amerikanern erbeuteten deutschen Heeresakten verschaffte. Dies ist umso bemerkenswerter, wenn man bedenkt, dass die Beschlagnahmung der militärischen Akten auch dazu hatte dienen sollen, den Deutschen - und insbesondere den ehemaligen Generalstabsoffizieren - die dokumentarische Grundlage für eine Wiederbewaffnung und damit für eine erneute militärische Aggression zu entziehen. ${ }^{787}$ Die Amerikaner hatten die Heeresakten deshalb bereits im Sommer 1945 zu großen Teilen in die Vereinigten Staaten verschifft und in der Nähe von Washington D.C. eingelagert, wo ausschließlich akkreditierte Nachrichtenoffiziere sowie amtliche Mitarbeiter der Historical Division Zugang zu den Unterlagen hatten. ${ }^{788}$ Während zivile Historiker lange Zeit nicht auf die Originalunterlagen zurückgreifen konnten, ${ }^{789}$ verschickte die Historical Division schon seit 1948 einen Großteil der für die Anfertigung der kriegsgeschichtlichen Studien relevanten deutschen Akten an die Control Group, die diese dann an die entsprechenden „Heimarbeiter“ weiterleitete. ${ }^{790}$

Der exklusive Zugang zu den beschlagnahmten Wehrmachtsakten stellte im Kampf um die Deutungshoheit über die Geschichte des Zweiten Weltkrieges einen wichtigen Faktor dar, ermöglichte er den ehemaligen Wehrmachtsoffizieren doch, für ihre Interpretationen des Zweiten Weltkrieges eine besondere Legitimität in Anspruch zu nehmen. Diese stützte sich zum einen auf die Möglichkeit des Aktenstudiums, wurde aber zusätzlich auch mit der besonderen Erfahrung des Miterlebens und der Nähe zu den militärischen und politischen Entscheidungsträgern des Dritten Reiches begründet. Diese Zeitzeugenschaft, so argumentierten die Control Group-Mitglieder immer wieder, befähige die ehemaligen Offiziere ganz besonders, die Akten in ihrem historischen Kontext richtig zu deuten. Laut Franz Halder verfügten die mit der Historical Division kooperierenden ehemaligen Generalstabsoffiziere demnach über die besten Voraussetzungen, die Geschichte des Zweiten Welt-

787 Eckert, Kampf um die Akten, S. 39-40.

788 Die deutschen Heeresakten standen zunächst unter der Verwaltung der G-2-Abteilung des War Department, die allerdings im Sommer 1947 die Betreuung der Akten an das Büro des Generaladjutanten der U.S. Army abgab, das die sogenannte German Military Documents Section (GMDS) in die Departmental Records Branch (DRB) eingliederte. Mitte 1948 wurden auch die bis dahin noch in Berlin gelagerten Akten aus Sorge vor einem Übergriff der Sowjets aus der Stadt ausgeflogen und in die USA gebracht. Die GMDS wurde 1953 in Captured Records Section (CRS) umbenannt, blieb aber Teil der DRB. Siehe Eckert, Kampf um die Akten, S. 117-118 und S. 206, Fußnote 10; vgl. auch Henke, Das Schicksal deutscher Zeitgeschichtlicher Quellen in Kriegs- und Nachkriegszeit, S. 577-578.

789 Echternkamp, Another Turn of the Tide?, URL: http://escholarship.org/uc/item/ 5hp2z2m5 (letzter Zugriff: 24. 2. 2015), S. 3.

790 Robinett, German Participation in the U.S. Army Historical Program, S. 5, in: George C. Marshall Research Library, Bestand 28, Box 16, Folder 19. Vgl. auch Aktenvermerk von Paul Kluke zu einem Gespräch mit Charles B. Burdick vom 31.3. 1955, in: IfZArch, ID 103/206. Darin heißt es: „,[Blumentritt] habe [zur Erstellung einer Studie über die Heeresgruppe Mitte] 3 große Kisten mit allem diesbezüglichen Material (Lagekarten, Kriegstagebücher [...]) aus Washington erhalten. Auch Dr. Burdick versicherte mir, dass dieses Aktenmaterial nicht mehr nach Washington zurückgeschickt wird, sondern schon in Deutschland zur Rückgabe verbleibt.“" 
krieges zu schreiben: dem Zugang zu den Dokumenten einerseits und „der persönlichen Erinnerung [...] des Kriegsgeschehens“ sowie der „Kenntnis der persönlichen Eigenart der handelnden Personen " andererseits. ${ }^{791}$ Sie könnten sich deshalb in ihrem Urteil zu Recht „unabhängig fühlen“792 Auch Günther Blumentritt war überzeugt, dass die militärischen Dokumente des Zweiten Weltkrieges von denjenigen ausgewertet werden müssten, „die die Dinge erlebt, erfühlt, gesehen“ hätten und den konkreten Entstehungskontext der Quellen kennen würden. ${ }^{793}$

Den Versuchen ziviler Historiker, sich der Geschichte des Zweiten Weltkrieges zu nähern, standen die Vertreter der ehemaligen Wehrmachtselite dagegen skeptisch bis ablehnend gegenüber. Mancher fand die Vorstellung, dass ,junge Historiker“, denen die konkrete Erfahrung des Miterlebens fehlte, die Geschichte des Krieges allein „auf Grund der Akten und Dokumente“ schreiben sollten, geradezu „absurd“.794 Denn die „wesentlichen Zusammenhänge“795 konnten in den Augen der alten Eliteoffiziere eben nicht „aus den Dokumenten allein“796 erforscht werden, deren historischer Aussagewert „höchst problematisch bleiben “797 müsse, „wenn sie nicht durch Leute erläutert [würden], die diese Vorgänge mitgemacht“798 hätten. Wer nur auf der Grundlage der Akten forsche, fände eben „keine Wahrheit“, sondern fabuliere „eine Legende“ zusammen. ${ }^{799}$ Aus derlei Befürchtungen leitete Halder schließlich geradezu eine Pflicht der ehemaligen Generalstabsoffiziere zu historischer Betätigung ab:

„Wer in aller Welt“, schrieb er im Juni 1956 an Gotthard Heinrici, „soll denn die Fäden aufzeigen, wenn wir es nicht tun, die aus der alten Schule hervorgegangen sind und die Entwicklung miterlebt haben? Tun wir es nicht, dann werden andere aus weiß Gott welchen Blickrichtungen heraus und ohne das [durch das] innere Miterleben begründete Verständnis den Versuch dazu machen." ${ }^{\circ 00}$

Indem sie die Autorität über die Historiographie des Zweiten Weltkrieges dem Imperativ einer eng definierten Zeitzeugenschaft unterwarfen, plädierten die ehemaligen Wehrmachtsoffiziere also dafür, die Deutungshoheit den ehemaligen Akteuren selbst zu überlassen. ${ }^{801}$

Mit dieser Sichtweise fanden die Deutschen durchaus Unterstützung bei den amerikanischen Adressaten ihrer kriegsgeschichtlichen Studien. Denn auch die

791 Halder, Zum 21. 11. 1955. Ansprache anlässlich des 10. Jahrestages der Kooperation mit der Historical Division, 15. 11. 1955, in: BArch, N 220/118.

792 Franz Halder, Schreiben an Waldemar Erfurth, 2. 12. 1952, in: BArch, ZA 1/2651.

793 Günther Blumentritt, MS \# B-710. Das Doppelgesicht der Kriegsgeschichte, November 1947, S. 18, in: NARA, Mikrofiche Publication M 1035: Foreign Military Studies. Hervorhebung im Original.

794 Hans Doerr, Schreiben an Franz Halder, 10. 10. 1957, in: BArch, N 220/82.

${ }^{795}$ Franz Halder, Schreiben an den Chief, Historical Division, USAREUR, 12. 9. 1958, in: BArch, N 220/201.

796 Ebd.

797 Blumentritt, MS \# B-710. Das Doppelgesicht der Kriegsgeschichte, November 1947, S. 17, in: NARA, Mikrofiche Publication M 1035: Foreign Military Studies.

798 Ebd.

799 Ebd., S. 7.

800 Franz Halder, Schreiben an Gotthard Heinrici, 4. 6. 1956, in: BArch, N 265/72.

801 Vgl. hierzu in Bezug auf die deutsche Geschichtsschreibung nach 1945 im Allgemeinen Conrad, Auf der Suche nach der verlorenen Nation, S. 245-246. 
amerikanischen Militärs begegneten den zivilen Historikern innerhalb der Historical Division mit Skepsis. Im Herbst 1947 beklagte sich Hugh M. Cole bei seinem ehemaligen Chef, S.L.A. Marshall, über die angeblich mangelhafte Kompetenz der zivilen Bearbeiter der Weltkriegs-Serie und verlieh seiner Auffassung Ausdruck, dass es diesen „drittklassigen Historikern, die nie in der Armee gedient hätten“, nicht erlaubt werden dürfe, Form und Inhalt der Weltkriegs-Serie zu bestimmen. ${ }^{802}$ Auch Paul M. Robinett, der Leiter der Applied Studies Section, zu der auch die Foreign Studies Branch gehörte, machte keinen Hehl daraus, dass es seiner Meinung nach professionellen Soldaten vorbehalten bleiben sollte, die amtliche Kriegsgeschichte der U.S. Armee niederzuschreiben. 1954 sagte Robinett zum Beispiel bei der jährlichen Sitzung des Advisory Committee, es sei für einen Mitarbeiter der Historical Division nicht ausreichend, lediglich Historiker zu sein oder einen Doktortitel zu besitzen, er müsse außerdem ein „Mann vom Fach“ sein und die militärischen Mühlen selbst durchlaufen haben: „Ein Doktortitel ist keine grundlegende Voraussetzung. Erfahrung ist viel wichtiger." ${ }^{\text {"83 }}$ Zwar sprach sich Orlando Ward, seines Zeichens Chief of Military History (1949-1953), grundsätzlich für die Kooperation von Militärs und zivilen Historikern bei der Abfassung der amtlichen Kriegsgeschichte aus, doch auch er maß den Militärs die größere Bedeutung bei. Im wissenschaftlichen Beirat äußerte er sich 1952 folgendermaßen: „I would say it is a fifty-fifty business. That's the way I feel about it. If it were all military I think it would be tragic. On the other hand, I feel it would be more tragic if they were all civilians. "804

Gegenüber Albert Kesselring wurde Ward etwas deutlicher: In einem Brief vom Januar 1952 ließ er ihn wissen, dass die Interpretation der Fakten aus den militärischen Akten seiner Meinung nach durch Personen unterstützt und ergänzt werden müsste, die mit den Ereignissen durch eigenes Erleben vertraut seien. ${ }^{805}$ Auch außerhalb der Historical Division war die Ansicht verbreitet, dass Kriegsgeschichte in erster Linie professionellen Soldaten vorbehalten bleiben sollte. So glaubte beispielsweise General Edward M. Almond - der als Kommandant des Army War College einen der Abnehmer deutscher Studien repräsentierte - ebenfalls, dass

802 Hugh M. Cole, Schreiben an S.L.A. Marshall, 14.10.1947, in: UTEP, MS 186, Box 80, Folder 1378. Originalzitat: „We have been having some little trouble with the editorial personnel, who in my opinion are not competent to pass on either form or content. However, I hope that they will see the light and crawl back in their holes when it comes to dealing with our section. I have tried to tell Greenfield, Kemper and Clark that if we are going to write a history according to pre-conceived ideas and orders from others we had better get a three star General in here to set the cadence instead of allowing some third-rate historians, who have never even served in the Army, to give us the big picture."

${ }^{803}$ Paul M. Robinett, Zitat aus dem Protokoll des Jahrestreffens des Historical Advisory Committee, Mai 1954, S. 14, in: NARA, RG 319, Box 49, Folder 2. Originalzitat: „It is not enough for a man to be [a] historian and not enough to be a Ph.D. He must be a practitioner, been through the mill. [...] [A] Ph.D. [is] not the fundamental requirement. Experience [is] much better."

${ }^{804}$ Minutes of Closed Session of Historical Advisory Committee, 12.4.1952, S.3, in: NARA, RG 319, Box 16, Folder 3.

805 Orlando Ward, Schreiben an Albert Kesselring, 10.1.1952, in: NARA, RG 319, Box 8, Folder 8 . 
auch das umfassendste Aktenstudium die Eindrücke derjenigen nicht ersetzen könne, die an den Ereignissen teilgenommen hätten. ${ }^{806}$

Die Vorstellung von der besonderen Qualifikation der Zeitzeugen für die geschichtswissenschaftliche Aufarbeitung des Dritten Reiches beschränkte sich keineswegs auf Militärkreise dies- und jenseits des Atlantiks, sondern entsprach zumindest teilweise dem Zeitgeist der westdeutschen Nachkriegs-Historiographie. Zeithistoriker wie Paul Kluke, Gerhard Ritter und Theodor Schieder vertraten bisweilen ebenfalls die Meinung, dass nicht „objektivierende Distanz, sondern im Gegenteil eine möglichst große Nähe zu den Trägern des Geschehens [...] dem historischen Verstehen zuträglich" sei. ${ }^{807}$ Auch wenn die deutschen Historiker dies sicherlich nicht als exklusives Kriterium für die Befähigung zu zeitgeschichtlicher Forschung verstanden wissen wollten, bot die über die universitäre Wissenschaft hinaus weithin unbestrittene „Privilegierung der Stimme der Beteiligten“ nach 1945 bestimmten Personengruppen die Möglichkeit, ihre eigene Vergangenheit unter dem Deckmantel der Wissenschaftlichkeit umzudeuten und sich so zu rehabilitieren. ${ }^{808} \mathrm{Im}$ Falle der ehemaligen Wehrmachtselite erhielt diese Stimme durch den von der Historical Division sanktionierten exklusiven Aktenzugang zusätzliche Legitimität.

\section{Eine Dependance der Control Group in Washington?}

Die Gelegenheit, über den unmittelbaren Aktenzugang noch stärker als bisher auf die thematische und inhaltliche Ausrichtung der kriegsgeschichtlichen Studien einzuwirken, ergab sich Anfang 1951. Der Ausbruch des Koreakrieges im Sommer zuvor hatte die nachrichtendienstliche Nutzung der deutschen Militärakten als Informationsquelle zur Sowjetunion und zur Roten Armee rapide ansteigen lassen, ${ }^{809}$ wobei eine wirklich effektive Auswertung der deutschen Erfahrungen aus den Heeresakten dadurch beeinträchtigt wurde, dass noch rund 40 Prozent der in Alexandria, Virginia, lagernden deutschen Akten unzureichend erfasst waren. ${ }^{810}$ Vor diesem Hintergrund bemühte sich das Department of the Army seit Ende 1950 darum, Hans von Greiffenberg nach Washington zu bringen und mit der Auswertung der deutschen Akten zu betrauen. ${ }^{811}$

Für ein Jahresgehalt von 6000 Dollar ${ }^{812}$ sollte der ehemalige Generalstabsoffizier die beschlagnahmten deutschen Militärakten auf „Mittel und Methoden“ hin prüfen, die sich für die U.S. Armee "gegen die Sowjetunion und ihre Satelliten“

806 Almond, Schreiben an A. R. Bolling, 31. 1. 1952, in: NARA, RG 319, Box 56, Folder 9.

807 Conrad, Suche nach der verlorenen Nation, S. 246.

808 Ebd., S. 249-250.

${ }^{809}$ Eckert, Kampf um die Akten, S. 211. Vgl. zur steigenden Nachfrage nach deutschen Studien infolge des Koreakrieges oben, Teil III, Kapitel 2.

810 Eckert, Kampf um die Akten, S. 212.

811 Frank C. Mahin, Memorandum für Wilbur S. Nye: Paperwork on General Greiffenberg, 11.1.1951, in: NARA, RG 549, Box 3154, Folder 4; W. S. Nye, Schreiben an Orlando Ward, 24. 1. 1951, in: NARA, RG 319, Box 8, Folder 5; Orlando Ward, Schreiben an Wilbur S. Nye, 7. 3. 1951, in: NARA, RG 319, Box 8, Folder 5.

812 Department of the Army. Contract for Personal Services, in: NARA, RG 549, Box 9, Folder: v. Greiffenberg, Hans; Paul M. Robinett, Schreiben an Hans von Greiffenberg, 6. 2. 1951, in: NARA, RG 549, Box 3154, Folder 4. 
als nützlich erweisen könnten. ${ }^{813}$ Dazu sollte Greiffenberg auf der Grundlage der deutschen Erfahrungen Vorschläge für eine Verbesserung der taktischen Doktrin der U.S. Armee machen, um die Stärken der amerikanischen Soldaten auszunützen und die Auswirkungen möglicher Schwächen weitestgehend zu minimieren. Darüber hinaus sah die Stellenbeschreibung vor, dass Greiffenberg „die Charakteristika der Russen im Denken, im Handeln und in der Technik" anhand einer Geschichte der deutschen und russischen Operationen nach 1943 herausarbeiten würde. ${ }^{814}$ Schließlich sollte der ehemalige Generalstabsoffizier die Autoren der World War II Series unterstützen und gelegentlich Vorträge an den Service Schools halten. ${ }^{815}$ Während die Historical Division sich noch um die Einreisegenehmigung für den Deutschen kümmerte, starb Hans von Greiffenberg allerdings völlig unerwartet am 30. Juni 1951 an einem Schlaganfall. Nachdem man einige Wochen hin und her überlegt hatte, wer anstelle von Greiffenberg nach Washington entsandt werden könnte, ${ }^{816}$ entschied die Historical Division Ende August, nun doch keinen deutschen Offizier in die USA zu holen. ${ }^{817}$

Dass sich das Zeitfenster für die Entsendung eines ehemaligen deutschen Offiziers nach Washington im Sommer 1951 wieder geschlossen hatte, hing vor allem damit zusammen, dass die Entscheidung für eine westdeutsche Wiederbewaffnung Bewegung in die bis dahin festgefahrenen amerikanischen Pläne brachte, die deutschen Militärakten an die Bundesrepublik zu übergeben. ${ }^{818}$ Da die Vor-

813 Orlando Ward, Memorandum for General von Greiffenberg, betr. Possible Duty Assignments, 1. 5. 1951, in: NARA, RG 549, Box 9, Folder: v. Greiffenberg, Hans.

814 Ward, Memorandum for General von Greiffenberg, betr. Possible Duty Assignments, 1.5.1951, in: NARA, RG 549, Box 3154, Folder 4. Originalzitat: „Write a history of some engagement on the Russian front subsequent to 1943, [...] and highlight the incidents which bring out the characteristics of the Russians in thought, in execution, and in technique."

815 Paul M. Robinett, Memorandum for Chief, Military History, betr. Duty Assignments for General Greiffenberg, 20. 4. 1951, in: NARA, RG 549, Box 9, Folder: v. Greiffenberg, Hans; Ward, Memorandum for General von Greiffenberg, betr. Possible Duty Assignments, 1.5. 1951, in: NARA, RG 549, Box 9, Folder: v. Greiffenberg, Hans; Orlando Ward, Schreiben an das Office, Assistant Chief of Staff, G-2, betr. Case of Hans von Greiffenberg, o. D., in: NARA, RG 549, Box 9, Folder: v. Greiffenberg, Hans.

${ }^{816} \mathrm{Im}$ Gespräch waren dabei unter anderem Alfred Toppe, Anton von Bechtolsheim, Burkhart Müller-Hillebrand, Günther Blumentritt und Fritz Bayerlein, wobei Wilbur S. Nye aufgrund seiner militärischen Erfahrung, seiner guten Englischkenntnisse und seiner sympathischen Persönlichkeit zu Bechtolsheim tendierte. Nye fühlte in dieser Frage sowohl bei Bechtolsheim als auch bei Toppe und Bayerlein vor, die sich alle drei prinzipiell bereit erklärten, nach Washington zu gehen. W. S. Nye, Schreiben an Orlando Ward, 5. 7. 1951, in: NARA, RG 319, Box 8, Folder 4; Ders., Schreiben an Orlando Ward, 11.7.1951, in: NARA, RG 319, Box 8, Folder 4; Ders., Schreiben an Orlando Ward, 13.7.1951, in: NARA, RG 319, Box 8, Folder 4; Ders., Schreiben an Orlando Ward, 20.7. 1951, in: NARA, RG 319, Box 8, Folder 4.

${ }^{817}$ Leonard O. Friesz, Schreiben an Wilbur S. Nye, 21. 8. 1951, in: NARA, RG 319, Box 8, Folder 4.

818 Bereits im März hatte es in einem Memorandum der Documents Records Branch geheißen, dass die veränderte weltpolitische Lage wohl die Rückgabe der Akten an Deutschland erforderlich machen würde. Im weiteren Jahresverlauf drängte das Department of the Army schließlich darauf, dass die Bundesrepublik zumindest diejenigen Akten erhalten sollte, die sie zur Vorbereitung und Erfüllung des ihr zugedachten Verteidigungsbeitrages benötigte. Siehe Eckert, Kampf um die Akten, S. 213-214. 
bereitungen bereits so weit fortgeschritten waren, hätte Hans von Greiffenberg die ihm zugedachte Stelle wohl trotz der in Aussicht genommenen Aktenrückgabe angetreten. Nach seinem Tod sah die Historical Division jedoch wohl keinen Sinn mehr darin, die langwierige Prozedur der Sicherheitsüberprüfung und VisumsBeantragung für einen anderen deutschen Offizier noch einmal anzustrengen, wenn die fraglichen Akten in der Zwischenzeit möglicherweise gar nicht mehr verfügbar sein würden. Die kriegsgeschichtliche Abteilung begründete das Abrücken von ihren Plänen denn auch damit, dass die deutschen Akten bald an die Bundesrepublik zurückgegeben würden. ${ }^{819}$

Die Vorstellung der baldigen Rückführung der deutschen Militärakten nach Deutschland löste bei den ehemaligen Offizieren um Franz Halder keineswegs Begeisterung aus, im Gegenteil. Schließlich drohte die Übergabe der Bestände an die Bundesrepublik das exklusive Benutzungsrecht der ehemaligen deutschen Offiziere zu beenden und diese der universitären Forschung zugänglich zu machen. ${ }^{820}$ Franz Halder betonte deshalb immer wieder, dass die Bundesregierung weder über die nötigen Räumlichkeiten noch über das Personal für die Erschließung der Akten verfüge und auch die notwendigen Finanzmittel für den Aufbau eines geeigneten Archivs nicht vorhanden seien. ${ }^{821}$ Deshalb, so Halders Argument, solle die „wirre Masse“ der deutschen Akten zunächst in Washington „unter Mitwirkung geeigneter deutscher Kräfte“ - soll heißen: von ihm entsandten ehemaligen deutschen Offizieren - „fachmännisch geordnet“" werden. ${ }^{822}$ Für den Fall einer Übergabe drängte Halder darauf, dass sich die Amerikaner zumindest auch in Zukunft das Benutzungsvorrecht für die laufenden Arbeiten der Control Group sichern würden. ${ }^{823}$

Um die andauernde Verfügbarkeit der Akten für die Control Group sicherzustellen, schlug Alfred Toppe der Historical Division vor, die Akten nicht direkt an die Bundesregierung abzugeben, sondern „schrittweise [...] unter Verwaltung der Historical Division nach Deutschland“ zu bringen. „In den schönen Alpen“ fände sich „sicherlich ein stilles Plätzchen“, an dem dann die Control Group „wertvolle Vorarbeit und Hilfe“ für eine „spätere eigene deutsche Kriegsgeschichtsschreibung“ leisten könne. ${ }^{824} \mathrm{Zu}$ diesem Zweck, so Toppes Anregung, könnte die Control Group zu einem „Forschungsinstitut" erweitert werden, das dann unter anderem als Anlaufstelle für „alle westlichen Armeen“ dienen sollte. ${ }^{825}$ Eine solche Konstruktion hätte der ehemaligen Wehrmachtselite die Kontrolle über die Verfügbarkeit der Militärakten unter anderem für die Planung der Bundeswehr, aber auch für die wissenschaftliche Forschung überantwortet. Die schleppenden Verhandlungen um die Rückführung der Akten machten Toppes ohnehin reichlich unrealistischen Traum vom Forschungsinstitut der Control Group in den Alpen allerdings zunichte. ${ }^{826}$

${ }^{819}$ Friesz, Schreiben an Wilbur S. Nye, 21. 8. 1951, in: NARA, RG 319, Box 8, Folder 4.

${ }^{820}$ Vgl. Eckert, Kampf um die Akten, S. 431-436.

${ }^{821}$ Franz Halder, Schreiben an Gotthard Heinrici, 14. 8. 1952, in: BArch, N 265/71.

$822 \mathrm{Ebd}$.

823 Ebd.

824 Alfred Toppe, Schreiben an Helm, 25. 8. 1952, in: BArch, N 220/202.

825 Ders., Schreiben an Franz Halder, 26. 8. 1952, in: BArch, N 220/192.

826 Die Rückgabe der deutschen Militärakten verzögerte sich noch um mehrere Jahre und als die Bestände ab 1958 nach und nach an die Deutschen zurückgegeben wurden, gin- 
Stattdessen zeichnete sich bald ab, dass die Rückgabe der deutschen Militärakten keineswegs kurz bevorstand, sondern noch mehrere Jahre dauern würde. ${ }^{827}$ Franz Halder und seine Mitarbeiter bemühten sich daher in den kommenden zwei Jahren immer wieder, einen Vertreter des ehemaligen Generalstabes in Washington zu platzieren. So drängte Halder zum Beispiel im Januar 1952 bei Wilbur S. Nye darauf, „die Erfahrungen des ehemaligen deutschen Generalstabs in Führung, Organisation, Versorgung, und Ausbildung noch in höherem Maße nutzbar“ zu machen und wies darauf hin, dass dazu eine „zentrale Steuerung [der] Zusammenarbeit von Washington aus erfolgen“ müsse, wobei er implizierte, dass dies durch einen deutschen Offizier geschehen sollte. ${ }^{828}$ Nachdem auch Alfred Toppe im August 1952 bei der Historical Division in Europa erneut den Gedanken lanciert hatte, einen ehemaligen deutschen Offizier nach Washington zu schicken, ${ }^{829}$ regte Halder im September die „[z] eitlich begrenzte Entsendung eines ehemaligen deutschen Offiziers nach Washington“ an, der „das dortige Material [...] sichten“ und die „Auswahl und Formulierung der Themen für die Control Group" mitbestimmen sollte. ${ }^{830}$

Langfristig, so stellten Halder und Toppe sich die Entwicklung Anfang 1953 vor, sollte „eine Gruppe höchst qualifizierter deutscher Fachleute “ in Washington etabliert werden, die dort durch die Arbeit mit den Akten, aber auch durch Vorträge an den amerikanischen Militärschulen und persönliche Kontakte auf eine „Breitenstreuung" der deutschen Erfahrungen und Wertvorstellungen hinarbeiten sollte. ${ }^{831}$ Kurzfristig wünschte sich Halder zumindest die Entsendung eines ehemaligen Generalstabsoffiziers - er dachte dabei vor allem an seinen engen Mitarbeiter Alfred Toppe - in die amerikanische Hauptstadt, der das Verlangen der Amerikaner nach dem „geistige[n] Angebot“ der ehemaligen Wehrmachtselite anregen, „möglichst günstige Voraussetzungen für die Stillung des allmählich zunehmenden Appetits“ schaffen und so den Aufbau der späteren Gruppe vorbereiten sollte. ${ }^{832}$ Tatsächlich

gen sie zunächst an die Dokumentenzentrale des Militärgeschichtlichen Forschungsamtes und erst ab 1968 schließlich ans Bundesarchiv-Militärarchiv. Henke, Das Schicksal deutscher Zeitgeschichtlicher Quellen in Kriegs- und Nachkriegszeit, S. 599.

827 Franz Halder rechnete zum Beispiel Anfang 1953 damit, dass noch mindestens fünf Jahre vergehen würden, bis die Wehrmachtsakten nach Deutschland zurückkehren würden: Halder, Schreiben an Alfred Toppe, 9. 3. 1953, in: BArch, N 220/203. Das Amt Blank hatte zwar im Frühjahr 1952 Ausbildungshandbücher und Merkblätter aus den beschlagnahmten Heeresakten als Dauerleihgabe erhalten, außerdem brachten die Amerikaner die Heerespersonalakten im Herbst 1953 in einer Einrichtung von G-2 in Oberursel unter, wo die Mitarbeiter des Amtes Blank die Unterlagen ab April 1954 einsehen konnten; 1955 wurden die Wehrmachtspersonalakten schließlich an das Bundesverteidigungsministerium abgegeben. Der Großteil der militärischen Akten wurde jedoch erst zwischen 1958 und 1968 an die Bundesrepublik zurückgegeben. Vgl. Eckert, Kampf um die Akten, S. 226-227, S. 321-324 und S. 328; Henke, Das Schicksal deutscher Zeitgeschichtlicher Quellen in Kriegs- und Nachkriegszeit, S. 582-600.

828 Halder, Schreiben an Wilbur S. Nye, 12.1.1952, in: BArch, N 220/202.

829 Toppe, Schreiben an Helm, 25. 8. 1952, in: BArch, N 220/202.

${ }^{830}$ Franz Halder, Schreiben an Historical Division, USAREUR, Foreign Military Studies Branch: Besprechungspunkte und Anregungen der Control Group für Herrn Oberst Nye anlässlich seiner Reise nach Washington, 18. 9. 1952, in: BArch, N 220/192.

831 Halder, Schreiben an Alfred Toppe, 9. 3. 1953, in: BArch, N 220/203.

832 Ebd. 
hielt sich Toppe im Sommer 1952 sowie im Winter und Frühjahr 1953 zusammen mit Rudolf Hofmann jeweils für mehrere Wochen in Washington auf, wo er Recherchen in den deutschen Wehrmachtsakten durchführte. ${ }^{833}$

Letztlich konnten Halder und Toppe ihren Plan, gleichsam eine Dependance der Control Group in Washington aufzubauen, jedoch nicht in die Tat umsetzen, weil die Idee bei den Amerikanern auf „Zu viele Schwierigkeiten“ stieß.834 Worin diese „Schwierigkeiten“ genau bestanden, erschließt sich aus den Quellen leider nicht, es scheint jedoch nicht unwahrscheinlich, dass die Planungen der Control Group nicht zuletzt aufgrund der zunehmenden Kürzungen im Budget der U.S. Armee und damit auch der Historical Division zunächst unter der Regierung Truman und dann noch massiver unter der Eisenhower-Administration scheiterten. Wie auch immer die Schwierigkeiten genau aussahen, sie waren jedenfalls substantiell genug, um Franz Halder im Sommer 1953 davon zu überzeugen, seine Pläne endgültig fallenzulassen. ${ }^{835}$

Dass es ihm nicht gelungen war, die kriegsgeschichtlichen Ideale des preußischdeutschen Generalstabs auf die Historical Division zu übertragen, lag in Halders Augen vor allem daran, dass die Bedeutung kriegsgeschichtlicher Arbeit in der U.S. Armee noch nicht erkannt worden war und es der Historical Division in der Folge an einem klaren und mit strategischen Konzeptionen verknüpften Programm sowie sorgfältiger Planung fehlte. ${ }^{836}$ Ernüchtert schrieb er im März 1954 an Waldemar Erfurth: „In den Washingtoner Betrieb Format und Schwung hineinzubringen erscheint mir für einen ehemaligen deutschen Offizier gänzlich aussichtslos. "837 In Zukunft, so viel stand für Halder ab 1954 fest, war bei seiner Arbeit als Leiter der Control Group allein ausschlaggebend, dass sich diese „für Deutschland“ lohnen würde. ${ }^{838}$ In der Folge wandten er und seine Mitarbeiter ihre Aufmerksamkeit ab Mitte der 1950er Jahre verstärkt der Verbreitung der kriegsgeschichtlichen Studien in der Bundesrepublik und insbesondere der im Entstehen begriffenen Bundeswehr zu.

\section{Halders kriegsgeschichtlicher Autorenkreis}

Ganz unter dem Diktum, dass sich die kriegsgeschichtliche Kooperation auch für die Bundesrepublik „lohnen“ sollte, stand eine weitere Hilfestellung der Historical Division für die Geschichtspolitik der ehemaligen Wehrmachtselite: Sie genehmigte die Veröffentlichung der kriegsgeschichtlichen Studien in deutschen Fachpublikationen. Das war insofern von Bedeutung, als die ehemalige Wehrmachts-

833 Toppe, Schreiben an Franz Halder, 26. 8. 1952, in: BArch, N 220/192; Melvin C. Helfers, Report of Activities, Foreign Studies Branch (1.-31.1.1953), 2.2.1953, in: NARA, RG 319, Box 21, Monthly Progress Reports 1952-53; Ders., Report of Activities, Foreign Studies Branch (1.-31.3. 1953), 1. 4. 1953, in: NARA, RG 319, Box 21, Monthly Progress Reports 1952-53.

${ }^{834}$ Franz Halder, Schreiben an Hans W. Helm, 22. 6. 1953, in: BArch, N 220/203.

835 Ebd.

836 Vgl. Ders., Schreiben an Waldemar Erfurth, 19.2. 1954, in: BArch, N 257/v. 8; Ders., Schreiben an Waldemar Erfurth, 3.3. 1954, in: BArch, N 257/v. 8. Halder lag mit dieser Einschätzung durchaus nicht falsch, vgl. oben, Teil II, Kapitel 1. 1 und Teil III, Kapitel 2.

837 Halder, Schreiben an Waldemar Erfurth, 3. 3. 1954, in: BArch, N 257/v. 8.

838 Ebd. 
elite erreichen musste, dass ihre Studien in Deutschland einer breiteren Öffentlichkeit bekannt gemacht wurden, um den Vorteil des privilegierten Aktenzugangs geschichtspolitisch auch zum Tragen zu bringen. Ab 1953 hatte Franz Halder deshalb verstärkt darauf hingearbeitet, bei der Historical Division die Freigabe geeigneter kriegsgeschichtlicher Studien für die Veröffentlichung in Deutschland zu erwirken. ${ }^{839}$ Dabei hatte der ehemalige Generalstabschef argumentiert, dass die unter seiner Leitung entstandenen Arbeiten „ein Gegengewicht gegen die subjektive Memoirenliteratur und die sensationslüsternen Tatsachenberichte der illustrierten Gazetten“ darstellen könnten. ${ }^{840}$ Solange die deutschen Militärakten sich noch in den USA befänden, könne ein solches Gegengewicht nur dadurch erreicht werden, dass das ,von qualifizierten ehemaligen Offizieren aufgrund amtlicher Dokumente erarbeitete Gedankengut der deutschen Öffentlichkeit zugänglich" gemacht werde. ${ }^{841}$

Allerdings hatte sich die Historical Division zunächst gegen die Publikation kriegsgeschichtlicher Studien in deutschen Zeitschriften gesträubt, ${ }^{842}$ aber immerhin zugestanden, dass Mitglieder der Control Group und ausgewählte „Heimarbeiter“ auf ihrer Tätigkeit für die Amerikaner basierende, jedoch privat verfasste, historische Studien in Deutschland veröffentlichen konnten, solange ihre dienstliche Tätigkeit für die Historical Division davon nicht beeinträchtigt wurde. Die Bezugnahme und Zitierung von Originaldokumenten aus dem Bestand der beschlagnahmten deutschen Heeresakten wurde jedoch mit Verweis auf das Bissel-Sinclair-Abkommen ${ }^{843}$ untersagt. $^{844}$ Erst Anfang November 1957 genehmig-

839 Ders., Halbjahresbericht der Control Group für die Zeit vom 1. Juli bis 31. Dezember 1953, in: BArch, ZA 1/1842; Ders., Halbjahresbericht der Control Group für die Zeit vom 1. Januar bis 30. Juni 1954, in: BArch, ZA 1/1843; Ders., Halbjahresbericht der Control Group für die Zeit vom 1. Juli bis 31. Dezember 1954, in: BArch, ZA 1/1844; Ders., Schreiben an Anton von Bechtolsheim, 4. 3. 1954, in: BArch, N 220/203; Executive C. D. McFerren, OCMH, Schreiben an den Chief, Historical Division, EUCOM, betr.: Release of Certain Manuscripts for Publication in German Military Journals, 30.3. 1954, in: NARA, RG 319, Box 11, Folder 2.

840 Halder, Schreiben an Anton von Bechtolsheim, 4. 3. 1954, in: BArch, N 220/203.

${ }^{841}$ Franz Halder, Memorandum, 4.3. 1954, in: BArch, N 220/203.

842 Wilbur S. Nye, Schreiben an den Chief of Military History, DA, betr.: Release of Certain Manuscripts for Publication in German Military Journals, 20.4. 1954, in: NARA, RG 319, Box 11, Folder 2.

${ }^{843}$ Amerikaner und Briten hatten sich bereits vor Ende des Zweiten Weltkrieges darauf geeinigt, dass alle Unterlagen, die in der Zeit ihres gemeinsamen Oberkommandos (SHAEF) gesammelt worden waren, gemeinsamer Besitz beider Regierungen bleiben sollten. Im Bissel-Sinclair-Abkommen, das nach den beiden Unterhändlern, Clayton Bissel (USA) und John Alexander Sinclair (GB), benannt ist, hatten Amerikaner und Briten dann im Mai 1945 u. a. festgelegt, dass die beschlagnahmten deutschen Akten unabhängig von ihrer Verwahrung in Großbritannien oder den USA weiterhin gemeinsamer Besitz der beiden Staaten bleibe. Die Historical Division fürchtete deshalb Verstimmungen bei den Briten, wenn durch die Veröffentlichung der auf diesen Akten beruhenden deutschen Studien bekannt würde, dass die Amerikaner den ehemaligen Wehrmachtsoffizieren so großzügigen Zugang zu den beschlagnahmten Heeresakten gestatteten. Vgl. zum Bissel-Sinclair-Abkommen Eckert, Kampf um die Akten, S. 33-34.

844 Vgl. Wilbur S. Nye, Schreiben an Franz Halder, 2. 4. 1954, in: BArch, N 220/203. Allerdings hielten sich nicht alle Autoren an diese Vorgaben: In einer Besprechung von 
ten die Amerikaner schließlich auch die Veröffentlichung der im Rahmen der Kooperation entstandenen deutschen Studien in deutschen Fachverlagen, vorausgesetzt diese waren nicht mit einer Geheimhaltungsstufe belegt; außerdem musste gegebenenfalls die Erstveröffentlichung durch das Department of the Army abgewartet werden. ${ }^{845}$

Die Freigabe der Studien zur Veröffentlichung veranlasste Franz Halder, einen „kriegsgeschichtlichen Studienkreis ehemaliger deutscher Generalstabsoffiziere“ zu gründen, der es sich zum Ziel machte, „das Gedankengut deutscher Führungskunst für das zukünftige Soldatentum nutzbar zu machen".846 Außerdem sollte die Publikation ausgewählter Studien durch „eine gerechte Würdigung der Leistung des deutschen Heeres im vergangenen großen Krieg als ein besonders wirksames Mittel zur Stärkung des Wehrgedankens im heutigen Deutschland“ dienen. ${ }^{847}$

Die Leitung des sogenannten Autorenkreises übernahm Halder selbst, der auch die zu veröffentlichenden Studien auswählte und sie „auf eventuelle textliche Änderungen“ prüfte, die „für die Ausgabe im deutschen Bereich ratsam“ erschienen. ${ }^{848}$ Dass es sich beim Autorenkreis in erster Linie um ein Gremium der Control Group handelte, wird auch dadurch deutlich, dass neben Halder Alfred Gause, Rudolf Hofmann, Burkhart Müller-Hillebrand, Alfred Philippi, Hellmuth Reinhardt, Ludwig Rüdt von Collenberg, Alfred Toppe, Wilhelm Willemer und Alfred Zerbel zu den Gründungsmitgliedern zählten. ${ }^{849}$ Darüber hinaus gehörten mit Günther Blumentritt, Waldemar Erfurth, Adolf Heusinger und Walter Warlimont

Müller-Hillebrands Buch „Das deutsche Heer 1933-1945“, die im April 1954 in der Wehrwissenschaftlichen Rundschau erschien, wies der Rezensent ausdrücklich darauf hin, dass das Buch „[a]uf Grund deutscher Dokumente und Originalakten, die von der Historical Division der U.S. Army z[ur] V[erfügung] gestellt wurden, entstanden sei. Die Historical Division reagierte ungehalten auf den Zwischenfall und wies die Control Group ausdrücklich darauf hin, dass derlei in Zukunft zu vermeiden sei. Vgl. Wilbur S. Nye, Schreiben an A. C. Smith, 4. 5. 1954, in: NARA, RG 319, Box 11, Folder 2; G.V.S., Buchbesprechung: Das deutsche Heer 1933-1945 von Burkhart Müller-Hillebrand, in: Wehrwissenschaftliche Rundschau 4 (1954); A. C. Smith, Schreiben an Wilbur S. Nye, 26. 4. 1954, in: NARA, RG 319, Box 11, Folder 2. Auch in den kommenden Jahren kam es jedoch immer wieder zu Verstößen gegen diese Auflage. So zitierte zum Beispiel Alfred Philippi in seiner im März 1956 als Beiheft der Wehrwissenschaftlichen Rundschau erschienenen Studie „Das Pripjet-Problem“ zahlreiche Originaldokumente; Franz Halder musste seine Mitarbeiter daraufhin erneut ausdrücklich darauf hinweisen, dass eine Bezugnahme auf Originaldokumente in privaten Veröffentlichungen untersagt war. Vgl. Vorschlag eines Schreibens an OCMH betreffend Veröffentlichung Alfred Philipp „Das Pripjet-Problem“ (Beiheft 2 zur Wehrwissenschaftlichen Rundschau, März 1956), o. D., in: BArch, N 220/204; Franz Halder, Entwurf eines Schreibens der Control Group an alle deutschen Mitarbeiter an den kriegsgeschichtlichen Arbeiten der Historical Division, 20. 6. 1956, in: BArch, N 220/204.

845 Edward B. James, Memorandum for Chief, Foreign Military Studies Branch, betr. Release of Completed Unclassified Historical Studies for Publication in the German Language, 8.11. 1957, in: BArch, N 220/120.

846 Franz Halder, Anmerkungen zu „Sinn und Aufgaben des Autorenkreises“, 19. 11. 1957, in: BArch, N 220/120.

847 Ebd.

848 Ebd.

${ }^{849}$ Liste der Gründungsmitglieder des Autorenkreises, in: BArch, N 220/120. 
weitere langjährige Mitarbeiter der Historical Division zu den Mitgliedern. ${ }^{850}$ Der Autorenkreis schloss sich als geschlossene Gruppe dem Arbeitskreis für Wehrforschung (AfW) an, ${ }^{851} \mathrm{zu}$ dem die Control Group bereits seit mehreren Jahren enge Verbindungen hatte.

Der AfW ging auf eine Initiative von Georg von Sodenstern zurück, Professoren und Nachwuchswissenschaftler aus den Geistes- und Naturwissenschaften für Fragen der Wehrforschung zu interessieren, Forschungsprojekte anzuregen und deren Ergebnisse zu veröffentlichen. ${ }^{852}$ Nachdem Sodensterns Bemühungen, private Geldgeber aus der Wirtschaft und wissenschaftliche Fördermittel für die Finanzierung wehrwissenschaftlicher Forschungsprojekte zu gewinnen, erfolglos geblieben war, hatte schließlich auf Vermittlung der Dienststelle Blank das Bundespresseamt die Finanzierung des AfW übernommen. Dank der monatlichen Zuwendungen konnte im April 1954 ein kleines Büro in Frankfurt unter der Leitung von Jürgen Rohwer eingerichtet werden. Außerdem stellte der Verlag Mittler \& Sohn dem AfW ab Oktober 1954 seine vier Jahre zuvor begründete Zeitschrift Wehrwissenschaftliche Rundschau als offizielles Organ zur Verfügung. ${ }^{853}$

Auch wenn der AfW also seit 1954 durch die Wehrwissenschaftliche Rundschau öffentlich präsent war, wurde der ansonsten zunächst nur lose konstituierte Arbeitskreis erst im April 1956 formal als Verein gegründet. ${ }^{854}$ Unter den Mitgliedern waren mit Günther Blumentritt, Waldemar Erfurth, Ludwig Freiherr Rüdt von Collenberg, Rudolf Hofmann, Alfred Philippi, Alfred Toppe (Schriftleiter) und Wilhelm Willemer zahlreiche ehemalige Offiziere aus dem Umfeld der Control Group. ${ }^{855}$ Da der Initiator des Arbeitskreises, Georg von Sodenstern, am

${ }^{850}$ Liste weiterer Mitglieder des Autorenkreises, in: BArch, N 220/120.

${ }^{851}$ Halder, Anmerkungen zu „Sinn und Aufgaben des Autorenkreises“, 19. 11. 1957, in: BArch, N 220/120.

852 Jürgen Rohwer, Bericht über die bisherige Arbeit und den augenblicklichen Stand der Vorhaben des „Arbeitskreises für Wehrforschung“. Referat gehalten am 17. 10.1956 auf der 1. Mitgliederversammlung des Arbeitskreises für Wehrforschung, S. 1, in: BArch, N 281/11; vgl. auch Arbeitskreis für Wehrforschung (Hg.), 15 Jahre Arbeitskreis für Wehrforschung, S. 1-2.

${ }^{853}$ Rohwer, Bericht über die bisherige Arbeit und den augenblicklichen Stand der Vorhaben des „Arbeitskreises für Wehrforschung“. Referat gehalten am 17. 10. 1956 auf der 1. Mitgliederversammlung des Arbeitskreises für Wehrforschung, S. 1, in: BArch, N 281/11; vgl. auch Rohwer, Vom Naval Historical Team zum Arbeitskreis für Wehrforschung, in: Klüvert (Hg.), Marinegeschichte, Seekrieg, Funkaufklärung, S. 86. Schriftleiter der Wehrwissenschaftlichen Rundschau war seit August 1951 Alfred Toppe, im Frühjahr 1957 folgte ihm Alfred Philippi in dieser Position nach.

854 Sitz des Vereins war Frankfurt am Main, ab 1959 Stuttgart. Vgl. Satzung für den Arbeitskreis für Wehrforschung vom 14.04. 1956, in: IfZArch, ID 30/22; Mitteilung des Arbeitskreises für Wehrforschung und der Arbeitsgemeinschaft für Wehrtechnik vom 26. 10. 1959, in: IfZArch, ID 300/22.

855 Vgl. Liste der Mitglieder des Arbeitskreises für Wehrforschung, o. D., in: IfZArch, ED 91/32. Gründungsmitglieder waren Admiral a. D. Erich Förste, Kapitän z. See a. D. Winfried B. Hagen, Konteradmiral a. D. Rolf Johannesson, Jürgen Rohwer, Generalleutnant a. D. Erich Schneider, Professor Dr. Ing. Friedrich Seewald, General der Flieger a. D. Wilhelm Speidel, General a. D. Kurt von Tippelskirch und Generalmajor a. D. Alfred Toppe. Vgl. Arbeitskreis für Wehrforschung (Hg.), 15 Jahre Arbeitskreis für Wehrforschung, S. 4. 
22. Juli 1955 unerwartet verstorben war, wurde bei der ersten Mitgliederversammlung des Vereins am 17. und 18. Oktober 1956 der ehemalige General Kurt von Tippelskirch zum Vorsitzenden des Präsidiums gewählt. ${ }^{856}$

Unter seiner Führung erweiterte der AfW das Programm der Wehrwissenschaftlichen Rundschau, zu der künftig auch thematische Beihefte erschienen. Außerdem begründete der Arbeitskreis die Schriftenreihe Studien und Dokumente zur Geschichte des Zweiten Weltkrieges, die beim Musterschmidt Verlag erschien. ${ }^{857}$

Als auch Kurt von Tippelskirch nur knapp ein Jahr später, im Mai 1957, verstarb, schaltete sich Franz Halder im Herbst 1957 hinter den Kulissen in die Frage der Neubesetzung des AfW-Präsidiums ein, um sicherzustellen, dass der neue Vorsitzende des Arbeitskreises „in einem nahen persönlichen Kontakt“ mit ihm verbunden sein würde. ${ }^{858}$ Tatsächlich hatte Franz Halder, selbst kein offizielles Mitglied des Arbeitskreises, ${ }^{859}$ „ein gewisses Gewicht“ bei der künftigen Weichenstellung des Arbeitskreises. ${ }^{860}$ Dabei spielte neben Halders Position als ehemaliger Chef des Generalstabes vor allem auch die Tatsache eine Rolle, dass die Historical Division erst vor Kurzem die Veröffentlichung der deutschen Studien genehmigt hatte. Denn wenn der Arbeitskreis für Wehrforschung diesen attraktiven Pool militärischer Studien für seine Publikationen nutzen wollte, musste er sich zwangsläufig mit Halder gut stellen, der als Leiter der Control Group maßgeblich darüber mitentschied, welche Studien veröffentlicht werden würden.

Somit standen die Chancen, einen Vertrauten aus dem Umfeld des ehemaligen Generalstabschefs als Präsidenten des Arbeitskreises zu installieren, nicht schlecht. Tatsächlich hatte Präsidiumsmitglied Erich Schneider ${ }^{861}$ Halder Ende September wissen lassen, dass der Arbeitskreis „den größten Wert“ darauf lege, „dass sein künftiger Präsident“ mit der „Zustimmung und Unterstützung“ des ehemaligen

856 Vgl. Thilo Vogelsang, Bericht über die Tagung vom 20.10.1956, S. 7, in: IfZArch, ID 300/22; Rohwer, Bericht über die bisherige Arbeit und den augenblicklichen Stand der Vorhaben des „Arbeitskreises für Wehrforschung“. Referat gehalten am 17.10. 1956 auf der 1. Mitgliederversammlung des Arbeitskreises für Wehrforschung, S. 3, in: BArch, N 281/11. Tippelskirch war gleichzeitig Vorsitzender des Verbandes deutscher Soldaten.

${ }^{857}$ Rohwer, Bericht über die bisherige Arbeit und den augenblicklichen Stand der Vorhaben des „Arbeitskreises für Wehrforschung“. Referat gehalten am 17.10. 1956 auf der 1. Mitgliederversammlung des Arbeitskreises für Wehrforschung, S. 3, in: BArch, N 281/11. Bevor Kurt von Tippelskirch Präsident des Arbeitskreis wurde, leitete Jürgen Rohwer die Geschäfte. Vgl. hierzu Jürgen Rohwehr, Brief an Leo Freiherr Geyr von Schweppenburg vom 6.9.1955, in: IfZArch, ED 91/32. Anschließend wirkte er bis Herbst 1959 als Geschäftsführer des Arbeitskreises. Im Oktober 1959 übernahm er die Leitung der Stuttgarter Bibliothek für Zeitgeschichte. Als Geschäftsführer des AfW folgte ihm Gerhard Hümmelchen nach. Vgl. Mitteilung des Arbeitskreises für Wehrforschung und der Arbeitsgemeinschaft für Wehrtechnik vom 26. 10. 1959, in: IfZArch, ID 300/22.

${ }^{858}$ Franz Halder, Schreiben an August Winter, 3. 10. 1957, in: BArch, N 220/90.

${ }^{859}$ Vgl. Liste der Mitglieder, IfZArch, ED 91/32.

${ }^{860}$ Halder, Tagesnotizen aus der Zeit der Control Group, Oktober 1957-Juni 1958, Eintrag vom 1. 10. 1957, in: BArch, N 220/113.

861 Schneider war außerdem Präsident der eng mit dem AfW verbundenen Arbeitsgemeinschaft für Wehrtechnik. 
Generalstabschefs rechnen könne. ${ }^{862}$ Er bat Halder deshalb um seine „persönliche Meinung“ zu einer Reihe möglicher Kandidaten, zu denen auch Anton von Bechtolsheim sowie der ehemalige Generalleutnant Friedrich Sixt und der ehemalige Generalmajor Erich Hampe gehörten. ${ }^{863}$ Halder sagte daraufhin zwar seine Unterstützung für eine Kandidatur von Bechtolsheims zu, bei dem er sich „der inneren Verbindung“ mit dem ehemaligen Generalstab sicher sei, brachte aber gleichzeitig Friedrich von Boetticher als den von ihm favorisierten Kandidaten ins Spiel. ${ }^{864}$

In den folgenden Oktoberwochen bemühten sich Franz Halder und Alfred Philippi, die „alten Generalstabskreise“ für die Wahl Boettichers „zusammenzuschließen". ${ }^{865}$ Am 3. Oktober brachte Halder in einem Brief an August Winter zum Ausdruck, dass Boetticher und Bechtolsheim die von ihm bevorzugten Kandidaten für den AfW-Vorsitz seien und mahnte zu einer geschlossenen Haltung der ehemaligen Generalstabsoffiziere in der Nachfolgefrage:

„Wie auch schließlich die Entscheidung fallen mag, ich würde es begrüßen, wenn wir Männer des alten Generalstabs [...] im Geltendmachen unseres Schwergewichts zusammenstehen und eine einheitliche Linie wahren könnten." 866

Wenig später sandte Halder seinen Vertrauten, Alfred Philippi, zu Sondierungsgesprächen aus, um sich zunächst mit Winter, wenige Tage später auch mit Jürgen Rohwer zu treffen und über die anstehende Präsidentenwahl zu sprechen. ${ }^{867}$

Erst nachdem sowohl Erich Schneider als auch Winter und Rohwer für eine Kandidatur Boettichers gewonnen waren, ${ }^{868}$ fragte Halder schließlich diesen selbst nach seiner Bereitschaft, die Nachfolge von Kurt von Tippelskirch anzutreten. Auch dabei unterstrich er sein Interesse, den Arbeitskreis als Organ des ehemaligen Generalstabs zu erhalten:

Es liegt mir auch am Herzen, dass für diesen vom alten Generalstab ausgehenden Arbeitskreis das alte Vertrauensverhältnis der Generalstabskameraden die tragende Säule bleibt. Aus diesem Grund ist es mir auch persönlich besonders wichtig, einen als prominenter Vertreter des alten deutschen Generalstabs bekannten militärischen Würdenträger an die Spitze des Arbeitskreises zu bringen. ${ }^{869}$

Tatsächlich erklärte sich Boetticher unter Vorbehalt der Klärung einiger Detailfragen grundsätzlich bereit, die Aufgabe zu übernehmen. Wenig später machte er dann jedoch überraschend einen Rückzieher. Als Grund für seine Absage führte er an, dass der Historiker Gerhard Ritter auf der Ende Oktober stattfindenden

862 Erich Schneider, Schreiben an Franz Halder, 27. 9. 1957, in: BArch, N 220/122.

863 Ebd.

${ }^{864}$ Franz Halder, Schreiben an Erich Schneider, 1. 10. 1957, in: BArch, N 220/122.

865 Halder, Tagesnotizen aus der Zeit der Control Group, Oktober 1957-Juni 1958, Eintrag vom 1. 10. 1957, in: BArch, N 220/113.

866 Ders., Schreiben an August Winter, 3. 10. 1957, in: BArch, N 220/90.

867 Ders., Tagesnotizen aus der Zeit der Control Group, Oktober 1957-Juni 1958, Einträge vom 7. 10. und 10. 10. 1957, in: BArch, N 220/113.

868 Ebd., Eintrag vom 10. 10. 1957.

${ }^{869}$ Franz Halder, Schreiben an Friedrich von Boetticher, 10.10.1957, in: BArch, N 220/122. 
Arbeitstagung des AfW den Eröffnungsvortrag zum „Verhältnis der politischen und militärischen Führung in Deutschland“ hielt. ${ }^{870}$ Da Boetticher die Thesen Ritters zum Schlieffenplan, die dieser im Jahr zuvor in einer kritischen Studie vorgelegt hatte, ${ }^{871}$ scharf ablehnte, sah er sich nicht in der Lage, den Vorsitz eines Vereins zu übernehmen, der den Historiker auf seinen Tagungen sprechen ließ.872

Nachdem Friedrich von Boetticher also nicht zur Verfügung stand, wurde schließlich Halders zweiter Wunschkandidat - Anton von Bechtolsheim - für das Präsidium des Arbeitskreises für Wehrforschung nominiert und Ende Oktober auf der Jahrestagung des Vereins gewählt. ${ }^{873}$ Bechtolsheim enttäuschte den ehemaligen Generalstabschef nicht. Bereits am 4. November besprach der neue Präsident des AfW mit Halder die „nächsten wesentlichen Aufgaben“ und die „Programmgestaltung“ des Arbeitskreises. ${ }^{874}$ Wenige Wochen später trafen Halder, Bechtolsheim und August Winter außerdem in Stuttgart zusammen, um noch vor der ersten Sitzung des neuen Präsidiums das künftige Programm des AfW abzustimmen und die geplante Eingliederung von Halders Autorenkreis in den Arbeitskreis für Wehrforschung zu besprechen. ${ }^{875} \mathrm{Im}$ Dezember berichtete Alfred Philippi von der Präsidiumssitzung des AfW, dass Bechtolsheim nicht nur „die Geschäfte in feste Hand genommen" habe, sondern dass auch das Arbeitsprogramm des Vereins „entsprechend unserer Anregungen in Stuttgart“ künftig unter dem Dachthema „Übergang vom Frieden in überraschenden totalen Kriegszustand" stehe und der AfW außerdem den Vorschlag, die deutschen Studien herauszugeben dankbar angenommen habe. ${ }^{876}$

Nach dem unerwarteten Tod Anton von Bechtolsheims am 9. Februar 1961 versuchte Franz Halder erneut, Einfluss auf die Nachfolge im Amt des AfW-Präsidenten $\mathrm{zu}$ nehmen. ${ }^{877}$ Am 17. Februar wandte er sich diesbezüglich an Adolf Heusinger: Um den Arbeitskreis für Wehrforschung als Hort „der schöpferischen und moralischen Kräfte des ehemaligen Generalstabs“ zu erhalten, so Halder, wäre es ratsam, dass „einer [der] bewährten Spitzenvertreter des alten Generalstabs die Nachfolge“ Bechtolsheims übernehmen würde. ${ }^{878}$ Als geeigneten Kandidaten nannte er den ehemaligen General der Infanterie Gerhard Matzky ${ }^{879}$. Da

${ }^{870}$ Halder, Tagesnotizen aus der Zeit der Control Group, Oktober 1957-Juni 1958, Einträge vom 21. 10. und 28. 10. 1957, in: BArch, N 220/113.

871 Ritter, Der Schlieffenplan.

872 Friedrich von Boetticher, Schreiben an Franz Halder, 12.10.1957, in: BArch, N 220/122.

873 Protokoll der zweiten Mitgliederversammlung des Arbeitskreises für Wehrforschung am 25. 10. 1957 in Bad Godesberg, S.2, in: IfZArch, ID 300/22; Halder, Tagesnotizen aus der Zeit der Control Group, Oktober 1957-Juni 1958, Eintrag vom 28. 10. 1957, in: BArch, N 220/113; Arbeitskreis für Wehrforschung (Hg.), 15 Jahre Arbeitskreis für Wehrforschung, S. 6.

${ }^{874}$ Halder, Tagesnotizen aus der Zeit der Control Group, Oktober 1957-Juni 1958, Eintrag vom 4. 11. 1957, in: BArch, N 220/113.

875 Ebd., Eintrag vom 25. 11. 1957.

876 Ebd., Eintrag vom 11. 12. 1957.

877 Franz Halder, Tagesnotizen aus der Zeit der Control Group, 1961, in: BArch, N 220/116, Eintrag vom 9.2. 1961.

878 Ders., Schreiben an Adolf Heusinger, 17. 2. 1961, in: BArch, N 220/84.

879 Matzky war von 1957 bis 1960 Kommandeur des I. Korps in Münster gewesen. 
Halder jedoch fürchtete, dass im Präsidium des AfW „junge maritim orientierte Kräfte am Werk" seien, die den ehemaligen Vizeadmiral und Inspekteur der Marine (1957-1961) Friedrich Ruge als Nachfolger Bechtolsheims „mit Nachdruck propagier[t]en", bat er Heusinger darum, bei der Besetzung des AfW-Vorsitzes seinen Einfluss als Generalinspekteur zugunsten Matzkys geltend zu machen. 880 Auch Jürgen Rohwer, August Winter und Otto Wustmann gegenüber warb Halder für Matkzy als Präsidenten des AfW. ${ }^{881}$ Anders als 1957 konnte sich Halder dieses Mal bei der Besetzung des Präsidiumspostens jedoch nicht durchsetzen. Stattdessen wurde, unterstützt vom Bundesverteidigungsministerium, Friedrich Ruge zum Vorsitzenden des AfW gewählt. ${ }^{882}$

\section{Kontakte zu Journalisten, Verlegern und Wissenschaftlern}

Die Kooperation mit der Historical Division erwies sich noch auf eine dritte Art als äußerst nützlich für die Geschichtspolitik der ehemaligen Wehrmacht: Sie erleichterte ihnen den Kontakt zu deutschen und amerikanischen Historikern und Politikwissenschaftlern. Dies geschah auf dreierlei Weise. Zum einen machte der privilegierte Zugriff auf die deutschen Heeresakten die ehemaligen Offiziere zu noch gefragteren Gesprächspartnern bei deutschen und amerikanischen Militärhistorikern, als dies aufgrund der Zeitzeugenschaft der Militärs ohnehin der Fall war. So wandte sich zum Beispiel Hans-Günther Seraphim, Leiter des zeitgeschichtlichen Referats am Institut für Völkerrecht der Universität Göttingen ${ }^{883}$, im Juni 1952 an Halder und bat um Überlassung von Studien für das Archiv des Instituts. Da man bei Seraphim, der während des Nürnberger Prozesses als historischer Sachverständiger der Verteidigung agiert hatte, ${ }^{884}$ davon ausging, dass er im Sinne der ehemaligen Wehrmacht handeln würde, unterstützte Franz Halder - sonst bei der Weitergabe der Studien an Universitäten äußerst zurückhaltend ${ }^{885}$ - die Bitte und schlug vor, Mikrofilme der deutschen Studien an das Archiv weiterzugeben. Dabei machte er jedoch zur Bedingung, dass die Arbeiten nur für zeitgeschichtliche Studien innerhalb des Archivs verwendet würden und selbst dann nicht als Quellen genannt, nicht wörtlich zitiert und die Autoren nicht namentlich genannte werden dürften. ${ }^{886}$

Zweitens stellte die Historical Division auch ganz aktiv den Kontakt zwischen den deutschen Militärs und amerikanischen Historikern, Journalisten und Ver-

880 Halder, Schreiben an Adolf Heusinger, 17.2. 1961, in: BArch, N 220/84.

881 Ders., Tagesnotizen aus der Zeit der Control Group, 1961, Einträge vom 28. 2., 2.3., 15.3., 20.3. und 10.4.1961, in: BArch, N 220/116.

882 Ebd., Eintrag vom 10.4. 1961.

883 Die Universität Göttingen war in den 1950er Jahren ein wichtiges Zentrum der Geschichtsschreibung über den Zweiten Weltkrieg.

884 Vgl. Conrad, Suche nach der verlorenen Nation, S. 188 und S. 237. Im Anschluss an den Nürnberger Prozess hatte Seraphim die Erschließung der Nürnberger Dokumente am Archiv des Instituts für Völkerrecht in Göttingen übernommen.

885 Vgl. Halder, Tagesnotizen aus der Zeit der Control Group, August 1954 bis September 1955, Eintrag vom 24.1. 1955, in: BArch, N 220/111.

886 Franz Halder, Schreiben an Historical Division, EUCOM, FMSBr, betr. Überlassung von Ausarbeitungen der Control Group an das Institut für Völkerrecht an der Universität Göttingen, 16. 6. 1952, in: BArch, N 220/202. 
legern her, die Arbeiten zum Zweiten Weltkrieg oder zum deutschen Militär veröffentlichen wollten. So wandte sich beispielsweise das Verlagshaus Doubleday, Doran \& Company, das ein Buch zu den amerikanischen Operationen in Europa herausbringen wollte, im Sommer 1947 an die Historical Division und bat um die Kontaktvermittlung zu einem kompetenten deutschen Offizier. ${ }^{887}$ Der Leiter der Historical Division in Europa, Harold E. Potter, war gerne bereit, dem Verlag die Namen mehrerer deutscher Militärs zu nennen und empfahl Gerd von Rundstedt, Heinz Guderian, Bodo Zimmermann und Walter Warlimont. ${ }^{888}$ Im Dezember 1949 gab die Operational History (German) Section die Adressen von Blumentritt und Zimmermann an einen UP-Korrespondenten weiter, der um die Vermittlung von Kontakten zu ehemaligen deutschen Offizieren für verschiedene Interviews gebeten hatte. ${ }^{889}$

Auch in den 1950er Jahren fungierte die Historical Division immer wieder als Kontaktvermittlungsstelle zwischen amerikanischen Journalisten und Wissenschaftlern einer- und der ehemaligen Wehrmachtselite andererseits. So besuchte zum Beispiel der Soziologe und Politikwissenschaftler Morris Janowitz (19221988) Anfang 1955 die Control Group und sprach mehrmals mit Franz Halder über die „soziale und gesellschaftliche Struktur“ des deutschen Offizierskorps. 890 Die Ergebnisse der Gespräche flossen möglicherweise in Janowitz’ 1960 veröffentlichtes Buch The Professional Soldier ein. ${ }^{891}$ Wenige Wochen nach der Unterredung mit dem Soziologen erreichte die Control Group über das amerikanische Hauptquartier in Heidelberg die Anfrage eines Journalisten der Saturday Evening Post, der deutsche Offiziere als Autoren für Arbeiten über die Kämpfe der Wehrmacht und der U.S. Armee in den Jahren 1944/45 suchte. Franz Halder gab daraufhin unter anderem Günther Blumentritt und Bodo Zimmermann als Kontaktpersonen an. ${ }^{892}$

Schließlich erhöhte die bloße Tatsache, dass die Historical Division mit den ehemaligen Repräsentanten der Wehrmacht zusammenarbeitete, deren Reputation - das galt vor allem für amerikanische Nachwuchswissenschaftler. Einer der amerikanischen Junghistoriker, die über die Historical Division in engen Kontakt mit ehemaligen deutschen Offizieren kamen und diesen für ihre Arbeit nutzten, war Charles Burton Burdick (1927-1998). Burdick, der während des Zweiten Weltkrieges in der U.S. Armee gedient hatte, absolvierte von 1946 bis 1949 ein Bachelor-Studium der Geschichte am San José State College in Kalifornien und promovierte anschließend an der Stanford University zum Thema Deutsche militärische Planungen für den Krieg im Westen. In diesem Zusammenhang wandte er

887 Potter, Schreiben an Allen F. Clark, 1.7. 1947, in: NARA, RG 549, Box 3142, Folder 7.

${ }^{888}$ Harold E. Potter, Schreiben an John T. Sargent, Doubleday, Doran \& Company, 1. 7. 1947, in: NARA, RG 549, Box 3142, Folder 7.

889 Captain Berle K. Hufford, Operational History Branch Weekly Reports No. 99 and 100, 15. 12. 1949, in: NARA, RG 319, Box 7, Folder 3.

${ }^{890}$ Halder, Tagesnotizen aus der Zeit der Control Group, August 1954 bis September 1955, Einträge vom 27. und 28. 1. 1955, in: BArch, N 220/111.

891 Janowitz, The Professional Soldier.

892 Halder, Tagesnotizen aus der Zeit der Control Group, August 1954 bis September 1955, Eintrag vom 21.2. 1955, in: BArch, N 220/111. 
sich Ende 1952 an Günther Blumentritt und bat ihn um Auskunft. ${ }^{893}$ Über die folgenden Jahre hinweg unterhielt der Amerikaner eine regelmäßige Korrespondenz mit dem deutschen General. ${ }^{894}$ Burdick zeigte sich äußerst dankbar, dass Blumentritt ihm mit seiner Erfahrung behilflich war: „In a work of this type I feel it is extremely difficult to obtain all necessary facts, so someone's guidance is necessary. You have been my guide and I cannot express my appreciation sufficiently for your assistance. " 895

Neben fachlichen Fragen diskutierten die beiden in ihren Briefen zunehmend auch aktuelle politische Ereignisse und Entwicklungen, wie zum Beispiel die deutsche Wiederbewaffnung, die Bundestagswahlen von 1953 und den Krieg in Indochina. ${ }^{896}$ Immer wieder sprach sich Burdick angesichts der sowjetischen Bedrohung eindeutig für eine deutsche Wiederbewaffnung aus. ${ }^{897}$ Da er eine Verständigung mit der Sowjetunion für ausgeschlossen hielt, glaubte er, dass die „freie Welt stark“ sein müsse. „Ohne Einheit und bewaffnete Macht“, davon war der Amerikaner überzeugt, werde die westliche „Zivilisation zu Grunde gehen“. 898 Einer kritischen Geschichtsschreibung über die Rolle des deutschen Militärs in der Weimarer Republik und im Dritten Reich, wie sie der Engländer John Wheeler-Bennett in seinem Buch The Nemesis of Power vorlegte, ${ }^{899}$ stand Burdick reserviert gegenüber, war er doch der Meinung, dass „die ganze [deutsche] Armee nicht für die Fehler einiger weniger verdammt werden sollte“.900

Auch nach dem Abschluss seiner Promotion im Jahr 1954 blieb Charles B. Burdick weiterhin an deutscher Militärgeschichte interessiert. Nachdem er im Herbst 1954 ein Fulbright-Stipendium für einen Aufenthalt an der Universität Göttingen erhalten hatte, beantragte er bei der Historical Division in Europa die Benutzung der im Rahmen der kriegsgeschichtlichen Kooperation entstandenen deutschen Studien. ${ }^{901}$ Da Burdick, der seit dem Krieg Reserveoffizier des militärischen Nachrichtendienstes der U.S. Armee war, im Sommer 1955 seinen Reservedienst in der Historical Division in Deutschland ableistete, ${ }^{902} \mathrm{kann}$ wohl davon ausge-

893 Charles B. Burdick, Schreiben an Günther Blumentritt, 9. 12. 1952, in: BArch, N 252/45.

${ }^{894}$ Vgl. die Korrespondenz in Blumentritts Nachlass: BArch, N 252/45.

895 Charles B. Burdick, Schreiben an Günther Blumentritt, 23. 10. 1953, in: BArch, N 252/45.

896 Vgl. Ders., Schreiben an Günther Blumentritt, 20.4. 1953, in: BArch, N 252/45; Burdick, Schreiben an Günther Blumentritt, 23. 10. 1953, in: BArch, N 252/45; Charles B. Burdick, Schreiben an Günther Blumentritt, 20.12. 1953, in: BArch, N 252/45; Ders., Schreiben an Günther Blumentritt, 31.3. 1954, in: BArch, N 252/45; Ders., Schreiben an Günther Blumentritt, 28. 4. 1954, in: BArch, N 252/45; Ders., Schreiben an Günther Blumentritt, 14. 6. 1954, in: BArch, N 252/45.

897 Burdick, Schreiben an Günther Blumentritt, 20.4. 1953, in: BArch, N 252/45; Ders., Schreiben an Günther Blumentritt, 23. 10. 1953, in: BArch, N 252/45; Ders., Schreiben an Günther Blumentritt, 20.12. 1953, in: BArch, N 252/45.

898 Burdick, Schreiben an Günther Blumentritt, 28.4. 1954, in: BArch, N 252/45. Originalzitat: „[...] I do feel, like you, that the free world must be strong. Without unity and armed might our civilization will collapse."

899 Wheeler-Bennett, The Nemesis of Power.

900 Burdick, Schreiben an Günther Blumentritt, 20. 12. 1953, in: BArch, N 252/45.

901 Charles B. Burdick, Schreiben an OCMH, 21.1. 1955, in: NARA, RG 319, Box 11, Folder 3.

902 Ders., Schreiben an Günther Blumentritt, 30. 6. 1955, in: BArch, N 252/45. 
gangen werden, dass er auch tatsächlich Zugang zu den deutschen Studien erhielt. Während seines kurzen Dienstes bei der Historical Division kam Burdick auch mit Franz Halder in Kontakt und bat den ehemaligen Generalstabschef sogar um ein Bild von sich. ${ }^{903}$

Nach seiner Rückkehr in die Vereinigten Staaten trat Burdick eine Stelle an der San José State University an; 1976 übernahm er die Leitung des historischen Fachbereichs und baute bis zu seinem Ausscheiden aus der Lehre im Jahr 1988 ein Programm für Militärgeschichte auf. ${ }^{904}$ Dabei blieb Burdick auch der Historical Division weiterhin verbunden. Als erster Historiker überhaupt veröffentlichte er 1971 einen Aufsatz, in dem er die Entstehungsgeschichte der kriegsgeschichtlichen Kooperation nachzeichnete. Allerdings blieb der Artikel überwiegend deskriptiv und warf kaum kritische Fragen bezüglich der Motive und Auswirkungen der Kooperation auf.905 1979 war Burdick als Mitherausgeber an der Veröffentlichung von 213 ausgewählten deutschen kriegsgeschichtlichen Studien beteiligt. ${ }^{906}$ 1988 publizierte er eine Biographie über den ehemaligen General der Gebirgstruppen und langjährigen „Heimarbeiter“ für die Historical Division, Hubert Lanz, die sich stark auf kriegsgeschichtliche Studien ehemaliger Wehrmachtsoffiziere stützte. ${ }^{907}$

Wie schon in der Korrespondenz mit Günther Blumentritt in den 1950er Jahren schien auch in Burdicks Lanz-Biographie immer wieder durch, dass er die apologetische Argumentation der ehemaligen Wehrmachtsführung weitgehend akzeptierte. Obwohl Lanz zu den wenigen deutschen Generälen gehörte, die nach 1945 für Kriegsverbrechen verurteilt wurden, klang es schon im Vorwort, als sei der Offizier nicht Beteiligter sondern Opfer der „Schreckenszeit des Zweiten Weltkrieges“ gewesen. ${ }^{908}$ In Burdicks Augen war Lanz, der als Kommandeur des in Griechenland stationierten XXII. Gebirgs-Armeekorps immerhin für die Erschießung von über 5000 italienischen Kriegsgefangenen auf den griechischen Inseln Kefalonia und Korfu verantwortlich zeichnete, „ein Soldat von beispielhafter Tapferkeit, von Mut und voll Berufsstolz“- auch wenn er „in verschiedener Hinsicht irrte“.909 Der Amerikaner stellte die Hinrichtung der kommandierenden italienischen Offiziere als rechtmäßig dar, auf die Ermordung der in die Tausende gehenden Mannschaften ging er überhaupt nicht ein. ${ }^{910}$ In Bezug auf Lanz’ Anklage im Südost-Generä-

${ }^{903}$ Halder, Tagesnotizen aus der Zeit der Control Group, August 1954 bis September 1955, Eintrag vom 24. 6. 1955, in: BArch, N 220/111.

904 Biographical Sketch im Findbuch zur Charles B. Burdick Military History Collection, MSS-2010-03-01, San José State University Library Special Collections and Archives, URL: http://pdf.oac.cdlib.org/pdf/csju/spcoll/ead_burdick_history.pdf (letzter Zugriff: 24.2.2015).

905 Burdick, Vom Schwert zur Feder, S. 69-80.

906 Detwiler/Burdick/Rohwer (Hg.), World War II German Military Studies.

907 Burdick, Hubert Lanz. Burdick verzichtete auf genaue Nachweise seiner Quellen in Fußnoten, führte jedoch im Literaturverzeichnis 12 kriegsgeschichtliche Studien auf: MS \# D-406, P-003, P-034, P-55a, P-114c, P-148, P-149/17, P-149/33, P-149/67, P-149/71, P-211/17, T-15.

908 Burdick, Hubert Lanz, S. xi.

909 Ebd.

910 Vgl. ebd., S. 194-195. 
le-Prozess ${ }^{911}$ ergriff Burdick in seiner Studie eindeutig Partei für den Deutschen: Die amerikanischen Ankläger, die er als „die eifrigsten Rechts- und Racheverfechter" bezeichnete, hätten regelrecht nach einem Grund gesucht, um Lanz vor Gericht stellen zu können. Vor allem den amerikanischen Hauptankläger Telford C. Taylor beurteilte Burdick äußerst kritisch: Dem „junge[n] ehrgeizige[n] und willensstarke[n] Jurist[en] “ sei es in erster Linie um „Ruhm [...] und Karriere“ gegangen und er habe deshalb „stets an eine ,dramatische Inszenierung “" gedacht. „In diesem Würfelspiel um Gerechtigkeit“ sei Lanz „ein Verlierer“ gewesen. ${ }^{912}$

Ein weiteres Beispiel für den Erfolg der deutschen Apologie bei amerikanischen Nachwuchswissenschaftlern bietet die Dissertationsschrift von Anne Armstrong. Sie hatte während des Krieges Politikwissenschaft an der Columbia University in New York studiert und anschließend einige Zeit für die amerikanische Militärregierung in Berlin und München gearbeitet, bevor sie, vermutlich Ende der 1940er Jahre, schließlich an der Columbia University eine Promotion über die alliierte Politik der bedingungslosen Kapitulation begann. ${ }^{913}$ Im Herbst 1950 trat Armstrong, die bislang Reserveoffizierin der Air Force gewesen war, in den aktiven Militärdienst ein. ${ }^{914}$ In ihrer Freizeit arbeitete sie weiter an ihrer Dissertation. In diesem Zusammenhang hatte sie sich im März 1950 erstmals an Günther Blumentritt gewandt und ihn um Unterstützung bei ihrer Arbeit gebeten. ${ }^{915}$ Ähnlich wie im Fall von Charles B. Burdick entwickelte sich in der Folge auch zwischen Armstrong und dem deutschen General eine rege Korrespondenz. ${ }^{916}$

Neben dem Austausch mit Blumentritt stützte sich Armstrong in ihrer Arbeit auch maßgeblich auf Interviews und Korrespondenzen mit anderen deutschen Zeitzeugen, darunter Franz Halder, Heinz Guderian, Albert Kesselring und Walter Warlimont. ${ }^{917}$ In ihrer 1961 auch in Deutschland erschienenen Dissertation ging die Amerikanerin der Frage nach, „welche Auswirkungen [die] Forderung [nach bedingungsloser Kapitulation] auf den Verlauf und die Dauer des Krieges hatte [und] ob sie den Zielen der Alliierten nützlich [...] war“.918 Wie die Korrespondenz mit Günther Blumentritt anschaulich zeigt, war die Studie dabei keineswegs ergebnisoffen angelegt. Offensichtlich tief geprägt vom Ost-West-Konflikt war es das erklärte Ziel der Autorin zu beweisen, dass die Politik der bedingungslosen Kapitulation angesichts des sowjetischen Expansionsstrebens „töricht und kostspielig" gewesen sei. ${ }^{919}$ Vor dem Hintergrund des Kalten Krieges war Armstrong überzeugt, dass der Westen sich frühzeitiger mit den Deutschen gegen die Sowjet-

911 Lanz wurde 1947 zu zwölf Jahren Haft verurteilt, bereits 1951 wurde er jedoch aus dem Kriegsverbrechergefängnis in Landsberg entlassen.

912 Ebd., S. 225.

913 Vgl. das Vorwort in: Armstrong, Bedingungslose Kapitulation.

914 Burdick, Schreiben an Günther Blumentritt, 6. 9. 1950, in: BArch, N 252/45.

915 Ders., Schreiben an Günther Blumentritt, 4. 3. 1950, in: BArch, N 252/45.

916 Siehe BArch, N 252/45.

917 Vgl. das Vorwort in: Armstrong, Bedingungslose Kapitulation. Unter Armstrongs amerikanischen Interviewpartnern nahm bezeichnenderweise Senator James O. Eastland einen prominenten Platz ein. Vgl. zu dessen Einstellung gegenüber Deutschland oben, Teil III, Kapitel 3.2.

918 Armstrong, Bedingungslose Kapitulation, S. 14.

919 Anne Armstrong, Schreiben an Günther Blumentritt, 26. 3. 1950, in: BArch, N 252/45. 
union hätte verbünden sollen. ${ }^{920}$ Auch stand sie der Verantwortung des preußisch-deutschen Militarismus am Zweiten Weltkrieg äußerst skeptisch gegenüber. Die Annahme, dass die deutschen Generäle eine Bedrohung für den Frieden gewesen seien, schrieb sie bezeichnenderweise dem propagandistischen Einfluss von Kommunisten und deren Sympathisanten zu. ${ }^{921}$

Die apologetische Argumentation ihrer deutschen Gesprächspartner ist in Armstrongs Dissertation unverkennbar und die Amerikanerin gab sie weitestgehend unreflektiert wieder. So bediente die Autorin die Legende vom „unpolitischen Soldaten“, wenn sie schrieb: „Der Berufssoldat enthielt sich [in der Weimarer Republik] nicht nur der Parteipolitik, sondern er betrachtete auch die politische Willensbildung [...] als das Vorrecht des Zivilisten. "922 Und auch wenn die Militärs die Abkehr vom „Versailler System“ und die deutsche Aufrüstung „willkommen“ geheißen hätten, sei die Armee doch „im großen und ganzen [...], was die inneren Angelegenheiten des Reiches betraf, unpolitisch“ geblieben und habe sogar „ihren Einfluss eher dazu [benutzt], die Schritte, die Hitler in Richtung auf den Krieg von 1939 hin unternahm, zu hemmen, als sie zu fördern“.923 Hitlers Deutschland sei „weniger militaristisch“ gewesen als das Kaiserreich; die Wehrmacht „und insbesondere der Generalstab“ hätten das „Zentrum des Widerstandes“ gegen das Regime dargestellt. ${ }^{924}$

Neben dem Argument von der vermeintlichen unpolitischen und rein auf Pflichterfüllung abzielenden Haltung der Generalität bediente Armstrong in ihrer Arbeit auch die Metapher von Deutschland als „Bollwerk“ gegen den Osten sowie die Vorstellung, dass Amerikaner und Briten sich früher mit dem Deutschen Reich hätten einigen sollen, um die Ausdehnung des sowjetischen Machtbereichs nach Westen zu verhindern. Da diese Argumentationslinie zur Weltanschauung der Autorin passte und ihre These stützte, dass die Politik der bedingungslosen Kapitulation ein Fehler gewesen sei, gab Armstrong die Meinung der ehemaligen Wehrmachtsgeneräle völlig unkritisch und unreflektiert wider. So zitierte sie zum Beispiel aus einem Brief von Heinz Guderian, in dem dieser den amerikanischen Präsidenten Roosevelt als „den Totengräber nicht nur Deutschlands, sondern auch Europas“ bezeichnete. „Durch die Zerstörung Deutschlands“, so hieß es weiter, „war Europa des Dammes gegen den Bolschewismus beraubt“.925 Immer und immer wieder ließ Armstrong die deutschen Generäle zu Wort kommen, die alle einhellig beteuerten, das Bestehen auf einer bedingungslosen Kapitulation sei eine falsche Politik gewesen und habe zur Verlängerung des Krieges beigetragen. ${ }^{926} \mathrm{Ge}$ -

920 Ebd.

921 Armstrong, Schreiben an Günther Blumentritt, 4. 8. [ohne Jahr, sicher 1950], in: BArch, N 252/45.

922 Armstrong, Bedingungslose Kapitulation, S. 34-35.

923 Ebd., S. 36.

924 Ebd.

925 Heinz Guderian an Anne Armstrong, 28. 3. 1950, zit. nach Armstrong, Bedingungslose Kapitulation, S. 158.

926 Walter Warlimont nannte die Forderung nach bedingungsloser Kapitulation zum Beispiel „ein Messer, mit dem Deutschlands Wider[stands]willen geschärft“ worden sei. Blumentritt beteuerte, die Forderung habe „naturgemäß zu einem verschärften deutschen Widerstand“ geführt; Guderian glaubte, dass dadurch die „Hoffnung auf einen 
genteilige Meinungen berücksichtigte die Autorin in ihrer Arbeit kaum und so ist es nicht verwunderlich, dass sie sich den deutschen Militärs uneingeschränkt anschloss. In ihren Schlussfolgerungen schrieb sie:

„Viele Menschen wären geschont, viele Städte vor totaler Zerstörung bewahrt und für Europa, für den Westen ebenso wie für Deutschland wären bedeutsame menschliche, kulturelle und wirtschaftliche Werte erhalten geblieben, hätten die Alliierten eine andere Politik als die der Forderung nach totaler Niederlage Deutschlands betrieben."927

$\mathrm{Zu}$ keinem Zeitpunkt stellte die Autorin die retrospektiven Aussagen ihrer Gesprächs- und Briefpartner infrage oder thematisierte das enorme Ausmaß der deutschen Kriegs- und NS-Verbrechen, die doch die bedingungslose Kapitulation unausweichlich und unverhandelbar machen mussten. ${ }^{928}$

\section{Weitergabe der Studien an die Bundeswehr}

Abgesehen von der privilegierten Verfügbarmachung der Heersakten, der Freigabe der kriegsgeschichtlichen Studien zur Veröffentlichung und der Kontaktvermittlung zu Journalisten und Wissenschaftlern leistete die Historical Division noch auf eine vierte Art und Weise Hilfestellung dabei, dass sich die Apologie der ehemaligen Wehrmachtselite verfestigen konnte: Sie genehmigte die Weitergabe der deutschen Studien an das Amt Blank und später die Bundeswehr. Bereits Ende 1951 hatte sich Wilbur S. Nye an die Historical Division in Washington gewandt und vorgeschlagen, der Dienststelle Blank die deutschen Studien zu Planungs- und Trainingszwecken zu überlassen. ${ }^{929}$ Tatsächlich erlaubte die Historical Division knapp ein Jahr später, dass Mitarbeiter der Planungsabteilung der Dienststelle Blank Einblick in die Arbeiten der ehemaligen deutschen Offiziere nehmen durften. ${ }^{930}$ Unter strenger Geheimhaltung besuchten im Dezember 1952 mehrere Vertreter des Amtes die Control Group in Königstein und zeigten sich vom Wert der Studien „für die augenblickliche militärische Planungsaufgabe der Dienststelle" sehr angetan. ${ }^{931}$ Die grundsätzliche leihweise Überlassung der Studien war allerdings zu diesem Zeitpunkt noch nicht möglich, so dass die Besucher

vernünftigen Frieden“ zerstört worden sei; und auch Franz Halder zeigte sich überzeugt, dass die Politik der bedingungslosen Kapitulation den Krieg verlängert habe. Armstrong, Bedingungslose Kapitulation, S. 157-159 und S. 163.

927 Ebd., S. 272.

928 Vgl. auch folgende kritische Rezensionen: Alfred J. Hotz, Rezension: Anne Armstrong, Unconditional Surrender, in: Annals of the American Academy of Political and Social Science 341 (1962), S. 116; Dunlop, Rezension: Anne Armstrong, Unconditional Surrender, in: International Affairs 38 (1962), S. 553; Spencer, Rezension: Anne Armstrong, Unconditional Surrender, in: International Journal 18 (1963), S. 133.

929 Wilbur S. Nye, Schreiben an den Chief of Military History, Department of the Army, betr. MS No. P-060 Series, Small Unit Tactics, 19. 12. 1951, in: NARA, RG 319, Box 4, Folder 1 .

930 Erfahrungsmaterial der Historical Division, Königstein/Taunus, 24. 11. 1952, in: BArch, BW 9/583a; Siehe zu den im Folgenden beschriebenen Kontaken zwischen der Dienststelle Blank und der Control Group Searle, Wehrmacht Generals, West German Society, and the Debate on Rearmament, 1949-1959, S. 115-116.

931 Bogislaw von Bonin, Ergebnis des Besuchs bei der „Kontrollgruppe Königstein“ der Historical Division, Karlsruhe, 18. 12. 1952, in: BArch, BW 9/583a. 
aus Bonn jeweils zur Auswertung der Arbeiten in den Taunus reisen und auszugsweise Abschriften bzw. Kopien anfertigen mussten. ${ }^{932}$ Diese Kopien gingen dann an die Abteilung H/G3 des Amtes Blank, wo sie dann von anderen interessierten Fachabteilungen eingesehen bzw. ausgeliehen werden konnten. ${ }^{933} \mathrm{Da}$ sich die kurzen Besuche in Königstein als kaum ausreichend erwiesen, um die umfangreichen Studien befriedigend auszuwerten, beantragte das Amt Blank im Januar 1953, dass ausgewählte Studien auch nach Bonn ausgeliehen werden konnten. ${ }^{934}$ Tatsächlich erreichte Wilbur S. Nye im März 1953, dass die nicht-klassifizierten Studien leihweise an Adolf Heusinger, damals Leiter der militärischen Abteilung im Amt Blank, weitergegeben wurden. ${ }^{935}$ Heusingers Mitarbeiter machten in der Folge tatsächlich erheblichen Gebrauch von den Studien der Control Group - insbesondere solchen, die sich mit dem Ostfeldzug befassten. ${ }^{936}$

Nach der Aufstellung der Bundeswehr wurden schließlich auch einzelne Studien an verschiedene Truppenteile ausgeliehen. ${ }^{937} \mathrm{Um}$ den damit verbundenen hohen Verwaltungsaufwand zu reduzieren, bat die Europaabteilung der Historical Division im August 1957 in Washington um die Erlaubnis, Kopien der wichtigsten Studien dauerhaft an die Bundeswehr abgeben zu dürfen. ${ }^{938}$ Tatsächlich genehmigte Washington im September die Weitergabe zumindest der nicht-klassifizierten Studien für den Dienstgebrauch im Verteidigungsministerium und übertrug Franz Halder die Aufgabe, die entsprechenden Studien auszuwählen, den Kontakt nach Bonn herzustellen und die Übergabe zu koordinieren. 939

\section{Kriegsgeschichte vs. Militärgeschichte}

Nachdem die Historical Division ihn also in der Frage der Übergabe der deutschen Studien zu ihrem Verbindungsmann zum Bundesverteidigungsministerium ernannt hatte, machte sich Franz Halder intensiv Gedanken darüber, an wen genau die Studien abgegeben werden sollten - schließlich, so der Leiter der Control

932 Ebd.

933 Studien der „Kontrollgruppe Königstein“ der Historical Division, Karlsruhe, 21. 5. 1953, in: BArch, BW 9/583a.

934 Besprechung mit General Reinhardt bei Historical Division in Königstein am 22./23. Januar 1953, 27. 1. 1953, in: BArch, BW 9/2723-3.

935 Wilbur S. Nye, Schreiben an den Chief of Military History, 18. 2. 1953, in: NARA, RG 319, Box 4, Folder 5; Chief W. A. Perry, Security Division, ACoS, G-2, Schreiben an den Commander-in-Chief, USAREUR, 12.3. 1953, in: NARA, RG 319, Box 4, Folder 5.

936 Searle, Wehrmacht Generals, West German Society, and the Debate on Rearmament, 1949-1959, S. 116.

937 Edward B. James, Schreiben an R. W. Stephens, 23. 8. 1957, in: NARA, RG 549, Box 1155, Folder 2.

938 Ebd.

939 Schreiben von OCMH an Edward B. James, Chief, Historical Division, Hqs. USAREUR, 10. 9. 1957, in: NARA, RG 549, Box 1155, Folder 3; Historical Division Chief, USAREUR, Disposition Form for ACofS, G3, betr. Delivery of Unclassified Historical Studies to the German Government, 28. 10. 1957, in: NARA, RG 549, Box 1155, Folder 3; Chief of Staff Major General Charles L. Dasher, USAREUR, Schreiben an Adolf Heusinger, o. D. [vermutlich Oktober 1957], in: NARA, RG 549, Box 1155, Folder 3; Chief FMSBr Lloyd E. Jones, Schreiben an Franz Halder, betr. Übergabe abgeschlossener historischer Studien an die deutsche Regierung, 5. 12. 1957, in: BArch, ZA 1/2552. 
Group, hätten er und seine Mitarbeiter ,ja nicht gearbeitet [...], um die Schatztruhen irgendeines Referenten oder eines Archivs zu füllen“. Stattdessen wollte er das Ergebnis der jahrelangen Arbeit „wirksam machen [...] für die Ausbildung des Offizierskorps und insbesondere des Generalstabes“ der Bundeswehr. ${ }^{940}$ Dabei ging es Halder vor allem darum zu verhindern, dass die Studien an die Militärgeschichtliche Forschungsstelle des BMVtg abgegeben würden. ${ }^{941}$ Das lag vor allem daran, dass Halder und seine Mitarbeiter dem Leiter der Forschungsstelle, Hans Meier-Welcker ${ }^{942}$, äußerst kritisch gegenüberstanden. ${ }^{943}$

Tatsächlich unterschied sich Meier-Welckers Geschichtsverständnis in wichtigen Punkten grundlegend von dem der ehemaligen Wehrmachtselite. ${ }^{944}$ Für Franz Halder und seine Kollegen stellte die Beschäftigung mit vergangenen Kriegen zuallererst ein wertvolles „Belehrungs- und Erziehungsmittel“945 innerhalb des Militärs dar, mithilfe dessen „Lehren [...] für alle Gebiete des unendlich vielgestaltigen Bereiches der militärischen Kriegführung “946 gezogen werden sollten. Kriegsgeschichte wurde verstanden als ein geistiger „Pflanzgarten “947, in dem der Führungsnachwuchs des Heeres die hohe Kunst der militärischen Führung erlernen sollte. ${ }^{948}$ Dabei sollte die Auswertung früherer Erfahrungen „in der Hand von besonders ausgewählten und zu höchsten Aufgaben berufenen Soldaten liegen “.949 Das galt insbesondere für die Geschichte des Zweiten Weltkrieges, die in Halders Augen nur von den „überragendsten Köpfen mit dem größten Weitblick und der größten Erfahrung“, von den „besten Fachleuten“ und „auserlesenen Geistern“ erfasst und dargestellt werden könne. ${ }^{950}$ Gemeint war damit vor allem die ältere

940 Franz Halder, Schreiben an Cord von Hobe, 1. 10. 1957, in: BArch, ZA 1/2552.

941 Ebd.

942 Der ehemalige Oberstleutnant i. G. Hans Meier-Welcker hatte nach dem Krieg Geschichte und Philosophie an der Universität Tübingen studiert. Nach seiner Promotion war er 1952 mit der Leitung des Referats "Zeitgeschichte und Wehrwissenschaft“ in der Dienststelle Blank betraut worden, der 1954 eine Dokumentenzentrale für militärisches Schriftgut angeschlossen worden war. Als 1957 das Bundesverteidigungsministerium eine Militärgeschichtliche Forschungsstelle - das spätere Militärgeschichtliche Forschungsamt - einrichtete, übernahm Meier-Welcker, mittlerweile Oberst in der Bundeswehr, auch die Leitung dieser Dienststelle. Vgl. Gersdorff, Die Arbeit des Militärgeschichtlichen Forschungsamtes, in: Gersdorff (Hg.), Geschichte und Militärgeschichte, S. 75; Wohlfeil, Oberst i. G. Dr. Hans Meier-Welcker als Militärhistoriker, S. 4, URL: http://www.comunicarte.de/RainerWohlfeil/RWTexte/svz108.pdf (letzter Zugriff: 24. 2. 2015); Rink, Hans Meier-Welcker, in: Militärgeschichte 17 (2007), S. 31.

943 Vgl. zum Beispiel Halders Äußerungen in einem Schreiben an Hans Dörr vom 15. 10. 1957, in: BArch, N 220/82.

944 Wohlfeil, Oberst i. G. Dr. Hans Meier-Welcker als Militärhistoriker, S. 2; zu den Konflikten, die Meier-Welcker ausfechten musste, siehe Wohlfeil, Militärgeschichte, in: Militärgeschichtliche Mitteilungen 52 (1993), S. 323-344.

945 Halder, Schreiben an Hans W. Helm, 22. 6. 1953, in: BArch, N 220/203.

946 Ders., Zum 21.11. 1955. Ansprache anlässlich des 10. Jahrestages der Kooperation mit der Historical Division, 15. 11. 1955, in: BArch, N 220/118.

947 Ders., Schreiben an Hans W. Helm, 22. 6. 1953, in: BArch, N 220/203.

948 Ders., Zum 21.11. 1955. Ansprache anlässlich des 10. Jahrestages der Kooperation mit der Historical Division, 15. 11. 1955, in: BArch, N 220/118.

949 Ebd.

950 Franz Halder, Schreiben an William Schmidt, Geschäftsleiter der Darmstädter Verlagsgesellschaft Wehr und Wissen, 20.3. 1957, in: BArch, N 220/81. 
Generation der ehemaligen Generalstabsoffiziere, die „seinerzeit selbst die Verantwortung mitgetragen“ hätten und deren „Urteilsfähigkeit in langer und schwerer Führertätigkeit geschult worden sei. ${ }^{951}$

Im Gegensatz zu diesem dezidiert anwendungsorientierten Verständnis von Kriegsgeschichte vertrat Hans Meier-Welcker die Auffassung, dass aus der Kriegsgeschichte keineswegs unmittelbare strategische oder taktische Lehren für die Zukunft gezogen werden könnten und forderte deshalb eine Beschäftigung mit der Geschichte des Militärs in der Gesamtheit seiner sozialen Erscheinung und gesellschaftlichen Einbindung, ohne dabei vornehmlich auf den unmittelbaren militärischen Nutzen abzuzielen. ${ }^{952}$ Außerdem widersprach er der traditionellen Vorstellung, dass vornehmlich Soldaten und Offiziere legitimiert und befähigt seien, die Geschichte des Militärs zu erforschen und darzustellen. ${ }^{953}$

In einem Vortrag, gehalten auf einer Konferenz der Historical Division im Mai 1957, machte Meier-Welcker deutlich, dass Geschichtswissenschaft ein Selbstzweck sei und dass die Ergebnisse historischer Forschung daher auch dann von Wert seien, wenn sich aus ihnen kein direkter praktischer Nutzen ergäbe. „Ich bin der Meinung“, so Meier-Welcker, „dass wir unserer geschichtswissenschaftlichen Forschung nachgehen sollten, ohne ständig über ihren unmittelbaren Nutzen nachzudenken. "954 Darüber hinaus forderte der Leiter des MGFA, dass die Militärgeschichte denselben wissenschaftlichen Standards folgen müsse wie andere historische Teildisziplinen auch. ${ }^{955}$ Auch müsse alles getan werden, um die erneute „Isolierung der Militärgeschichte von der allgemeinen Geschichte zu verhindern“, 956 denn in Deutschland sei die Geschichtsauffassung in ihrer Entwicklung viel zu lange stark gehemmt worden - ein Manko, das sich laut Meier-Welcker vor allem in den Reihen des Offizierskorps noch immer zeige. ${ }^{957}$

Bei Franz Halder und seinen Untergebenen trafen die Bemühungen MeierWelckers, die traditionelle Kriegsgeschichte zu einer modernen Militärgeschichte

951 Halder, Schreiben an Hans Dörr, 15. 10. 1957, in: BArch, N 220/82.

952 Wohlfeil, Oberst i. G. Dr. Hans Meier-Welcker als Militärhistoriker, S. 3 und S. 7-8; Meier-Welcker, Über Kriegsgeschichte als Wissenschaft und Lehre, in: Wehrwissenschaftliche Rundschau 5 (1955), S. 1-8; Ders., Entwicklung und Stand der Kriegsgeschichte als Wissenschaft, in: Wehrwissenschaftliche Rundschau 6 (1956), S.1-10; Ders., Über den Unterricht in Kriegsgeschichte. Entwicklung und Auffassungen, in: Wehrwissenschaftliche Rundschau 6 (1956), S. 539-546; Ders., Unterricht und Studium in der Kriegsgeschichte angesichts der radikalen Wandlung im Kriegswesen, in: Wehrkunde 9 (1960), S. 608-612.

953 Wohlfeil, Oberst i. G. Dr. Hans Meier-Welcker als Militärhistoriker, S. 5.

954 Hans Meier-Welcker, Organization and Working Methods of the Bundeswehr Institute of Military History [Englische Version des Redemanuskripts, vorgetragen bei einer Konferenz der Historical Division am 24. 5. 1957], S. 6, in: NARA, RG 319, Box 17, Folder 5. Originalzitat aus der auf Englisch vorliegenden Abschrift des Vortrages: „It is my opinion, that we should do our work of historical research without constantly thinking of its immediate benefits."

955 Ebd., S. 5.

956 Ebd.

957 Ebd., S. 4. 
zu erweitern, ${ }^{958}$ auf scharfe Ablehnung. Der Leiter der Militärgeschichtlichen Forschungsstelle habe es verstanden, bei den ehemaligen Generalstabsoffizieren das Bild zu erwecken, „dass er der kriegsgeschichtlichen Arbeit von Soldaten kein Vertrauen entgegen bringe ".959 Halder wollte deshalb unbedingt verhindern, dass die kriegsgeschichtlichen Studien der Control Group an Meier-Welcker übergeben und dort womöglich kritisch bearbeitet werden würden:

„Wenn ein Mann die Fähigkeit logischen und kritischen Denkens nur einer auf Universitäten geschulten und mit dem Doktorgrad beginnenden Klasse zutraut, dann ist zu befürchten, dass er das von uns erarbeitete Material auf Jahre hinaus von gelehrten Historikern zerfasern lässt, ohne dass diejenigen es in die Hände bekommen, für die es von Anfang an bei uns gedacht war, nämlich die Schulen und Akademien. Damit würde unsere jahrelange Arbeit den ihr innewohnenden Wert weitgehend verlieren. "960

Der ehemalige Generalstabschef wandte sich deshalb vertraulich an seinen Schwiegersohn Cord von Hobe, der im Führungsstab der Bundeswehr III tätig war, um herauszufinden, ob die kriegsgeschichtlichen Studien nicht an „eine andere Persönlichkeit“ - zum Beispiel an den ersten Generalinspekteur der Bundeswehr Hans Röttiger - übergeben werden könnten. Dadurch sollte sichergestellt werden, dass „die Arbeiten nicht „als von der überholten alten Generation stammend und daher unerheblich in irgendwelchen Truhen oder Kästen" verschwinden würden. ${ }^{961}$ Hobe ließ Halder wissen, dass Meier-Welcker „nach der Geschäftsordnung [...] die richtige Stelle " für die Übernahme der Studien sei. ${ }^{962}$ Allerdings teilte er die Bedenken seines Schwiegervaters und wandte sich deshalb hinter dem Rücken Meier-Welckers an Adolf Heusinger. Dieser schlug sozusagen als Kompromisslösung vor, alle Studien mit einem „praktischen und sofort nutzbaren Wert für die Ausbildung“ an den Kommandeur der Führungsakademie der Bundeswehr in Hamburg, Generalmajor Heinz Gaedcke, abzugeben; kriegsgeschichtliche Dokumente und Quellenmaterial sollten dagegen an Meier-Welckers Forschungsstelle gehen. ${ }^{963}$

Obwohl sich Hobe bemühte, dass Meier-Welcker „keinen Wind von der Sache“ bekam, ${ }^{964}$ erfuhr der Leiter der Forschungsstelle schließlich doch von der geplanten Übergabe der Studien. Im Januar 1958 wandte er sich an Halder und erkundigte sich, wann mit der Abgabe der Studien zu rechnen sei. Dabei verband er den Verweis auf die „Bedeutung der Studien für die [...] historische Arbeit“ mit der Bitte um einen ersten Überblick über das zu erwartende Material. ${ }^{965}$ Halder ver-

958 Vgl. zur begrifflichen Unterscheidung grundlegend Wohlfeil, Wehr-, Kriegs- oder Militärgeschichte, in: Militärgeschichtliche Mitteilungen 1 (1967), S. 21-29; zur Entwicklung der modernen Militärgeschichte siehe die Aufsätze in Kühne/Ziemann (Hg.), Was ist Militärgeschichte?, insbesondere die Beiträge von Kühne und Ziemann, S. 9-46, und Wette, S. 49-71.

959 Halder, Schreiben an Cord von Hobe, 1. 10. 1957, in: BArch, ZA 1/2552.

960 Ebd.

961 Ebd.

962 Cord von Hobe, Schreiben an Franz Halder, 7. 10. 1957, in: BArch, ZA 1/2552.

963 Ebd.

964 Ebd.

965 Hans Meier-Welcker, Schreiben an Franz Halder, 24. 1. 1958, in: BArch, ZA 1/2552. 
sprach zwar, sich bei der Historical Division darum zu bemühen, dass die Übergabe bald in Gang komme, versuchte aber gleichzeitig, jegliche Eigeninitiative Meier-Welckers in dieser Frage im Keim zu ersticken: Es gebe „keinen Grund, warum von [Meier-Welckers] Dienststelle aus etwas unternommen werden sollte." Darüber hinaus versprach er, Meier-Welcker eine Liste aller für die Übergabe infrage kommender Studien zukommen zu lassen, die Halder selbst mit Hinweisen versehen wollte, wie „diese Studien möglicherweise nützlich verwendet werden können, z. B. als Material für kriegsgeschichtliche Forschungsarbeiten, als Lehrbeispiele für Schulen, als Archivmaterial usw. "966

Letztlich zog sich die Übergabe der Studien noch geraume Zeit hin. In der Zwischenzeit bewerkstelligte Halder jedoch, dass Cord von Hobe im September 1958 direkt bei der Historical Division in Karlsruhe eine Auswahl der für seine Abteilung als wertvoll erachteten Studien treffen konnte. ${ }^{967}$ Damit erreichte der Control Group-Chef, dass die kriegsgeschichtlichen Studien in erster Linie an die Ausbildungsabteilung des BMVtg gingen; ${ }^{968}$ allerdings konnte er nicht verhindern, dass auch Hans Meier-Welcker letztlich Kopien so gut wie aller Studien für das Militärgeschichtliche Forschungsamt erhielt. ${ }^{969}$

Während Franz Halder und Hans Meier-Welcker in Deutschland Ende der 1950er Jahre also um die Ausrichtung der kriegs- bzw. militärgeschichtlichen Forschung in Deutschland und deren Nutzbarmachung für die Bundeswehr konkurrierten, spielte sich auf der anderen Seite des Atlantiks interessanterweise ein ganz ähnlicher Konflikt ab. Auch in der Historical Division in Washington rangen

966 Franz Halder, Schreiben an Hans Meier-Welcker, 29. 1. 1958, in: BArch, ZA 1/2552.

967 Conference Colonel Lay, General Halder, Mr. Heitmann, 24. 9. 1958, in: NARA, RG 319, Box 11, Folder 5.

968 Ebd. Bis Herbst 1960 gab die Historical Division über 2000 Manuskripte an die Bundeswehr ab: Asst. AG USA J. L. Lancaster, Foreign Military Studies Program, 31. 10. 1960, in: NARA, RG 319, Box 11, Folder 5. Zu den ersten Studien, die an das BMVtg abgegeben wurden, zählten unter anderem Rudolf Hofmanns umfangreiche Arbeit über den Feldzug gegen die Sowjetunion im Mittelabschnitt der Ostfront (MS \# P-114b), Burkhart Müller-Hillebrands vergleichend angelegte Studie zur Deutschen und Russischen militärischen Führung im Zweiten Weltkrieg (MS \# P-145), mehrere umfangreiche Studien zu ausgewählten Operationsbeispielen des Ostfeldzuges auf Armee- und Divisionsebene (MS \# P-143a und MS \# P-143c) sowie: Burkhart Müller-Hillebrand, Die militärische Zusammenarbeit Deutschlands und seiner Verbündeten während des Zweiten Weltkrieges (MS \# P-108); Rudolf Hofmann u.a., Deutsche Angriffe gegen ständige und verstärkte feldmäßige Befestigungsanlagen im Zweiten Weltkrieg (MS \# P-203); Edgar Röhricht, Große Kesselschlachten im Zweiten Weltkrieg (MS \# P-209); Joachim Schwatlo-Gesterding, Die Naht - Begriffsbestimmung der Naht im Angriff und in der Abwehr sowie zwischen Verbündeten (MS \# P-212). Vgl. Edward J. Barta, Schreiben an den Chief, Military History, DA, betr. Transfer of Completed Unclassified Historical Studies to the German Government, 2.12.1957, in: NARA, RG 549, Box 1155, Folder 3; Edward B. James, Memorandum for Chief, FMS Branch, betr. Delivery of Unclassified Completed Historical Studies to the German Government, 5. 12.1957, in: NARA, RG 549, Box 1155, Folder 2.

969 Conference Colonel Lay, General Halder, Mr. Heitmann, 24.9. 1958, in: NARA, RG 319, Box 11, Folder 5; Kenneth E. Lay, Schreiben an den Chief of Military History, DA, betr. Foreign Military Studies Program, 1. 12. 1958, in: NARA, RG 549, Box 1156, Folder 2. 
1957/58 zwei unterschiedliche Auffassungen über den Charakter und Wert der historischen Erforschung von Krieg und Militär miteinander, wobei die Fronten zwischen den Berufssoldaten der Abteilung auf der einen und den zivilen Historikern auf der anderen Seite verliefen.

Diese Spannungen zwischen Militärs und Geschichtswissenschaftlern lassen sich besonders anschaulich an einem Konflikt zwischen Paul M. Robinett und Kent Roberts Greenfield aus dem Jahr 1958 darstellen. Robinett hatte die Historical Division Ende September 1957 verlassen und sich in seine Heimatstadt Mountain Grove in Missouri zurückgezogen. Allerdings hatte der ebenfalls bald ausscheidende Richard W. Stephens ihm vor seiner Abreise signalisiert, dass Robinett im April 1958 seine Nachfolge als Chief of Military History antreten könne. ${ }^{970}$ Der ehrgeizige Robinett hatte sich bereits 1954 für den Posten des Chief of Military History empfohlen, war damals aber nicht zum Zuge gekommen. ${ }^{971}$ Knapp vier Jahre später schien der Posten zum Greifen nahe und damit die Möglichkeit, die amtliche Geschichtsschreibung der U.S. Armee auf sein Verständnis von Kriegsgeschichte auszurichten. ${ }^{972}$

Allerdings hatten wohl weder die Personalverantwortlichen im General Staff noch Robinett selbst mit dem massiven Widerstand von Chief Historian Kent Roberts Greenfield sowie der anderen zivilen Historiker in der Historical Division und im Advisory Committee gerechnet. Diese lehnten Robinetts Berufung an die Spitze der Abteilung aufgrund differierender Geschichtsauffassungen scharf ab. Vor allem hinsichtlich von Methode und Zweck der historischen Arbeit klafften die Auffassungen von Robinett und Greenfield stark auseinander. Robinett vertrat die Meinung, dass historische Studien - ähnlich wie die nachrichtendienstliche Aufklärung - durch die Darstellung und Ursachenanalyse militärischer Ereignisse vor allem zur Ergänzung der militärischen Planung und der Entwicklung von Militärdoktrin dienen sollte. ${ }^{973}$ Greenfield glaubte dagegen, dass es nicht die Aufgabe der Militärhistoriker sei, applikatorische Lehren aus der Geschichte zu

970 Vgl. Colonel D. C. Sweger, Schreiben an Paul M. Robinett, 22. 1.1958, in: George C. Marshall Research Library, Bestand 28, Box 14, Folder 11; Paul M. Robinett, Schreiben an Secretary of the Army, Wilber M. Brucker, 30.3. 1958, in: George C. Marshall Research Library, Bestand 28, Box 14, Folder 9; Ders., Schreiben an Chief of Staff, U.S. Army, Maxwell D. Taylor, 1. 4. 1958, in: George C. Marshall Research Library, Bestand 28, Box 14, Folder 9.

971 Paul M. Robinett, Schreiben an General Ridgway, 8. 7.1954, in: George C. Marshall Research Library, Bestand 28, Box 2, Folder 10. Der Chief of Staff ließ Robinett damals mitteilen, dass es verfrüht sei, die Nachfolgefrage zu stellen; letztlich wurde Richard W. Stephens der neue Chief of Military History. Vgl. General Charles L. Bolte, Schreiben im Auftrag von General Ridgway an Paul M. Robinett, 20. 7. 1954, in: George C. Marshall Research Library, Bestand 28, Box 2, Folder 10.

972 Vgl. Robinett, Schreiben an Chief of Staff, U.S. Army, Maxwell D. Taylor, 1.4. 1958, in: George C. Marshall Research Library, Bestand 28, Box 14, Folder 9.

973 Vgl. zum Beispiel Paul M. Robinett, Speech on Military History [ohne Datum], Blatt 2, in: George C. Marshall Research Library, Bestand 28, Box 17, Folder 16; Ders., The Value of History in the Military Profession [ohne Datum], in: George C. Marshall Research Library, Bestand 28, Box 17, Folder 28; siehe auch Robinett, Schreiben an Chief of Staff, U.S. Army, Maxwell D. Taylor, 1.4.1958, in: George C. Marshall Research Library, Bestand 28, Box 14, Folder 9. 
ziehen und plädierte für eine personelle Trennung von historischer Forschung und operationeller Analyse. Was die Armee wie auch die amerikanische Öffentlichkeit bräuchten, so der Chief Historian, sei eine von der Voreingenommenheit und Zielsetzung militärischer Doktrin möglichst unbeeinflusste Geschichtsschreibung. ${ }^{974}$ Während Greenfield außerdem dafür eintrat, dass sich die Historiker so weit als möglich ideologischer Beeinflussung enthalten sollten, ${ }^{975}$ betrachtete Robinett die Geschichte des Krieges als geeignetes Mittel, um traditionelle Leitbilder wie „Pflicht, Ehre und Vaterland“976 zu transportieren und Kameradschaftsgeist und Moral innerhalb der Truppe zu fördern. ${ }^{977}$

Die Abneigung der zivilen Historiker gegenüber Robinett war durchaus nicht einseitig, sondern wurde von diesem leidenschaftlich erwidert. Und der pensionierte Brigadier General scheute sich auch nicht, seine Geringschätzung gegenüber den Geschichtswissenschaftlern zum Beispiel bei den Sitzungen des Advisory Committee zum Ausdruck zu bringen und deutlich zu machen, dass es seiner Meinung nach professionellen Soldaten vorbehalten bleiben sollte, die Militärgeschichte der USA zu schreiben. ${ }^{978}$ Angesichts dieses offenen Misstrauens in die Kompetenz der zivilen Historiker befürchtete Greenfield, dass es im Falle von Robinetts Berufung an die Spitze der Historical Division zu einer Demoralisierung und Spaltung der Mitarbeiter kommen würde. ${ }^{979}$ Darüber hinaus glaubte er, dass Robinett die Stellung und Autorität als Chief of Military History dazu missbrauchen würde, die Ausrichtung und Organisation der Abteilung zugunsten seiner applikatorischen Auffassung von Militärgeschichte zu verändern. ${ }^{980}$ Greenfield bemühte sich deshalb, Robinetts Ernennung zum Chief of Military History zu verhindern, und intervenierte zu diesem Zweck, unterstützt von Mitgliedern des Advisory Committee, ${ }^{981}$ beim Secretary of the Army, Wilber

${ }^{974}$ Kent Roberts Greenfield, Schreiben an Paul M. Robinett, 15.4.1958, in: George C. Marshall Research Library, Bestand 28, Box 14, Folder 7.

975 Ebd.

976 Robinett, Schreiben an Chief of Staff, U.S. Army, Maxwell D. Taylor, 1.4.1958, in: George C. Marshall Research Library, Bestand 28, Box 14, Folder 9. Originalzitat: „I thought that something useful could be accomplished [...] by exploring the possibility of utilizing historical perspective as an adjunct to planning in much the same way military intelligence is used, and by fostering those time tested concepts of Duty, Honor, and Country in the Army through the study of American military history." Hervorhebung im Original.

977 Ders., The Value of History in the Military Profession [ohne Datum], in: George C. Marshall Research Library, Bestand 28, Box 17, Folder 28.

978 Ders., Zitat aus dem Protokoll des Jahrestreffens des Historical Advisory Committee, Mai 1954, S. 14, in: NARA, RG 319, Box 49, Folder 2. Dort heißt es: „It is not enough for a man to be [a] historian and not enough to be a Ph.D. He must be a practitioner, been through the mill. [...] [A] Ph.D. [is] not the fundamental requirement. Experience [is] much better."

979 Auf Nachfrage setzte Greenfield Robinett die Gründe für seine Intervention in einem Schreiben auseinander. Greenfield, Schreiben an Paul M. Robinett, 15.4.1958, in:

980 Ebd. George C. Marshall Research Library, Bestand 28, Box 14, Folder 7.

981 Der Historiker Ellis (1901-1989), Präsident der University of Missouri, rief Secretary of the Army Wilber M. Brucker persönlich an, um sich gegen Robinetts Ernennung auszu- 
M. Brucker. ${ }^{982}$ Der geballte Widerstand zeigte Erfolg: Um „ernste Spannungen“ und „Persönlichkeitskonflikte“ innerhalb der Historical Division zu vermeiden, entschieden sich Brucker und der Chief of Staff der U.S. Armee, Maxwell D. Taylor, schließlich gegen die Ernennung Robinetts zum Chief of Military History. ${ }^{983}$

sprechen. Vgl. R. W. Stephens, Schreiben an Paul M. Robinett, 21.2. 1958, in: George C. Marshall Research Library, Bestand 28, Box 14, Folder 10.

982 Vgl. hierzu Ders., Schreiben an Paul M. Robinett, 11.2.1958, in: George C. Marshall Research Library, Bestand 28, Box 14, Folder 10; Stephens, Schreiben an Paul M. Robinett, 21.2. 1958, in: George C. Marshall Research Library, Bestand 28, Box 14, Folder 10 .

983 Maxwell D. Taylor, Schreiben an Paul M. Robinett, 22.4. 1958, in: George C. Marshall Research Library, Bestand 28, Box 14, Folder 7; Wilber M. Brucker, Schreiben an Paul M. Robinett, 11.4. 1958, in: George C. Marshall Research Library, Bestand 28, Box 14, Folder 7; vgl. auch Stephens, Schreiben an Paul M. Robinett, 11.2. 1958, in: George C. Marshall Research Library, Bestand 28, Box 14, Folder 10. 
